Portland State University

PDXScholar

Fall 11-29-2012

\title{
Safety Effectiveness of Red Light Treatments for Red Light Running
}

Carl Scott Olson

Portland State University

Follow this and additional works at: https://pdxscholar.library.pdx.edu/open_access_etds

Part of the Other Civil and Environmental Engineering Commons Let us know how access to this document benefits you.

Recommended Citation

Olson, Carl Scott, "Safety Effectiveness of Red Light Treatments for Red Light Running" (2012).

Dissertations and Theses. Paper 882.

https://doi.org/10.15760/etd.882

This Thesis is brought to you for free and open access. It has been accepted for inclusion in Dissertations and Theses by an authorized administrator of PDXScholar. Please contact us if we can make this document more accessible: pdxscholar@pdx.edu. 
Safety Effectiveness of Red Light Treatments for Red Light Running

by

\section{Carl Scott Olson}

A thesis submitted in partial fulfillment of the requirements for the degree of

Master of Science

in

Civil and Environmental Engineering

Thesis Committee:

Christopher M. Monsere, Chair

Miguel Figliozzi

Peter Koonce

\section{Portland State University}

2012 
(C) 2012 Carl Scott Olson 


\begin{abstract}
Crashes resulting from automobiles running a red light are typically severe in nature. One way to try to reduce the number and severity of these types of crashes is by increasing the red clearance interval of a traffic signal. In Portland, Oregon, eight intersections received a variety of treatments including red extensions. Determining which treatment had what effect can be difficult to weed out. Using a combination of crash analysis and a model simulating an intersection with red extensions, this paper describes the estimated impact of red light running intersection upgrades and red extensions on crashes. By performing a variety of before and after crash analysis, a reduction of angle crashes after treatments was detected, with a crash modification factor of $0.64+/-0.28$ using the Empirical-Bayes method. Output from the simple simulation also suggest that red light running crashes can be reduced with red extension technology and confirms crash modification values determined from the Empirical-Bayes method.
\end{abstract}


To my wife Lisa

for your love, support, and motivation

this wouldn't be possible without you 


\section{ACKNOWLEDGEMENTS}

First off, I would like to acknowledge Dr. Chris Monsere for the many years of guidance during my time an undergrad and graduate student. I would also like to thank Dr. Monsere for providing me the opportunity to work with him as a Graduate Research Assistant on a variety of exciting and interesting transportation projects. If it wasn't for you and your classes, I wouldn't be in the transportation industry. I would also like to acknowledge my other committee members, Dr. Miguel Figliozzi and Peter Koonce. Both of you have motivated me throughout my scholastic career to learn as much as I can and I am honored to have you on my thesis committee. I would also like to thank Peter for providing city resources to help in my analysis. I would like to thank Mark Haines for starting this project and providing me with the initial crash data to begin my analysis. I would like to thank Paul Zebell for providing a variety of information on the red extension technology and for recording start-up time at the Powell Boulevard and $82^{\text {nd }}$ Avenue intersection. Thank you Kristi Currans for providing me with some of your R code to use as a spring board in beginning my model. I would also like to thank DKS Associates, and in particular Peter Coffey and Jim Peters for not only being understanding when I needed to take some time to work on this thesis, but for also pushing me to complete it in a timely manner. I would like to thank my mother-in-law Angie for proof reading my thesis during its draft stages. I know it might not have been the most enjoyable thing to do, but it meant a lot to me. Finally, thank you to my family for supporting me and keeping me going. 


\section{TABLE OF CONTENTS}

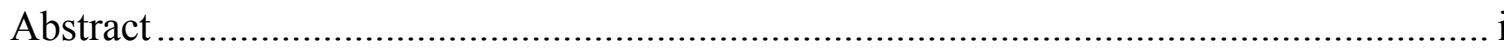

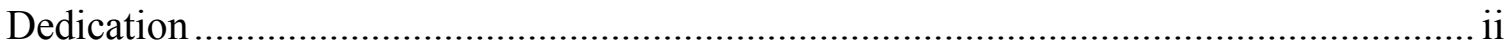

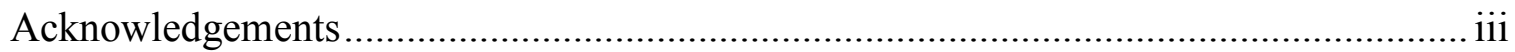

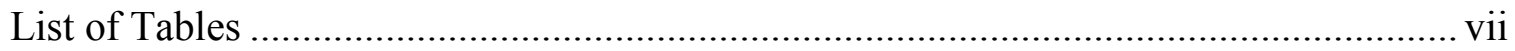

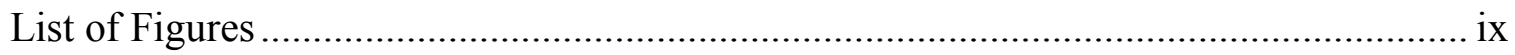

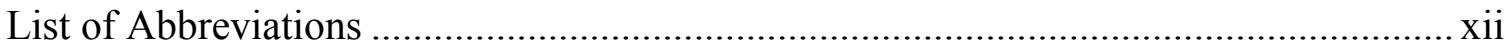

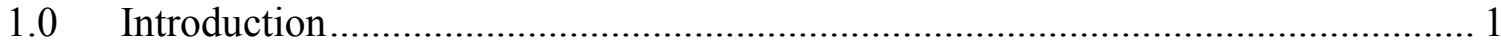

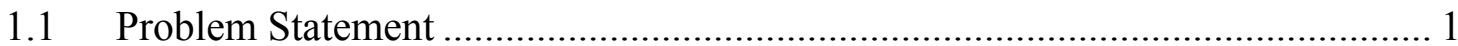

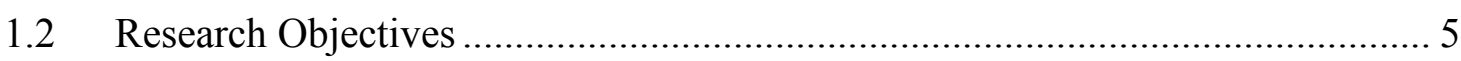

$1.3 \quad$ Project Scope

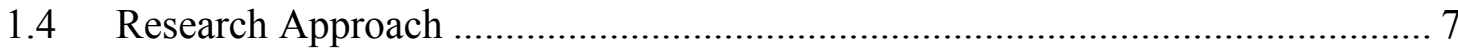

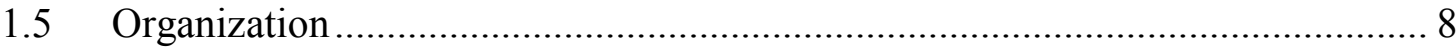

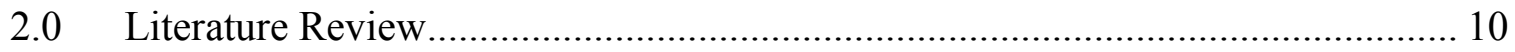

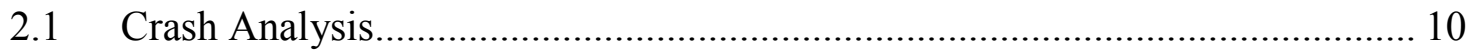

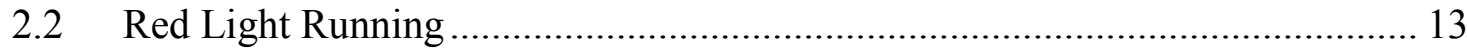

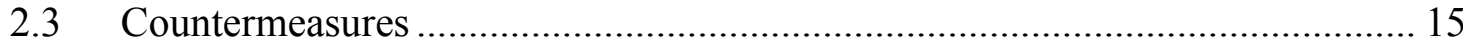

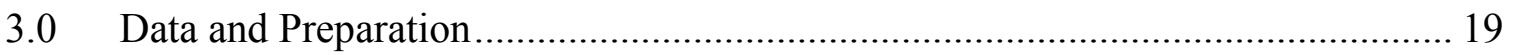

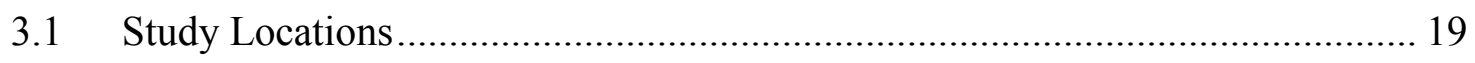




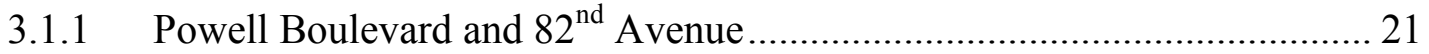

3.1.2 Powell Boulevard and Foster Road / 50 ${ }^{\text {th }}$ Avenue ................................... 23

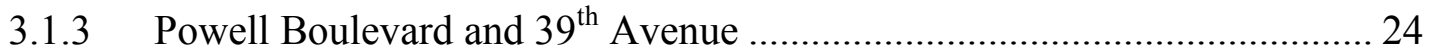

3.1.4 Powell Boulevard and Milwaukie Avenue .............................................. 25

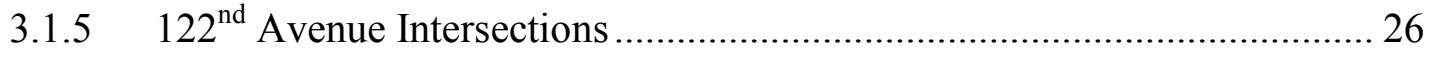

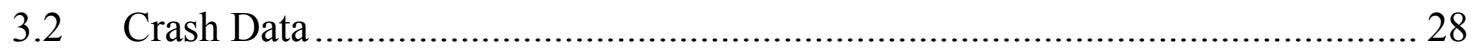

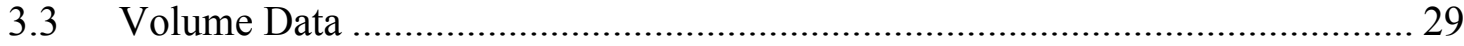

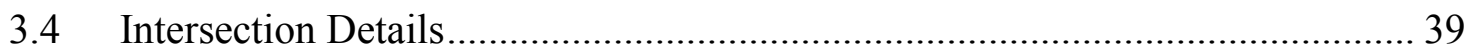

4.0 Before and After Crash Analysis ............................................................... 47

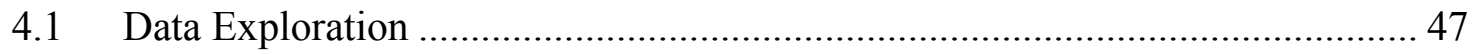

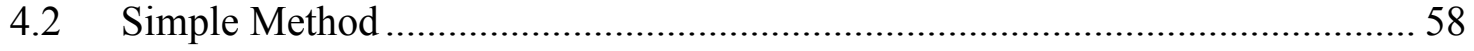

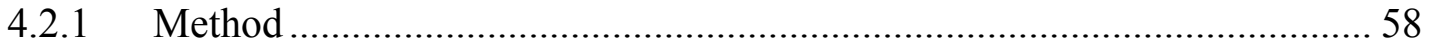

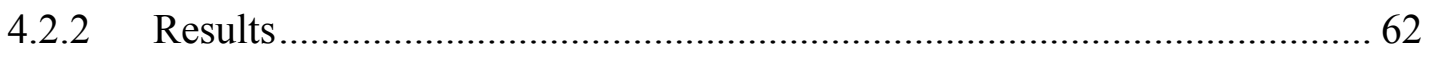

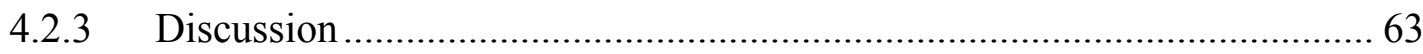

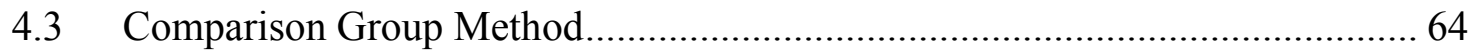

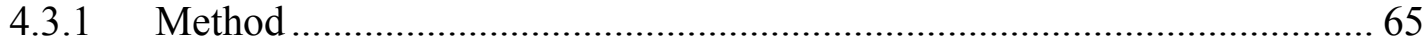

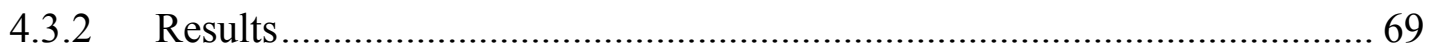

4.3.3 Discussion ..................................................................................... 70

4.4 Empirical-Bayes (EB) Method ............................................................... 71 
4.4.1 Method

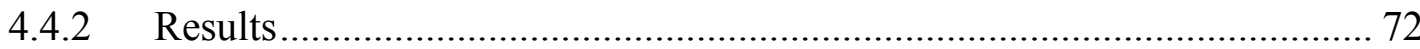

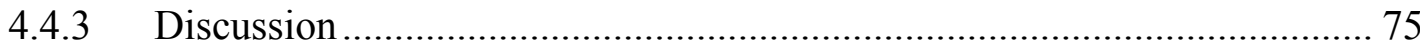

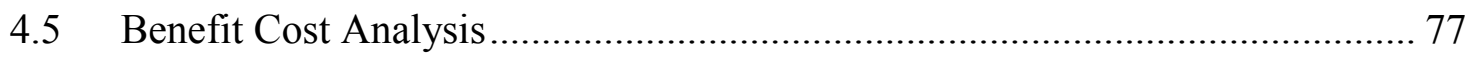

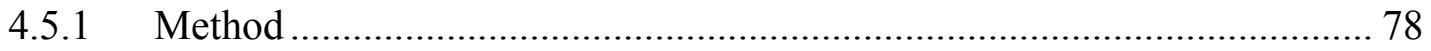

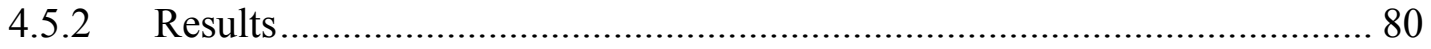

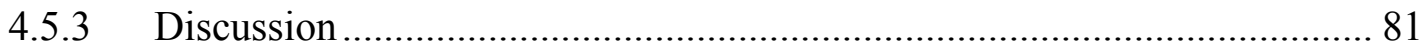

5.0 Red Light Running Simple Simulation Model ............................................... 82

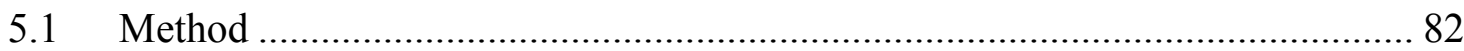

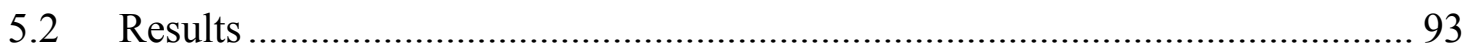

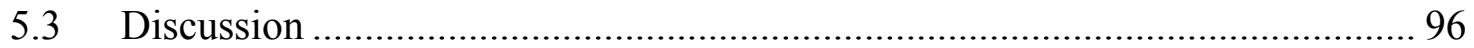

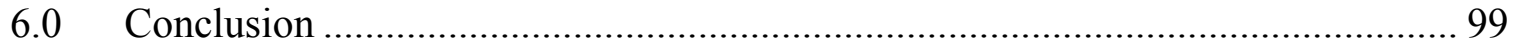

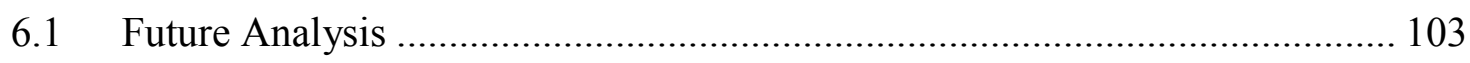

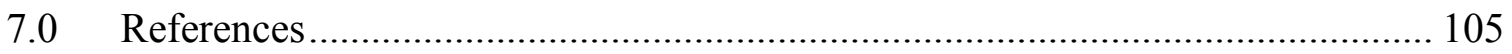

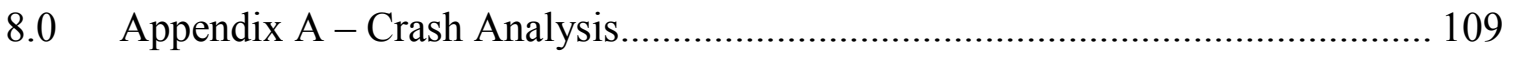

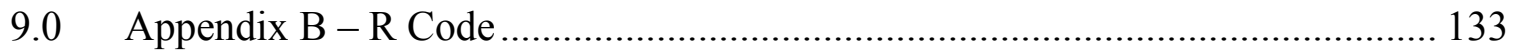




\section{LIST OF TABLES}

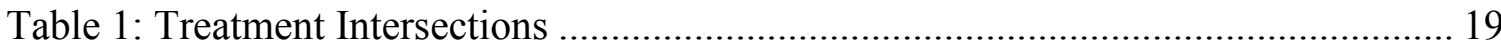

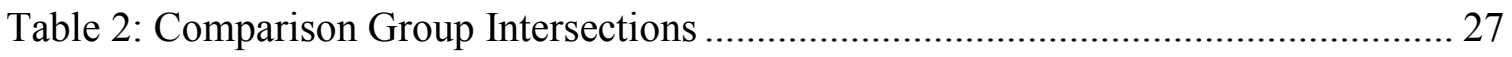

Table 3: Sample Volume Data from PortlandMaps................................................... 32

Table 4: Sample data from ODOT Gresham ATR Trend Summary Report for 2010..... 33

Table 5: Monthly Growth Factors for One-day Counts .............................................. 34

Table 6: AADT Calculation Table for 39th Avenue at Powell Boulevard...................... 35

Table 7: Yearly AADT and Growth Factors for AADT (2000-2005)........................... 36

Table 8: Yearly AADT and Growth Factors for AADT (2006-2011)............................ 37

Table 9: Intersection Details for Powell Boulevard Corridor ........................................ 42

Table 10: Intersection Details for 122nd Avenue Corridor ......................................... 43

Table 11: Intersection Details for Comparison Group - Part 1 .................................... 44

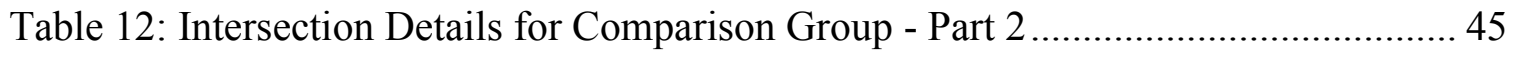

Table 13: Intersection Details for Comparison Group - Part 3 ..................................... 46

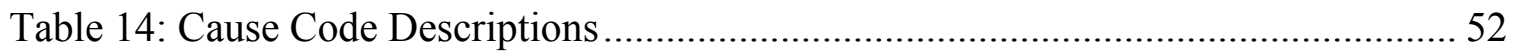

Table 15: Simple Method Input Table - Total Crashes ............................................ 59

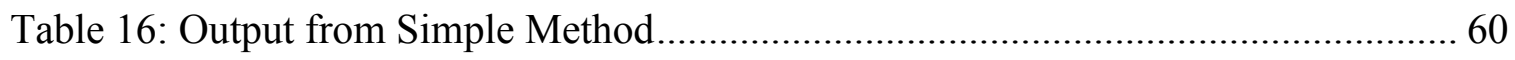

Table 17: Locally-Derived Values for Multiple-Vehicle Collisions in Oregon ............... 67

Table 18: Locally-Derived Values for Single-Vehicle Crashes in Oregon ..................... 67

Table 19: Locally-Derived Values for Unlighted Intersections in Oregon...................... 67

Table 20: Crash Modification Value Limits at the 95\% Confidence Level by Collision

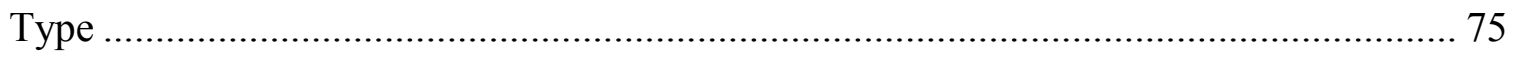


Table 21: Expected and Observed Crashes with and without Treatments...................... 78

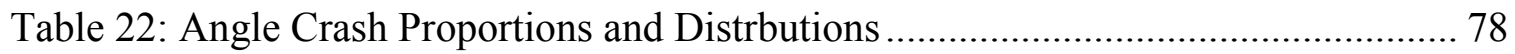

Table 23: Rear End Crash Proportions and Distributions......................................... 79

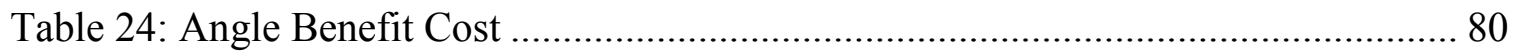

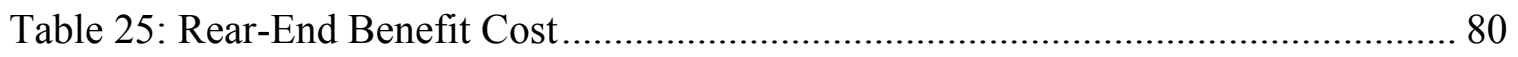

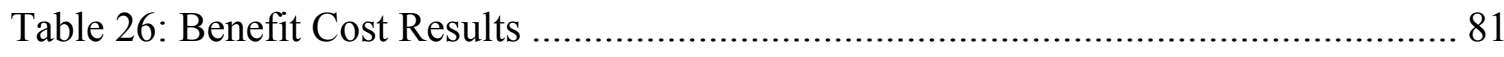

Table 27: Results of Model Simulation Runs using 48-hour Inter-Arrival Rate............. 93

Table 28: Results of Model Simulation Runs using P.M. Peak Inter-arrival Rate ........... 94

Table 29: Results of Model Simulation Runs using P.M. Off-peak Inter-arrival Rate .... 94 


\section{LIST OF FIGURES}

Figure 1: Inductive Loops for Red Extensions .................................................... 2

Figure 2: Loops and Conflicting Traffic .............................................................. 3

Figure 3: Extension Activation Period.................................................................. 4

Figure 4: Results of Extension Activated ............................................................... 4

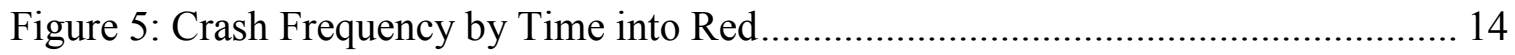

Figure 6: Probability of Vehicle Stopping/Running at $45 \mathrm{mph}$ (Raka) and $57.5 \mathrm{mph}$

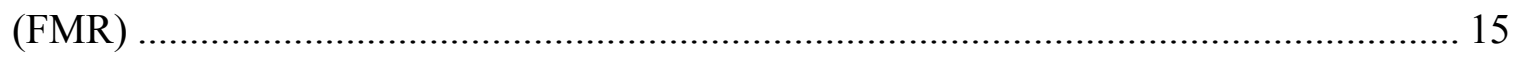

Figure 7: Map of Intersection Locations with Red Extension and Install Year............... 20

Figure 8: Powell Boulevard and 82nd Avenue ....................................................... 21

Figure 9: Powell Boulevard and Foster Road / 50th Avenue ...................................... 23

Figure 10: Powell Boulevard and 39th Avenue ...................................................... 24

Figure 11: Powell Boulevard and Milwaukie Avenue ............................................. 25

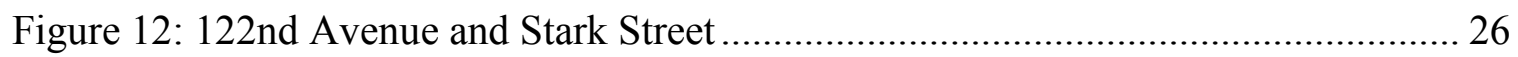

Figure 13: Map of Treatment and Comparison Group Intersections ............................. 28

Figure 14: ODOT Transportation Volume Table ................................................... 29

Figure 15: PortlandMaps Sample showing Traffic Count Locations near SE Powell

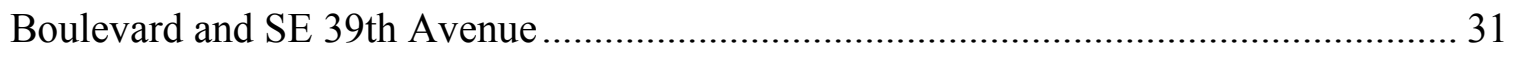

Figure 16: Example Plot showing Measure ADT and Estimated AADT for $122^{\text {nd }}$ Avenue

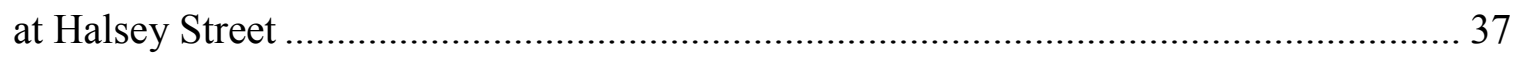

Figure 17: Plot of all Approach Leg AADT Values for the Treatment Intersections....... 38

Figure 18: TriMet's Interactive Map Showing Bus Stops........................................ 41 
Figure 19: Total Crashes per Year for each Treatment Intersection and Comparison

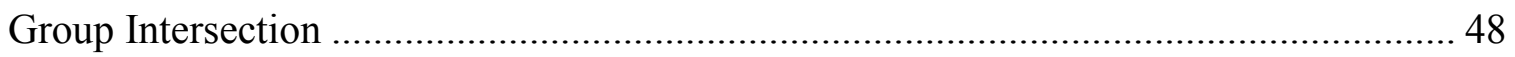

Figure 20: Crash Severity Level for Total Crashes .................................................. 49

Figure 21: Crash Severity Level for Angle Crashes ................................................. 50

Figure 22: Collision Type for Total Crashes ....................................................... 51

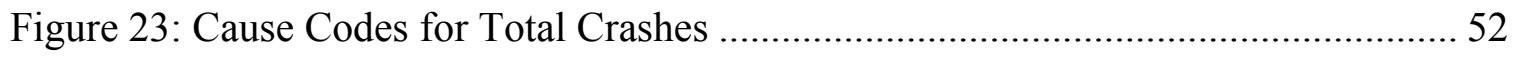

Figure 24: Cause Codes for Angle Crashes ............................................................... 53

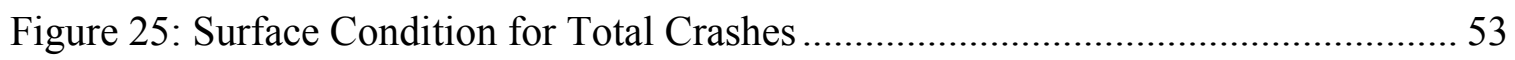

Figure 26: Surface Condition for Angle Crashes...................................................... 54

Figure 27: Total Crashes by Day of Week............................................................ 54

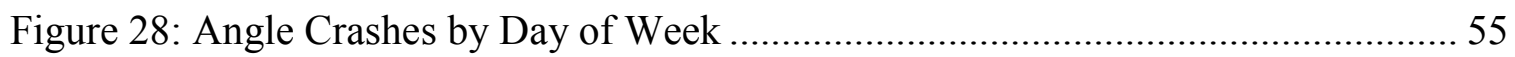

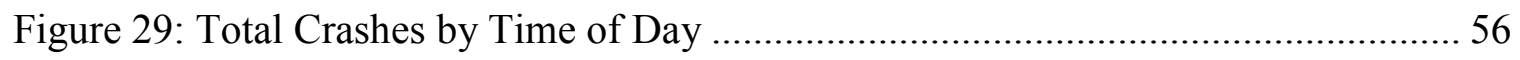

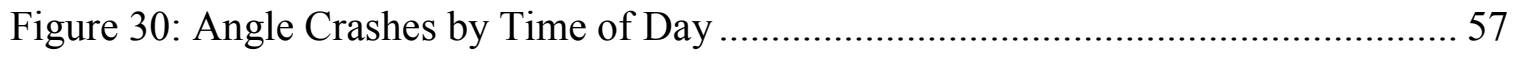

Figure 31: Crash Modification Factors for the Simple Method at the 95\% Confidence

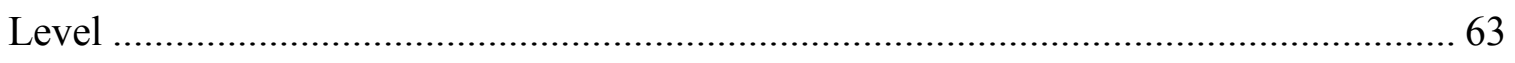

Figure 32: Crash Modification Factor Results for Comparison Group Method at the 95\%

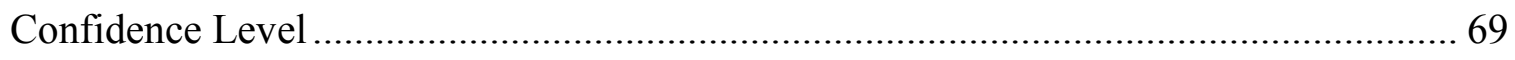

Figure 33: Crash Modification Factor Results for EB Method at the 95\% Confidence

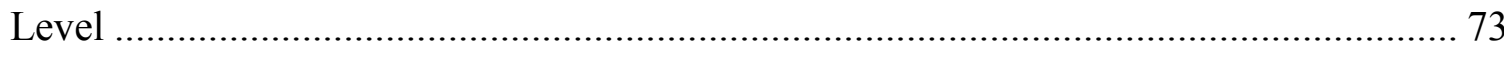

Figure 34: Crash Modification Factors for EB Method by Collision Type at the 95\%

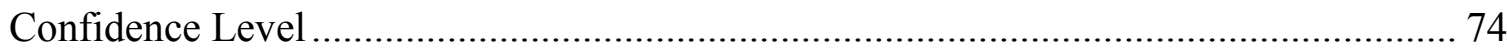


Figure 35: Crash Modification Factors for EB Method with a Revised Fatal and Injury

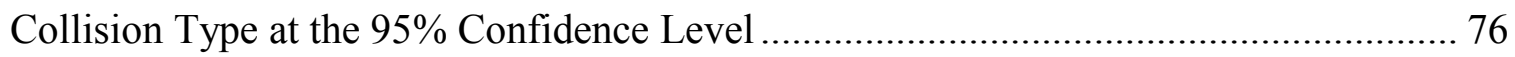

Figure 36: Record Drawing for Powell Boulevard and 82nd Avenue........................... 83

Figure 37: Inter-arrival Distribution for the NB Right Lane on 82nd Avenue at Burnside

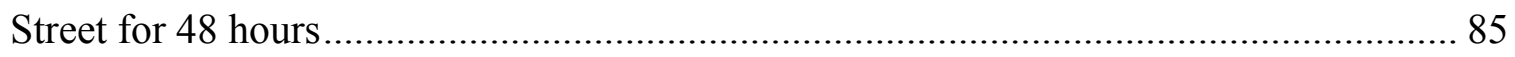

Figure 38: Inter-arrival Distribution for the NB Left Lane on 82nd Avenue at Burnside

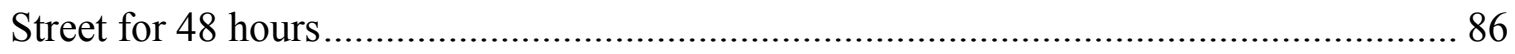

Figure 39: Inter-arrival Distribution for the SB Right Lane on 82nd Avenue at Burnside

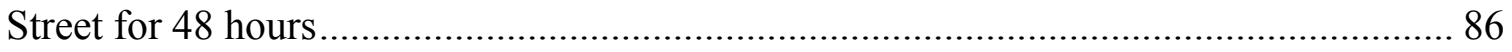

Figure 40: Inter-arrival Distribution for the SB Left Lane on 82nd Avenue at Burnside

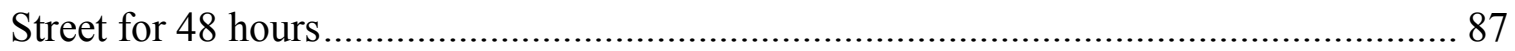

Figure 41: Inter-arrival Distribution for all lanes on 82nd Avenue at Burnside Street

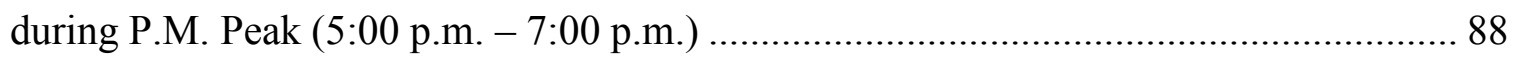
Figure 42: Inter-arrival Distribution for all lanes on 82nd Avenue at Burnside Street

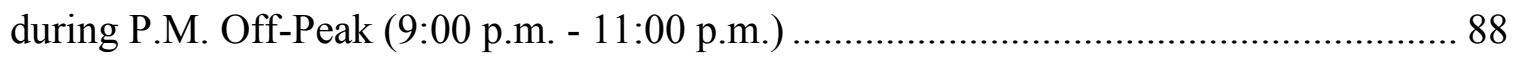
Figure 43: Go/No Go Probability Plot for $35 \mathrm{mph}$ based on Distance from Stop Bar ..... 91 Figure 44: Startup Distribution for the vehicles on Powell Boulevard.......................... 92 


\section{LIST OF ABBREVIATIONS}

3SG: 3-Leg Signalized Intersection

3ST: 3-Leg Unsignalized Intersection

4SG: 4-Leg Signalized Intersection

4ST: 4-Leg Unsignalized Intersection

AADT: Annual Average Daily Traffic

AASHTO: American Association of State Highway and Transportation Officials

ADT: Average Daily Traffic

ATR: Automatic Traffic Recorder

C_i: Calibration Factor

CDC: Center for Disease Control

CDS: Crash Data System

CMF: Crash Modification Factor

CY: Current Year

DMV: Department of Motor Vehicles

EB: Empirical-Bayes

EBL: Eastbound Left 
EBR: Eastbound Right

FHWA: Federal Highway Administration

FY: Future Year

FI: Fatal and Injury

HSM: Highway Safety Manual

ITE: Institute of Transportation Engineers

NB: Northbound

NBL: Northbound Left

NBR: Northbound Right

ODOT: Oregon Department of Transportation

PED: Pedestrian

PDO: Property Damage Only

SB: Southbound

SBL: Southbound Left

SBR: Southbound Right

SCATS: Sydney Coordinated Adaptive Traffic System

SPF: Safety Performance Function 
UNK: Unknown

USDOT: United States Department of Transportation

VAR: Variance

W/I: Within

WBL: Westbound Left

WBR: Westbound Right 


\subsection{INTRODUCTION}

Crashes are among the highest cause of death to individuals in the United States and for individuals between the ages of five and 34, it is the leading cause of death (Centers for Disease Control and Prevention, 2010). The National Highway Traffic Safety Administration estimates that in 2009 alone there was more than 4.4 million intersection or intersection-related crashes. Of these crashes, more than 12,500 were fatal and approximately 1,444,000 resulted in injuries (National Highway Traffic Safety Administration, 2010). Crashes at intersections account for almost half of the total crashes. Angle crashes are typically the most severe of crash types at an intersection (with red light running being the common cause) (Federal Highway Administration, 2009).

Many different methods have been employed in an attempt to reduce red light related crashes. In Portland Oregon, one engineering countermeasure that has been used is red extensions. From 2005 through 2009, the City of Portland installed red extensions at eight different intersections. Along with the red extension installations, various other intersection upgrades were also performed. The goal of these upgrades was to reduce crashes and improve safety. This study looks at red extensions and the other intersection treatments and hopes to answer the question "Are they working?"

\subsection{Problem Statement}

What are red extensions? Simply put, red extensions are the lengthening of the red clearance interval of a signal phase. The red clear is the final interval before a conflicting 
movement receives a green interval. The goal behind a red extension is to avoid displaying a green indication when someone is running a red light. By using inductive loop detectors located downstream of a stop bar within an intersection, the presence of a vehicle entering the intersection during the onset of amber and red clear can trigger an extension of the red clear phase to provide additional time for the vehicle to clear the intersection.

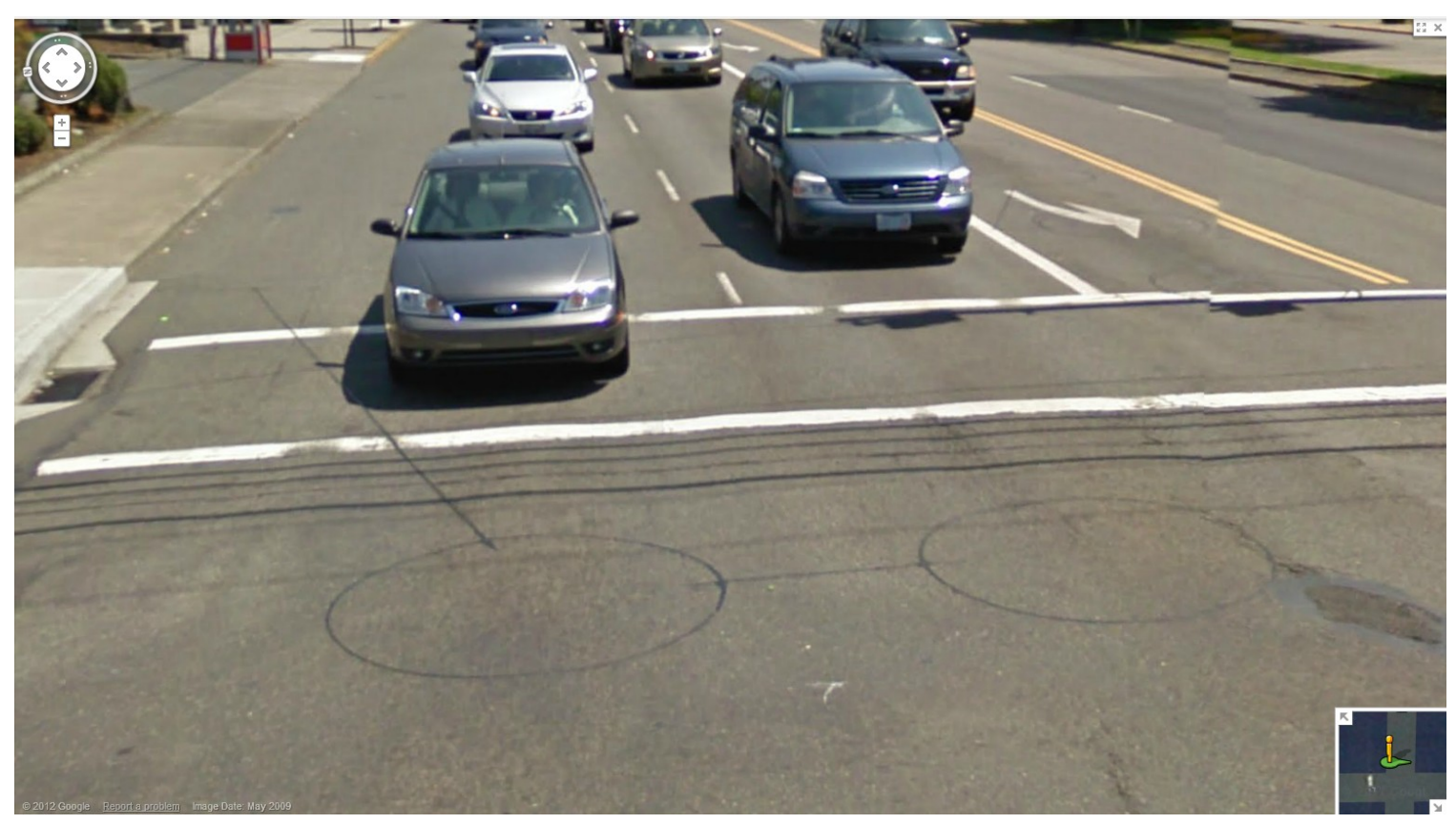

Figure 1: Inductive Loops for Red Extensions ${ }^{1}$

As seen in Figure 1, the inductive loops are installed downstream of a crosswalk or stop bar.

The goal is to detect only vehicles that are entering the intersection and not ones that are stopped at an intersection. Locating an inductive loop too close to the stop bar or

\footnotetext{
${ }^{1}$ Source: Google maps
} 
in a crosswalk could result in the unwarranted activation of the red extension due to someone stopping past a stop-bar or in a crosswalk.

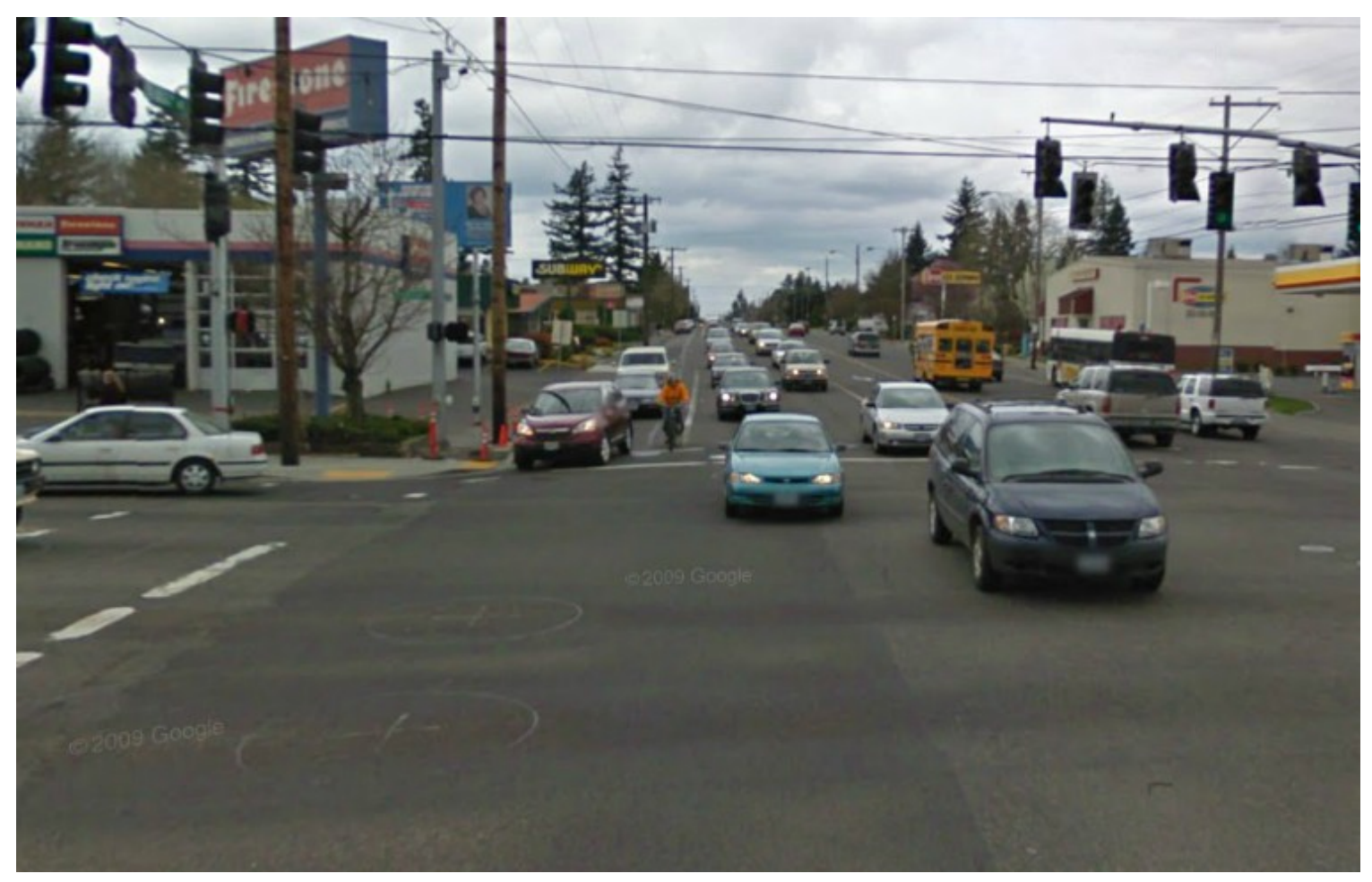

Figure 2: Loops and Conflicting Traffic ${ }^{2}$

Figure 2 shows the painted location of two new loops that are being installed at the intersection of $122^{\text {nd }}$ Avenue and Division Street in Portland Oregon. Notice that the loops are installed in a location that is downstream of the crosswalk but not in the conflicting lane's path of travel.

At intersections where the red extensions are located, the through movements are timed to have 3.6 seconds of amber and a one-second red clearance interval. The red

\footnotetext{
${ }^{2}$ Source: Google maps
} 
clearance interval is extended when a vehicle is detected during the last half of amber and any time during the one-second red clear interval as shown in Figure 3.

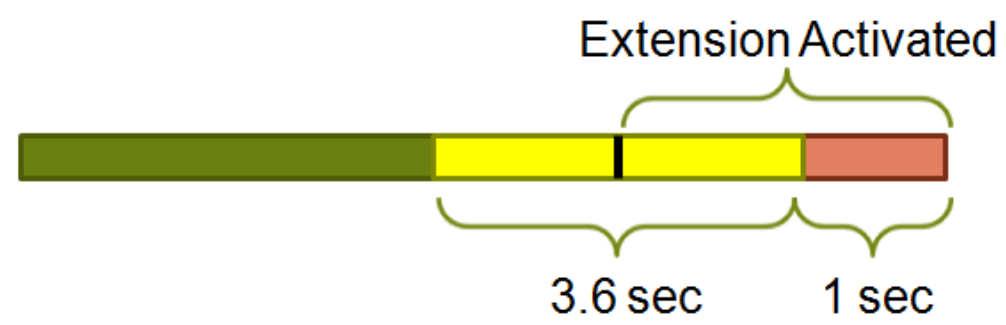

Figure 3: Extension Activation Period

When a vehicle is detected during the last 1.8 seconds of amber or during the one second of red clear, the intersection controller extends the red clearance interval by a predetermined amount. At the locations in Portland, 1.8 seconds is added to the red clearance interval. The result is a full 2.8 seconds of red clear. When coupled with 3.6 seconds of amber, the through movement receives 5.2 seconds of clearance as seen in Figure 4.

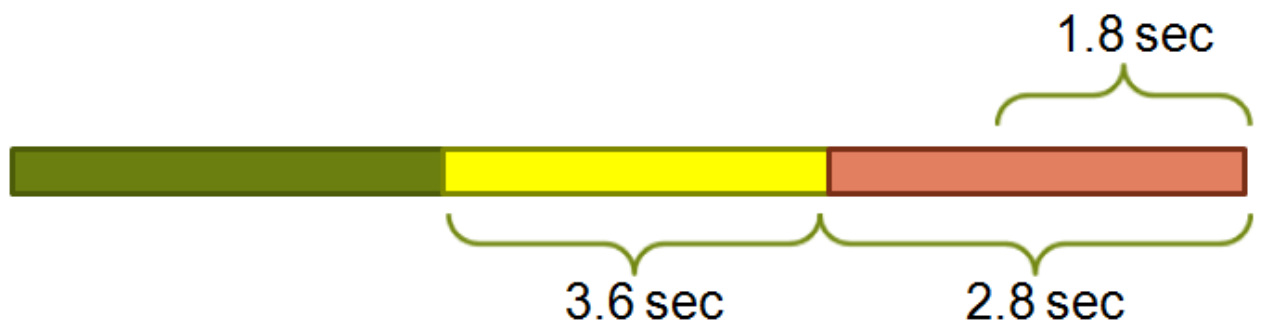

Figure 4: Results of Extension Activated 
Travelling at a speed of $35 \mathrm{mph}$ (the posted speed limit at each treatment site), a vehicle travels approximately 90 feet in 1.8 seconds. 1.8 seconds was chosen by the City of Portland because the distance from any red extension inductive loop to the other side of the intersection was equal to or less than 90 feet.

Along with the installation of red extensions, various other upgrades were performed at some of the intersections. These include:

- Upgrading green and amber signal heads from 8-inches to 12-inches in size

- Changing from guide wire to mast arm signal mounting

- Movement of utility lines from the line-of-sight of the signal heads

- Changing from fixed to actuated signal timing

The earliest install date of the red extensions is as far back as 2005. Until now however, there has been no before and after study attempting to measure their effect on safety. There will be difficulties in performing a safety analysis of the red extensions. When more than one intersection treatment is performed at an intersection during a study time period, it can be difficult to control for the different variables. The problem is compounded by not having good records of the various changes that have occurred over the years and knowing which treatment had what affect might be impossible.

\subsection{Research Objectives}

The objective of this research is to determine to what degree red extensions located in Portland, Oregon are reducing red light running related crashes. The possibility exists that the effect of red extensions may not be seen with the crash data alone. 
Additionally, it is unwise to assume that crashes always decrease with the implementation of new technology, as it is difficult to predict and control for all variables, both known and unknown. To aid in the analysis, the methods in the Highway Safety Manual will be used along with current studies. In hopes of specifically analyzing the resultant crash modification factors of red extension, a simple model was created simulating an intersection with and without red extensions.

\subsection{Project Scope}

The study area for this research is within the city of Portland, Oregon. The research focuses on eight intersections where red extension treatments have been installed. The locations of the intersections along with other background details are discussed in the following chapter.

Crash data were obtained from the Oregon Department of Transportation (ODOT) along with volume data for ODOT owned and/or operated facilities. Additional volume data was obtained from the City of Portland. Information regarding intersection characteristics was obtained from a variety of sources including Google street view, TriMet, PortlandMaps, and PORTAL.

To determine the effect of red extensions, holding all other changes constant, an intersection simulation model was created. This model used three different types of data obtained from the City of Portland. These are: volume data recorded by inductive loops, time into green that vehicles clear the stop bar, and time into amber/red that vehicles clear the stop bar. 


\subsection{Research Approach}

This research takes two approaches to analyze the effect of red extensions. The first is with the use of crash data. The second is through the creation of a simple simulation model with and without red extensions.

The first step taken in determining the validity of this study was a simple before and after crash comparison. By comparing the number of crashes before a treatment to the number of crashes after a treatment, a rough estimation of the changes in crashes was determined.

With a reduction determined from the simple approach, a more robust approach as detailed by the Highway Safety Manual (HSM) was employed. This method is called the Comparison Group method. Using the HSM, regression models are used to predict crash frequencies at each of the intersections. Using a combination of observed and predicted crash frequencies at the treatment and non-treatment intersection and comparing the differences, crash modification factors can be determined. Unfortunately, there are difficulties with using the comparison group method. These difficulties include, but are not limited to, the selection of comparison intersections and dealing with zero crash years. Details on these are discussed later.

The final method employed in the crash analysis was the Empirical-Bayes (EB) method as outlined by the Highway Safety Manual. The Empirical-Bayes method does not use comparison group intersections and uses only intersections where the treatment was applied. Using the observed crash frequency along with the predicted crash 
frequency, expected crash frequency is determined. Comparing expected crash frequency to actual crash frequency, the estimated safety effectiveness of treatments can be estimated.

For both the comparison group method and the Empirical-Bayes method, the Annual Average Daily Traffic (AADT) is required to calibrate for changes in volume of vehicles from year to year. For intersections not included in the state highway system, values for AADT were estimated using seasonal factors obtained from a local Automatic Traffic Recorder (ATR) and one day volume counts performed by the City of Portland.

The final part of the experimental design was the creation of an intersection model in the statistical program $\mathrm{R}$. This model simulates an intersection with and without red extensions. The model uses data obtained from the City of Portland regarding start-up time at the onset of green, volume data recorded from inductive loop detectors and go / no-go decision variables from research. By using a Monte Carlo simulation approach, the number of interactions (crashes) over time can be estimated.

\subsection{Organization}

Section 2 of this document begins by highlighting the impetus of this research. This section begins by looking at details on crash analysis including current research along with challenges that are present. Following crash analysis, one crash type is looked at, red light running and, finally, countermeasures that have been used to reduce red light running. The section ends with a discussion on red extensions currently in use in Portland. Section 3 details the data preparation that was required before performing the 
crash analysis. Data were received from many different sources, and a large amount of time went simply into the archival, formatting, and discovery of the data. Section 4 describes the crash analysis that was performed. The section details the three different crash analyses that were performed including the simple before/after method, the comparison group method, and the Empirical-Bayes method. Section 5 details the red extension simulation model that was developed. The creation of the model along with the results of the simulation is included in this section. Section 6 provides the conclusion to the document, highlighting the key results and findings from the previous two sections. Areas for further study and data needs are also addressed. Section 7 lists all of the references that were used in the creation of this document. The appendix includes additional data, crash analysis, and the $\mathrm{R}$ programming code that was used in the model. 


\subsection{LITERATURE REVIEW}

This chapter describes the current state of knowledge and practice in crash analysis, the specific nuances associated to red light running and red light running related crashes, and finally different countermeasures that have the potential to reduce red light related crashes. The chapter will conclude by looking at one countermeasure in particular, red extensions. Throughout the chapter and when applicable, connections will be made between the different topics and the locations within Portland, Oregon, where our analysis is focused.

\subsection{Crash Analysis}

On the most basic level, to perform a crash analysis of a new treatment after it has been installed, a comparison must be made of the number of before and after crashes. However, to look at before and after crashes, crash data are essential. This crash data needs to identify location, type of collision, severity, date and time, and much more. To begin, crash data must be obtained.

In the state of Oregon, reporting crashes is the responsibility of the individuals involved. In the event that a police officer responds to the scene of a crash, a crash report may be filled out by the officer and become part of the crash database. As per the Oregon Department of Motor Vehicles (DMV), a crash must be reported to DMV within 72 hours of a crash when any of the following conditions are met (Oregon Department of Transportation, 2012):

- Damage to your vehicle is greater than or equal to $\$ 1500$ 
- Damage to any vehicle is greater than or equal to $\$ 1500$ and any vehicle was towed from the scene as a result of the crash

- There were any injuries or death as a result of the crash

- Damage to any person's property is greater than or equal to $\$ 1500$ not including the automobiles involved in the crash

One of the difficulties in performing a crash analysis is having accurate crash data. Since crash reporting in the state of Oregon is the responsibility of the individuals involved, many crashes are not always reported. This non-reporting of crashes could be related to the individuals attempting to avoid the repercussions of the crash. These repercussions could include anything from an increase in automobile insurance rates, to law enforcement penalties including jail time if one or more of the individuals involved were under the influence of intoxicants; and other considerations.

In a study performed in Oregon (Malik, Bertini, \& Monsere, 2003) on Highway 18 , there were many inconsistencies found with the number of actual crashes and the crashes being reported to the Oregon Department of Transportation. It is estimated that unreported crashes amounted to $50 \%$ of total crashes for the year 2000 on Highway 18 , and this number might even be on the low side. However, from both literature reviewed by the authors and from their own studies, nearly all fatalities were reported.

By nature, crashes are rare and random events. When this rare and random event is narrowed down further to a specific crash type, researchers can find themselves struggling for a sufficient amount of data. To aid in the analysis of crashes and various 
treatments, the Highway Safety Manual (HSM) was created and published in 2010. The Highway Safety Manual (HSM) provides guidance on how to perform a variety of crash analysis. The first edition was published in 2010 and provides a method for individuals to assess crash frequency and crash severity on a variety of infrastructures (Highway Safety Manual, 2010).

Part of the Highway Safety Manual is the ability to calibrate crash prediction models to local jurisdiction conditions. This local calibration is important as no one place is exactly the same as another. Recently, a project was completed in Oregon that aids individuals who are estimating the safety of a transportation facility to generate Safety Performance Functions that are calibrated based on historic safety performance in Oregon (Dixon, Monsere, Xie, \& Gladhill, 2012). With these calibrated Safety Performance Functions, expected facility safety performance more closely matches conditions encountered in Oregon.

The Highway Safety Manual has many crash modification factors (CMFs) available with regard to a particular treatment's effect on crashes. A crash modification clearinghouse is also available which receives, rates, and stores a variety of crash modification factors. Unfortunately, there is not a crash modification factor for every possible treatment, and this is especially true for new treatments, as is the case in red extensions. Of the intersection upgrades that were performed at the eight treatment intersections, none were available from the crash modification clearinghouse (U.S. Department of Transportation, Federal Highway Administration, 2012). 


\subsection{Red Light Running}

Red light running and red light running related crashes are an ongoing concern for transportation professionals and the general public. 165,000 people are injured in red light running related crashes each year and deaths associated to red light running were 762 in 2008 (Federal Highway Administration, 2012). Unfortunately, about half of all the people that die in red light related crashes are not the individuals who ran the red light, but are individuals who are struck by the red light runner themselves (Insurance Institute for Highway Safety, 2007).

Determining why an individual runs a red light can provide insight into an underlying problem. An individual may run a red light for a variety of reasons. It could be that a person is in a hurry and simply didn't want to stop for an amber signal or a recently changed red light. Another possibility is that a red light runner simply didn't see the signal head itself. Sometimes intersection characteristics can result in a higher than normal occurrence of red light running. Characteristics like intersection volume, geometric design, and signal timing can all affect the frequency of red light runners (Federal Highway Administration, 2009).

Instead of looking at what intersection characteristics might lead to an increase in red light running, one study looked simply at the time into red that the red light running event is occurring (Zimmerman \& Bonneson, 2005). When red light running resulted in a crash, the average time into red that a crash occurred was 8.7 seconds and a median time into red was 6.7 seconds. Figure 5 shows the time into red for right-angle crashes as seen in Zimmerman et al. 


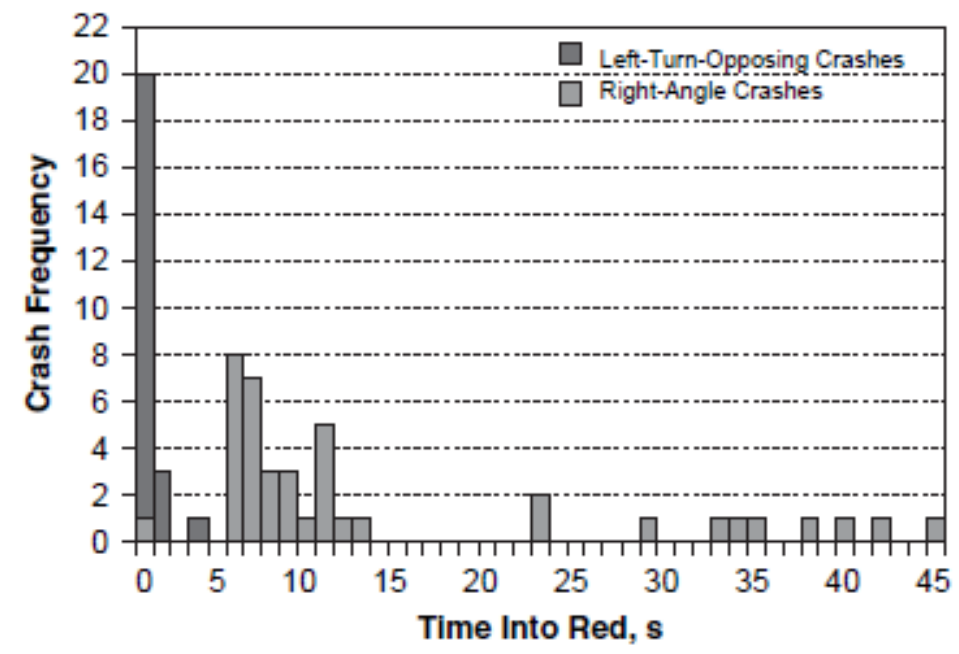

Figure 5: Crash Frequency by Time into Red ${ }^{3}$

A problem that many individuals face on a daily basis is whether to go or not go at the onset of an amber indication. The decision point where a driver is unsure whether to go or not go is called a dilemma zone. Depending on the posted speed of the road, the speed of the vehicle, and the distance of the vehicle from the intersection, the dilemma zone's location may vary. Commonly accepted locations of the dilemma zone are in the range of 2.5 to 5.5 seconds away from an intersection (Hurwitz, Wang, Knodler, Ni, \& Moore, 2012).

\footnotetext{
${ }^{3}$ From Zimmerman, K \& Bonneson J. A. (2005). Investigation of Time into Red for Red Light-Related Crashes. Journal of the Transportation Research Record, No. 1922, 21-28.
} 


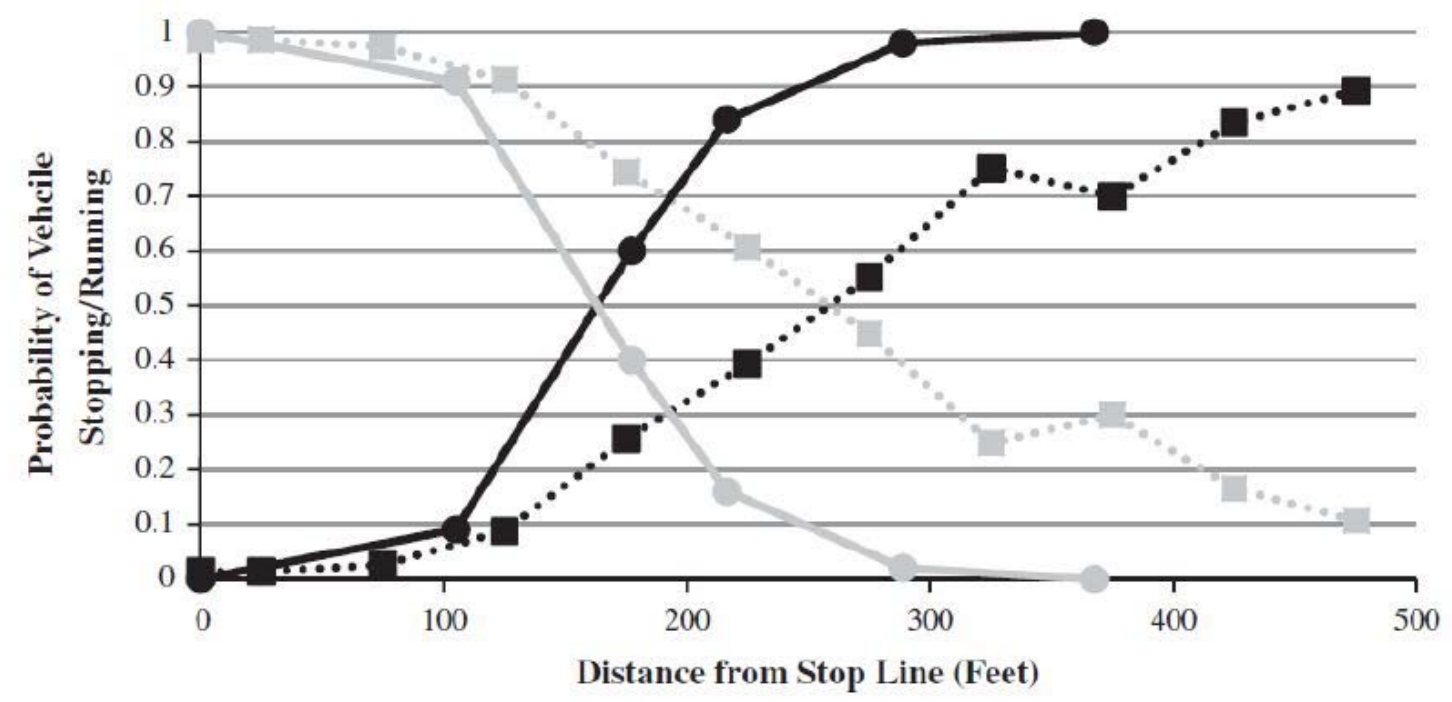

\begin{tabular}{|c|c|}
\hline •・・ Stopping (FMR) & … Running (FMR) \\
\hline Stopping (Raka et al. 2007) & - Running (Raka et al. 2007) \\
\hline
\end{tabular}

Figure 6: Probability of Vehicle Stopping/Running at $45 \mathrm{mph}$ (Raka) and $57.5 \mathrm{mph}$ $(\text { FMR })^{4}$

From this research, some basic conclusions can be drawn on the probability that an individual will run a red or amber light based upon distance from the stop bar and current speed.

\subsection{Countermeasures}

In hopes of reducing these red light crashes, many novel countermeasures have been studied and installed. One common countermeasure is the installation of red light running cameras. These cameras take a photo of a vehicle or vehicles that run a red light. From the photo, local law enforcement is able to issue a citation to individuals who fail to follow a traffic control device. Some studies have shown that while these cameras

${ }^{4}$ From Hurwitz, D. S. Wang, H., Knodler, M. A., Ni, D., \& Moore, D. (2012). Fuzzy Sets to Describe Driver Behavior in the Dilemma Zone of High-Speed Signalized Intersections. Elsevier. 
sometimes reduce the amount of red light runners, thus decrease red light running related crashes, red light crashes may remain constant (Retting, Ferguson, \& Hakkert, 2003). Instead of the common angle crashes experienced by red light running related crashes, crashes shift to rear-end crashes due to individuals slamming on their brakes at the onset of amber and red. This sudden increase in stopping has the potential to increase the amount of rear-end crashes due to inattentive drivers.

One way that many municipalities have attempted to improve safety at intersections experiencing red light running is through the signal timing. As mentioned above, when an individual is caught in a decision zone at the onset of amber, they must make a decision to proceed through an upcoming intersection or attempt to stop. To help facilitate in the decision-making process, some engineers have experimented with signal timing. The Institute of Transportation Engineers (ITE) has produced a handbook detailing suggested signal timing parameters based on approach speed at the intersection.

When adjusting signal timings, there is concern about drivers adapting to the change and therefore not changing their bad habits or patterns. In a study by Bonneson et al. the effects of amber interval timing was explored with relation to the frequency of red light runners. By increasing the length of the amber clearance interval, a decrease in the number of red light violations was detected. However, it was also noticed that drivers adapted to the longer amber clearance interval but that their adaptation did not undo all of the positive effects of the altered signal timings (Bonneson \& Zimmerman, 2004). 
Visibility of signals and signal heads can have an impact on red light running. One study compared the rates of drivers running amber and red lights depending on the type of signal mounting at an intersection. When comparing a mast arm to a diagonal span wire, there was no change in the rate of amber light runners, however there was a change in the number of red light runners (Shattler, McAvoy, Christ, \& Glauber, 2011). Mast arm signalized intersections had fewer red light runners when compared to intersections with diagonal span wires. Many of the treatment intersections in Portland had span wires, however they were not diagonal.

In "Engineering Countermeasures to Reduce Red-Light Running" produced by the U.S Department of Transportation, Federal Highway Administration, four different categories of ways to reduce red light running are provided. These are "Improve Signal Visibility/Conspicuity", "Increase the Likelihood for Stopping", "Remove Reasons for Intentional Violations", and "Eliminate the Need to Stop" (Federal Highway Administration, 2009). Under the "Remove Reasons for Intentional Violations" category, things like cycle length, signal timing, and dilemma zone protection are listed. One item that stands out is "Provide or Adjust All-Red Clearance Interval". One solution is to adjust an all-red clearance interval dynamically when a particular situation warrants it with the use of red extensions.

Studies in California have looked at dynamic all-red extensions as a way to reduce red light running (Wang, Zhang, Zhou, Zhang, \& Wang, 2011). By using existing advanced inductive loops, Wang et al. created a red light running prediction function to estimate when a red light was going to be run. Unfortunately predicting which vehicles 
were going to run was difficult. Correct prediction values from $44.9 \%$ to $89.8 \%$ were achieved.

Finally, in Portland, Oregon, red extension inductive loops were installed at a few high-crash intersections as a way to dynamically adjust the red clearance interval. In the following sections, various crash analyses were performed in an attempt to quantify the safety impact of the red extension technology. As a final piece, a model of the red extension inductive loops installed in Portland was created and numerous simulation runs were performed and the resulting output was assessed. However, before any analysis can be performed, sufficient data must be obtained and prepared for use in both the crash analyses and modeled intersection. 


\subsection{DATA AND PREPARATION}

In this chapter, the many different forms of data and the sources that were used in this research are looked at. These data sources included, but were not limited to, crash data and volume data. In many cases, the data was not usable in its raw format and required data preparation before being used. Examples of the data preparation will be discussed along with details of the study locations.

\subsection{Study Locations}

Eight different intersections in Portland, Oregon received a variety of intersection treatments outlined in section 1.1, including red extensions. Many of the intersections were chosen due to a combination of crash frequency and high volume. Table 1 below lists the treatment intersections along with the install date of the red extensions.

\section{Table 1: Treatment Intersections}

\begin{tabular}{|l|c|}
\hline Treatment Intersections & Install Date \\
\hline Powell Boulevard and 82nd Avenue & $8 / 9 / 2005$ \\
\hline Powell Boulevard and Foster Road / 50th Avenue & $8 / 9 / 2005$ \\
\hline Powell Boulevard and 39th Avenue (Cesar E. Chavez Boulevard) & $9 / 6 / 2005$ \\
\hline Powell Boulevard and Milwaukie Avenue & $12 / 17 / 2007$ \\
\hline 122nd Avenue and Halsey Street & $4 / 1 / 2009$ \\
\hline 12nnd Avenue and Glisan Street & $4 / 7 / 2009$ \\
\hline 122nd Avenue and Stark Street & $4 / 8 / 2009$ \\
\hline 122nd Avenue and Division Street & $4 / 9 / 2009$ \\
\hline
\end{tabular}

For intersections that received signal upgrades, many of these occurred at the same time as the red extension install. Details on each of the upgrades and/or changes that occurred 
at the sites are murky at best. Later in this chapter, intersections will be addressed in detail along with any known upgrades and changes.

Each of the intersections that received red extensions are on a major corridor within Portland, these being Powell Boulevard and $122^{\text {nd }}$ Avenue. Figure 7 below is a map with the eight treatment sites indicated. The year of installation is included for each location. Powell Boulevard is a major east/west arterial while $122^{\text {nd }}$ Avenue is a major north/south arterial.

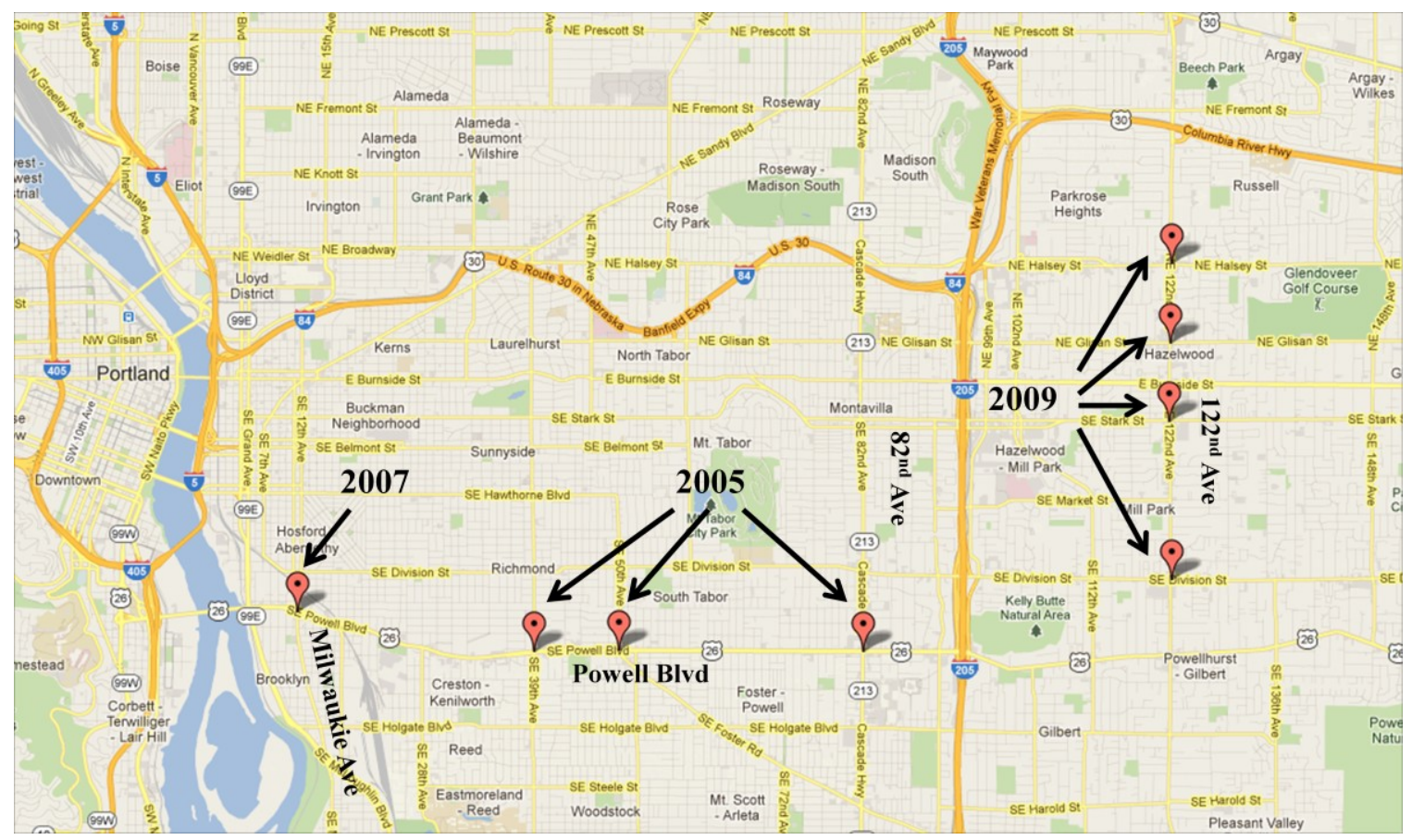

Figure 7: Map of Intersection Locations with Red Extension and Install Year

Much of Powell Boulevard has two lanes in each direction with a center lane for left turning traffic. Annual Average Daily Traffic throughout the corridor in 2010 ranged from 41,000 at Powell Boulevard and Milwaukie Avenue to 24,600 at Powell Boulevard

\footnotetext{
${ }^{5}$ Base-map source: Google maps
} 
and $82^{\text {nd }}$ Avenue (Oregon Department of Transportation, 2010). Powell Boulevard is also a state highway with the designation of US26. Powell Boulevard is served by a bus route that runs every 15 minutes or better during the weekday morning and afternoon peak times and less frequently during off-peak times. In 2010, the intersections of Powell Boulevard and Foster Road $/ 50^{\text {th }}$ Avenue, $39^{\text {th }}$ Avenue, and Milwaukie Avenue were upgraded to the Sydney Coordinated Adaptive Traffic System (SCATS), which adapts the signal timing at those intersections to respond to vehicle demand.

\subsubsection{Powell Boulevard and $82^{\text {nd }}$ Avenue}

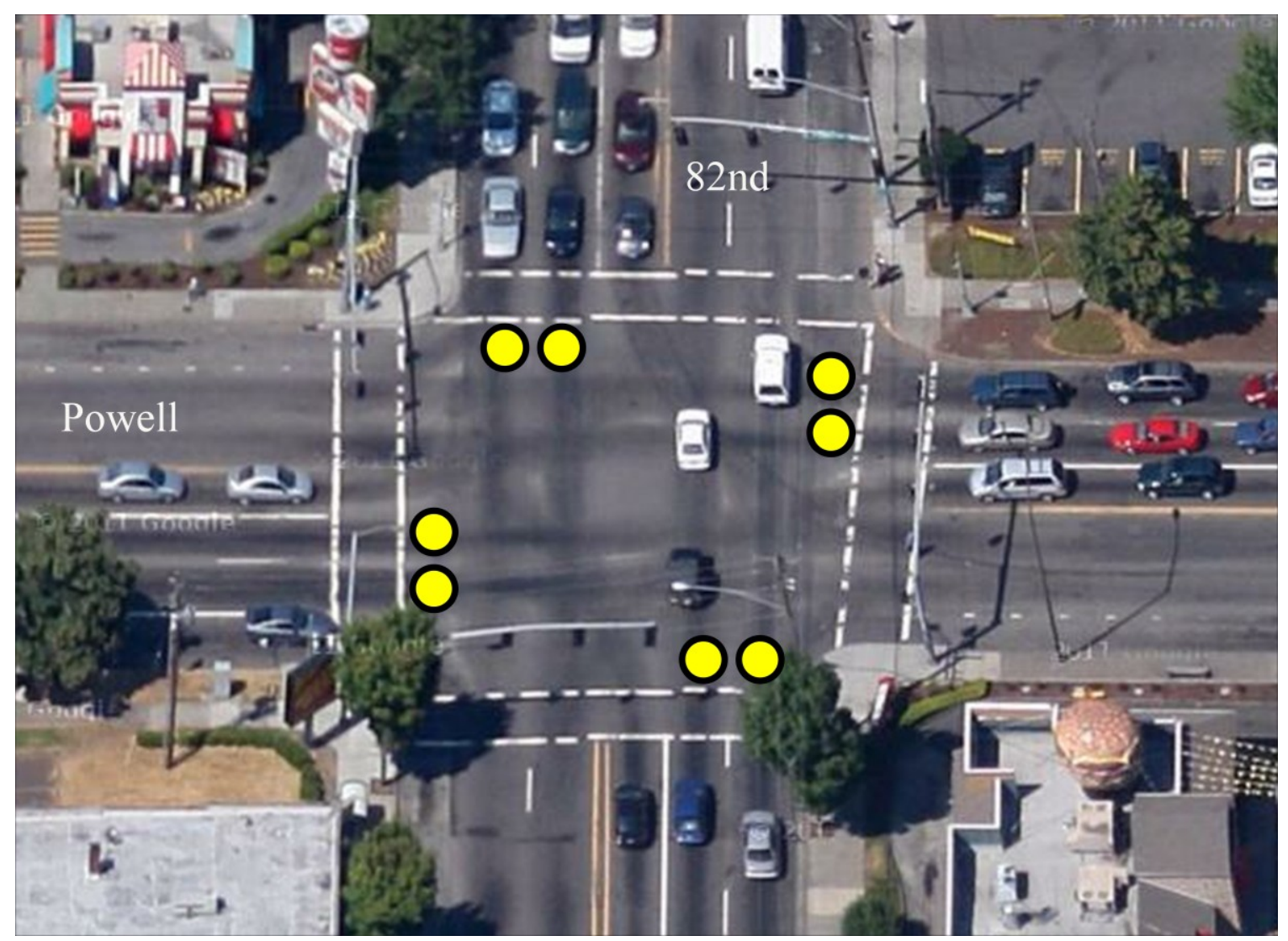

Figure 8: Powell Boulevard and 82nd Avenue ${ }^{6}$

\footnotetext{
${ }^{6}$ Aerial image source: Google maps
} 
Powell Boulevard and $82^{\text {nd }}$ Avenue is one of the highest frequency crash locations in Portland. In November 2010, the Portland Tribune released an article identifying Portland's most hazardous intersections based simply on number of crashes. For the years 2000 through 2009, Powell Boulevard and $82^{\text {nd }}$ Avenue experienced the greatest amount at 356 crashes (Korn, 2010). From 2000 through 2011, there were 19 angle crashes at Powell Boulevard and $82^{\text {nd }}$ Avenue. Of the 19 angle crashes, 10 were caused by a north or southbound vehicle, and nine were from an east or westbound vehicle. 12 of the crashes occurred from 7 a.m. to 1 p.m. with eight of them occurring from 11 a.m. to 1 p.m.

Figure 8 shows an aerial photo of Powell Boulevard and $82^{\text {nd }}$ Avenue. In the figure, the approximate locations of the red extension inductive loops are shown. The intersection has two lanes in each direction with left turn lanes and a right turn only lane in the eastbound direction.

In addition to the red extension upgrade in 2005, the intersection of Powell Boulevard and $82^{\text {nd }}$ Avenue underwent other changes. These were:

- Changing of the signal supports from span wire to mast arms (City of Portland, 2004)

- Relocation of utility lines located in front of signal heads (Hatch, 2012)

- Changing the signal timing from fixed to actuated (Hatch, 2012) 


\subsubsection{Powell Boulevard and Foster Road $/ 50^{\text {th }}$ Avenue}

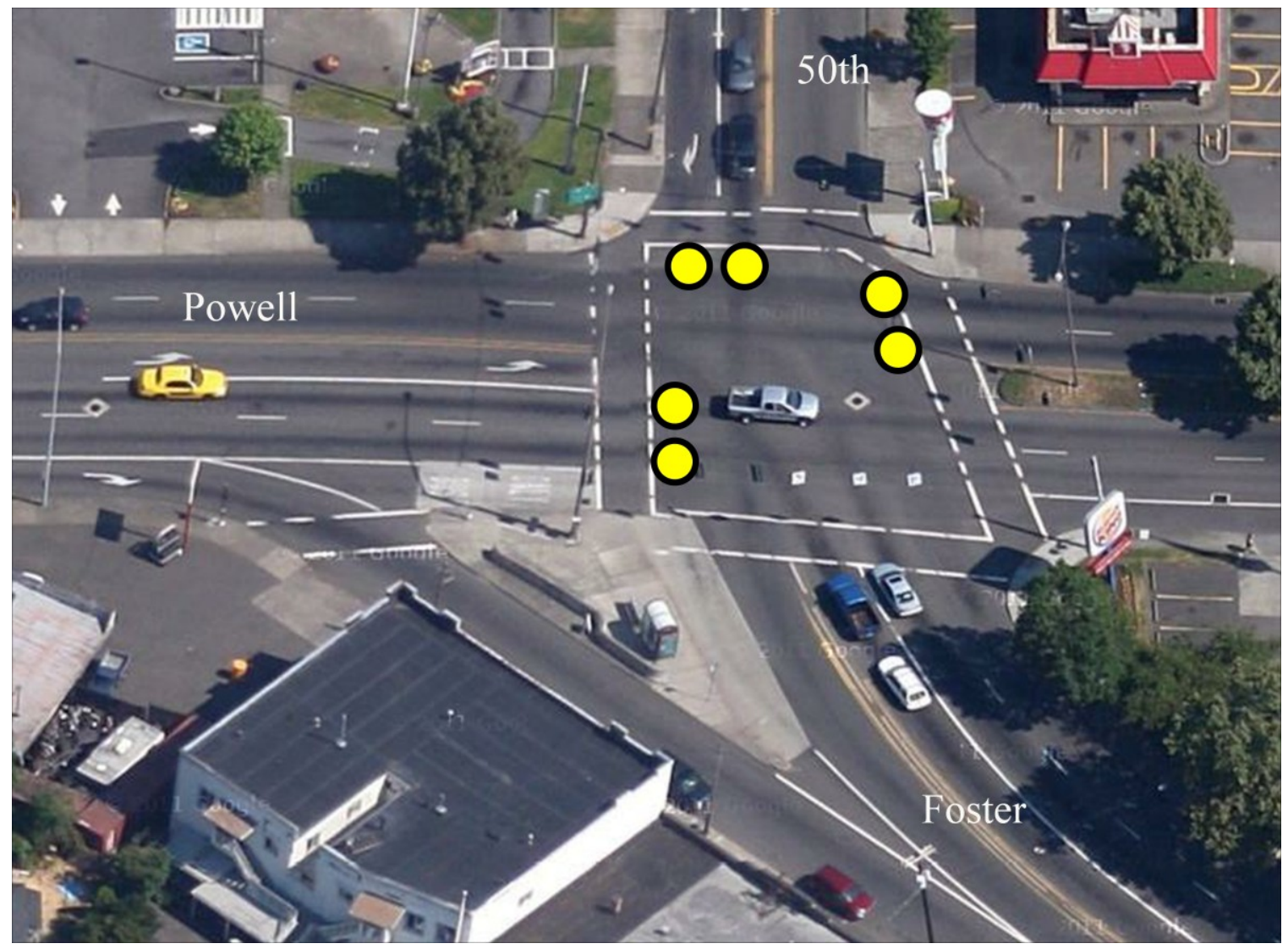

Figure 9: Powell Boulevard and Foster Road / 50th Avenue ${ }^{7}$

Figure 9 shows the intersection of Powell Boulevard and Foster Road $/ 50^{\text {th }}$ Avenue, the second intersection to receive red extensions. This intersection is unique from the other seven treatment locations. First, the intersection does not have red extensions for all directions. Northbound traffic does not have red extensions. Another interesting item to note is the location of the southbound outside lane red extension inductive loop. This loop is located downstream of a right turn only lane. Buses using the right turn only lane are permitted to go straight through the intersection to service a stop

\footnotetext{
${ }^{7}$ Aerial image source: Google maps
} 
and shelter on the south side of the intersection. Unlike the intersection at Powell Boulevard and $82^{\text {nd }}$ Avenue, this intersection still uses span wire for their signal head mounting. As mentioned earlier, this intersection was upgraded to SCATS in 2010.

\subsubsection{Powell Boulevard and $39^{\text {th }}$ Avenue}

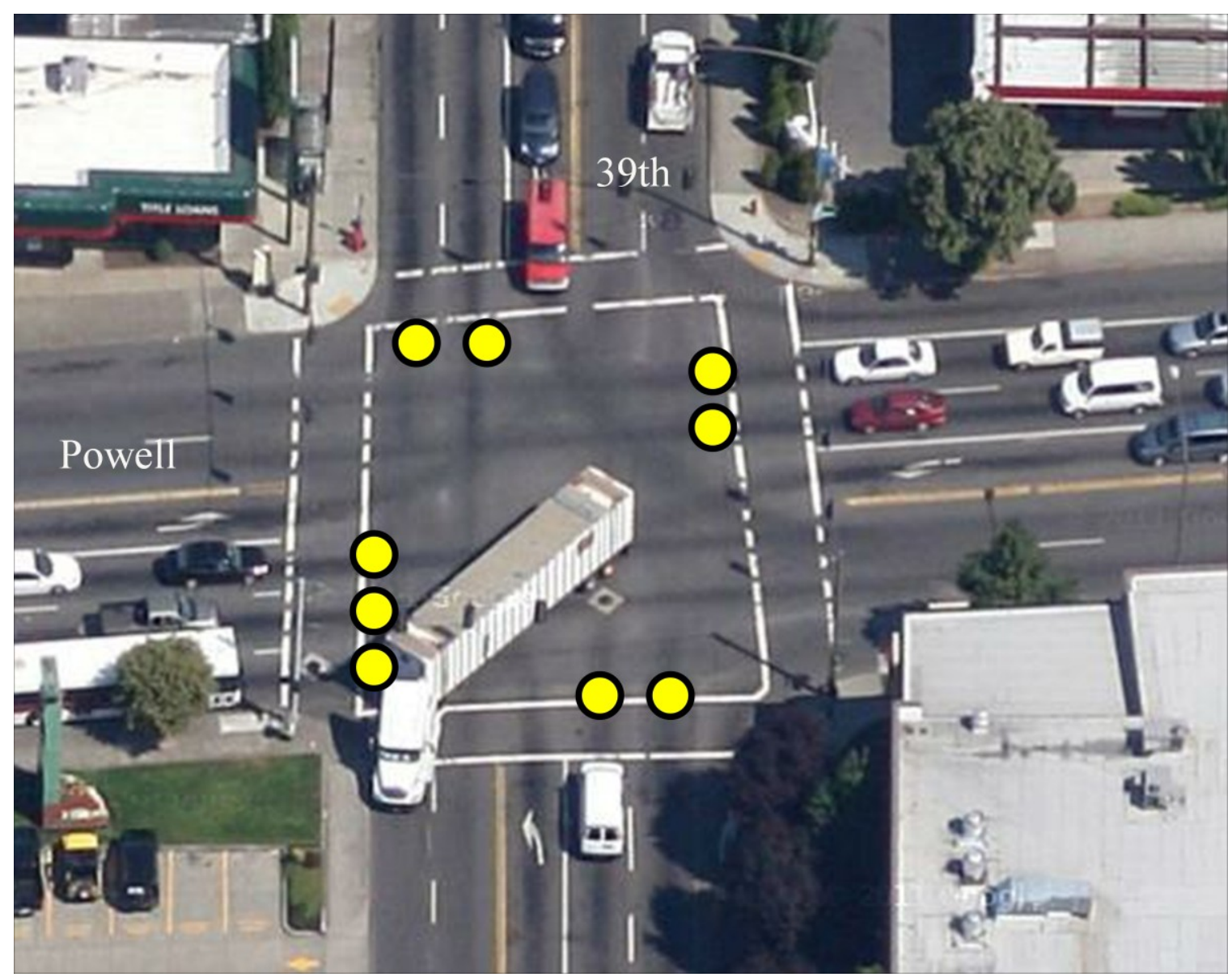

Figure 10: Powell Boulevard and 39th Avenue ${ }^{8}$

The Powell Boulevard and $39^{\text {th }}$ Avenue intersection features two lanes in each direction with an additional through/right turn lane in the eastbound direction. This additional through/right turn lane also has a corresponding red extension loop detector as

\footnotetext{
${ }^{8}$ Aerial image source: Google maps
} 
seen in Figure 10. This intersection uses a span wire mounting for the signal heads and features SCATS, effective 2010.

\subsubsection{Powell Boulevard and Milwaukie Avenue}

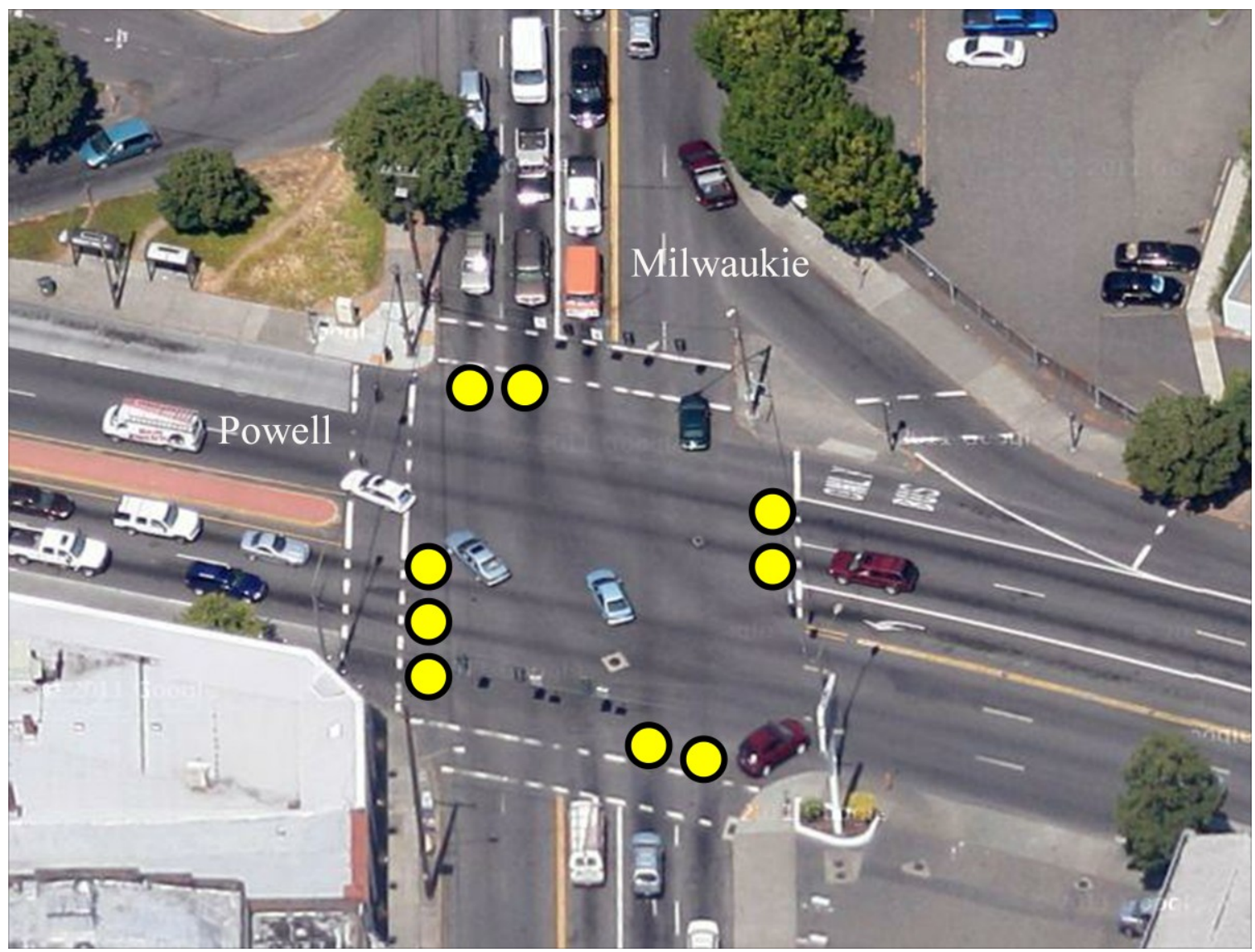

Figure 11: Powell Boulevard and Milwaukie Avenue?

The Powell Boulevard and Milwaukie Avenue intersection has some of the highest AADT for the Powell Boulevard corridor. The intersection features two lanes in each direction, and left turn lanes in the northbound, southbound, and westbound directions. Separated right turn lanes are present for the west and southbound directions.

\footnotetext{
${ }^{9}$ Aerial image source: Google maps
} 


\subsection{5 $122^{\text {nd }}$ Avenue Intersections}

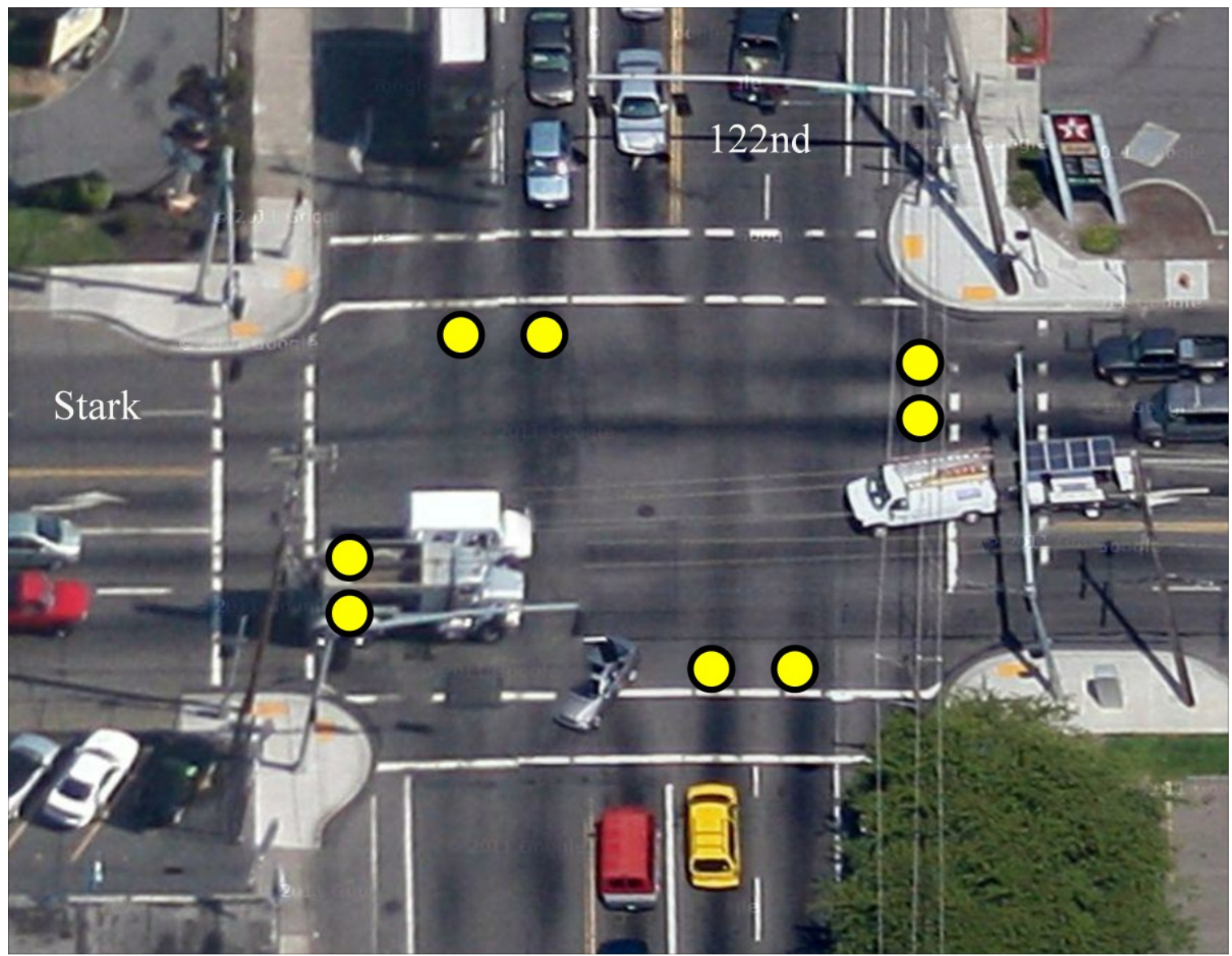

Figure 12: 122nd Avenue and Stark Street ${ }^{10}$

Figure 12 shows the intersection of $122^{\text {nd }}$ Avenue and Stark Street. The treatment intersections located along the $122^{\text {nd }}$ Avenue corridor feature similar intersection geometries and layouts. All intersections feature two lanes of traffic for each direction with left turn lanes also present. Depending on location, right turn lanes may also be present. All intersections feature mast arm signal head supports.

\footnotetext{
${ }^{10}$ Aerial image source: Google maps
} 
In addition to the study locations described above, 10 comparison intersections were also chosen. The comparison group includes intersections that are in the same geographical area as the study intersections, have similar geometric design, and have similar traffic and crash volumes. These comparison group intersections are listed in Table 2 and are shown in Figure 13 along with the treatment intersections.

\section{Table 2: Comparison Group Intersections}

\begin{tabular}{|l|}
\hline Comparison Group Intersections \\
\hline $82^{\text {nd }}$ Avenue and Division Street \\
\hline $82^{\text {nd }}$ Avenue and Foster Road \\
\hline Milwaukie Avenue and Holgate Boulevard \\
\hline Powell Boulevard and $26^{\text {th }}$ Avenue \\
\hline $82^{\text {nd }}$ Avenue and Holgate Boulevard \\
\hline $102^{\text {nd }}$ Avenue and Glisan Street \\
\hline $148^{\text {th }}$ Avenue and Division Street \\
\hline $122^{\text {nd }}$ Avenue and Powell Boulevard \\
\hline $39^{\text {th }}$ Avenue (Cesar E. Chavez Avenue) and Division Street \\
\hline $162^{\text {nd }}$ Avenue and Stark Street \\
\hline
\end{tabular}




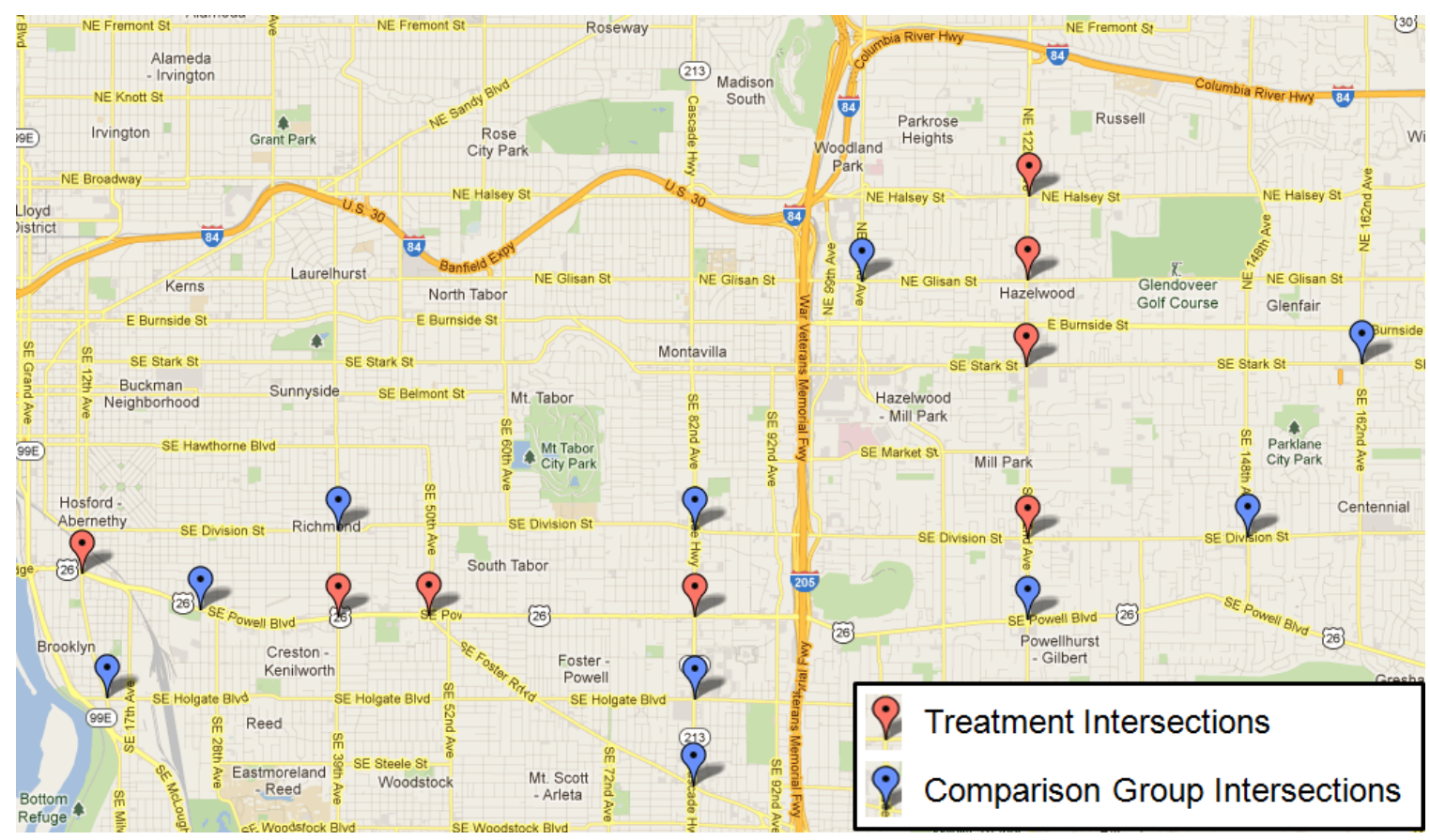

Figure 13: Map of Treatment and Comparison Group Intersections ${ }^{11}$

\subsection{Crash Data}

Crash data was obtained from the Oregon Department of Transportation via the City of Portland. The Oregon Department of Transportation's Crash Data System (CDS) allows for the retrieval of crash data, however, it only provides data up to five years old. Since the City of Portland keeps an ongoing database of crashes within the city, crashes for years 2000 through 2010 were obtained from the City. Crash data for 2011 was obtained directly from the Oregon Department of Transportation's CDS ${ }^{12}$.

The crash data include a variety of details for each crash. Each crash lists the vehicles involved along with the participants involved. Information regarding date, time, road conditions, collision type, etc., are provided with the crash data.

\footnotetext{
${ }^{11}$ Base-map source: Google maps

${ }^{12} \mathrm{https}$ ://zigzag.odot.state.or.us/
} 


\subsection{Volume Data}

For each approach at each intersection, Annual Average Daily Traffic (AADT) is required per year. For roads that are part of the Oregon Department of Transportation's highway system, yearly AADT values are measured and computed at various locations along that road by ODOT. Since Powell Boulevard is also a state highway, AADT values were readily available. Just like Powell Boulevard, $82^{\text {nd }}$ Avenue is also a state highway (OR213); therefore, yearly AADT values were also available.

Figure 14 shows an example of a Transportation Volume Table available through ODOT (Oregon Department of Transportation, 2010). The first column indicates the mile point on the highway where the AADT value is estimated. As noted in bold text in Figure 14, the mile point is measured from Pacific Highway West (OR99W). Column two is the AADT value for that year, and the third column is the description of the count location.

\section{MT. HOOD HIGHWAY NO. 26}

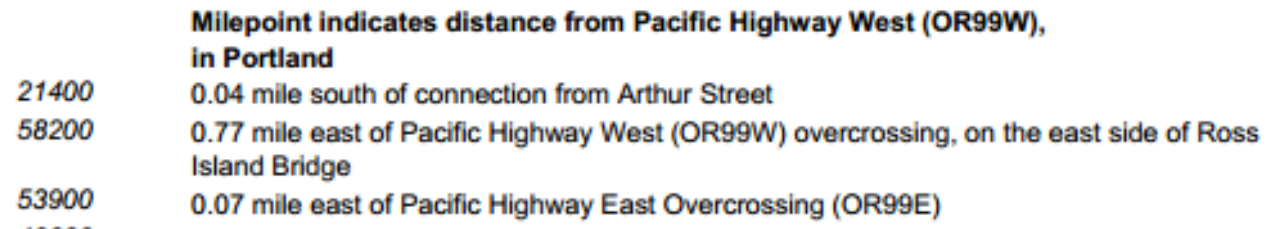

Figure 14: ODOT Transportation Volume Table 
When a location has two AADT values for positions on either side of the intersection, an average of those two values was used. For example, to determine an AADT value for S.E. $52^{\text {nd }}$ Avenue, an average of 21,900 and 23,700 AADT would be taken to get 22,800 AADT.

For streets that are not part of ODOT's highway network, obtaining reliable AADT values for each year can be difficult. The City of Portland hosts a website called PortlandMaps. Through this web interface, a variety of information can be obtained, including but not limited to, speed zones, historic traffic counts, turn movement counts, property information, and crime statistics. 


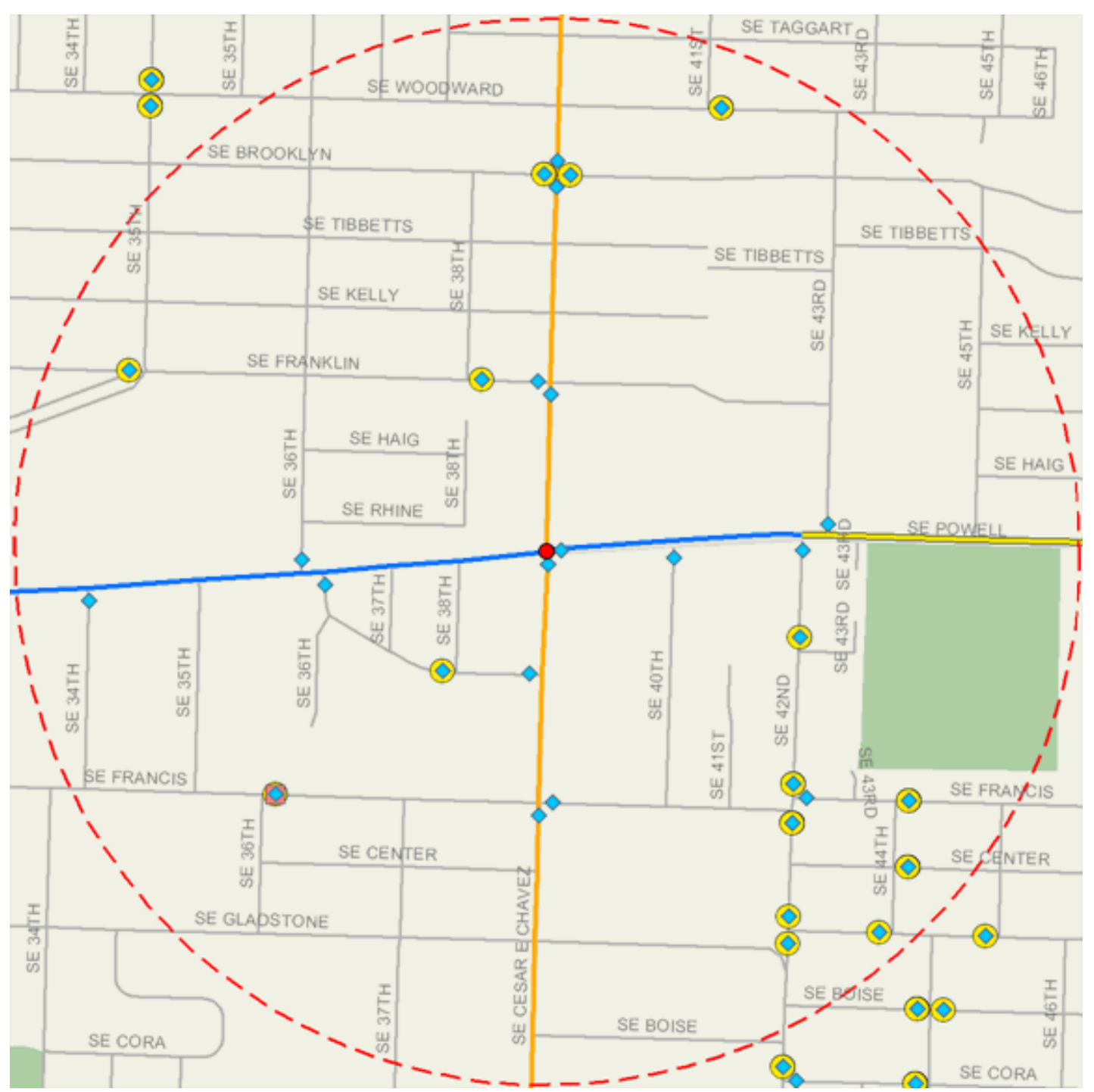

Figure 15: PortlandMaps Sample showing Traffic Count Locations near SE Powell Boulevard and SE 39th Avenue ${ }^{13}$

Figure 15 shows a sample map indicating traffic count locations (diamonds) within 2000 feet of the intersection of SE Powell Boulevard and SE $39^{\text {th }}$ Avenue for the last 10 years.

\footnotetext{
${ }^{13}$ Image source: portlandmaps.com
} 
Table 3: Sample Volume Data from PortlandMaps

\begin{tabular}{|c|c|c|c|c|}
\hline Location Description & Bound & Date & $\begin{array}{l}\text { Average Daily } \\
\text { Traffic Volume }\end{array}$ & Time of Week \\
\hline SE $39^{\text {th }}$ Ave / S. SE Powell Blvd & $\mathrm{N}$ & $11 / 03 / 2004$ & 10207 & Normal Weekday \\
\hline SE $39^{\text {th }}$ Ave / S. SE Powell Blvd & $\mathrm{S}$ & $11 / 03 / 2004$ & 9702 & Normal Weekday \\
\hline SE $39^{\text {th }}$ Ave / S. SE Powell Blvd & $\mathrm{N}$ & $11 / 08 / 2004$ & 9886 & Normal Weekday \\
\hline SE $39^{\text {th }}$ Ave / S. SE Powell Blvd & $\mathrm{S}$ & $11 / 08 / 2004$ & 9160 & Normal Weekday \\
\hline
\end{tabular}

Table 3 shows a sample of the available traffic volume counts that are available. On $11 / 03 / 2004$ and $11 / 08 / 2004$, a volume count was performed in the north and southbound directions at SE $39^{\text {th }}$ Avenue and SE Powell Boulevard. The location description states that the counts were performed on SE $39^{\text {th }}$ Avenue south of SE Powell Boulevard. The Average Daily Traffic (ADT) volumes are provided along with information on the Time of Week. With each location having measured ADT values separated by direction, the first step in converting the by-direction ADT values to AADT values is to sum both directions' ADT volumes together. This results in an ADT value for $11 / 03 / 2004$ of 19,909 and 19,046 for $11 / 08 / 2004$. Both of these counts were performed on normal weekdays in the same month and year, just days apart. Prior to converting these values to AADT, an average ADT value was calculated for the month of November to be 19,478 . The next step in converting the ADT values to AADT is to apply a growth factor.

In order to adjust ADT values to AADT values, monthly growth factors were applied. For counts performed within Portland, Oregon, monthly growth factors were derived from an Automatic Traffic Recorder (ATR) located in Gresham Oregon per guidance from ODOT (Tanner, 2012). For every year back to 1986, ODOT keeps records 
of the trend summaries of Permanent ATR's located in Oregon. An example of the data that is available is shown in Table 4.

Table 4: Sample data from ODOT Gresham ATR Trend Summary Report for 2010

\begin{tabular}{|l|c|c|}
\hline Month & Average Daily Traffic & Percent of ADT \\
\hline January & 30865 & 96 \\
\hline February & 32511 & 101 \\
\hline March & 32913 & 102 \\
\hline April & 32934 & 102 \\
\hline May & 32529 & 101 \\
\hline June & 33555 & 104 \\
\hline July & 34066 & 106 \\
\hline August & 33741 & 105 \\
\hline September & 32800 & 102 \\
\hline October & 30705 & 95 \\
\hline November & 29331 & 91 \\
\hline December & 31325 & 97 \\
\hline
\end{tabular}

In addition to the trend summaries per month, AADT is provided for each year. Using a combination of yearly AADT values and the percent of ADT values for each month, monthly growth and yearly growth tables were created to adjust all one day counts obtained from the City of Portland. 
Table 5: Monthly Growth Factors for One-day Counts

\begin{tabular}{|l|c|c|c|c|c|c|c|c|c|c|c|c|}
\hline & \multicolumn{10}{|c|}{ Percent of AADT for Weekday Traffic } \\
\hline & $\mathbf{2 0 0 0}$ & $\mathbf{2 0 0 1}$ & $\mathbf{2 0 0 2}$ & $\mathbf{2 0 0 3}$ & $\mathbf{2 0 0 4}$ & $\mathbf{2 0 0 5}$ & $\mathbf{2 0 0 6}$ & $\mathbf{2 0 0 7}$ & $\mathbf{2 0 0 8}$ & $\mathbf{2 0 0 9}$ & $\mathbf{2 0 1 0}$ & $\mathbf{2 0 1 1}$ \\
\hline January & 94 & 95 & 92 & 95 & 87 & 94 & 98 & 95 & 98 & 94 & 96 & 97 \\
\hline February & 98 & 97 & 98 & 98 & 104 & 98 & 101 & 98 & 102 & 98 & 101 & 100 \\
\hline March & 98 & 97 & 97 & 96 & 104 & 99 & 102 & 100 & 102 & 98 & 102 & 101 \\
\hline April & 100 & 99 & 98 & 99 & 105 & 100 & 103 & 101 & 102 & 101 & 102 & 101 \\
\hline May & 100 & 102 & 100 & 101 & 102 & 101 & 100 & 101 & 101 & 101 & 101 & 100 \\
\hline June & 105 & 104 & 104 & 105 & 107 & 105 & 103 & 104 & 102 & 103 & 104 & 103 \\
\hline July & 105 & 106 & 106 & 106 & 110 & 106 & 104 & 104 & 106 & 105 & 106 & 105 \\
\hline August & 106 & 107 & 106 & 106 & 106 & 106 & 104 & 105 & 107 & 105 & 105 & 106 \\
\hline September & 102 & 101 & 103 & 101 & 101 & 100 & 96 & 101 & 104 & 102 & 102 & 100 \\
\hline October & 99 & 97 & 99 & 99 & 95 & 97 & 97 & 96 & 100 & 98 & 95 & 97 \\
\hline November & 95 & 95 & 96 & 96 & 89 & 96 & 92 & 94 & 94 & 96 & 91 & 93 \\
\hline December & 98 & 101 & 100 & 98 & 91 & 98 & 100 & 99 & 82 & 98 & 97 & 97 \\
\hline
\end{tabular}

Table 5 shows the growth factors to be applied for counts performed in each month from 2000 through 2011. In the example used earlier, an average ADT value of 19,046 was calculated at $39^{\text {th }}$ Avenue south of Powell Boulevard. This count was performed in November, 2004. To adjust this volume to AADT the following equation is used:

$$
\mathrm{AADT}=\mathrm{ADT} /(\text { Monthly Growth Factor) }
$$

Using a monthly growth factor of $89 \%$, a resultant AADT value of 21,900 was obtained rounded to the nearest hundred.

Unfortunately counts are not available for every year. In these cases, a yearly growth factor was applied to estimate AADT for years before and after a year in which counts were available. Continuing to use the same location as before, the following table was produced. 
Table 6: AADT Calculation Table for 39th Avenue at Powell Boulevard

\begin{tabular}{|c|c|c|c|c|c|}
\hline Year & $\begin{array}{c}\text { \% Change AADT } \\
\text { on Powell Blvd }\end{array}$ & AADT & ADT & Date & Location \\
\hline 2000 & 100 & 23700 & & & \\
\hline 2001 & 101 & 24000 & & & \\
\hline 2002 & 101 & 24300 & & & \\
\hline 2003 & 78 & 18900 & 20028 & $7 / 1 / 2003$ & S of Int \\
\hline 2004 & 99 & 21900 & 19909 & $11 / 3 / 2004$ & S of Int \\
\hline 2005 & 102 & 20100 & 19046 & $11 / 8 / 2004$ & S of Int \\
\hline 2006 & 96 & 18400 & 18942 & $6 / 5 / 2006$ & S of Int \\
\hline 2007 & 99 & 20900 & & & \\
\hline 2008 & 96 & 23300 & 23349 & $10 / 29 / 2008$ & N of Int \\
\hline 2009 & 96 & 23100 & 24111 & $7 / 27 / 2010$ & N of Int \\
\hline 2010 & 1.00 & 22800 & 23962 & $8 / 2 / 2010$ & N of Int \\
\hline 2011 & 95 & 21600 & & & \\
\hline
\end{tabular}

AADT values for the years 2003, 2006, 2008, and 2010 were calculated from the traffic counts obtained from PortlandMaps. For years 2005, 2007, and 2009, an average of neighboring years was used. For example, the AADT for 2005 was the average of 2004's AADT and 2006's AADT. For years prior to 2003 and for 2011, a yearly growth factor was applied to estimate the AADT for those years.

Yearly AADT values for years where no counts were performed were calculated in one of two ways. If yearly AADT values were available for the cross street, the percent change in AADT from year to year was calculated for that cross street and the corresponding percent change was applied to the years that AADT was missing for the street in question. For example, in Table 6 , there is a column labeled "\% Change AADT". This column corresponds to the \% change in AADT from year to year of the Powell Boulevard AADT values at $39^{\text {th }}$ Avenue. It was assumed that whatever change that occurred for the cross street also translated to the other street and was a more accurate 
growth factor than that of the Gresham ATR. One example on how the growth factors were used is to take the 2010 AADT value from Table 6 of 22,800. To obtain the 2011 AADT value or any future value, the following equation would be used:

$$
\mathrm{AADT}_{\mathrm{FY}}=\mathrm{AADT}_{\mathrm{CY}} *(\% \text { Change } \mathrm{AADT})_{\mathrm{FY}}
$$

Where FY is Future Year and CY is Current Year. Therefore, the AADT for 2011 would be:

$$
\begin{gathered}
\mathrm{AADT}_{2011}=22,800 * 0.95 \\
\mathrm{AADT}_{2011}=21,600
\end{gathered}
$$

To obtain the 2003 AADT or any past value, equation (2) is rearranged to read:

$$
\mathrm{AADT}_{\mathrm{CY}}=\mathrm{AADT}_{\mathrm{FY}} /(\% \text { Change AADT })_{\mathrm{FY}}
$$

The calculation for the year 2002 AADT value is:

$$
\begin{gathered}
\mathrm{AADT}_{2002}=18,900 / 0.78 \\
\mathrm{AADT}_{2011}=24,300
\end{gathered}
$$

When there were no ODOT AADT values for either street, the Gresham ATR's yearly AADT values were used to estimate yearly AADT growth factors.

Table 7: Yearly AADT and Growth Factors for AADT (2000-2005)

\begin{tabular}{|l|c|c|c|c|c|c|}
\hline \multicolumn{6}{|c|}{ Yearly AADT and Growth of AADT from Previous Year - Gresham ATR } \\
\hline & $\mathbf{2 0 0 0}$ & $\mathbf{2 0 0 1}$ & $\mathbf{2 0 0 2}$ & $\mathbf{2 0 0 3}$ & $\mathbf{2 0 0 4}$ & $\mathbf{2 0 0 5}$ \\
\hline AADT & 37168 & 37504 & 38790 & 39138 & 37657 & 33743 \\
\hline Growth & 1.00 & 1.01 & 1.03 & 1.01 & 0.96 & 0.90 \\
\hline
\end{tabular}


Table 8: Yearly AADT and Growth Factors for AADT (2006-2011)

\begin{tabular}{|l|c|c|c|c|c|c|}
\hline \multicolumn{6}{|c|}{ Yearly AADT and Growth of AADT from Previous Year - Gresham ATR } \\
\hline & $\mathbf{2 0 0 6}$ & $\mathbf{2 0 0 7}$ & $\mathbf{2 0 0 8}$ & $\mathbf{2 0 0 9}$ & $\mathbf{2 0 1 0}$ & $\mathbf{2 0 1 1}$ \\
\hline AADT & 33471 & 33225 & 31776 & 32252 & 32273 & 30530 \\
\hline Growth & 0.99 & 0.99 & 0.96 & 1.01 & 1.00 & 0.95 \\
\hline
\end{tabular}

Table 7 and Table 8 show the yearly AADT values for the Gresham ATR for 2000 through 2011. Using 2000 as a base year (Growth $=100 \%)$, the change in AADT from the previous year is listed in the growth column for that year. For example, the change in AADT from 2010 to 2011 was 95\%, or in other words, the AADT in 2011 is $95 \%$ of 2010's AADT. Equations (2) and (4) can be used the same way, independent of how the growth factors were calculated. For the raw data, see the appendix.

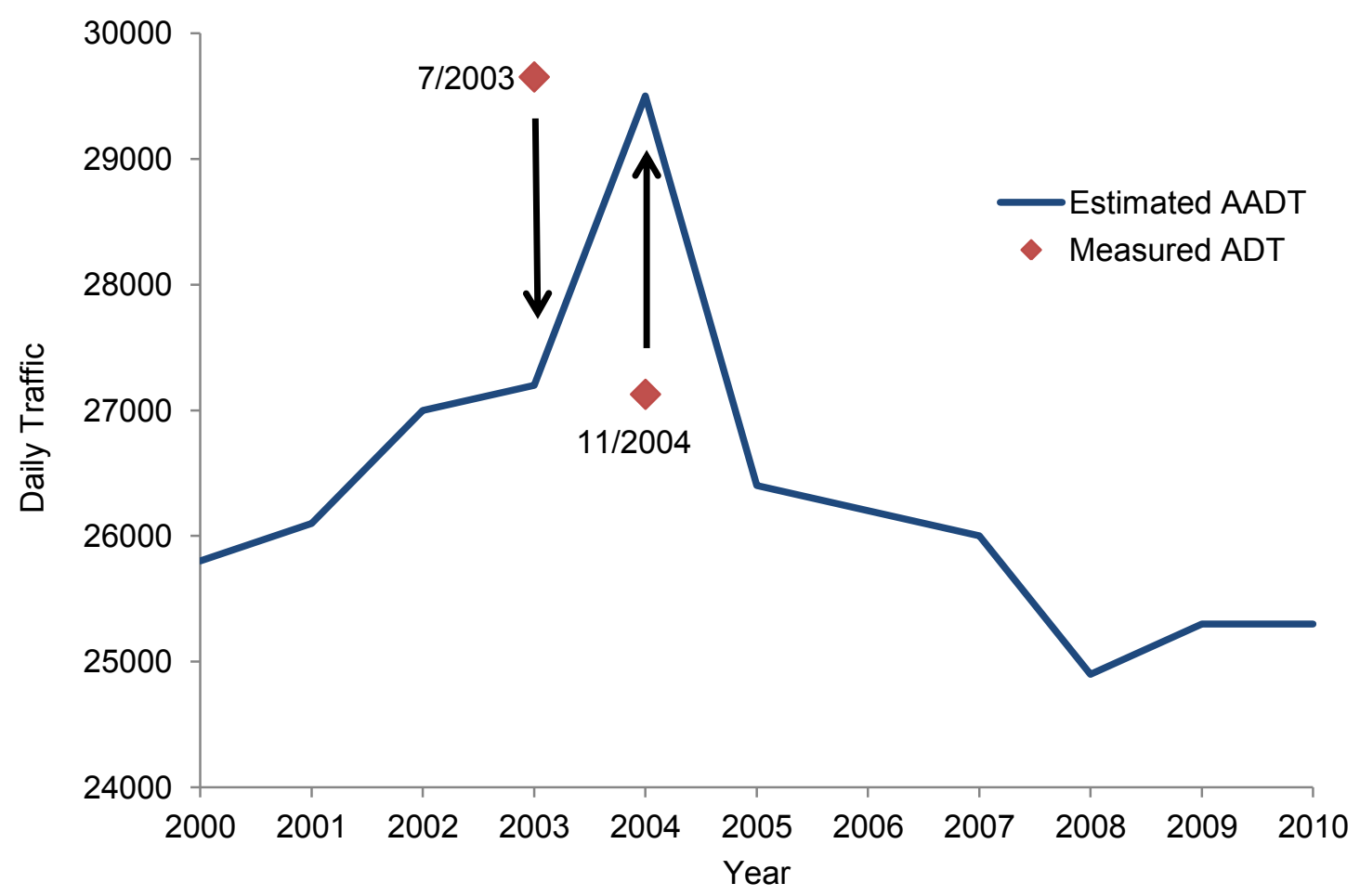

Figure 16: Example Plot showing Measure ADT and Estimated AADT for $122^{\text {nd }}$ Avenue at Halsey Street 
Figure 16 shows an example of a location where there were two traffic counts on one of the streets at an intersection. At the intersection of $122^{\text {nd }}$ Avenue and Halsey Street, $122^{\text {nd }}$ Avenue had two traffic counts that were performed, one in July of 2003 and one in November 2004. These counts were adjusted using the procedures described earlier, and AADT estimates were determined for these two years. From these years, estimated AADT values for future and past years were calculated from the growth factors found in Table 7 and Table 8.

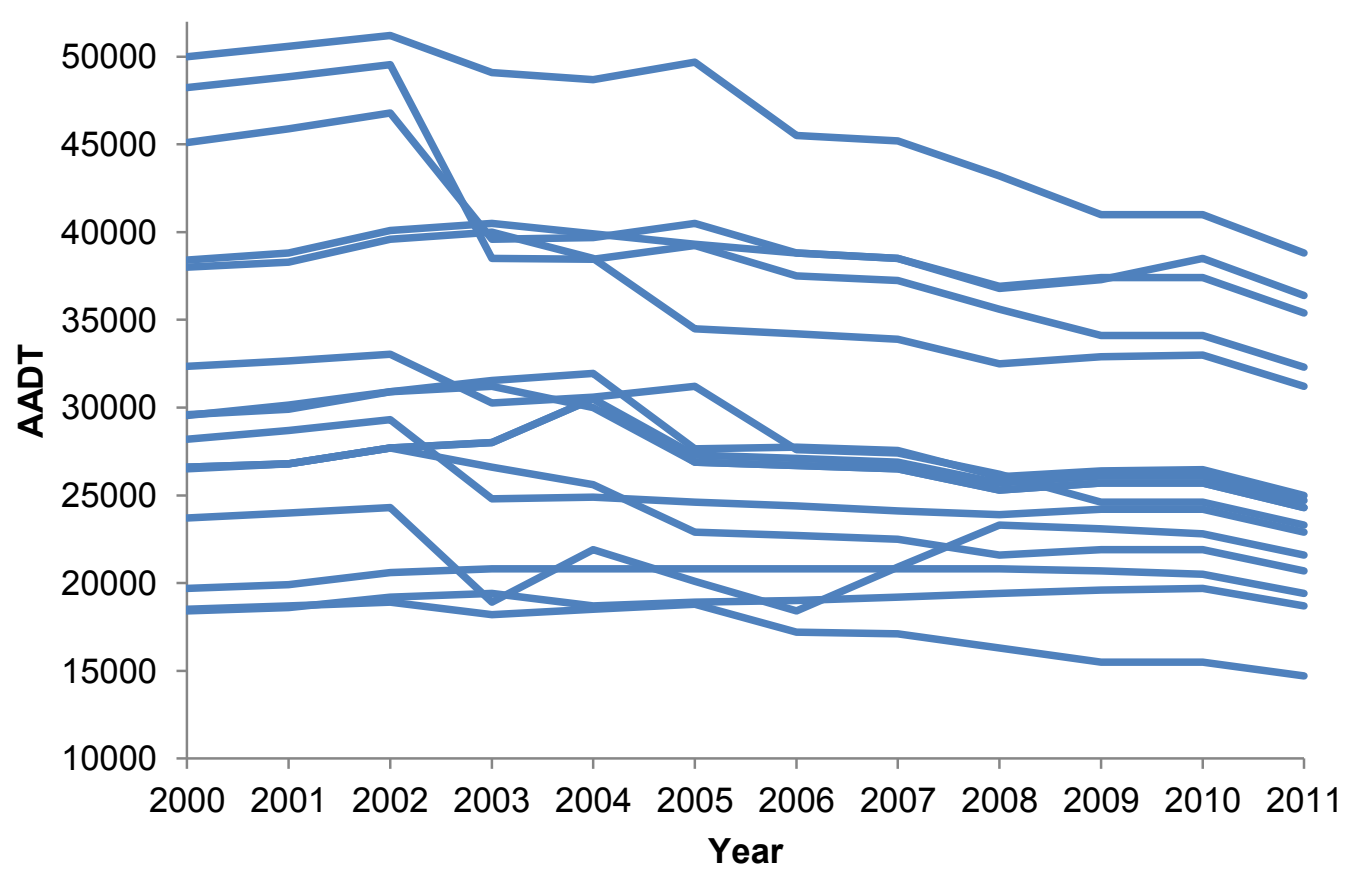

Figure 17: Plot of all Approach Leg AADT Values for the Treatment Intersections

Figure 17 shows the AADT values for each leg at the treatment intersections for the years 2000 through 2011. A general trend in a decreasing AADT values can be seen. 


\subsection{Intersection Details}

In addition to crashes and volumes, the following information was required for each intersection:

- Intersection type

- Presence of intersection lighting

- Calibration factor

- Number of approaches with left turn lanes

- Number of approaches with right turn lanes

- Number of approaches with left turn signal phasing

- Type of left turn signal phasing for each leg

- Number of approaches with right turn on red prohibited

- Presence of intersection red light cameras

- Sum of all pedestrian crossing volumes per day

- Maximum number of lanes crossed by a pedestrian

- Number of bus stops within 1000 feet of the intersection

- Presence of schools within 1000 feet of the intersection

- Number of alcohol establishments within 1000 feet of the intersection

Intersection type falls into one of four categories:

- Signalized four-leg intersection (4SG)

- Unsignalized four-leg intersection (4ST)

- $\quad$ Signalized three-leg intersection (3SG) 
- Unsignalized three-leg intersection (3ST)

Intersection lighting refers to the presence or absence of roadway lighting at the intersection. The calibration factor was provided by research for Oregon based upon locally derived crash proportions to be 1.05 for signalized four-leg intersections (Dixon, Monsere, Xie, \& Gladhill, 2012). A different calibration factor was not available for signalized four-leg intersections that run on SCATS. The number of approaches with left turn lanes and right turn lanes, the number of approaches with right turn on red prohibited, the presence of intersection red light cameras, and the maximum number of lanes crossed by a pedestrian were verified by field visits and/or by using Google maps and Google street view. The number of approaches with left turn signal phasing and the phasing for each leg were determined by the City of Portland Central Signal System, TransSuite. Since actual values of all pedestrian crossing volumes per day were not available, an estimated number of 700 was determined from Table 12-21 of the HSM (Highway Safety Manual, 2010). For the location of Powell Boulevard and $82^{\text {nd }}$ Avenue, a pedestrian crossing volume of 1,200 was estimated per day. This value was obtained from PORTAL using pedestrian actuations. The provided pedestrian actuations were approximately 600 for the east/west crossing. Assuming that there is one pedestrian per actuation, and doubling this value to account for the north/south movement, 1,200 pedestrians per day was obtained. 


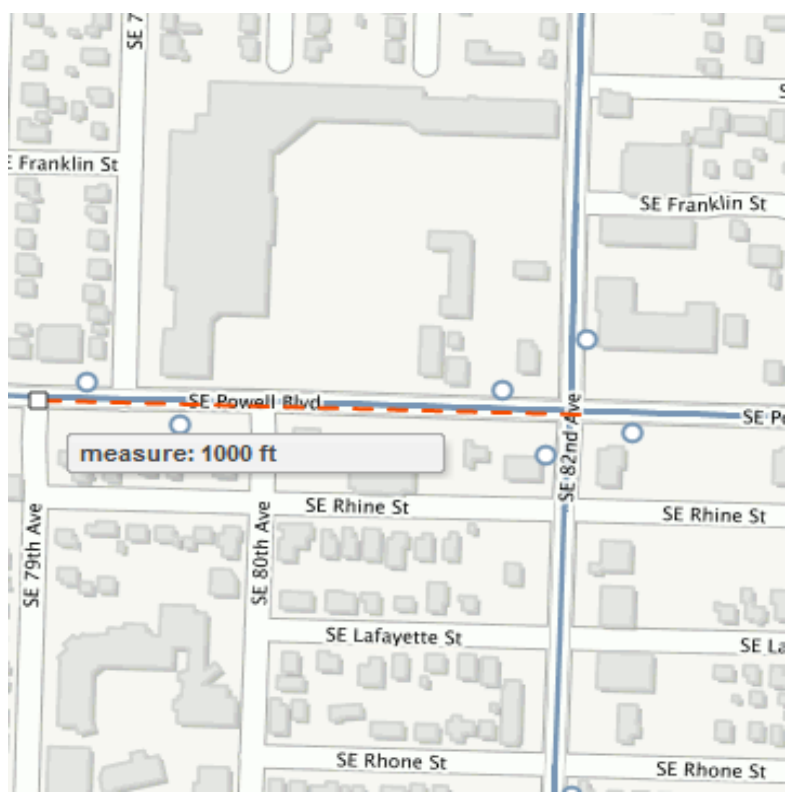

Figure 18: TriMet's Interactive Map Showing Bus Stops ${ }^{14}$

Figure 18 shows a sample map from TriMet's interactive route map. With the provided measuring tool, the number of bus stops within 1000 feet of each intersection was determined. PortlandMaps was used to determine the presence of schools within 1000 feet of an intersection. To determine the number of alcohol establishments within 1000 feet of an intersection, an ArcGIS shapefile was obtained from Metro with the locations of alcohol establishments in Portland. A summary of the intersection details is seen in Table 9 and Table 10 for the treatment intersections.

\footnotetext{
${ }^{14}$ Image source: TriMet, http://ride.trimet.org
} 
Table 9: Intersection Details for Powell Boulevard Corridor

\begin{tabular}{|c|c|c|c|c|}
\hline & $\begin{array}{l}\text { Powell \& } \\
\text { 82nd }\end{array}$ & $\begin{array}{c}\text { Powell \& } \\
\text { 50th }\end{array}$ & $\begin{array}{c}\text { Powell \& } \\
\text { 39th }\end{array}$ & $\begin{array}{l}\text { Powell \& } \\
\text { Milwaukie }\end{array}$ \\
\hline Intersection Type & $4 \mathrm{SG}$ & $4 \mathrm{SG}$ & 4SG & 4SG \\
\hline AADT Major (veh/day) & (varies) & (varies) & (varies) & (varies) \\
\hline AADT Minor (veh/day) & (varies) & (varies) & (varies) & (varies) \\
\hline Intersection lighting (present/not present) & present & present & present & present \\
\hline Calibration factor, $\mathrm{C}_{\mathrm{i}}$ & 1.05 & 1.05 & 1.05 & 1.05 \\
\hline Number of approaches w/ left-turn lanes & 4 & 2 & 4 & 3 \\
\hline Number of approaches w/ right-turn lanes & 1 & 2 & 2 & 2 \\
\hline $\begin{array}{l}\text { Number of approaches with left-turn } \\
\text { signal phasing }\end{array}$ & 4 & 3 & 4 & 3 \\
\hline Type of left-turn signal phasing for leg\#1 & protected & protected & protected & protected \\
\hline Type of left-turn signal phasing for leg\#2 & protected & protected & protected & protected \\
\hline Type of left-turn signal phasing for leg\#3 & protected & protected & protected & protected \\
\hline Type of left-turn signal phasing for leg $\# 4$ & protected & $\mathrm{n} / \mathrm{a}$ & protected & $\mathrm{n} / \mathrm{a}$ \\
\hline $\begin{array}{l}\text { Number of approaches with right-turn-on- } \\
\text { red prohibited }\end{array}$ & 0 & 0 & 0 & 0 \\
\hline $\begin{array}{l}\text { Intersection red light cameras (present/not } \\
\text { present) }\end{array}$ & $\begin{array}{c}\text { not } \\
\text { present }\end{array}$ & $\begin{array}{c}\text { not } \\
\text { present }\end{array}$ & $\begin{array}{c}\text { not } \\
\text { present }\end{array}$ & not present \\
\hline $\begin{array}{l}\text { Sum of all pedestrian crossing volumes } \\
\text { (Peds/Day) }\end{array}$ & 1200 & 700 & 700 & 700 \\
\hline $\begin{array}{l}\text { Maximum number of lanes crossed by a } \\
\text { pedestrian }\end{array}$ & 7 & 6 & 7 & 6 \\
\hline $\begin{array}{l}\text { Number of bus stops within } 1000 \mathrm{ft} \text { of } \\
\text { intersection }\end{array}$ & 10 & 13 & 11 & 7 \\
\hline $\begin{array}{l}\text { Schools within } 1000 \mathrm{ft} \text { of intersection } \\
\text { (present/not) }\end{array}$ & $\begin{array}{c}\text { not } \\
\text { present }\end{array}$ & present & $\begin{array}{c}\text { not } \\
\text { present }\end{array}$ & not present \\
\hline $\begin{array}{l}\text { Number of alcohol establishments w/i } \\
1000 \mathrm{ft}\end{array}$ & 1 & 1 & 0 & 3 \\
\hline
\end{tabular}


Table 10: Intersection Details for 122nd Avenue Corridor

\begin{tabular}{|l|c|c|c|c|}
\hline & $\begin{array}{c}\text { 122nd \& } \\
\text { Halsey }\end{array}$ & $\begin{array}{c}\text { 122nd \& } \\
\text { Glisan }\end{array}$ & $\begin{array}{c}\text { 122nd \& } \\
\text { Stark }\end{array}$ & $\begin{array}{c}\text { 122nd \& } \\
\text { Division }\end{array}$ \\
\hline Intersection Type & 4SG & 4SG & 4 SG & 4SG \\
\hline AADT_Major (veh/day) & (varies) & (varies) & (varies) & (varies) \\
\hline AADT Minor (veh/day) & (varies) & (varies) & (varies) \\
\hline Intersection lighting (present/not present) & present & present & present & present \\
\hline Calibration factor, C_i & 1.05 & 1.05 & 1.05 & 1.05 \\
\hline Number of approaches w/ left-turn lanes & 4 & 4 & 4 & 4 \\
\hline Number of approaches w/ right-turn lanes & 4 & 2 & 2 & 4 \\
\hline $\begin{array}{l}\text { Number of approaches with left-turn signal } \\
\text { phasing }\end{array}$ & 4 & 4 & 4 & 4 \\
\hline Type of left-turn signal phasing for leg\#1 & protected & protected & protected & protected \\
\hline Type of left-turn signal phasing for leg\#2 & protected & protected & protected & protected \\
\hline Type of left-turn signal phasing for leg\#3 & protected & protected & protected & protected \\
\hline Type of left-turn signal phasing for leg\#4 & protected & protected & protected & protected \\
\hline $\begin{array}{l}\text { Number of approaches with right-turn-on- } \\
\text { red prohibited }\end{array}$ & 0 & 0 & 0 & 0 \\
\hline $\begin{array}{l}\text { Intersection red light cameras (present/not } \\
\text { present) }\end{array}$ & $\begin{array}{c}\text { not } \\
\text { present }\end{array}$ & $\begin{array}{c}\text { not } \\
\text { present }\end{array}$ & $\begin{array}{c}\text { not } \\
\text { present }\end{array}$ & $\begin{array}{c}\text { not } \\
\text { present }\end{array}$ \\
\hline $\begin{array}{l}\text { Sum of all pedestrian crossing volumes } \\
\text { (Peds/Day) }\end{array}$ & 700 & 700 & 700 & 700 \\
\hline $\begin{array}{l}\text { Maximum number of lanes crossed by a } \\
\text { pedestrian }\end{array}$ & 6 & 6 & 6 & 6 \\
\hline $\begin{array}{l}\text { Number of bus stops within 1000ft of } \\
\text { intersection }\end{array}$ & 10 & 8 & 10 & 10 \\
\hline $\begin{array}{l}\text { Schools within 1000ft of intersection } \\
\text { (present/not) }\end{array}$ & $\begin{array}{c}\text { not } \\
\text { present }\end{array}$ & $\begin{array}{c}\text { not } \\
\text { present }\end{array}$ & $\begin{array}{c}\text { not } \\
\text { present }\end{array}$ & $\begin{array}{c}\text { not } \\
\text { present }\end{array}$ \\
\hline $\begin{array}{l}\text { Number of alcohol establishments w/i } \\
\text { 1000ft }\end{array}$ & 0 & 3 & 3 & 1 \\
\hline
\end{tabular}


Table 11: Intersection Details for Comparison Group - Part 1

\begin{tabular}{|c|c|c|c|c|}
\hline & $\begin{array}{l}\text { 82nd \& } \\
\text { Division }\end{array}$ & $\begin{array}{l}\text { 82nd \& } \\
\text { Foster }\end{array}$ & $\begin{array}{l}\text { Milwaukie } \\
\text { \& Holgate }\end{array}$ & $\begin{array}{l}\text { 26th \& } \\
\text { Powell }\end{array}$ \\
\hline Intersection Type & 4SG & $4 \mathrm{SG}$ & $4 \mathrm{SG}$ & $4 \mathrm{SG}$ \\
\hline AADT_Major (veh/day) & (varies) & (varies) & (varies) & (varies) \\
\hline AADT Minor (veh/day) & (varies) & (varies) & (varies) & (varies) \\
\hline Intersection lighting (present/not present) & present & present & present & present \\
\hline Calibration factor, $\mathrm{C}_{-} \mathrm{i}$ & 1.05 & 1.05 & 1.05 & 1.05 \\
\hline Number of approaches w/ left-turn lanes & 4 & 4 & 2 & 4 \\
\hline Number of approaches w/ right-turn lanes & 2 & 1 & 0 & 1 \\
\hline $\begin{array}{l}\text { Number of approaches with left-turn } \\
\text { signal phasing }\end{array}$ & 4 & 4 & 2 & 2 \\
\hline Type of left-turn signal phasing for leg\#1 & protected & protected & protected & protected \\
\hline Type of left-turn signal phasing for leg\#2 & protected & protected & protected & protected \\
\hline Type of left-turn signal phasing for leg\#3 & protected & protected & permissive & permissive \\
\hline Type of left-turn signal phasing for leg\#4 & protected & protected & permissive & permissive \\
\hline $\begin{array}{l}\text { Number of approaches with right-turn-on- } \\
\text { red prohibited }\end{array}$ & 0 & 0 & 0 & 0 \\
\hline $\begin{array}{l}\text { Intersection red light cameras (present/not } \\
\text { present) }\end{array}$ & $\begin{array}{c}\text { not } \\
\text { present }\end{array}$ & $\begin{array}{c}\text { not } \\
\text { present }\end{array}$ & not present & $\begin{array}{c}\text { not } \\
\text { present }\end{array}$ \\
\hline $\begin{array}{l}\text { Sum of all pedestrian crossing volumes } \\
\text { (Peds/Day) }\end{array}$ & 700 & 700 & 700 & 700 \\
\hline $\begin{array}{l}\text { Maximum number of lanes crossed by a } \\
\text { pedestrian }\end{array}$ & 6 & 6 & 4 & 6 \\
\hline $\begin{array}{l}\text { Number of bus stops within } 1000 \mathrm{ft} \text { of } \\
\text { intersection }\end{array}$ & 11 & 16 & 8 & 12 \\
\hline $\begin{array}{l}\text { Schools within } 1000 \mathrm{ft} \text { of intersection } \\
\text { (present/not) }\end{array}$ & present & $\begin{array}{c}\text { not } \\
\text { present }\end{array}$ & not present & present \\
\hline $\begin{array}{l}\text { Number of alcohol establishments w/i } \\
1000 f t\end{array}$ & 2 & 4 & 2 & 0 \\
\hline
\end{tabular}


Table 12: Intersection Details for Comparison Group - Part 2

\begin{tabular}{|l|c|c|c|c|}
\hline & $\begin{array}{c}\text { 82nd \& } \\
\text { Holgate }\end{array}$ & $\begin{array}{c}\text { 102nd \& } \\
\text { Glisan }\end{array}$ & $\begin{array}{c}\text { 148th \& } \\
\text { Division }\end{array}$ & $\begin{array}{c}\text { 122nd \& } \\
\text { Powell }\end{array}$ \\
\hline Intersection Type & 4SG & 4SG & 4 SG & 4SG \\
\hline AADT_Major (veh/day) & (varies) & (varies) & (varies) & (varies) \\
\hline AADT Minor (veh/day) & (varies) & (varies) & (varies) \\
\hline Intersection lighting (present/not present) & present & present & present & present \\
\hline Calibration factor, C_i & 1.05 & 1.05 & 1.05 & 1.05 \\
\hline Number of approaches w/ left-turn lanes & 4 & 4 & 4 & 4 \\
\hline Number of approaches w/ right-turn lanes & 0 & 1 & 4 & 3 \\
\hline $\begin{array}{l}\text { Number of approaches with left-turn signal } \\
\text { phasing }\end{array}$ & 4 & 4 & 4 & 4 \\
\hline Type of left-turn signal phasing for leg\#1 & protected & protected & protected & protected \\
\hline Type of left-turn signal phasing for leg\#2 & protected & protected & protected & protected \\
\hline Type of left-turn signal phasing for leg\#3 & protected & protected & protected & protected \\
\hline Type of left-turn signal phasing for leg\#4 & protected & protected & protected & protected \\
\hline $\begin{array}{l}\text { Number of approaches with right-turn-on- } \\
\text { red prohibited }\end{array}$ & 0 & 0 & 0 & 0 \\
\hline $\begin{array}{l}\text { Intersection red light cameras (present/not } \\
\text { present) }\end{array}$ & $\begin{array}{c}\text { not } \\
\text { present }\end{array}$ & $\begin{array}{c}\text { not } \\
\text { present }\end{array}$ & $\begin{array}{c}\text { not } \\
\text { present }\end{array}$ & $\begin{array}{c}\text { not } \\
\text { present }\end{array}$ \\
\hline $\begin{array}{l}\text { Sum of all pedestrian crossing volumes } \\
\text { (Peds/Day) }\end{array}$ & 700 & 700 & 700 & 700 \\
\hline $\begin{array}{l}\text { Maximum number of lanes crossed by a } \\
\text { pedestrian }\end{array}$ & 5 & 6 & 6 & 6 \\
\hline $\begin{array}{l}\text { Number of bus stops within 1000ft of } \\
\text { intersection }\end{array}$ & 9 & 8 & 6 & 10 \\
\hline $\begin{array}{l}\text { Schools within 1000ft of intersection } \\
\text { (present/not) }\end{array}$ & $\begin{array}{c}\text { not } \\
\text { present }\end{array}$ & $\begin{array}{c}\text { not } \\
\text { present }\end{array}$ & present & $\begin{array}{c}\text { not } \\
\text { present }\end{array}$ \\
\hline $\begin{array}{l}\text { Number of alcohol establishments w/i } \\
\text { 1000ft }\end{array}$ & 1 & 0 & 1 & 3 \\
\hline
\end{tabular}


Table 13: Intersection Details for Comparison Group - Part 3

\begin{tabular}{|c|c|c|}
\hline & $\begin{array}{l}\text { 39th \& } \\
\text { Division }\end{array}$ & $\begin{array}{l}\text { 162nd \& } \\
\text { Stark }\end{array}$ \\
\hline Intersection Type & $4 \mathrm{SG}$ & $4 \mathrm{SG}$ \\
\hline AADT_Major (veh/day) & (varies) & (varies) \\
\hline AADT Minor (veh/day) & (varies) & (varies) \\
\hline Intersection lighting (present/not present) & present & present \\
\hline Calibration factor, $\mathrm{C}_{\mathrm{i}}$ & 1.05 & 1.05 \\
\hline Number of approaches w/ left-turn lanes & 4 & 4 \\
\hline Number of approaches w/ right-turn lanes & 0 & 0 \\
\hline $\begin{array}{l}\text { Number of approaches with left-turn signal } \\
\text { phasing }\end{array}$ & 2 & 4 \\
\hline Type of left-turn signal phasing for leg\#1 & protected & protected \\
\hline Type of left-turn signal phasing for leg\#2 & protected & protected \\
\hline Type of left-turn signal phasing for leg\#3 & permissive & protected \\
\hline Type of left-turn signal phasing for leg\#4 & permissive & protected \\
\hline $\begin{array}{l}\text { Number of approaches with right-turn-on- } \\
\text { red prohibited }\end{array}$ & 0 & 0 \\
\hline $\begin{array}{l}\text { Intersection red light cameras (present/not } \\
\text { present) }\end{array}$ & $\begin{array}{c}\text { not } \\
\text { present }\end{array}$ & $\begin{array}{c}\text { not } \\
\text { present }\end{array}$ \\
\hline $\begin{array}{l}\text { Sum of all pedestrian crossing volumes } \\
\text { (Peds/Day) }\end{array}$ & 700 & 700 \\
\hline $\begin{array}{l}\text { Maximum number of lanes crossed by a } \\
\text { pedestrian }\end{array}$ & 5 & 5 \\
\hline $\begin{array}{l}\text { Number of bus stops within } 1000 \mathrm{ft} \text { of } \\
\text { intersection }\end{array}$ & 10 & 5 \\
\hline $\begin{array}{l}\text { Schools within } 1000 \mathrm{ft} \text { of intersection } \\
\text { (present/not) }\end{array}$ & present & $\begin{array}{c}\text { not } \\
\text { present }\end{array}$ \\
\hline $\begin{array}{l}\text { Number of alcohol establishments w/i } \\
1000 f t\end{array}$ & 2 & 2 \\
\hline
\end{tabular}

Table 11 through Table 13 show the intersection details for the comparison group intersections used in the before and after crash analysis. 


\subsection{BEFORE AND AFTER CRASH ANALYSIS}

Three methods were employed to analyze the before and after crashes at each of the eight locations with red extensions. These methods are:

- Simple

- Comparison Group

- Empirical-Bayes (EB)

Spreadsheets were created for each of the three methods to aid in the before and after analysis.

The Comparison Group and Empirical-Bayes methods followed the guidelines as defined by the Highway Safety Manual (HSM) published by the American Association of State Highway and Transportation Officials (AASHTO). Any deviations of these guidelines are discussed in the representative chapters.

As discussed earlier, the crash type that is most likely to be related to red light running related crashes are angle collisions. Angle crashes are crashes that occur when vehicles travelling in crossing paths collide. Additional focus is on specific crash type.

\subsection{Data Exploration}

Before any of the crash analysis methods were performed, a variety of graphs was created to better visualize the crash data that was available for the eight treatment intersections and to detect any trends in the data. All graphs located in this section show crash data and statistics for the years 2000 through 2011. 


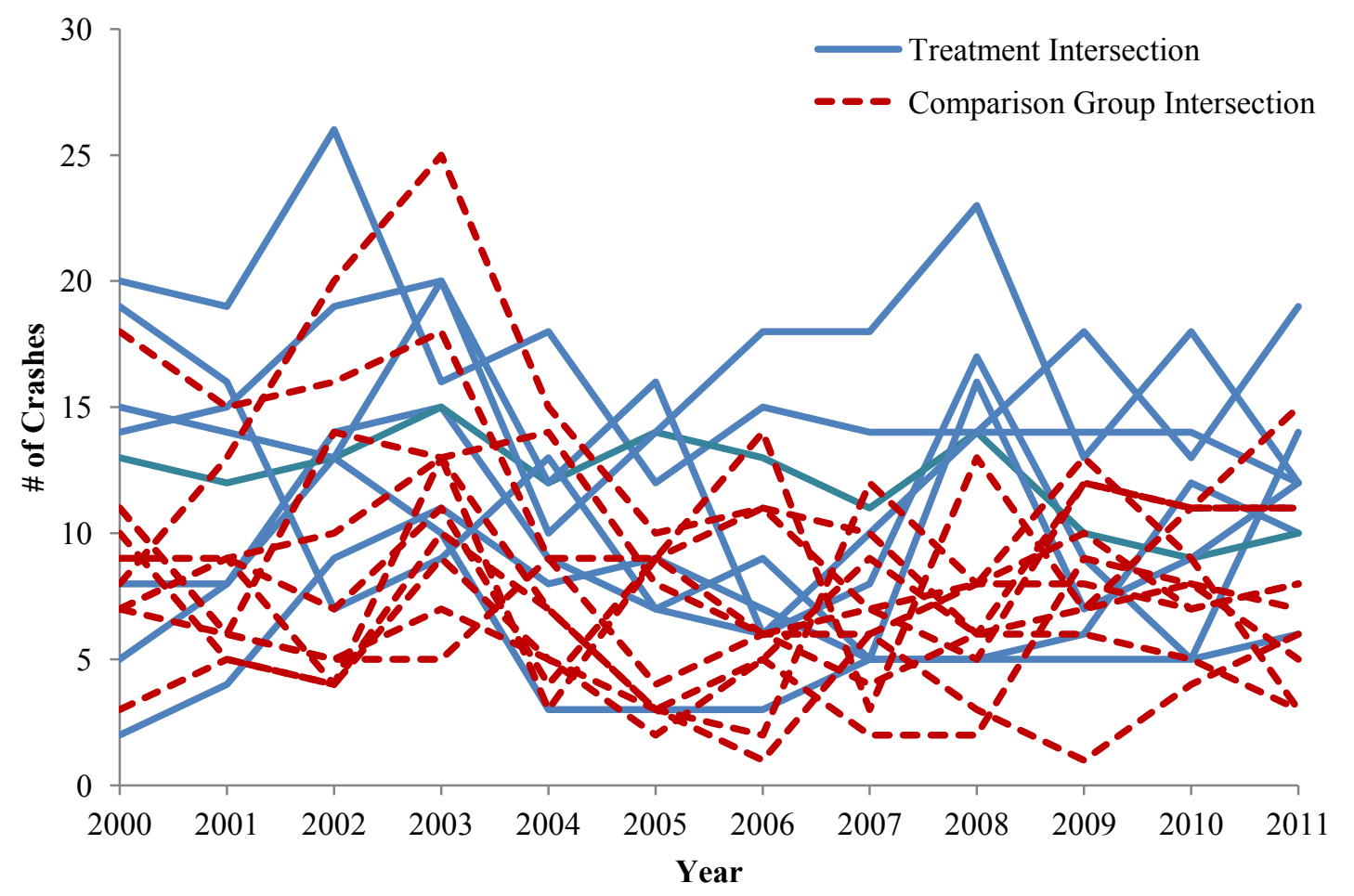

Figure 19: Total Crashes per Year for each Treatment Intersection and Comparison Group Intersection

Figure 19 shows the total crashes per year for each intersection used in the before and after analysis. For simplicity, treatment intersections are one color and comparison group intersections are another. 


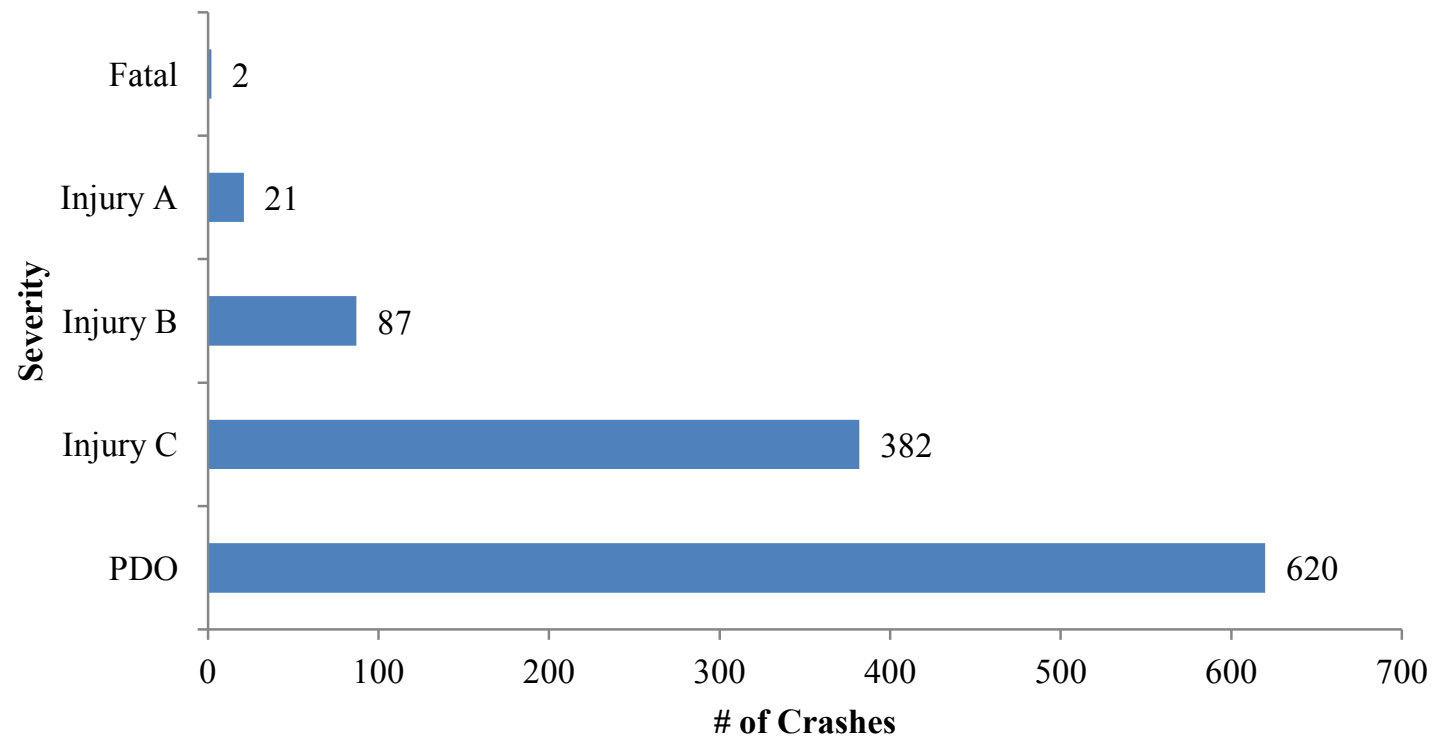

Figure 20: Crash Severity Level for Total Crashes

Figure 20 depicts all crashes separated by crash severity for the eight treatment intersections from 2000 through 2011. The severity levels are broken into fatal, injury A, injury B, injury C, and PDO. Fatal is used when an individual has died as a result of the crash. Injury A refers to an individual who suffers severe injuries as a result of the crash, sometimes described as incapacitating. Injury B is moderate injuries that are nonincapacitating. Injury $\mathrm{C}$ crashes are crashes where individuals report injury but no injuries are apparent and PDO are property damage only crashes (Oregon Department of Transportation, 2007). When defining the severity level of a crash, the most severe injury is applied to the crash (i.e., car one occupants are listed as Injury B, and car two occupants are listed as Injury C; crash receives an Injury B designation). 


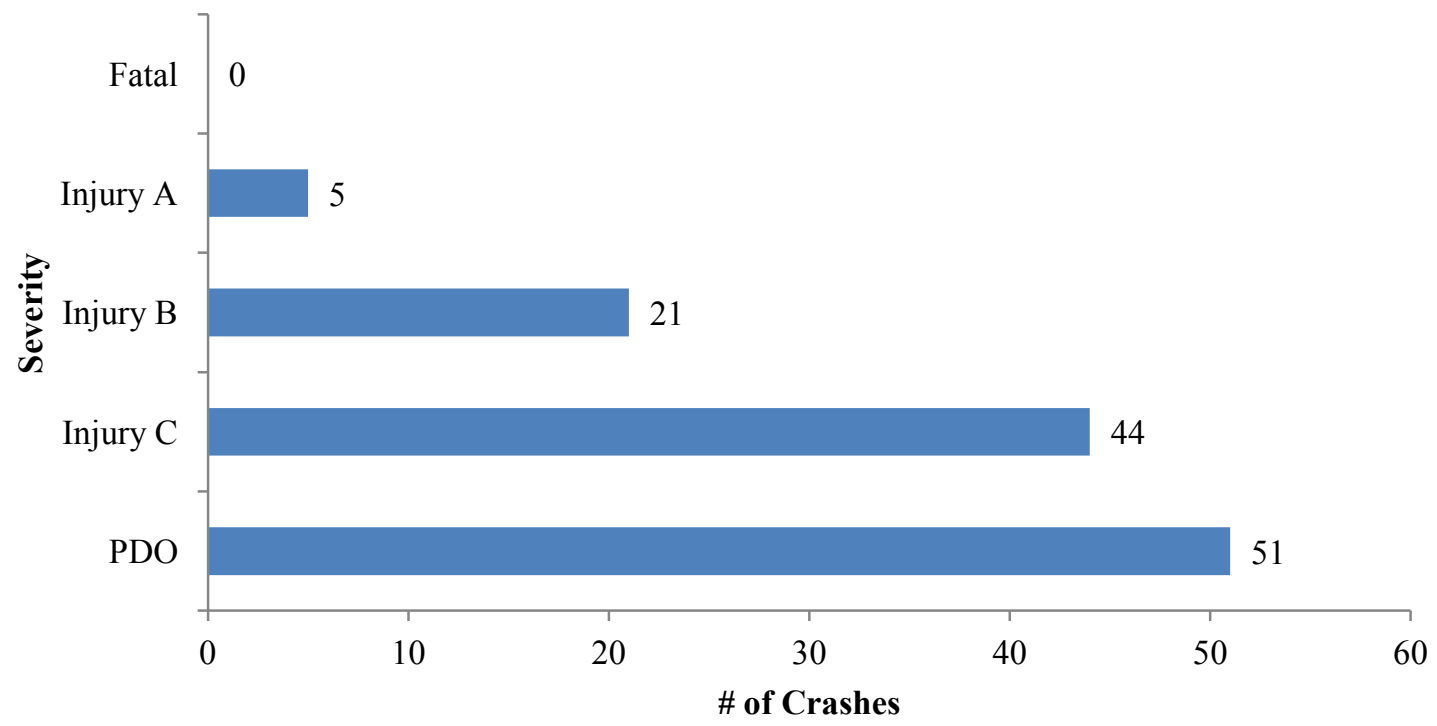

Figure 21: Crash Severity Level for Angle Crashes

Figure 21 shows the severity level for angle crashes at the eight treatment intersections from 2000 through 2011. For total crashes, PDO accounts for over 55\% of the severity level while PDO accounts for just over $42 \%$. The crash severity for angle crashes shows a higher proportion of crashes in the injury categories when compared to that of total crashes. This suggests that angle crashes are typically more severe in nature.

Figure 22 shows the different collision types for all crashes at the treatment locations. The majority of crashes fall within one of three categories: Rear, Turn, and Angle. Rear crashes are crashes that occur when one vehicle strikes the rear end of another vehicle. Turn crashes are crashes where one of the vehicles is involved in a turning movement and is struck by or strikes another vehicle. Angle crashes are crashes that occur when vehicles travelling in two different paths collide. The definition of sideswipe-meet is when two vehicles that are traveling in opposite directions side swipe 
while sideswipe-over is when two vehicles that are travelling in the same direction side swipe.

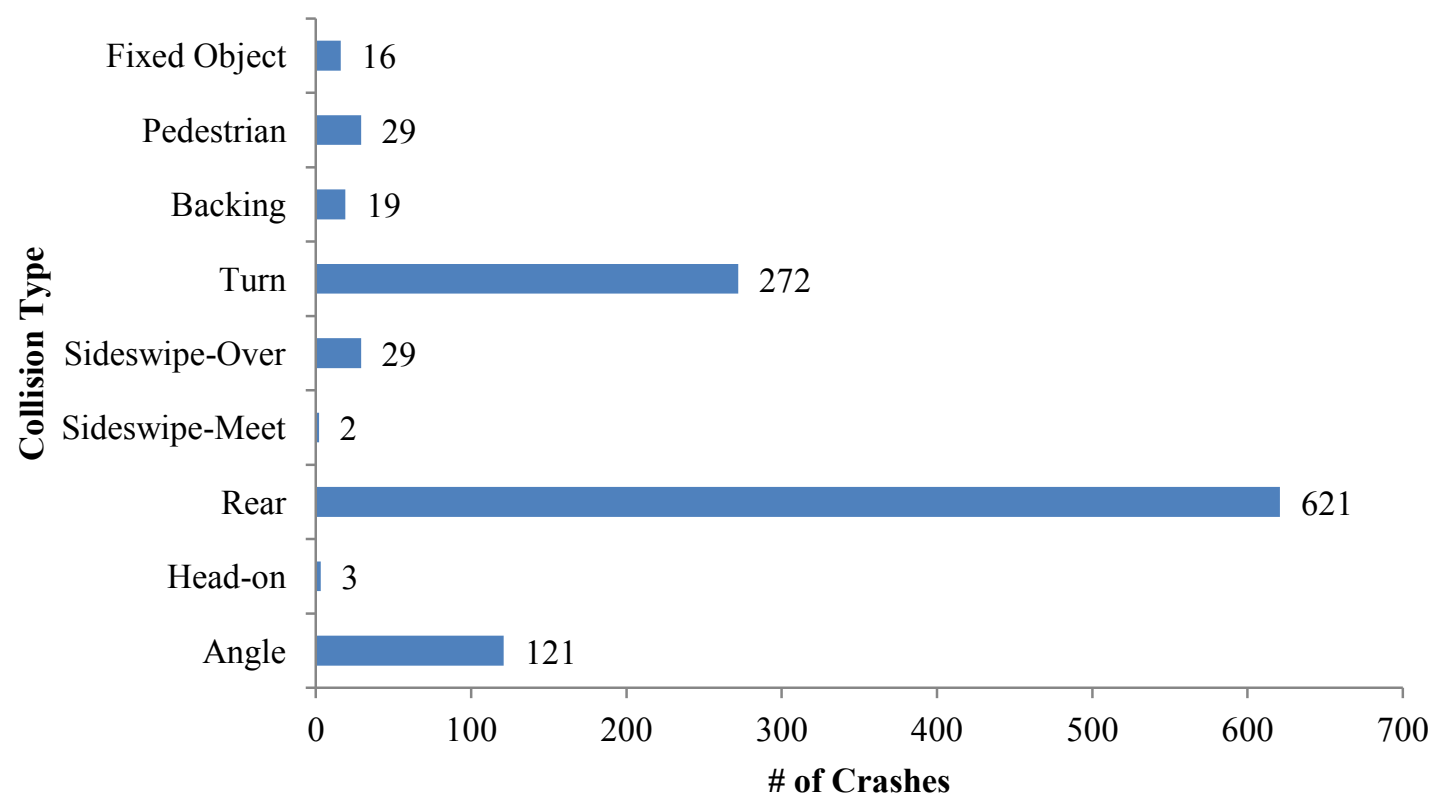

Figure 22: Collision Type for Total Crashes

Figure 23 shows total crashes broken down by cause. As defined by ODOT, the "crash level cause codes represent the circumstance(s) most responsible for the occurrence of the crash". Table 14 provides a description for the cause codes shown in Figure 23 (Oregon Department of Transportation, 2007). 
Table 14: Cause Code Descriptions

\begin{tabular}{|l|l|}
\hline Cause Code & Description \\
\hline CARELESS & Careless driving \\
\hline DEF BRKE & Inadequate or no brakes \\
\hline DIS TCD & Disregarded other traffic control device \\
\hline DIS-RAG & Disregarded red-amber-green traffic signal \\
\hline DRINKING & Alcohol involved \\
\hline IMP LN C & Improper lane change \\
\hline IMP-OVER & Improper overtaking \\
\hline IMP-TURN & Improper turn \\
\hline IN RDWY & Non-motorist illegally in roadway \\
\hline INATTENT & Inattentive driver \\
\hline LEFT-CTR & Drove left of center of two-way road \\
\hline NO-YIELD & Failure to yield \\
\hline OTHER & Other - not improper driving \\
\hline OTHER-IMP & Other improper driving \\
\hline PAS-STOP & Passed stop sign or red flasher \\
\hline RECKLESS & Reckless driving \\
\hline TOO-CLOS & Followed too closely \\
\hline TOO-FAST & Speed too fast for conditions \\
\hline (BLANK) & Unknown \\
\hline
\end{tabular}

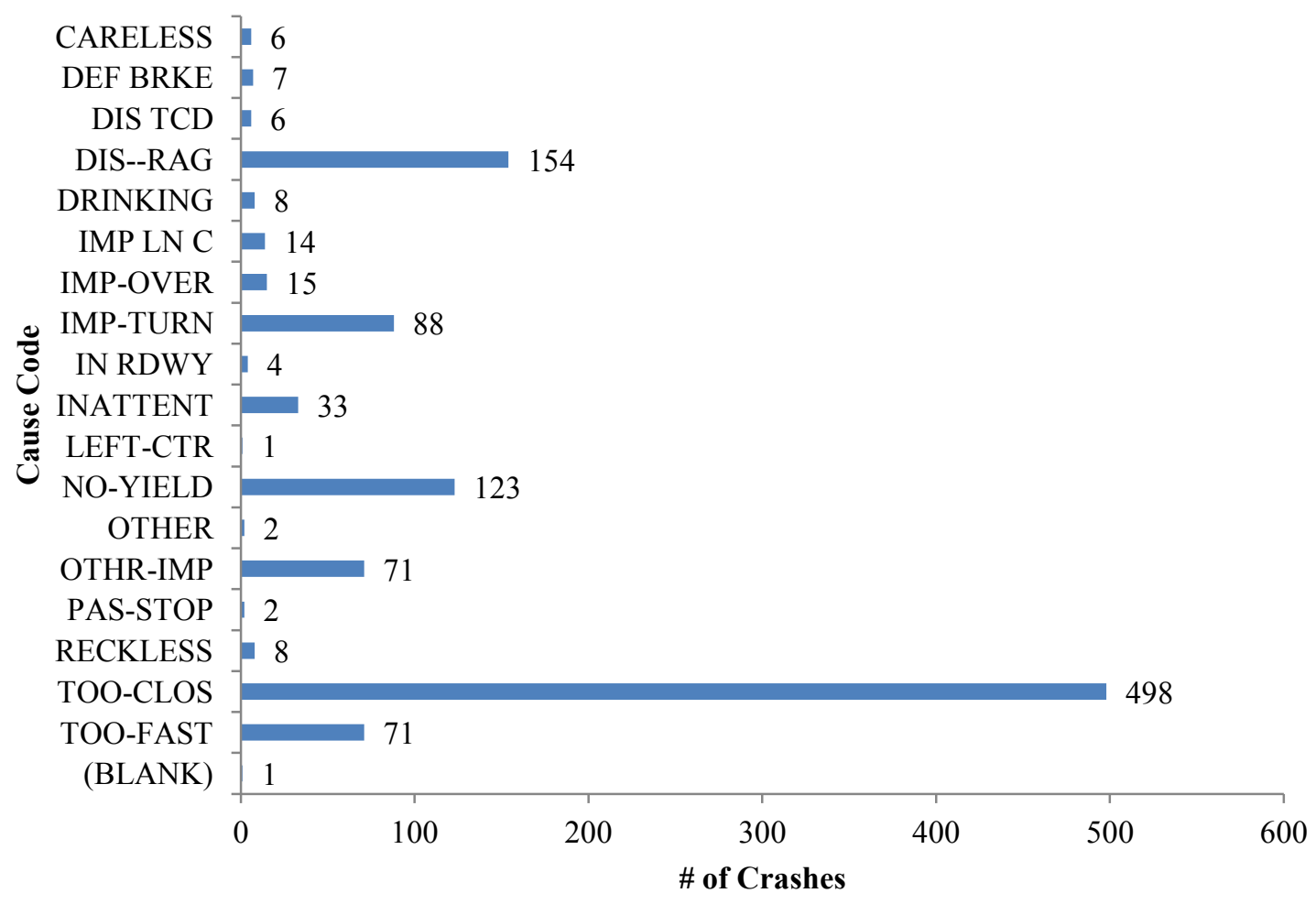

Figure 23: Cause Codes for Total Crashes 


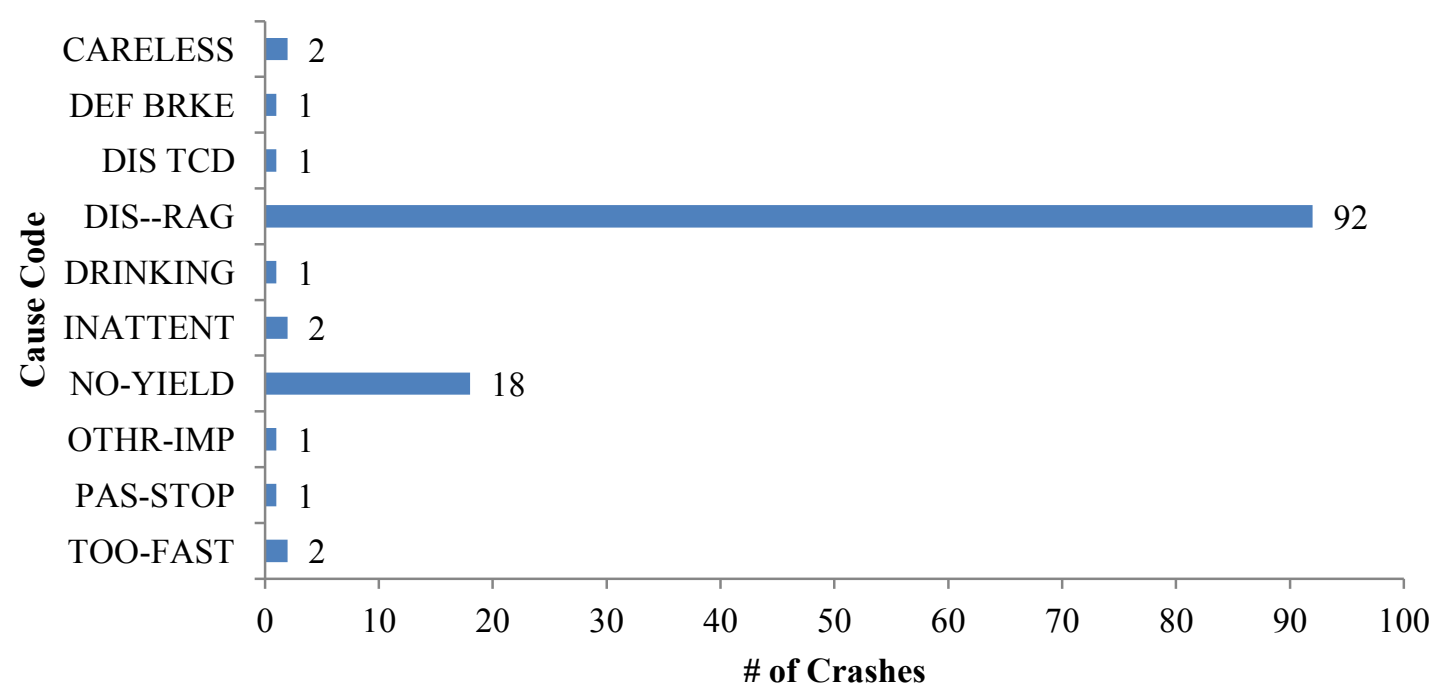

Figure 24: Cause Codes for Angle Crashes

Figure 24 shows the cause codes for angle only crashes. The highest frequency cause code for angle crashes is disregarding the red-amber-green traffic signal.

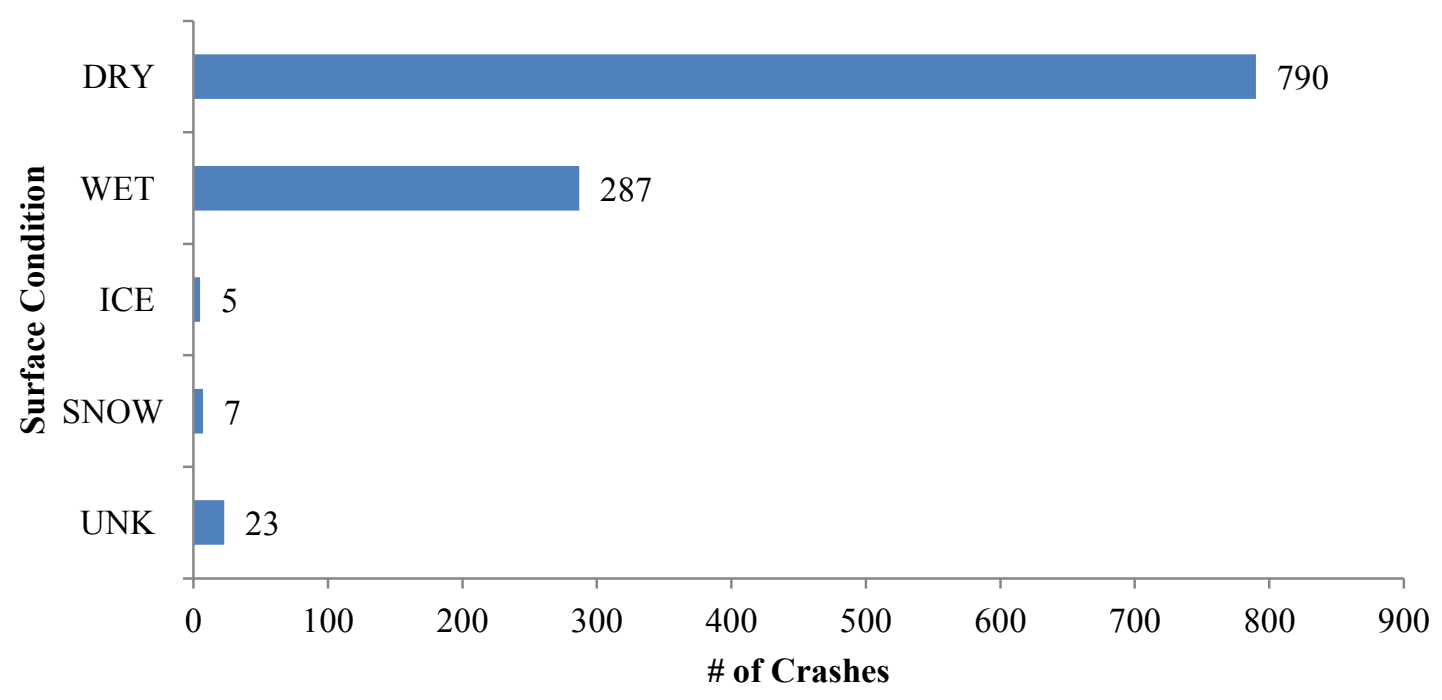

Figure 25: Surface Condition for Total Crashes 


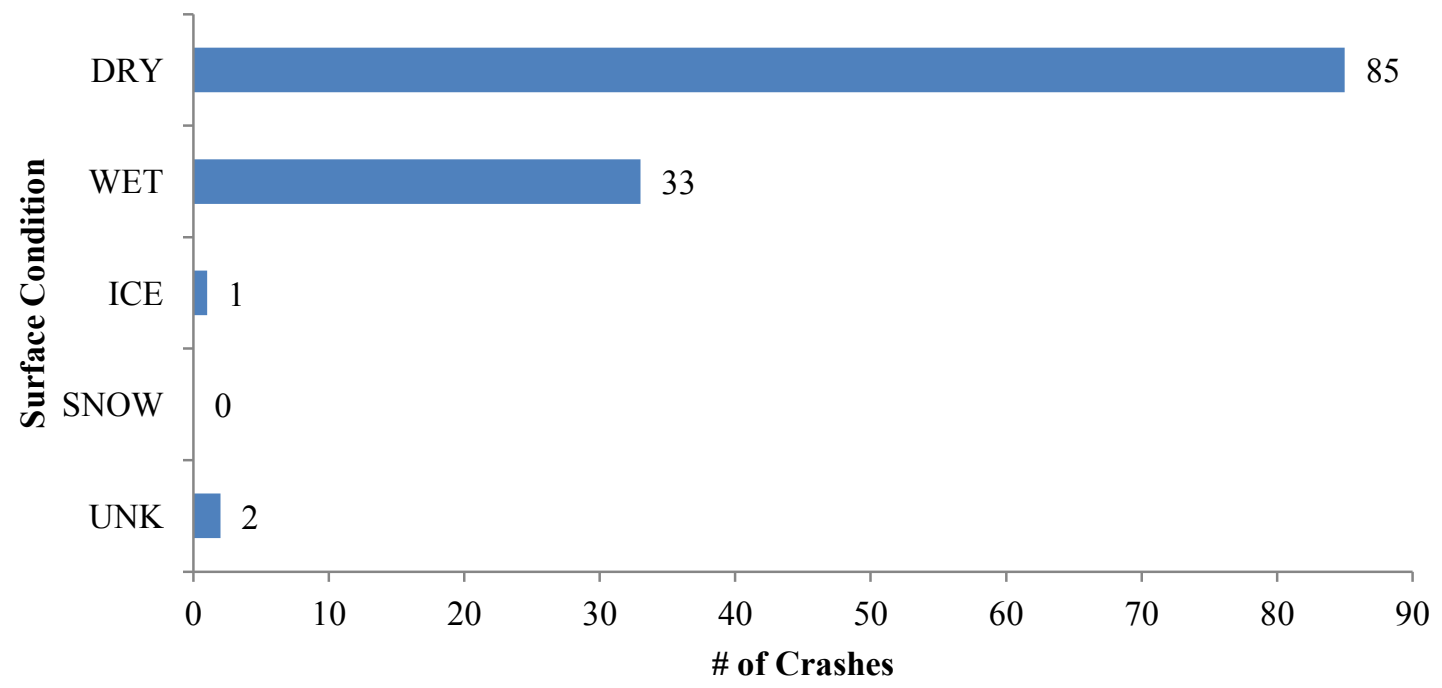

Figure 26: Surface Condition for Angle Crashes

Figure 25 and Figure 26 show the surface conditions for both total and angle crashes. Both crash types have similar magnitudes of the number of crashes for each surface condition.

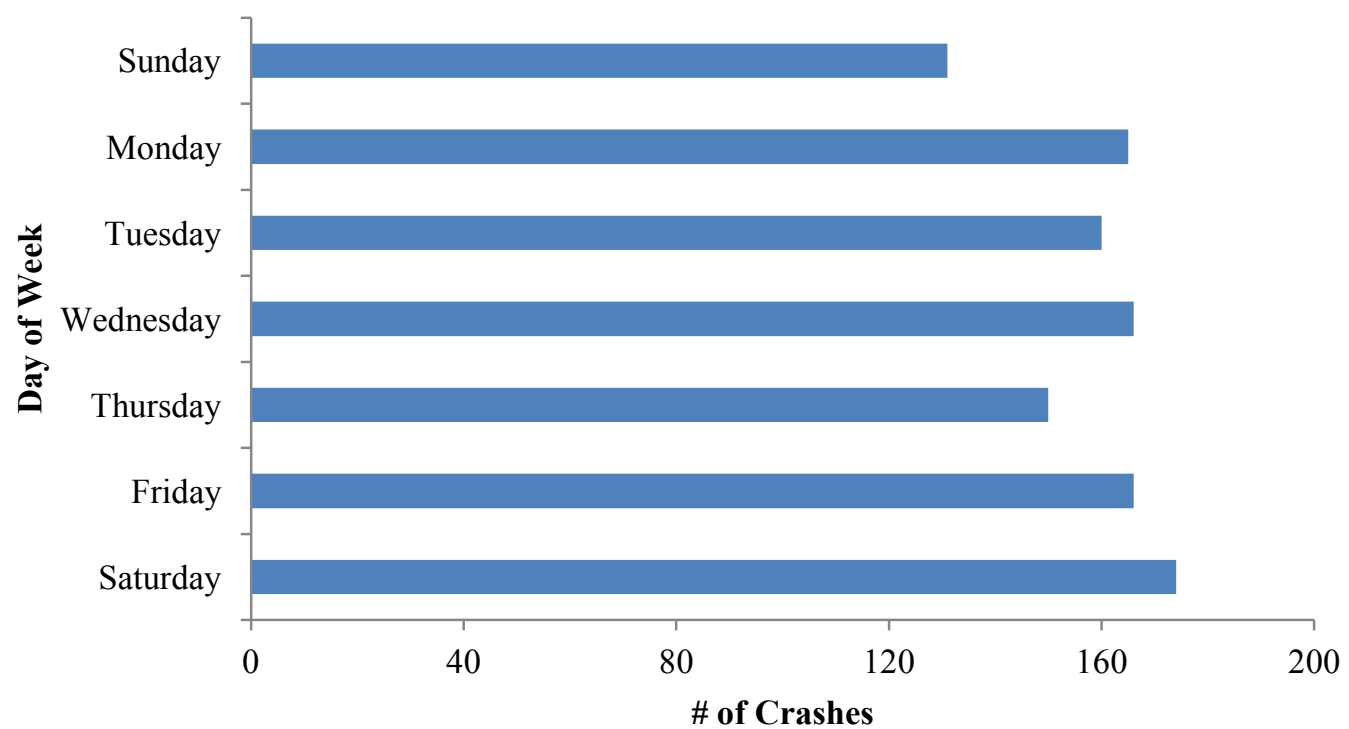

Figure 27: Total Crashes by Day of Week 


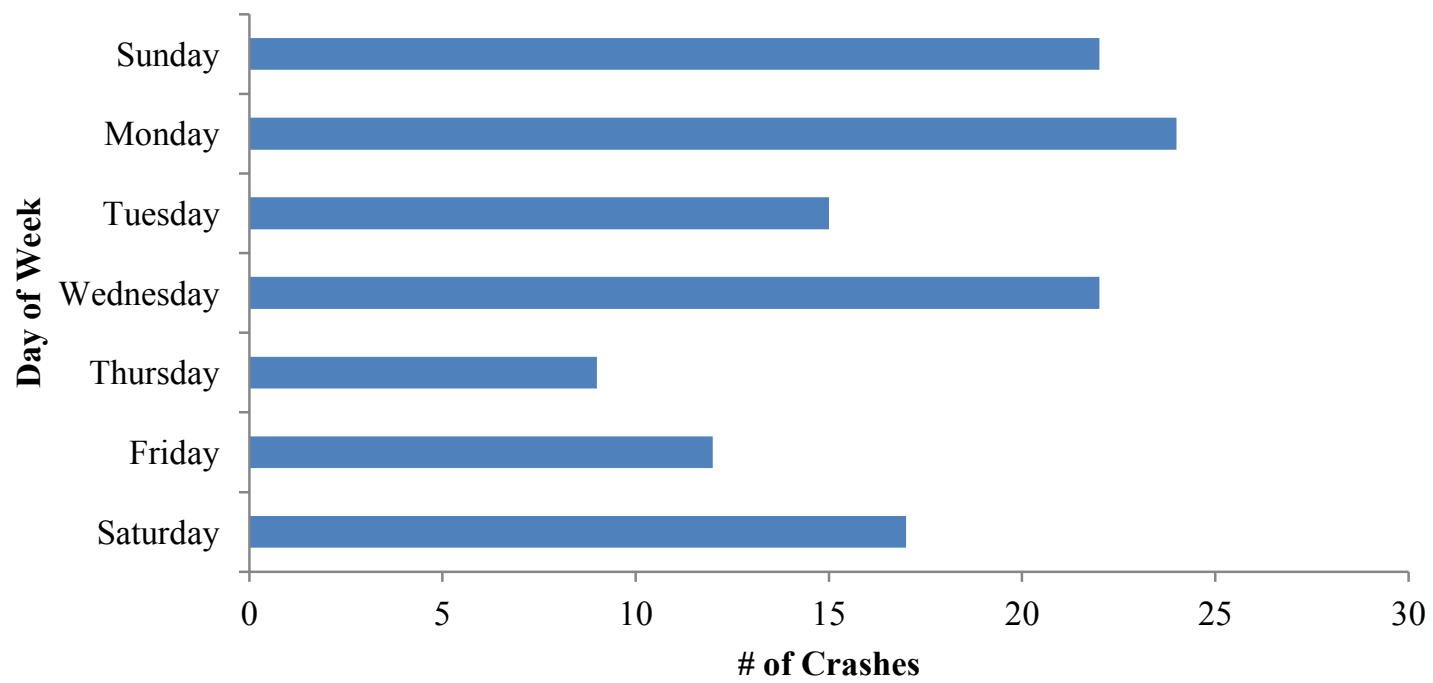

Figure 28: Angle Crashes by Day of Week

Figure 27 and Figure 28 show total and angle crashes by day of week. Total crashes remain fairly consistent throughout the week while angle crashes vary more so. 


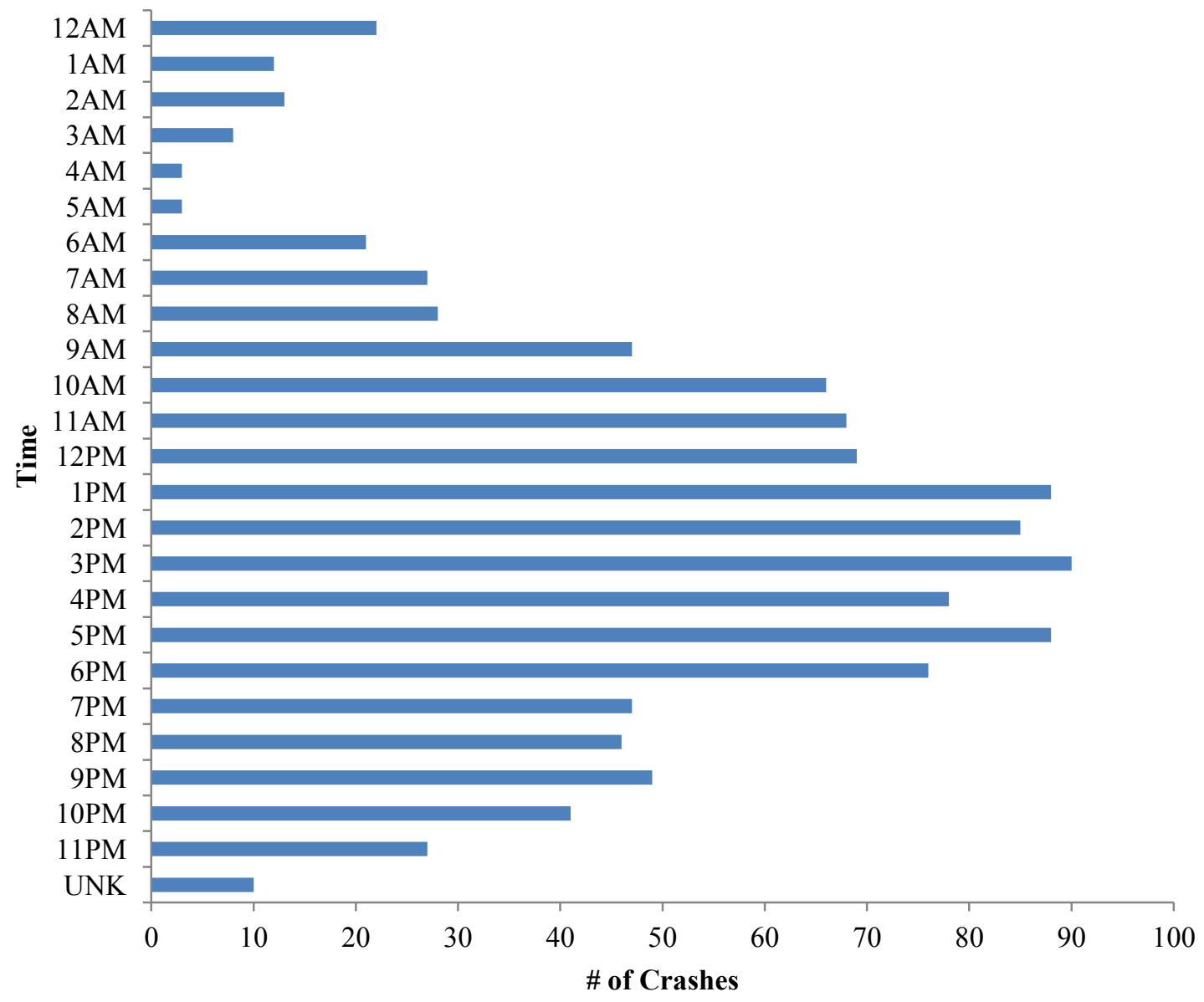

Figure 29: Total Crashes by Time of Day

Figure 29 shows the total crashes at the eight treatment intersections by time of day. The crash pattern follows a similar pattern that traffic volumes do throughout the day. 


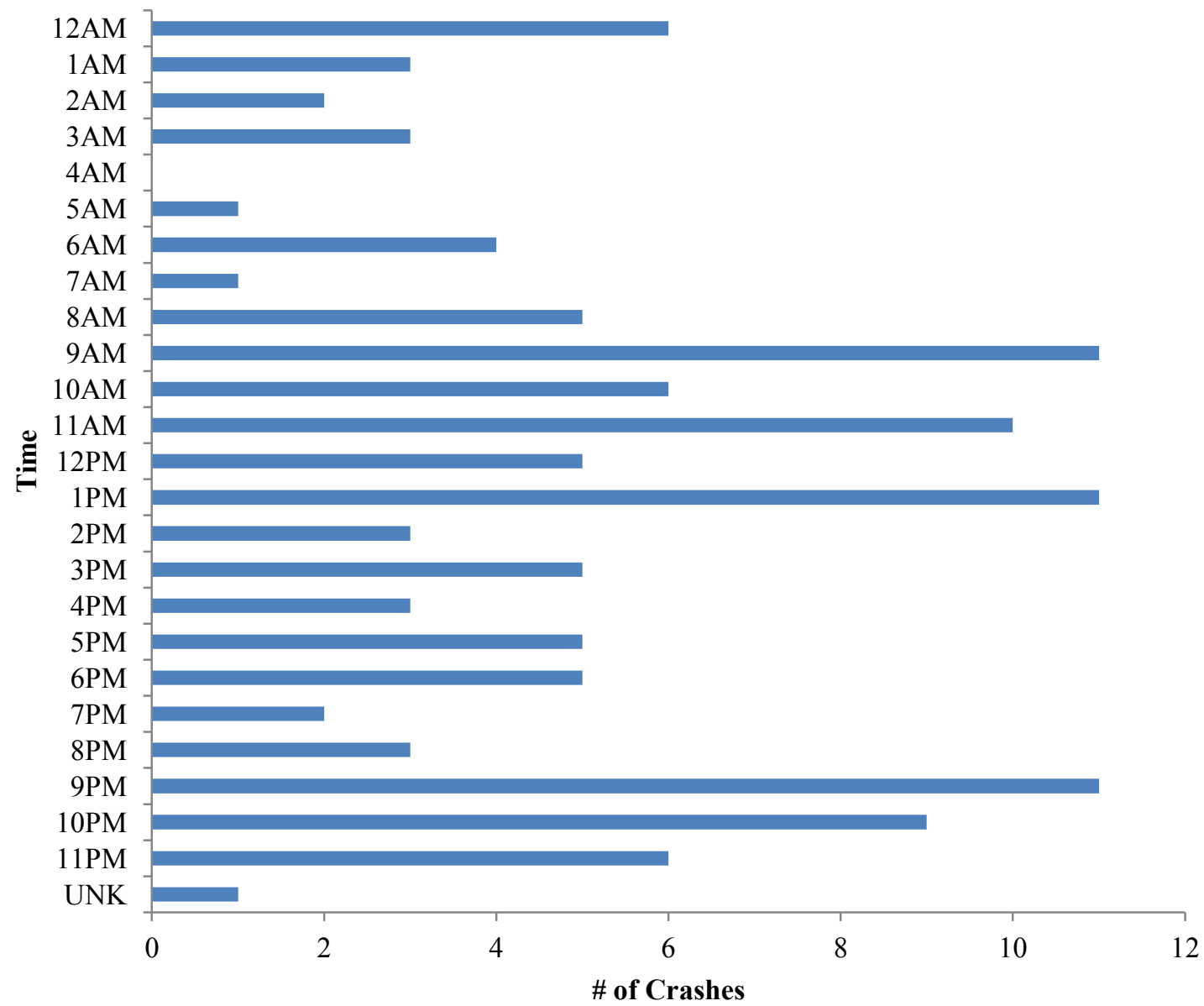

Figure 30: Angle Crashes by Time of Day

Figure 30 shows angle crashes by time of day. The volatility of angle crashes is apparent. An interesting item to note is that there appears to be an increase of crashes during off-peak times. These spikes happen between 9 a.m. and 1 p.m. and in the evening from 9 p.m. and 12 a.m., but with so few numbers of crashes, it is difficult to make any concrete conclusions. However, it does appear that angle crashes primarily occur during off-peak times. Potential causes of the increase of angle crashes during these off-peak times are discussed later. 
In data provided by the City of Portland, 63 vehicles were detected running the red light on $82^{\text {nd }}$ Avenue during a 48 -hour period. Of these 63 vehicles, 4 of them occurred after the all-red clearance interval. The remaining 59 occurred during the all-red clearance interval. Unfortunately, the time of day that these red light running events occurred was not recorded.

The data exploration piece of the crash analysis provided the first glimpse of the crash data. Anomalies in the crash data may be detected during the data exploration phase; however, before any conclusions can be drawn, further, more robust analysis is required.

\subsection{Simple Method}

The simple method is sometimes referred to as the Naïve method. Simply put, the simple before-after method compares crashes before and after a treatment has been installed. This method assumes that before experiences predict the after experiences.

\subsubsection{Method}

The simple method requires two pieces of information: crash data before and after a treatment was installed, and the date that the treatment was installed. 
Table 15: Simple Method Input Table - Total Crashes

\begin{tabular}{|ccccccccc|}
\hline$(1)$ & $(2)$ & $(3)$ & $(4)$ & $(5)$ & $(6)$ & $(7)$ & $(8)$ \\
\hline $\begin{array}{c}\text { Entity } \\
\text { Number } \\
\mathrm{j}\end{array}$ & $\begin{array}{c}\text { Years } \\
\text { Before }\end{array}$ & $\begin{array}{c}\text { Years } \\
\text { After }\end{array}$ & $\begin{array}{c}\text { Crashes } \\
\text { Before }\end{array}$ & $\begin{array}{c}\text { Crashes } \\
\text { After }\end{array}$ & \multicolumn{4}{c|}{} \\
\hline 1 & 5.60 & 6.40 & 108 & 96 & 1.14 & 123.54 & 141.32 \\
\hline 2 & 5.60 & 6.40 & 41 & 42 & 1.14 & 46.90 & 53.65 \\
\hline 3 & 5.67 & 6.33 & 58 & 62 & 1.12 & 64.72 & 72.23 \\
\hline 4 & 7.95 & 4.05 & 54 & 22 & 0.51 & 27.53 & 14.04 \\
\hline 5 & 9.25 & 2.75 & 119 & 27 & 0.30 & 35.44 & 10.55 \\
\hline 6 & 9.26 & 2.74 & 101 & 28 & 0.30 & 29.84 & 8.82 \\
\hline 7 & 9.27 & 2.73 & 129 & 31 & 0.30 & 38.07 & 11.23 \\
\hline 8 & 9.27 & 2.73 & 155 & 39 & 0.29 & 45.68 & 13.46 \\
\hline Sums & & & & 347 & & 411.72 & 325.30 \\
\hline
\end{tabular}

Table 15 shows an example of the required data and calculations that are performed when doing the simple method of crash analysis. For each treatment location, an entity number $\mathrm{j}$ is assigned (column 1). These entity numbers correspond to the same intersections, in order, as listed in Table 1. For each intersection, the Years Before and Years After columns indicate the number of study years that the crash data pertains to before and after a treatment was installed (columns 2 and 3). $K(j)$ refers to the number of observed crashes in the before time period for that entity; $\mathrm{j}$ (column 4). L(j) refers to the number of observed crashes in the after period for that entity; $\mathrm{j}$ (column 5). A ratio between the time after and the time before a treatment is calculated as $r_{d}(j)$ for each entity $\mathrm{j}$ (column 6). By taking this ratio and multiplying it by the number of crashes in the before period $(\mathrm{K}(\mathrm{j}))$ the number of expected crashes in the after period given there was no treatment for that entity is obtained (column 7). The variance of the expected crashes in the after period given there was no treatment is calculated as $r_{d}(j)^{2 *} K(j)$ and is shown in 
the last column in Table 15 (column 8). Once the table has been filled out, the estimates for effectiveness can be calculated.

Table 16: Output from Simple Method

\begin{tabular}{|c|r|}
\hline$\hat{\lambda}$ & 347 \\
\hline$\hat{\pi}$ & 411.72 \\
\hline $\operatorname{VAR}\{\hat{\lambda}\}$ & 347 \\
\hline $\operatorname{VAR}\{\hat{\pi}\}$ & 325.30 \\
\hline$\hat{\delta}$ & 64.72 \\
\hline$\hat{\theta}$ & 0.841 \\
\hline $\operatorname{VAR}\{\hat{\delta}\}$ & 672.30 \\
\hline $\operatorname{VAR}\{\hat{\theta}\}$ & 0.003 \\
\hline$\sigma\{\hat{\delta}\}$ & 25.93 \\
\hline$\sigma\{\hat{\theta}\}$ & 0.058 \\
\hline
\end{tabular}

Table 16 shows the output of the simple method. Calculations and definitions are as follows:

$$
\hat{\lambda}=\sum L(j)
$$

Where $\hat{\lambda}$ is the estimate of the number of crashes that took place in the after time period with the treatment.

$$
\hat{\pi}=\sum r_{d}(j) K(j)
$$

Where $\hat{\pi}$ is the estimate of the number of crashes in the after period if the treatment had not taken place. 


$$
\operatorname{VAR}\{\hat{\lambda}\}=\sum L(j)
$$

Where $\operatorname{VAR}\{\hat{\lambda}\}$ is the variance of $\hat{\lambda}$ and indicates how much noise there is in $\hat{\lambda}$.

$$
\operatorname{VAR}\{\hat{\pi}\}=\sum r_{d}(j)^{2} K(j)
$$

Where $\operatorname{VAR}\{\hat{\pi}\}$ is the variance of $\hat{\pi}$.

$$
\hat{\delta}=\hat{\pi}-\hat{\lambda}
$$

Where $\hat{\delta}$ is the reduction in crashes.

$$
\hat{\theta}=\frac{\hat{\lambda} / \hat{\pi}}{1+V A R\{\hat{\pi}\} / \hat{\pi}^{2}}
$$

Where $\hat{\theta}$ is the ratio of safety or the index of effectiveness. Values of $\hat{\theta}$ less than one indicate a reduction of crashes, while values greater than one indicate an increase in crashes.

$$
\begin{gathered}
V A R\{\hat{\delta}\}=\operatorname{VAR}\{\hat{\pi}\}-\operatorname{VAR}\{\hat{\lambda}\} \\
\operatorname{VAR}\{\hat{\theta}\}=\frac{\hat{\theta}^{2}\left[\left(\operatorname{VAR}\{\hat{\lambda}\} / \hat{\lambda}^{2}\right)+\left(\operatorname{VAR}\{\hat{\pi}\} / \hat{\pi}^{2}\right)\right]}{\left[1+V A R\{\hat{\pi}\} / \hat{\pi}^{2}\right]^{2}}
\end{gathered}
$$

Where $V A R\{\hat{\theta}\}$ is the variance of $\hat{\theta}$. 


$$
\sigma\{\hat{\delta}\}=\sqrt{\operatorname{VAR}\{\hat{\delta}\}}
$$

Where $\sigma\{\hat{\delta}\}$ is the standard deviation of $\hat{\delta}$.

$$
\sigma\{\widehat{\theta}\}=\sqrt{\operatorname{VAR}\{\widehat{\theta}\}}
$$

Where $\sigma\{\hat{\theta}\}$ is the standard deviation of $\hat{\theta}$.

To calculate the $95 \%$ confidence crash modification factor for the treatment, the following equation is used:

$$
1-(1-\widehat{\theta}+1.96(\sigma\{\widehat{\theta}\}))
$$

\subsubsection{Results}

Using equations (6) through (16), the same steps were performed to create tables similar to Table 15 and Table 16 for fatal and injury, PDO, and angle crashes. These additional tables can be seen in the appendix. 


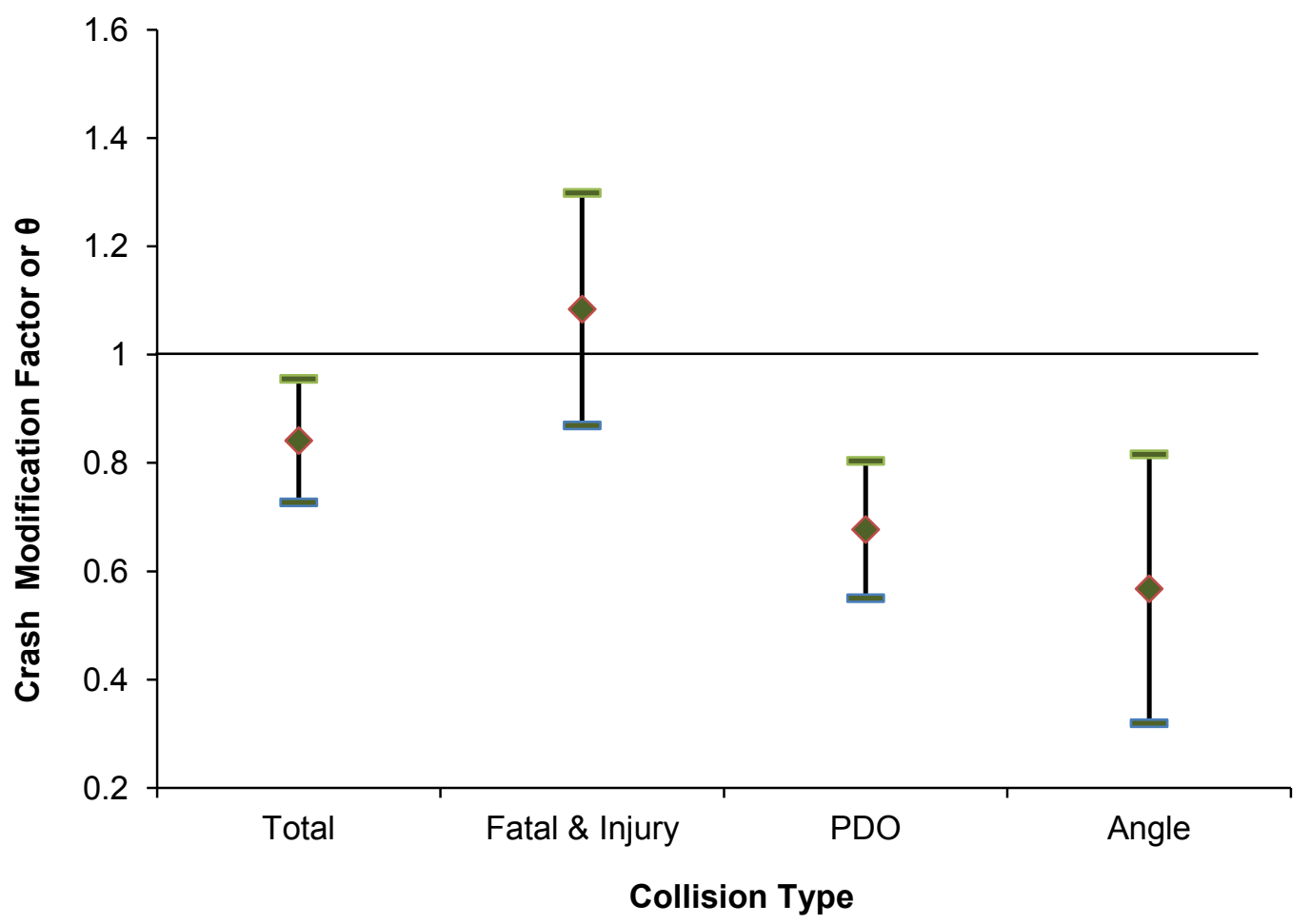

Figure 31: Crash Modification Factors for the Simple Method at the 95\% Confidence Level

Figure 31 shows the calculated crash modification factors for four different collision types. Based upon the simple method at the $95 \%$ confidence level, total crashes decreased; there was no statistically significant change in fatal and injury crashes; and both PDO and angle crashes decreased.

\subsubsection{Discussion}

There are many downsides to using the simple approach. First, the simple approach does not address regression to the mean. Regression to the mean occurs when relatively high or low measurements done at another time are compared. These less extreme measurements are more likely to be closer to the test subject's true mean 
(Barnett, van der Pols, \& Dobson, 2005). In the case of the eight treatment locations, these locations were chosen due to their high crash frequency. This high crash frequency could be considered an extreme. Measurements done at a later time do not necessarily indicate a change due to effects of a treatment but could simply be the result of measurements closer to the crash frequencies' true mean.

Another issue that the simple model does not take into account is a change in volume. As seen in the data preparation chapter, volumes have been decreasing over time for the last six years or so. By not taking this decrease in volumes into account, what is seen as fewer crashes, could simply be the result of less vehicles out on the road. There can be other factors that may influence crashes at an intersection. Things like pedestrian volume or proximity to schools and bus stops can affect the number of crashes experienced at a location.

\subsection{Comparison Group Method}

The comparison group method is one of two methods that can correct for a regression to the mean bias and account for other factors, including changes in vehicle volume. Many of the steps between the Comparison Group and Empirical-Bayes in this research are the same, including the calculations of the Safety Performance Functions (SPF) for each. The SPFs are a regression tool used to calculate expected crash frequency using factors like AADT and intersection design in their model. 


\subsubsection{Method}

The first step of the comparison group method is to choose appropriate comparison group sites. This is the most critical step in the comparison group method. Two main guidelines are to be followed when choosing comparison group sites (Hauer, 1997):

- The before and after period for the treatment sites and comparison group sites must be the same

- Crash counts for both the comparison group and treatment sites should be sufficiently large

When possible, the intersection geometry between the treatment sites and comparison group sites should also be similar (Highway Safety Manual, 2010). In addition, it is useful to choose sites that are in close proximity to the treatment sites to control for regional and weather related factors. A site in Alaska might not be the best when paired with a site from California. A list of the comparison group sites chosen are in Table 2.

After the comparison group sites have been chosen, intersection details are needed for both the treatment and comparison group sites. The details required to calculate SPFs were discussed earlier in the data preparation chapter, and a sample can be seen in Table 9. Values for the 10 comparison group sites can be seen in the appendix.

The predictive method for generating crash values for urban and suburban arterial intersections is outlined in Volume 2 of the HSM under Worksheet 2A. For this research, spreadsheets were used that were initially developed by Karen Dixon from Oregon State 
University. These spreadsheets mirrored the worksheets provided in the HSM but only allowed for the user to enter in one intersection for one year. The spreadsheets were modified to allow multiple years and multiple intersections to be entered into the same spreadsheet. Spreadsheet results were validated by using examples from the HSM and verifying that the results were the same. Obtaining the same results as the Highway Safety Manual confirmed the accuracy of the spreadsheets that were developed using Worksheets 2A through 2L of Volume 2 of the Highway Safety Manual. For brevity, the steps detailed in the worksheets are omitted from this chapter. To view these tables, please refer to the appendix.

Modifications were done to the predictive method tables to calibrate the regression to local conditions. For references made to Tables 12-11, 12-13, and 12-27, locally-derived values were used as determined by Dixon, et al. (Dixon, Monsere, Xie, \& Gladhill, 2012). The values for four-legged signalized intersections are displayed below in Table 17 through Table 19 where FI is fatal and injury and PDO is property damage only. 
Table 17: Locally-Derived Values for Multiple-Vehicle Collisions in Oregon

\begin{tabular}{|l|c|c|}
\hline \multirow{2}{*}{$\begin{array}{c}\text { Table 12-11: Distribution of Multiple-Vehicle Collisions } \\
\text { for Intersections by Collision Type }\end{array}$} \\
\hline \multirow{2}{*}{ Collision type } & \multicolumn{2}{|c|}{ 4SG } \\
\cline { 2 - 3 } & Focally-Derived Values \\
\cline { 2 - 3 } & 0.501 & PDO \\
\hline Rear-end collision & 0.002 & 0.402 \\
\hline Head-on collision & 0.236 & 0.000 \\
\hline Angle collision & 0.004 & 0.012 \\
\hline Sideswipe & 0.257 & 0.370 \\
\hline Other multiple-vehicle collision & &
\end{tabular}

Table 18: Locally-Derived Values for Single-Vehicle Crashes in Oregon

\begin{tabular}{|l|c|c|}
\hline \multirow{2}{*}{$\begin{array}{c}\text { Table 12-13: Distribution of Single-Vehicle Crashes for } \\
\text { Intersections by Collision Type }\end{array}$} \\
\hline \multirow{2}{*}{ Collision type } & \multicolumn{2}{|c|}{ Locally-Derived Values } \\
\cline { 2 - 3 } & FI & PDO \\
\cline { 2 - 3 } & 0.000 & 0.000 \\
\hline Collision with parked vehicle & 0.000 & 0.000 \\
\hline Collision with animal & 0.097 & 0.722 \\
\hline Collision with fixed object & 0.000 & 0.000 \\
\hline Collision with other object & 0.888 & 0.056 \\
\hline Other single-vehicle collision & 0.015 & 0.222 \\
\hline Noncollision & & \\
\hline
\end{tabular}

Table 19: Locally-Derived Values for Unlighted Intersections in Oregon

\begin{tabular}{|l|c|}
\hline \multicolumn{2}{|c|}{ Table 12-27: Nighttime Crash Proportions for } \\
Unlighted Intersections
\end{tabular}


Severity specific calibration factors were added to the SPF regression model. The factors that were added were specific to the fatal and injury crash type, as well as the PDO crash type. A severity specific calibration factor of 1.29 was applied to fatal and injury crashes and a severity specific calibration factor of 0.91 was applied to PDO crashes (Dixon, Monsere, Xie, \& Gladhill, 2012). In worksheet 2C, the predicted average crash frequency for multiple-vehicle collision was rebalanced based upon these updated calibration factors.

After the predicted crash frequency has been calculated for the treatment and comparison group sites, crash modification factors are calculated. For each treatment site, the comparison-group adjusted crash frequency in the before period is determined. A comparison ratio is calculated by comparing the adjusted crash frequency in the before period to that of the comparison-group adjusted crash frequency in the after period. Using the comparison ratio, the observed crashes at each treatment site are used to calculate the expected average crash frequency in the after period without a treatment. The observed crash frequency in the before and after period is tabulated for each treatment intersection, and an odds ratio is determined by dividing the observed crash frequency in the after period by the expected average crash frequency in the after period without the treatment. The natural $\log$ of the odds ratio is calculated along with the squared standard error of the $\log$ ratio. A weighted adjustment factor and, finally, a weighted product are determined. A combination of the odds ratio and standard error of the safety effectiveness provide the crash modification factors seen in Figure 32. 


\subsubsection{Results}

Repeating the above steps for total, fatal and injury, PDO, and angle crashes produces crash modification factors as pictured in Figure 32.

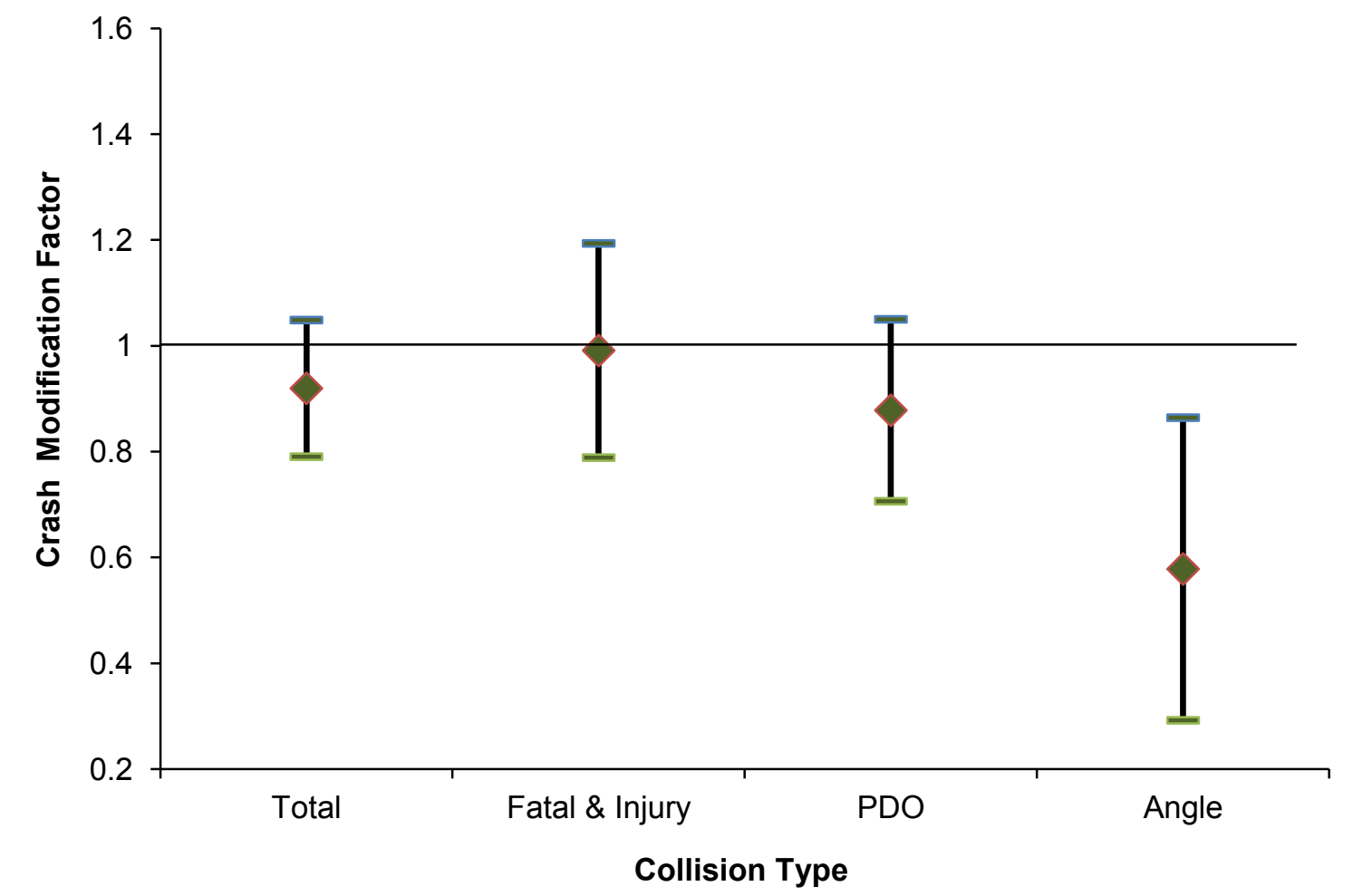

Figure 32: Crash Modification Factor Results for Comparison Group Method at the 95\% Confidence Level

One caveat of the comparison group method is that it cannot handle intersections that do not have any crashes in before or after treatment years. One of the intersections that received the red extension treatment did not have any angle crashes prior to the upgrade, and another intersection did not have any angle crashes after receiving the 
upgrade. The angle crash modification factor shown in the figure above is the result of adding a crash to two different intersections.

\subsubsection{Discussion}

There are two difficulties when using the comparison group method to perform a before and after analysis of a treatment. First, carefully choosing appropriate comparison group sites is imperative. Second, if one of the treatment sites has zero crashes in either the before or after treatment time periods, the comparison group method does not work as the zero crash time period introduces an instance of division by zero.

The division by zero problem arose when using the comparison group method to look at the collision type of angle crashes. Two different methods were performed to combat the division by zero dilemma. The first method was to remove the two intersections entirely from the list of treatment intersections. This resulted in there only being six treatment intersections and 10 comparison group intersections. The second method employed was to add a single crash to the before and after time periods to the intersections with zero crashes. Comparing the two resultant plots, the method of adding a crash to the before and after time periods appeared to be more conservative and was chosen as the method to present.

From Figure 32, at a 95\% confidence, a change in total, fatal and injury, or PDO crashes at the treatment intersections cannot be stated. Also, due to the division by zero issues encountered, angle crashes could have been positively affected, however since the most conservative of the two approaches was chosen, the argument could be made that 
angle crashes did in fact decrease. Another way, and probably the best way to combat the division by zero issue encountered by the comparison group method is to use the Empirical-Bayes method.

\subsection{Empirical-Bayes (EB) Method}

The EB method is similar to the comparison group method in that it calculates the predicted crash frequencies for treatment sites. However, instead of comparing the predicted and observed crash frequencies to comparison group sites, an expected crash frequency for each site during the after period is calculated given that no treatment was installed. An estimation of a treatment's effectiveness is then calculated from the combination of expected crash frequency, predicted crash frequency, and observed crash frequency. Finally, the precision of the treatment's effectiveness is estimated before being reported.

\subsubsection{Method}

The EB method follows the same steps as outlined above in the Comparison Group method when determining each treatment site's predicted crash values. The difference lies in the estimated value of the number of expected crash frequency in the after period, given that no treatment was installed. In order to calculate a number of expected crashes in the after period without treatment, an overdispersion number is needed. The HSM defines the overdispersion number as "an estimated parameter from a statistical model that when the results of modeling are used to estimate crash frequencies, indicates how widely the crash counts are distributed around the estimated mean" (Highway Safety Manual, 2010). Per the HSM, the overdispersion number (k) for multi- 
vehicle collisions at a 4-legged signalized intersection is 0.39 . The number of expected crashes before the treatment is calculated with the overdispersion factor. From the ratio of predicted crashes before and after treatment, the number of expected crashes in the after period without a treatment can be calculated. An Odds Ratio is then calculated from the observed crashes in the after period and the expected crashes in the after period given no treatment. Finally, the safety effectiveness of the treatment, the standard error of the odds ratio, and the standard error of the safety effectiveness can be calculated. From these, the corresponding crash modification factors can be estimated for the different collision types.

\subsubsection{Results}

The results for the crash modification factor can be seen in Figure 33. 


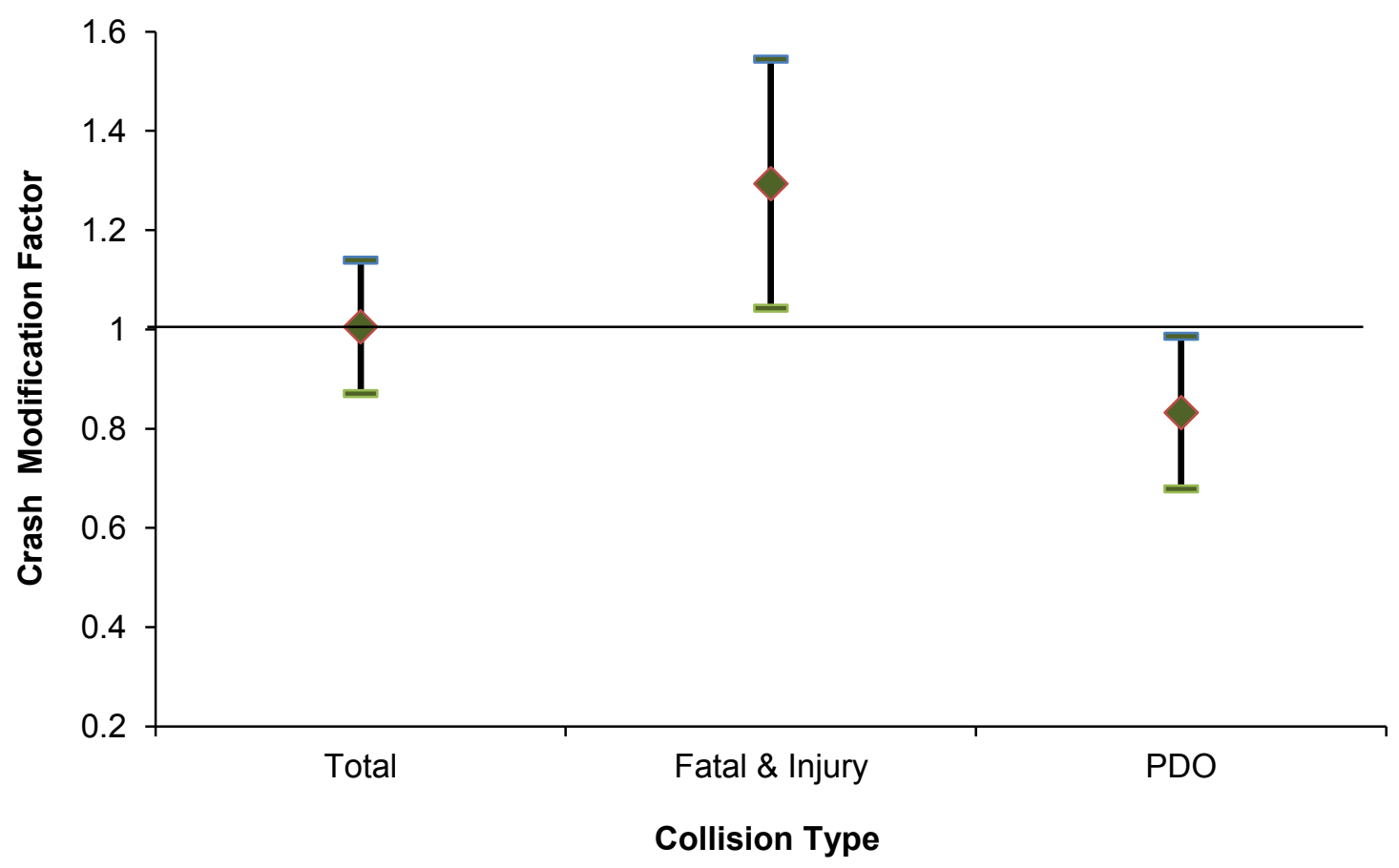

Figure 33: Crash Modification Factor Results for EB Method at the 95\% Confidence Level

Total crashes appear to have no change in the crash modification factor for the set of treatments. The set of treatments appear to have a negative impact on safety with regards to fatal and injury collision, however, they seem to have a positive effect on PDO crashes. 


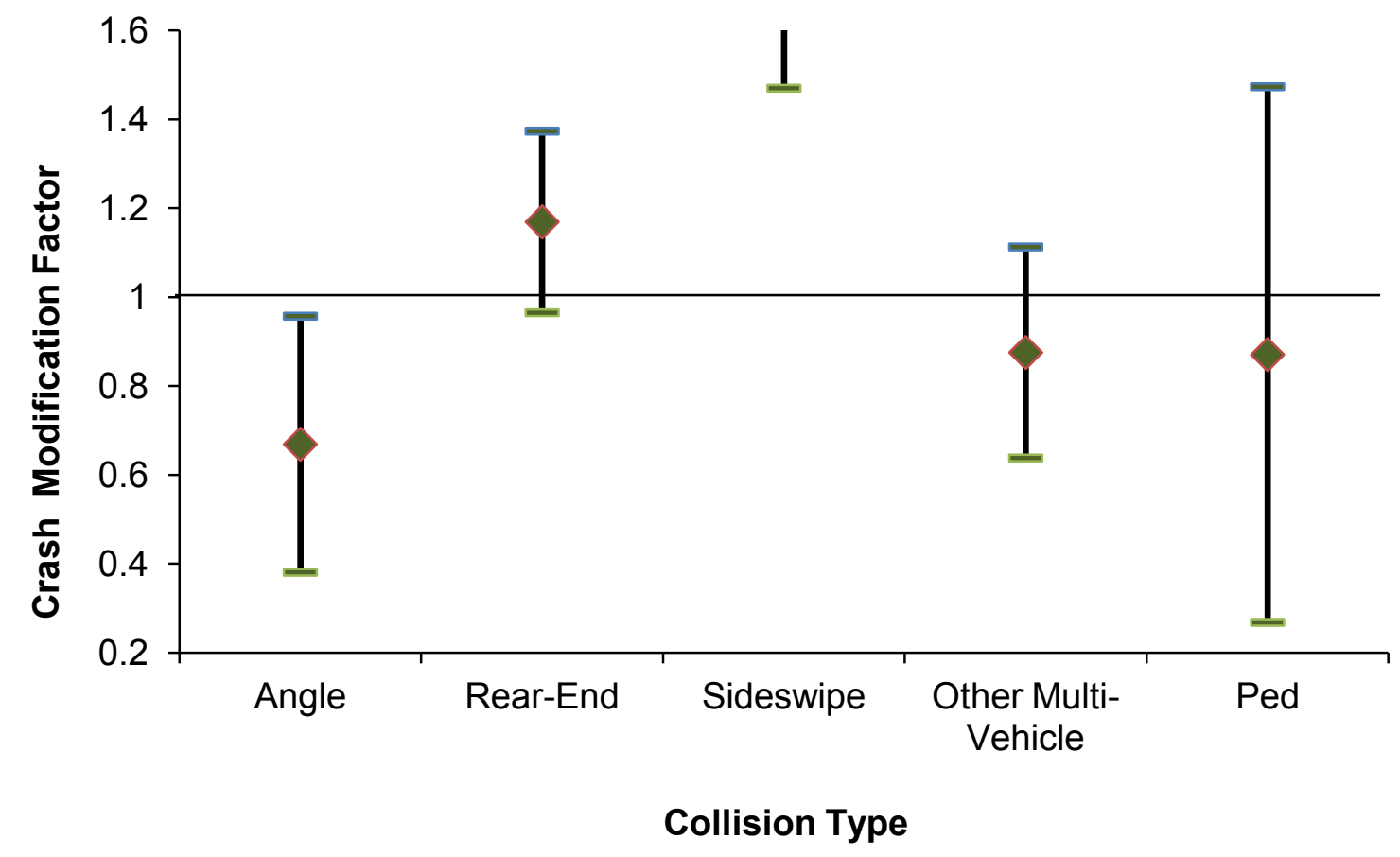

Figure 34: Crash Modification Factors for EB Method by Collision Type at the 95\% Confidence Level

Figure 34 shows the crash modification factors by collision type. Collision types not included on this figure are head-on and fixed object. These collision types had values far off the scale due to too little data available. Table 20 contains the crash modification factors at the $95 \%$ confidence level for all collision types that were observed at the eight treatment locations. 
Table 20: Crash Modification Value Limits at the 95\% Confidence Level by Collision Type

\begin{tabular}{|l|c|c|c|}
\hline & Upper Fence & Average & Lower Fence \\
\hline Angle & 0.92 & 0.64 & 0.36 \\
\hline Rear-End & 1.37 & 1.17 & 0.96 \\
\hline Sideswipe & 7.25 & 4.36 & 1.47 \\
\hline Other Multi-Vehicle & 1.11 & 0.88 & 0.64 \\
\hline Ped & 1.47 & 0.87 & 0.27 \\
\hline Fixed Object & 2.43 & 1.33 & 0.23 \\
\hline Head On & 15.79 & 5.14 & -5.52 \\
\hline
\end{tabular}

\subsubsection{Discussion}

The EB method provided the most robust crash analysis of any of the methods employed. The crash modification factor plot that was produced tells an interesting story. There is no detectable change in the total number of crashes at the treatment locations. However, there does appear to be an increase in fatal and injury crashes and a decrease in PDO and angle crashes. These results could indicate a shift from one collision type to another. One thought was that the inclusion of pedestrian and bicycle crashes in the fatal and injury category could be skewing the results. To test this hypothesis, crash modification factors were produced for fatal and injury less bike and ped collisions. The resultant graph can be seen in Figure 35. 


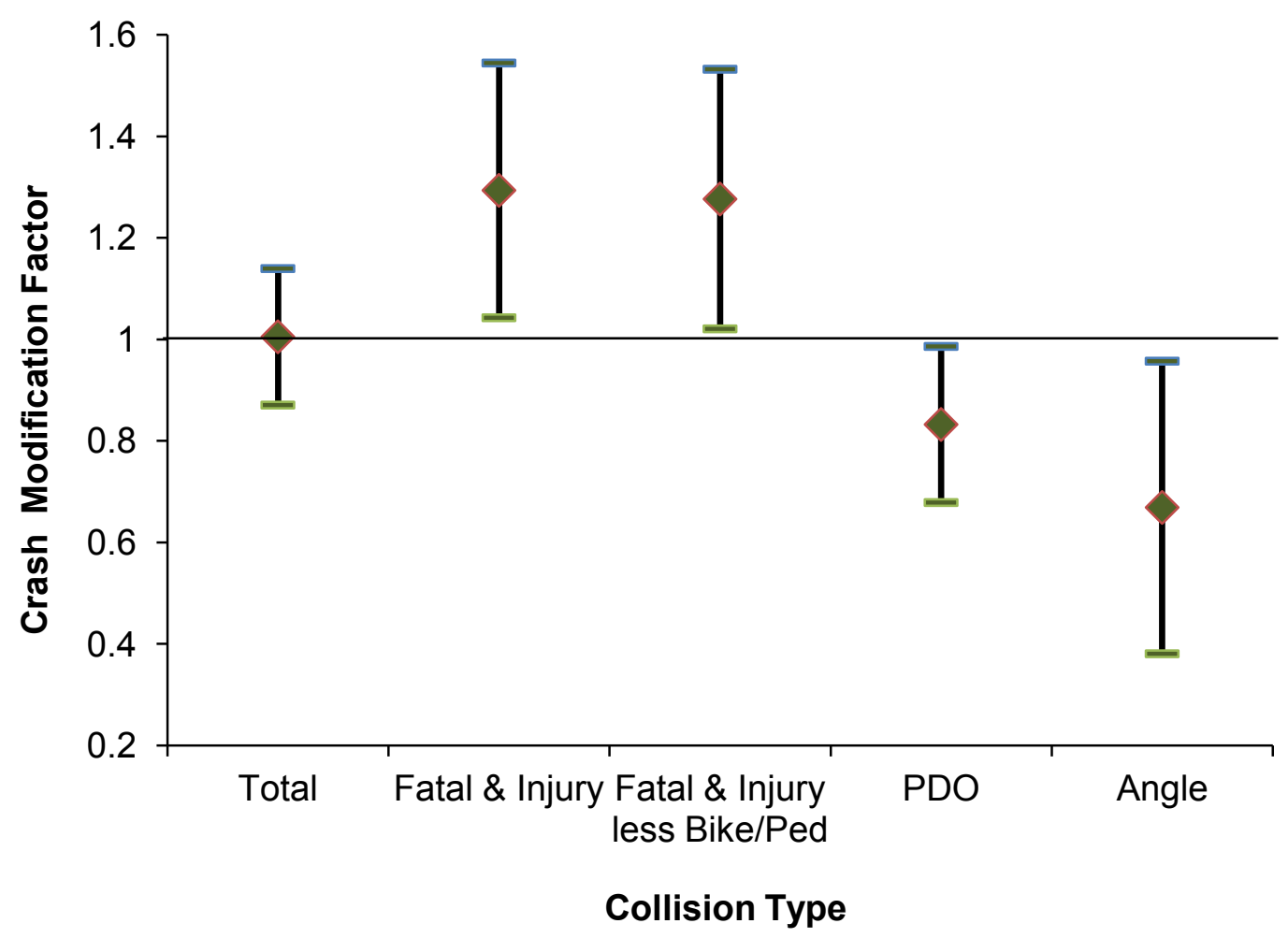

Figure 35: Crash Modification Factors for EB Method with a Revised Fatal and Injury Collision Type at the $95 \%$ Confidence Level

As seen in Figure 35, there was little to no change in the crash modification factor for fatal and injury when bike and ped crashes were removed. This suggests that these two crash types had very little effect on the crash modification factor.

By far, the most troubling results are the increase in the fatal and injury crashes. One possible reason for this increase could be an incorrect regional calibration factor for this collision type. An incorrect regional calibration factor could affect the model's ability to correctly predict fatal and injury crashes and when combined with observed crashes, is reporting an increase where one might not exist. Another reason could be that there truly is an increase in this collision type since the installation of the intersection 
treatments. One might argue that the true calibration factor should be a combination of the comparison group's calibration factors and the EB methods.

The one crash type that did increase was side-swipe collisions. It also appears that rear end crashes may have increased, but at the $95 \%$ confidence level, the conclusion that this is true cannot be stated. Angle crashes did decrease, but discovering which treatment or treatments caused this reduction is difficult. Most likely, the combination of all treatments aided in the reduction in angle crashes. For the intersections located on Powell

Boulevard that received SCATS (Milwaukie Avenue, $39^{\text {th }}$ Avenue, and $50^{\text {th }}$ Avenue) there has been a reduction in the number of cycle failures(Figliozzi, 2012). Cycle failures occur when all vehicles waiting in a queue to traverse an intersection are unable to clear the intersection during their phase. Vehicles that had been waiting, and find themselves with the possibility of waiting another cycle before travelling through the intersection, might be more prone to run a red light at the end of their phase.

\subsection{Benefit Cost Analysis}

A benefit cost analysis was performed based upon the crash analysis results of the Empirical-Bayes method. Specifically, the benefit cost of the expected number of crashes without the treatments was compared to the observed number of crashes with the treatments. 


\subsubsection{Method}

A simple benefit cost analysis was performed that looked at the shift from angle to rear end crashes. The cost of implementation was omitted from the benefit cost analysis.

Table 21: Expected and Observed Crashes with and without Treatments

\begin{tabular}{|c|c|c|}
\hline & Angle & Rear \\
\hline Expected Crashes in After Period w/o Treatment & 41.357 & 178.191 \\
\hline Observed Crashes in After Period w/ Treatment & 28 & 209 \\
\hline
\end{tabular}

Table 21 shows the number of angle and rear crashes in the after period. The expected number of crashes in the after period given that no treatments were installed is provided as determined by the Empirical-Bayes methods.

Table 22: Angle Crash Proportions and Distrbutions

\begin{tabular}{|l|r|r|r|r|}
\hline \multicolumn{5}{|c|}{ Angle } \\
\hline Severity & \multicolumn{1}{|c|}{$\begin{array}{c}\text { Total } \\
\text { Crashes }\end{array}$} & Percentage & $\begin{array}{c}\text { Expected w/o } \\
\text { Treatment }\end{array}$ & $\begin{array}{c}\text { Observed w/ } \\
\text { Treatment }\end{array}$ \\
\hline Fatal & 0 & $0.00 \%$ & 0 & 0 \\
\hline Injury A & 5 & $4.13 \%$ & 1.709 & 1.157 \\
\hline Injury B & 21 & $17.36 \%$ & 7.178 & 4.860 \\
\hline Injury C & 44 & $36.36 \%$ & 15.039 & 10.182 \\
\hline PDO & 51 & $42.15 \%$ & 17.431 & 11.802 \\
\hline
\end{tabular}


Table 23: Rear End Crash Proportions and Distributions

\begin{tabular}{|l|r|r|r|r|}
\hline \multicolumn{5}{|c|}{ Rear } \\
\hline Severity & \multicolumn{1}{|c|}{$\begin{array}{c}\text { Total } \\
\text { Crashes }\end{array}$} & Percentage & $\begin{array}{c}\text { Expected w/o } \\
\text { Treatment }\end{array}$ & $\begin{array}{c}\text { Observed w/ } \\
\text { Treatment }\end{array}$ \\
\hline Fatal & 0 & $0.00 \%$ & 0 & 0 \\
\hline Injury A & 4 & $0.64 \%$ & 1.15 & 1.346 \\
\hline Injury B & 33 & $5.31 \%$ & 9.47 & 11.106 \\
\hline Injury C & 265 & $42.67 \%$ & 76.04 & 89.187 \\
\hline PDO & 319 & $51.37 \%$ & 91.53 & 107.361 \\
\hline
\end{tabular}

Table 22 and Table 23 show the proportion of angle and rear end crashes. With these proportions, the total numbers of expected crashes without a treatment and observed with a treatment are distributed among severity levels. Three different cost values were tested in the benefit cost analysis and are labeled as Cost (1), Cost (2), and Cost (3). Cost (1) and Cost (2) are associated with FHWA values for the different severity types (U.S. Department of Transportation, Federal Highway Administration, 2005). Cost (3) are severity costs obtained from ODOT (Oregon Department of Transportation, 2007).

Applying these proportions to the expected and observed crashes for each of the crash types, an expected benefit cost dollar amount can be determined. Summing up the benefit cost dollar amounts, a resultant benefit cost amount can be determined from the decrease and/or increase in angle and rear end crashes for each of the cost methods employed. 


\subsubsection{Results}

The results of the crash benefit analysis are seen in Table 24 and Table 25 .

Table 24: Angle Benefit Cost

\begin{tabular}{|l|r|r|r|r|r|r|}
\hline \multicolumn{7}{|c|}{ Angle } \\
\hline & \multicolumn{7}{|c|}{ Expected w/o Treatment } & \multicolumn{3}{|c|}{ Observed w/ Treatment } \\
\hline Severity & Cost (1) & Cost (2) & Cost (3) & Cost (1) & Cost (2) & Cost (3) \\
\hline Fatal & $\$ 0$ & $\$ 0$ & $\$ 0$ & $\$ 0$ & $\$ 0$ & $\$ 0$ \\
\hline Injury A & $\$ 206,460$ & $\$ 206,460$ & $\$ 1,435,532$ & $\$ 139,780$ & $\$ 139,780$ & $\$ 971,901$ \\
\hline Injury B & $\$ 742,658$ & $\$ 334,910$ & $\$ 343,810$ & $\$ 502,803$ & $\$ 226,744$ & $\$ 232,770$ \\
\hline Injury C & $\$ 521,700$ & $\$ 701,715$ & $\$ 720,364$ & $\$ 353,207$ & $\$ 475,084$ & $\$ 487,709$ \\
\hline PDO & $\$ 151,183$ & $\$ 151,183$ & $\$ 261,472$ & $\$ 102,356$ & $\$ 102,356$ & $\$ 177,025$ \\
\hline Total & $\$ 1,622,001$ & $\$ 1,394,269$ & $\$ 2,761,178$ & $\$ 1,098,146$ & $\$ 943,964$ & $\$ 1,869,405$ \\
\hline Benefit Cost & $\mathbf{\$ 5 2 3 , 8 5 5}$ & $\$ \mathbf{4 5 0 , 3 0 5}$ & $\$ \mathbf{8 9 1 , 7 7 3}$ & & & \\
\hline
\end{tabular}

Table 25: Rear-End Benefit Cost

\begin{tabular}{|l|r|r|r|r|r|r|}
\hline & \multicolumn{7}{|c|}{ Expected w/o Treatment } & \multicolumn{2}{|c|}{ Observed w/ Treatment } \\
\hline Severity & Cost (1) & Cost (2) & Cost (3) & Cost (1) & Cost (2) & Cost (3) \\
\hline Fatal & $\$ 0$ & $\$ 0$ & $\$ 0$ & $\$ 0$ & $\$ 0$ & $\$ 0$ \\
\hline Injury A & $\$ 97,354$ & $\$ 97,354$ & $\$ 964,125$ & $\$ 114,186$ & $\$ 114,186$ & $\$ 1,130,821$ \\
\hline Injury B & $\$ 256,073$ & $\$ 373,063$ & $\$ 453,569$ & $\$ 300,347$ & $\$ 437,565$ & $\$ 531,991$ \\
\hline Injury C & $\$ 3,782,668$ & $\$ 2,995,810$ & $\$ 3,642,299$ & $\$ 4,436,686$ & $\$ 3,513,781$ & $\$ 4,272,048$ \\
\hline PDO & $\$ 1,049,260$ & $\$ 1,049,260$ & $\$ 1,373,018$ & $\$ 1,230,676$ & $\$ 1,230,676$ & $\$ 1,610,411$ \\
\hline Total & $\$ 5,185,354$ & $\$ 4,515,486$ & $\$ 6,433,011$ & $\$ 6,081,895$ & $\$ 5,296,208$ & $\$ 7,545,270$ \\
\hline Benefit Cost & $\mathbf{( \$ 8 9 6 , 5 4 1 )}$ & $\mathbf{( \$ 7 8 0 , 7 2 2 )}$ & $\mathbf{( \$ 1 , 1 1 2 , 2 5 9 )}$ & & & \\
\hline
\end{tabular}

Simply looking at these two crash types, the resultant benefit cost of the intersection treatments with respect to angle and rear end crashes summarized in Table 26. 


\section{Table 26: Benefit Cost Results}

\begin{tabular}{|l|r|}
\hline & Benefit Cost \\
\hline Cost (1) & $(\$ 372,686)$ \\
\hline Cost (2) & $(\$ 330,417)$ \\
\hline Cost (3) & $(\$ 220,487)$ \\
\hline
\end{tabular}

\subsubsection{Discussion}

The negative benefit cost values indicate that there is a negative benefit of the intersection treatments performed at the eight treatment intersections. Of the three cost values tested, the ODOT severity costs resulted in the most positive benefit cost value. Angle crashes are typically more severe in nature; however, there was a greater increase in the quantity of rear end crashes than the decrease in angle crashes and the costs of the less severe crashes simply totaled more than that of the more severe angle crashes. One item to note is the absence of fatal crashes in both observed time periods. Per the FHWA, angle crashes account for $42 \%$ of fatal crashes at intersections while rear end crashes account for 8\% (Federal Highway Administration, 2012). Over time, if fatal crashes were to occur, the benefit cost analysis value may result in a positive value, or in favor of the intersection treatments.

Further study is warranted to determine the effect of red extensions and the other intersection treatments on safety. One such way to simply look at collisions as a whole and try to predict the decrease in red light related crashes is by way of a simulation model. 


\subsection{RED LIGHT RUNNING SIMPLE SIMULATION MODEL}

As a final step to look at the possible effects of running a red extension at an intersection, a model was created to simulate an intersection. This model was created in the statistical program $\mathrm{R}$. The statistical program $\mathrm{R}$ was chosen over programs like VISSIM for a couple reasons, these are:

- the inability to make vehicles crash in VISSIM

- the inter-arrival rate data was easily imported into $\mathrm{R}$

- the author was very familiar with $\mathrm{R}$ over other programs

The goal of the simulation was to test an intersection with and without red extensions and determine the change in crashes, if any while holding all other factors constant. Whenever possible, field data from an intersection with red extensions was used.

\subsection{Method}

To begin the model creation, simple intersection geometry needed to be developed. A likely choice was to use the intersection of Powell Boulevard and $82^{\text {nd }}$ Avenue as a guide. Powell Boulevard and $82^{\text {nd }}$ Avenue was a good fit for the following reasons. First, the intersection featured a geometry that was uniform in geometric design. There are left turn lanes in each direction, two through lanes in each direction, and red extension inductive loops located in all through movements. Second, the City of Portland recorded the start-up time of automobiles reaching the inductive red extension loops at the start of green. Additionally, the City of Portland had recorded the number of activations of the red extension during an approximate 48 hour period. Finally, there are 
permanent count stations located on $82^{\text {nd }}$ Avenue that provided a rough picture on volumes throughout a day.

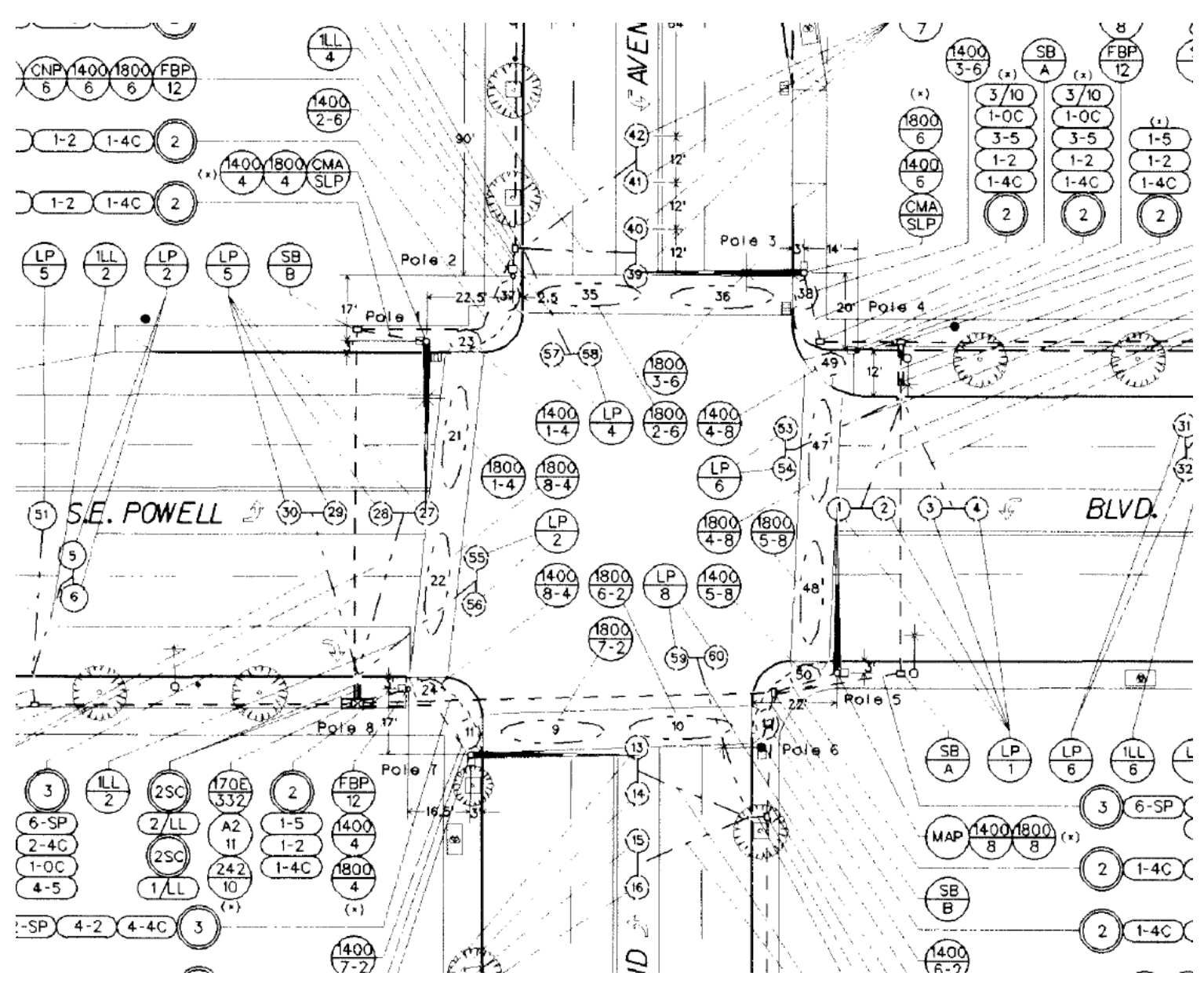

Figure 36: Record Drawing for Powell Boulevard and 82nd Avenue

Figure 36 shows a record drawing for the intersection of Powell Boulevard and $82^{\text {nd }}$ Avenue. This drawing was used to determine the distance from the stop bar to the location of the red extension loops located downstream. The red extension loops are listed as loops 53 through 60 . This drawing was also used to determine the location of conflict points for conflicting movements. 
The model required a variety of inputs to match real-world conditions as closely as possible. The first item to develop and input into the model was the inter-arrival rate of vehicles approaching the intersection. Located to the north of Powell Boulevard and $82^{\text {nd }}$ Avenue are count stations located at Burnside Street and $82^{\text {nd }}$ Avenue. These count stations provide volume information for vehicles heading north and south on $82^{\text {nd }}$ Avenue. The volume data are by lane and are recorded every minute.

Another data source which will be covered later is the start-up time of vehicles reaching the red extension inductive loops at the start of green. These readings were performed for an approximate 48 hour period on February $26^{\text {th }}$ through February $28^{\text {th }}$ of 2012 by the City of Portland. When choosing the volume information for the system detectors located on $82^{\text {nd }}$ Avenue at Burnside Street, the same 48 hour period as the startup data was chosen. Four different tables were read into $\mathrm{R}$ that contained the volume of vehicles that passed the system detectors for each minute in the 48 hour test period on a by-lane basis.

Using the volume of vehicles per minute, an inter-arrival rate is determined for each minute by dividing 60 seconds by the volume of vehicles for that minute. Using the inter-arrival rate of vehicles (seconds/vehicle) and the volume of vehicles for each minute, the volume count of vehicles is evenly distributed throughout that minute. For example, if at minute 15:00 there is a volume of one, that vehicle is assigned to minute 15:00. However, if there are two vehicles in that minute, one vehicle is assigned to 15:00 and another would be assigned to 15:30. This is repeated for all lanes, north and southbound. With the newly distributed vehicle counts in each minute, an adjusted inter- 
arrival rate is calculated. From these adjusted inter-arrival rates, plots are created for each of the lanes on $82^{\text {nd }}$ Avenue.

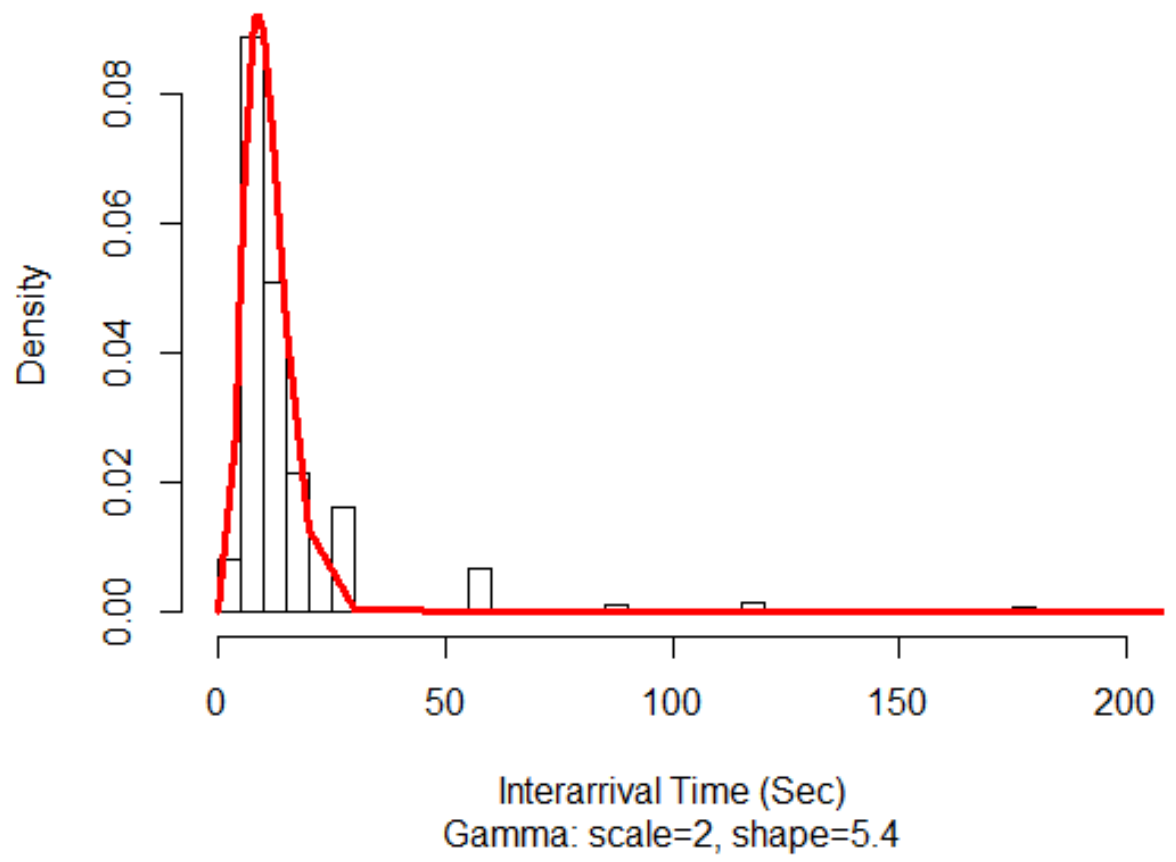

Figure 37: Inter-arrival Distribution for the NB Right Lane on 82nd Avenue at Burnside Street for 48 hours 


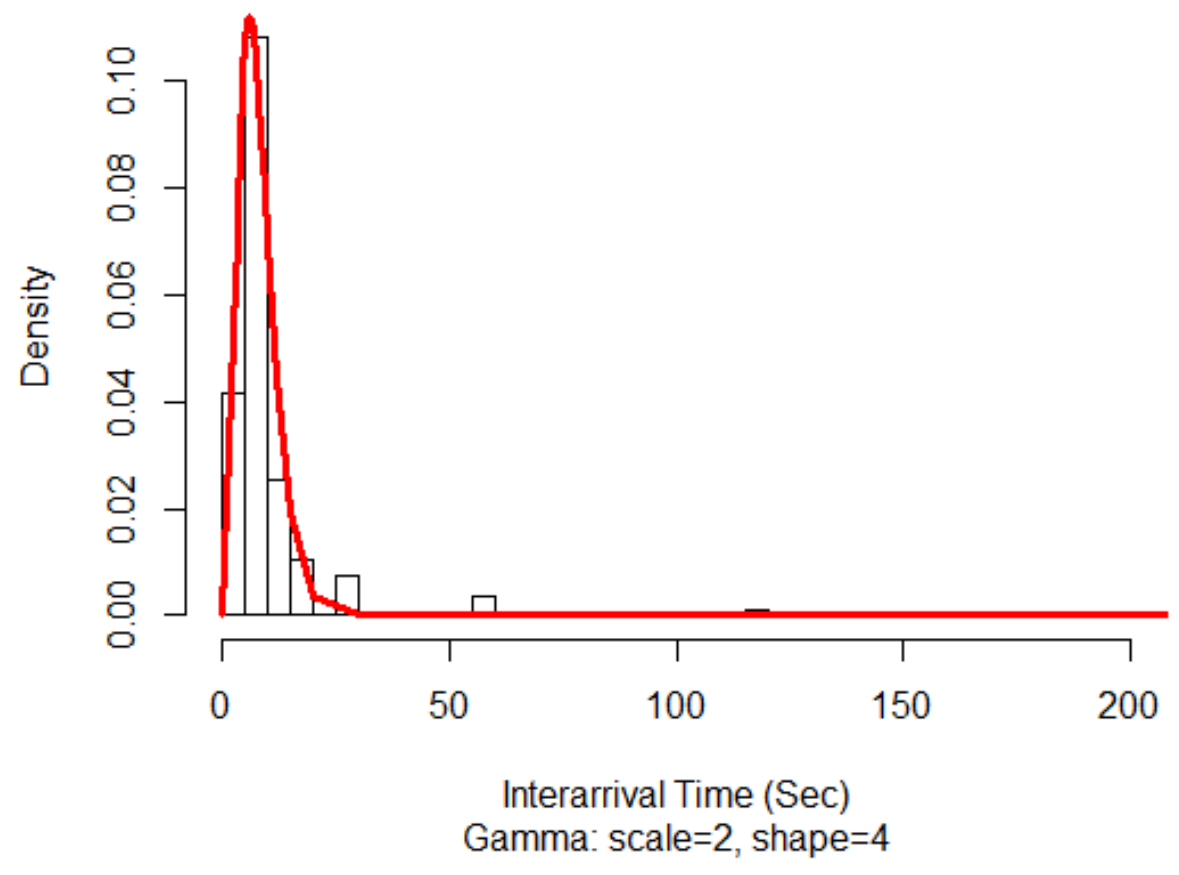

Figure 38: Inter-arrival Distribution for the NB Left Lane on 82nd Avenue at Burnside Street for 48 hours

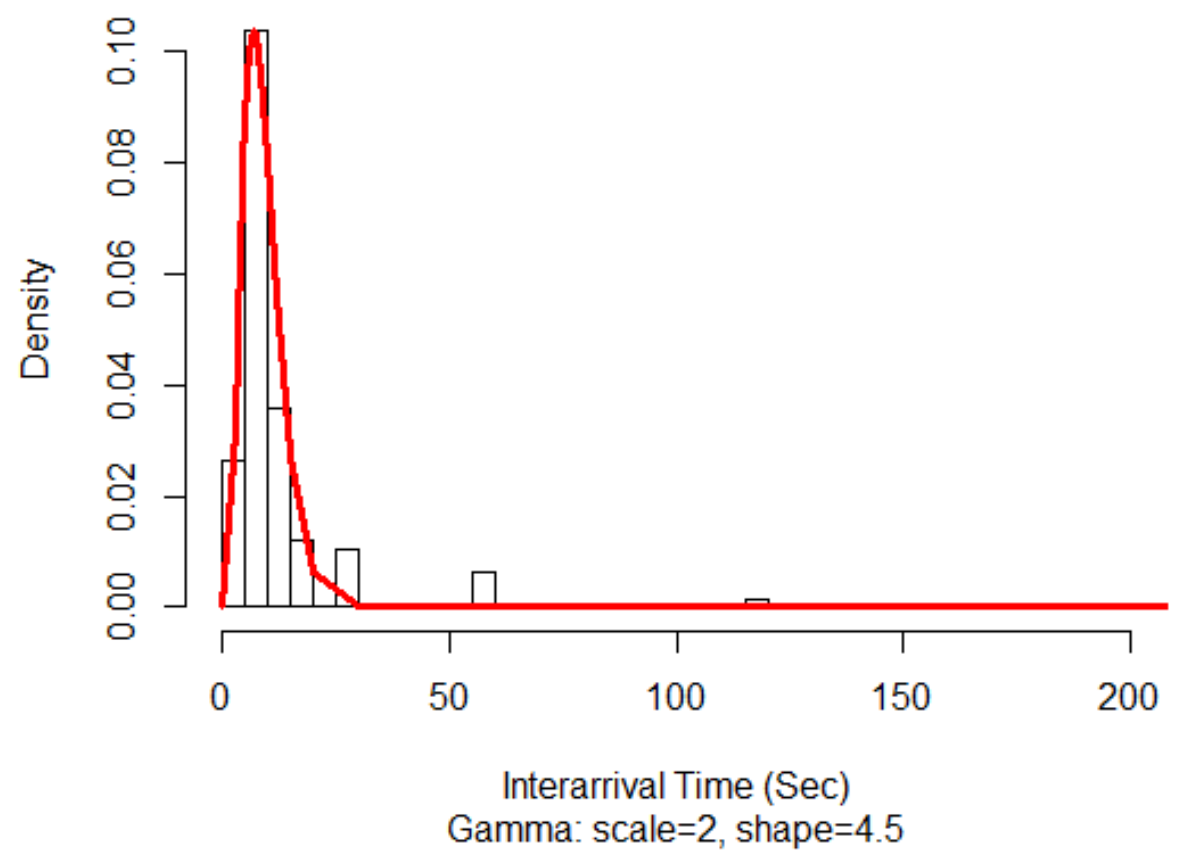

Figure 39: Inter-arrival Distribution for the SB Right Lane on 82nd Avenue at Burnside Street for 48 hours 


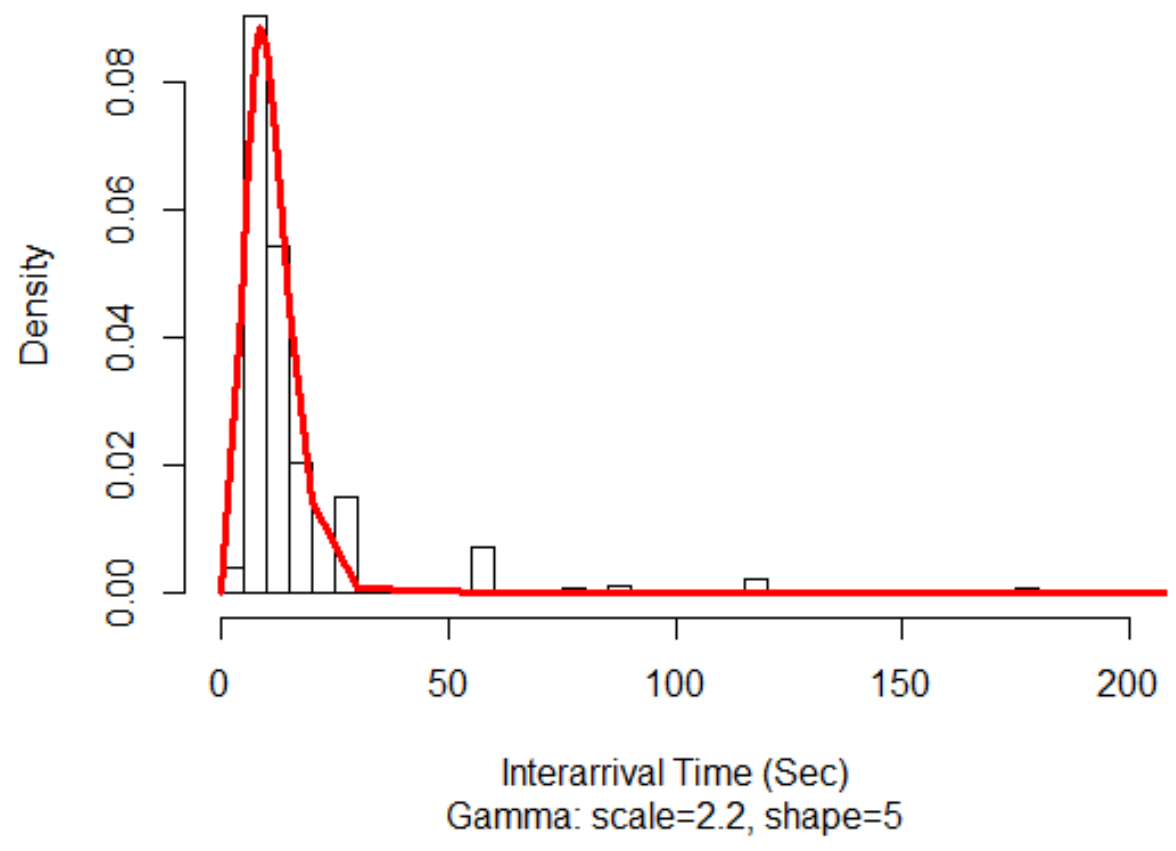

Figure 40: Inter-arrival Distribution for the SB Left Lane on 82nd Avenue at Burnside Street for 48 hours

Figure 37 through Figure 40 are histogram density plots of the inter-arrival rate of vehicles on $82^{\text {nd }}$ Avenue for the 48 hour time window. In each plot, a gamma probability density function has been visually fit to the plot of the histogram data and is denoted by the solid line. The scale and shape of the gamma function are provided as details below the $\mathrm{x}$-axis on each plot and are appropriately labeled. The gamma function from each of these plots provides the inter-arrival rates of vehicles for the model, when randomly generated from the function. 


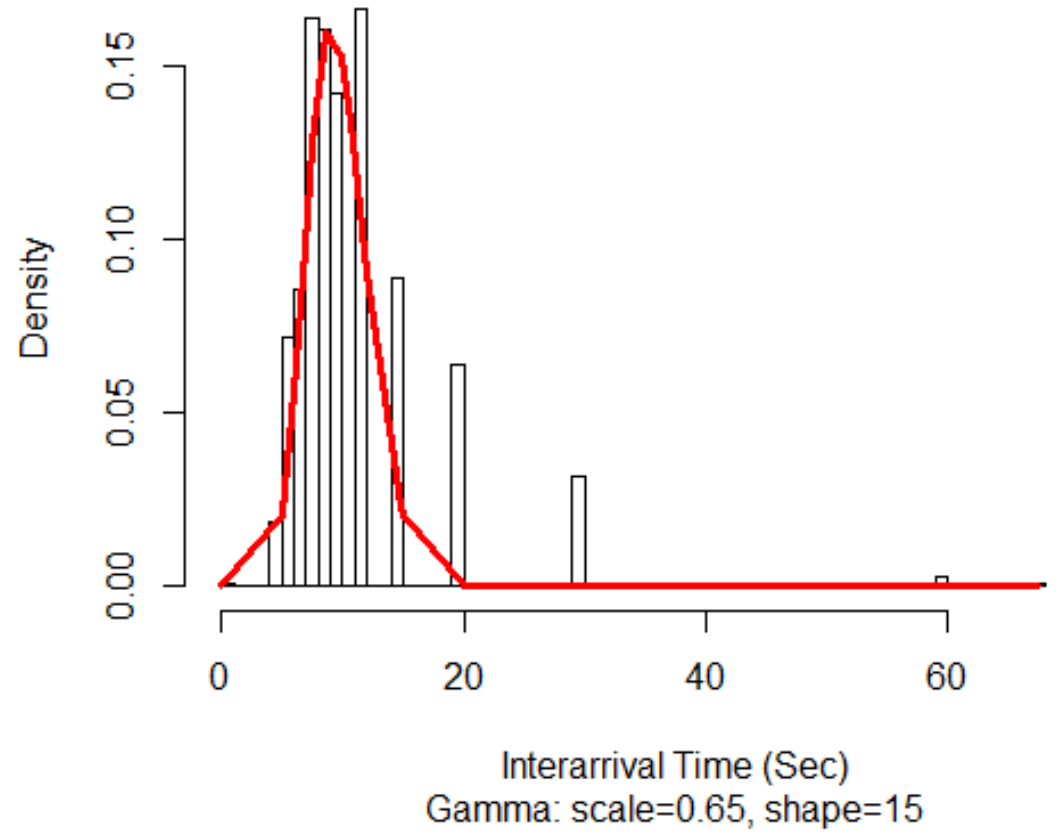

Figure 41: Inter-arrival Distribution for all lanes on 82nd Avenue at Burnside Street during P.M. Peak (5:00 p.m. - 7:00 p.m.)

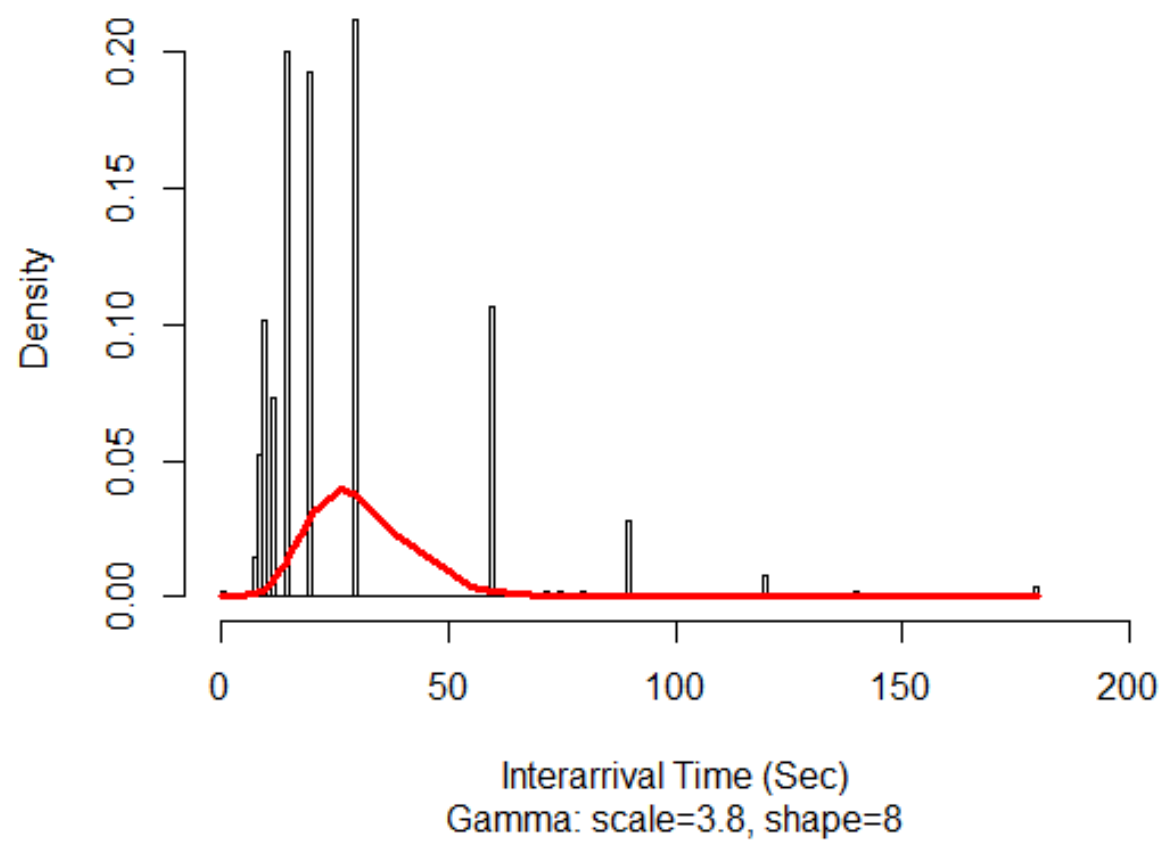

Figure 42: Inter-arrival Distribution for all lanes on 82nd Avenue at Burnside Street during P.M. Off-Peak (9:00 p.m. - 11:00 p.m.) 
Figure 41 and Figure 42 show the estimated inter-arrival rates for vehicles on $82^{\text {nd }}$ Avenue during p.m. peak and off-peak times. These rates were assumed for all lanes in order to test differences in the number of crashes during different times of the day.

In setting up the modeled intersection, some basic assumptions were made. First, turning movements were ignored. Since the red extension inductive loops are only located in through lanes, only those lanes were analyzed. Second, only the north and southbound directions were analyzed when an amber signal was displayed. This was done to keep the model simple, and due to the fact that only the inter-arrival rates for $82^{\text {nd }}$ Avenue were available. Third, it was assumed that at every phase change from $82^{\text {nd }}$ Avenue to Powell Boulevard, there was always a car at the stop bar on Powell waiting for a green indication. Fourth, the model did not take into account avoidance maneuvers that normal drivers would perform if faced with an impending collision. Fifth, the model assumed that all vehicles accelerated at a constant rate of $10 \mathrm{ft} / \mathrm{s}^{2}$ when starting from a stopped position. Sixth, all vehicles travelling northbound and southbound travel at the speed limit of $35 \mathrm{mph}$. Seventh, driver aggressiveness or recklessness was not factored into the problem beyond the go/no go decision equation discussed later. Finally, at a speed of $35 \mathrm{mph}$, it was assumed that vehicles traveled at approximately five feet per tenth of a second. For the purposes of this model, a total clearance time of 4.6 seconds is assumed without the red extension as pictured in Figure 3.

At the start of every simulation run, vehicles were sent both north and southbound towards the intersection based upon a randomly generated inter-arrival rate determined earlier for each lane. Vehicles from the last simulation run were cleared from the channel 
at the start of every run where new vehicles started at a distance of 500 feet from the intersection. A signal countdown timer began at the start of each simulation run. Vehicles would travel five feet per tenth of a second towards the intersection. A separate countdown timer for each lane would track the inter-arrival time for each vehicle. When the inter-arrival countdown timer would expire, a new car would be sent towards the intersection and a new random inter-arrival rate would be generated. The signal countdown timer would count down from 45 seconds, at which point, an amber indication would be displayed.

When an amber indication is displayed, each vehicle that is heading north or south faces a decision; to go or not to go. Based upon research (Zimmerman \& Bonneson, 2005) (Hurwitz, Wang, Knodler, Ni, \& Moore, 2012) a probability of going function was created. The function takes into account vehicle speed and vehicle distance from the stop bar at the onset of amber and can be seen in equation 17 below.

ProbGo $=1-\left(1 /\left(1+\mathrm{e}^{\wedge}\left(6.34-1.36^{*}(\right.\right.\right.$ distance from stop bar $) /($ vehicle speed $\left.\left.\left.)\right)\right)\right)$ 


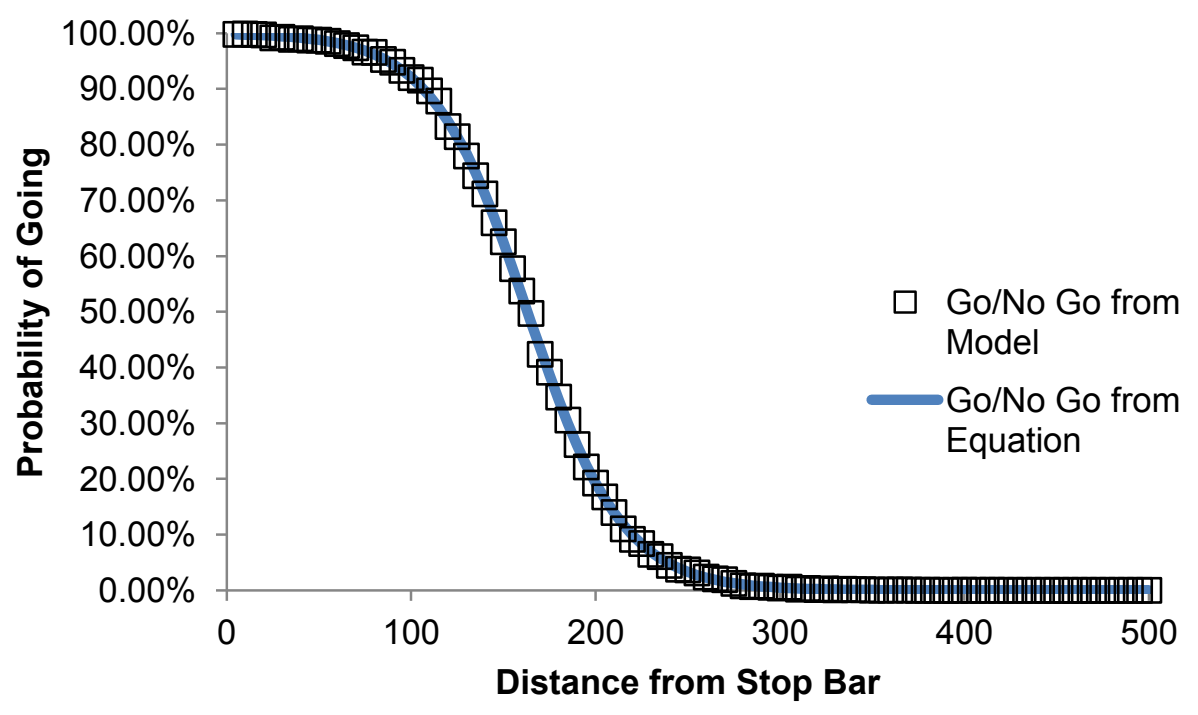

Figure 43: Go/No Go Probability Plot for $35 \mathrm{mph}$ based on Distance from Stop Bar

Figure 43 shows the graphical results of go/no go probability function. For each vehicle, a random value between 0 and $100 \%$ is chosen from a uniform distribution. This random value is then compared to the probability of that vehicle going based upon its distance from the stop bar. If that randomly generated value is less than the probability of going, the vehicle proceeds through the intersection. If the randomly generated value is greater than the probability of that vehicle going, the vehicle does not proceed through the intersection. If two vehicles are in one lane, and the vehicle closest to the stop bar does not proceed through the intersection, the vehicle behind that one also does not proceed through the intersection independent of its decision to go or not go.

For vehicles waiting at the stop bar on Powell Boulevard to enter the intersection, a plot of the time it takes for vehicles to reach the red extension inductive loops was created. Figure 44 shows the histogram distribution of the time it takes for vehicles to reach to red extension inductive loops at the start of green. A normal distribution is fitted 
to the first peak of the histogram which represent the first vehicles that enter the intersection. These values were provided by the City of Portland.

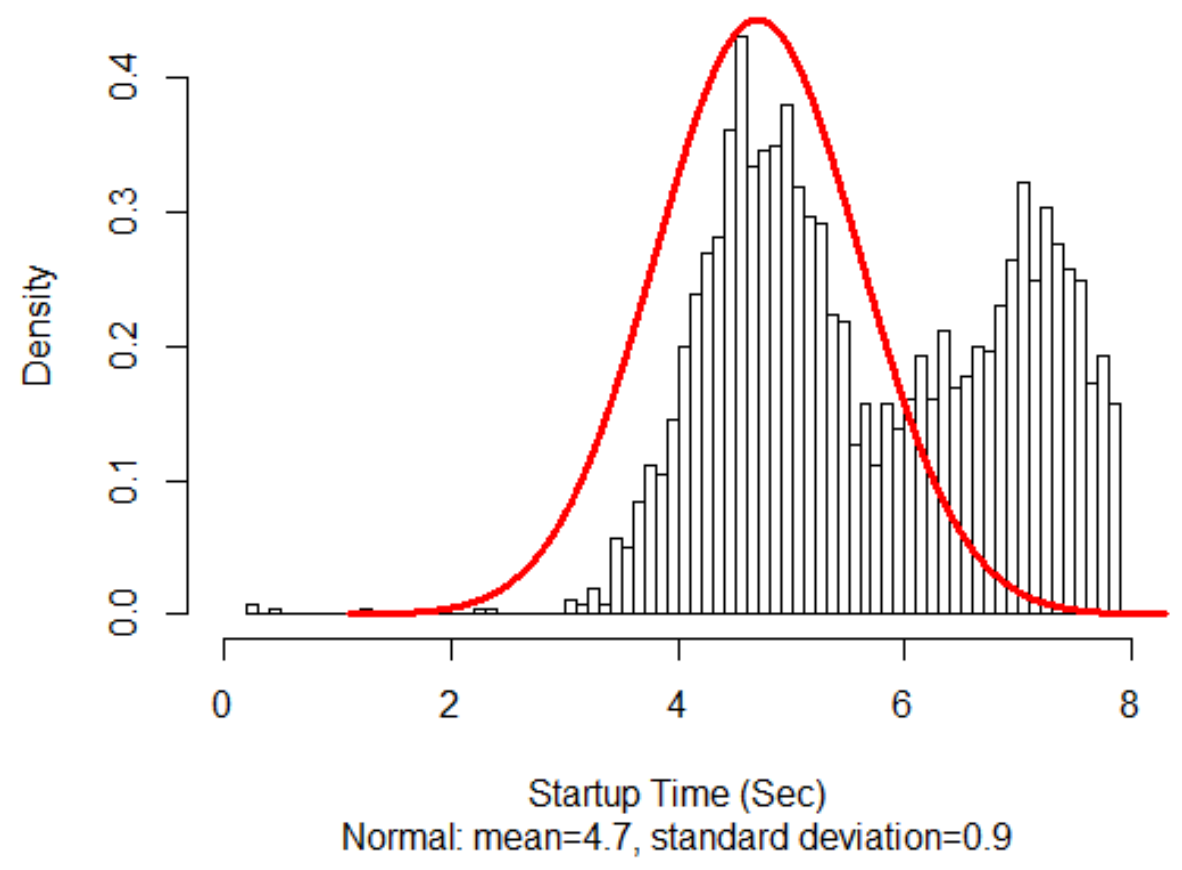

Figure 44: Startup Distribution for the vehicles on Powell Boulevard

At the end of every red clearance phase, the start-up time for each vehicle in each lane on Powell Boulevard is randomly generated based upon the normal distribution pictured in Figure 44.

For each vehicle in the north and southbound directions that decides to go, the time that that vehicle would cross the path, a conflicting movement in the intersection is recorded. For each conflict point, it is assumed that each vehicle remains in that conflict point for three tenths of a second. This is based on the assumption that on average, a vehicle is approximately 14 feet in length (Federal Highway Administration, U.S. DOT, 
2012). Any time that a vehicle in the west/east direction has the same time at a conflict point to that of a vehicle in the north/south direction, a crash occurs.

\subsection{Results}

300,000 simulation runs were performed for the intersection modeled as described above. Given that each run represents a 90 second cycle length, a broad assumption could be that 300,000 simulation runs roughly equates to $27,000,000$ seconds of time, or approximately 313 days. Table 27 shows the results of the 300,000 simulation runs using the inter-arrival rates obtained for the full 48-hour period.

Table 27: Results of Model Simulation Runs using 48-hour Inter-Arrival Rate

\begin{tabular}{|c|c|c|c|c|c|c|c|c|c|}
\hline & & \multicolumn{3}{|c|}{ Time of } \\
Location & Runner & \multicolumn{2}{|c|}{ Other Runners } & $\begin{array}{c}\text { EBR } \\
\text { Start }\end{array}$ & $\begin{array}{c}\text { EBL } \\
\text { Start }\end{array}$ & $\begin{array}{c}\text { WBR } \\
\text { Start }\end{array}$ & $\begin{array}{c}\text { WBL } \\
\text { Start }\end{array}$ \\
\hline NBR/WBL & -415 & 9.8 & -90 & -105 & & 5.9 & 4.7 & 4.0 & 4.5 \\
\hline NBR/WBR & -335 & 8.6 & -125 & -30 & -160 & 6.5 & 5.9 & 3.1 & 5.1 \\
\hline NBL/WBL & -335 & 8.3 & -5 & & & 4.3 & 3.6 & 5.5 & 2.4 \\
\hline NBR/WBL & -380 & 9.1 & & & & 6.1 & 5.9 & 4.7 & 3.6 \\
\hline SBR/EBL & -365 & 8.9 & -135 & & & 4.1 & 3.6 & 6.0 & 4.6 \\
\hline NBR/WBL & -350 & 8.6 & -120 & -100 & -115 & 5.0 & 5.0 & 5.0 & 3.1 \\
\hline SBR/EBL & -380 & 9.3 & -75 & & & 4.1 & 3.8 & 4.8 & 3.5 \\
\hline SBR/EBR & -380 & 9.4 & -75 & & & 4.1 & 3.8 & 4.8 & 3.5 \\
\hline NBR/WBL & -380 & 9.3 & & & & 2.8 & 4.5 & 4.6 & 4.0 \\
\hline SBL/EBL & -350 & 8.5 & -130 & -80 & & 4.4 & 2.6 & 4.6 & 6.9 \\
\hline NBL/WBL & -355 & 8.6 & & & & 7.1 & 5.2 & 3.6 & 2.7 \\
\hline SBR/EBL & -385 & 9.3 & & & & 5.3 & 4.0 & 4.8 & 4.3 \\
\hline
\end{tabular}


Table 28: Results of Model Simulation Runs using P.M. Peak Inter-arrival Rate

\begin{tabular}{|c|c|c|c|c|c|c|c|c|}
\hline Location & Runner & $\begin{array}{c}\text { Time of } \\
\text { Impact }\end{array}$ & \multicolumn{2}{|c|}{$\begin{array}{c}\text { Other } \\
\text { Runners }\end{array}$} & $\begin{array}{c}\text { EBR } \\
\text { Start }\end{array}$ & $\begin{array}{c}\text { EBL } \\
\text { Start }\end{array}$ & $\begin{array}{c}\text { WBR } \\
\text { Start }\end{array}$ & $\begin{array}{c}\text { WBL } \\
\text { Start }\end{array}$ \\
\hline NBR/WBL & -290 & 7.3 & -65 & & 3.5 & 5.9 & 6.0 & 2.0 \\
\hline NBR/WBR & -375 & 9.2 & -130 & -90 & 5.1 & 4.1 & 3.9 & 4.0 \\
\hline NBL/WBR & -310 & 8.1 & -155 & & 4.8 & 5.2 & 2.4 & 5.8 \\
\hline NBR/WBL & -380 & 9.3 & -170 & -70 & 4.2 & 5.1 & 5.3 & 3.8 \\
\hline NBR/WBL & -370 & 8.9 & -95 & & 5.2 & 4.5 & 4.2 & 3.6 \\
\hline NBR/WBL & -340 & 8.5 & -125 & & 4.9 & 3.1 & 3.5 & 3.2 \\
\hline NBR/WBL & -385 & 9.4 & & & 5.6 & 4.6 & 4.5 & 4.1 \\
\hline SBR/EBR & -370 & 9.1 & & & 3.8 & 4.8 & 4.7 & 4.0 \\
\hline NBR/WBR & -380 & 9.3 & -95 & & 2.5 & 5.6 & 3.8 & 4.6 \\
\hline SBR/EBL & -400 & 9.7 & -150 & & 5.0 & 4.4 & 5.1 & 5.3 \\
\hline NBR/WBR & -235 & 6.5 & -120 & & 4.5 & 3.6 & 1.2 & 5.2 \\
\hline NBR/WBR & -400 & 9.7 & & & 5.3 & 5.2 & 4.4 & 4.3 \\
\hline NBR/WBL & -435 & 10.4 & -130 & & 3.7 & 6.3 & 5.9 & 5.1 \\
\hline NBL/WBL & -355 & 8.6 & -55 & -5 & 5.1 & 4.0 & 4.9 & 2.7 \\
\hline SBL/EBL & -310 & 7.9 & -125 & & 4.9 & 2.2 & 5.9 & 3.0 \\
\hline SBL/EBL & -440 & 10.5 & -105 & & 4.9 & 4.8 & 5.2 & 4.1 \\
\hline
\end{tabular}

Table 29: Results of Model Simulation Runs using P.M. Off-peak Inter-arrival Rate

\begin{tabular}{|c|c|c|c|c|c|c|c|}
\hline Location & Runner & $\begin{array}{l}\text { Time of } \\
\text { Impact }\end{array}$ & $\begin{array}{c}\text { Other } \\
\text { Runners }\end{array}$ & $\begin{array}{l}\text { EBR } \\
\text { Start } \\
\end{array}$ & $\begin{array}{l}\text { EBL } \\
\text { Start }\end{array}$ & $\begin{array}{l}\text { WBR } \\
\text { Start }\end{array}$ & $\begin{array}{l}\text { WBL } \\
\text { Start }\end{array}$ \\
\hline NBR/WBR & -265 & 7.1 & & 5.7 & 4.4 & 1.8 & 3.4 \\
\hline NBR/WBR & -325 & 8.3 & & 5.9 & 5.9 & 3.0 & 6.1 \\
\hline SBR/EBR & -340 & 8.5 & & 3.2 & 5.2 & 5.9 & 4.6 \\
\hline SBL/EBL & -405 & 9.7 & & 4.6 & 4.0 & 5.6 & 4.5 \\
\hline
\end{tabular}

Three different simulations were performed. The difference between each simulation was which inter-arrival rate was used. The three inter-arrival rates used were the 48-hour inter-arrival rate, a p.m. peak inter-arrival rate, and a p.m. off-peak inter- 
arrival rate. For each simulation, 300,000 runs were performed and the results for each simulation are summarized in Table 27 through Table 29.

Each row in the table represents one crash that has occurred. For each crash detected, the conflict location is recorded. A value of SBR/EBR indicates that the crash occurred where the southbound right and eastbound right lanes intersect. The column labeled "Runner" indicates the vehicle that was involved in the crash that proceeded through an intersection during an amber or red phase. For example, a value of -300 indicates that a vehicle was 300 feet back from the stop bar at the onset of amber, made a decision to proceed through the intersection, and was involved in a crash. The time of impact column denotes the time at which the crash occurred in seconds, treating the zero point as the time that the amber signal was first displayed. The "Other Runners" columns indicate if there were any other vehicles that entered the intersection after the amber indication was displayed for that same run. Values in the "Other Runners" column denote their distance from the stop bar at the onset of amber. EBR Start, EBL Start, WBR Start, and WBL Start indicate the time that vehicles in the eastbound right, eastbound left, westbound right, and westbound left crossed the red extension inductive loops located within their lane.

Using the 48 hour inter-arrival rate, 12 crashes were detected. For p.m. peak interarrival rate, 16 crashes were detected, and for p.m. off-peak inter-arrival rate, four crashes were detected. These crashes do not take into account the red extension technology and simply show how many crashes were modeled for a base intersection. 
As shown in Figure 3, a red light can only be extended when a vehicle crosses the red extension inductive loop between 1.8 seconds into amber and the end of the red clearance phase. Back calculating for vehicle distance from the red extension inductive loops, vehicles that are between 70 and 210 feet from the intersection that choose to enter the intersection at the onset of amber, will trigger a red extension. Every vehicle that would have triggered a red extension is highlighted in the "Other Runners" column in each table.

\subsection{Discussion}

Many assumptions had to be made with this model. The vehicles did not perform any avoidance maneuvers nor did they accelerate through intersections during an amber or red clearance phase. The model also did not take into account the possibility of lagging left turns in the north/south directions. Due to these and other simplifying assumptions, the results should not be taken as concrete proof that the red extension technology will truly drop red light running crashes by $58 \%$. However, the model does show that there is the need to study the technology further. Some may argue that if even a handful of crashes could be prevented, it would be worth it. Given the low cost of implementation, even a small reduction is significant. Further refining of the model or a model analyzing the effects of red extensions does seem worthwhile.

As mentioned, over the course of 300,000 simulation runs, 12 crashes occurred in the north and southbound direction for the base model. Keep in mind that only the north and southbound locations were considered for red light running, therefore, an assumption could be made that considering red light runners in both locations, the number of crashes 
predicted by the model would be doubled. If crash data could be obtained for an extended period of time with the clarity and detail to definitively state how many of the crashes were due to red light running, the model could be further refined to more correctly take into account real-world conditions.

The interesting item to note is that a red extension does not usually "save" the vehicle that triggers the extension, but it "saves" a vehicle that enters the intersection after the initial extension event. This is due to the fact that for the red phase to be extended, a vehicle must be detected passing over the red extension inductive loops during the amber or red clear phase. The vehicle that is detected and triggers a red extension, will most likely be clear of any conflict points with any other conflicting movements by the time another vehicle reaches that point. In all the runs that resulted in a crash, none of the vehicles involved in a crash could have saved themselves. All crashes required an initial runner to trigger the red extension, thus saving the late runner. Of the 12 red light running crashes, 7 could have been prevented with the red extension technology, or $58 \%$ of the crashes could have been prevented.

Two additional simulation runs were performed. These runs included inter-arrival rates during p.m. peak and p.m. off-peak. The goal of performing these runs was to replicate the time of day pattern of angle crashes that was noted in Figure 30. Unfortunately, the results did not match the observed crashes. From the simulation, crashes increased during p.m. peak and decreased during p.m. off-peak which contradicts the observed pattern. The likely culprit for the difference is the inaccuracy in inter- 
arrival rates for p.m. peak and off-peak. With higher resolution data, and the ability to account for platooning, the results would most likely be different.

An interesting item to note is that during the off-peak time, when traffic volumes are significantly less, there we only four crashes detected. Of the four crashes, none of them would have been prevented by the red extension technology. In each case, the vehicle entered the intersection after the red clearance interval, and no other vehicles ran the red light that would have triggered a red extension. During the p.m. peak simulation, the volumes of vehicles were higher. This higher volume resulted in more crashes, but there was also a greater proportion of crashes that could have been avoided with red extensions. 16 crashes were recorded with 11 of them potentially avoided with red extensions, or a $69 \%$ reduction in the number of the crashes.

Actual dimensions of the intersection were used in determining conflict points and the location of the red extension inductive loops. In hopes of further calibrating the modeled intersection, actual measured inter-arrival rates and start up times were used. While some assumptions were made, the results of the many simulation runs reinforce the possibility that the red extension technology has the potential to positively impact safety at intersections where red light running is problematic. 


\subsection{CONCLUSION}

One of the most difficult things in performing a before and after crash analysis is obtaining sufficient and accurate data. With the help of many individuals, a fairly robust amount of data was made available for this research. One problem that did arise was the lack of an accurate log of the various changes that have occurred at the treatment intersections throughout the years. Without an accurate history, it is difficult to know accurately the effect of a singular treatment like red extension on safety.

Other treatments were performed at some of the intersections including changing from span wire to mast arm supports for the signal heads. These mast arm supports provided a rigid support that would not sway in the wind like its predecessor. Just the presence of a mast arm support can improve visibility of signal heads. This improved visibility may have contributed to an increase in intersection safety, but flushing out the extent of the change is difficult.

In the simple, comparison group, and EB method, angle crashes did decrease at the treatment intersections. This decrease shows that either one or many of the upgrades performed at the intersection improved safety for this collision type. With angle crashes being the crossing of two paths, an assumption could be made that the decrease was due to the increased signal visibility and/or the red extension technology.

To pull together all of the crash analysis, a simple model was created that attempted to replicate a real-world intersection in Portland, Oregon. The intersection simulation was modeled after the intersection of Powell Boulevard and $82^{\text {nd }}$ Avenue. 
Existing intersection geometries, arrival rates on $82^{\text {nd }}$ Avenue, existing signal timing, and start-up time on Powell Boulevard were used in calibrating the simulation. The observed crashes from 2000 to the intersection upgrade date in August 2005 yielded 19 angle crashes, or approximately 3.35 angle crashes per year. From August 2005 to the end of 2011, six angle crashes were recorded or approximately 0.95 angle crashes per year. From the simulation model, 12 red light running crashes were predicted per year. If red extension technology was in place at this intersection, these 12 crashes would have been reduced to only five. This reduction in crashes results in a crash modification factor of 0.42. Referencing Figure 34 and Table 20, this crash modification factor falls within the estimated range as determined by the Empirical-Bayes method.

Unfortunately, the simulation model was unable to replicate the same time-of-day crash trends that were seen from the data. From the angle crash data by time-of-day, angle crashes are more prevalent during off-peak times. This increase in angle crashes could be attributed to free-flow conditions and vehicles travelling at fast speeds. When vehicle flow is congested, few vehicles may be running the red light due to the fact that speeds are slower and drivers are not faced with as many dilemma zone problems. Unfortunately the model reported results that contradicted the crash data. The most likely reason for the difference lies in the inter-arrival rate assumptions made in the model. More detailed inter-arrival rate data would have the potential to remedy this discrepancy.

From the simulation model, there was not a single instance in which a crash could have been avoided by the vehicle that ran the red light triggering a red extension for themselves. If it was not for the fact that another vehicle also entered the intersection late 
on the same cycle, and during the time that a red extension could be triggered, the vehicles that avoided a crash would not have.

Driver adaptation to changes in signal timing can be a concern. Bonneson et al. noted that drivers did adapt to a lengthening of an amber clearance interval. It remains to be answered if drivers would adapt to a dynamic increase in a red clearance interval. The unique detail with the extension of a red clearance interval over an amber one is the required knowledge to detect an increase of a red clearance interval. When approaching an intersection, a driver may be able to identify a longer amber interval, and this can simply be done by looking at the signal ahead of them. To recognize a longer red clearance interval however requires looking at both their signal and the signal for conflicting movement. Therefore, driver adaptation to a dynamic extension of a red clearance interval should be lower than that of an increase in an amber clearance interval. Furthermore, the increase of a red clearance interval with respect to red extensions was done dynamically, while the study performed by Bonneson et al. was done for every cycle, further reducing the chance of detection by a driver.

Currently, a red extension is triggered as early as halfway into the amber clearance interval. For a vehicle travelling at $35 \mathrm{mph}$, there is not a need to trigger an extension this early in the clearance interval. Since it only takes a vehicle 1.8 seconds to clear an intersection, it may make sense to only trigger a red extension when there is less than 1.8 seconds left in the current movement's clearance. With a one second red clearance interval, a red extension would only need to be triggered during the last 0.8 seconds of an amber clearance. Given the argument that there is a about a second of 
startup loss time for a conflicting movement, there might not be any value in triggering a red extension during the amber clearance interval at all.

Ideally, determining if a vehicle will run a red light would occur prior to a vehicle entering an intersection. To do this, the speed and distance of each vehicle would need to be monitored as they approach an intersection. With advance inductive loops, a small sample of driver speed and distance is available, but only at a single point. By tracking these details for every vehicle over a large approach distance and not a single point, the probability of an individual running a red light could be more accurately predicted.

From the simulation model, it was shown that any vehicle that ran a red light and was involved in a crash did not trigger a red extension. An argument could be made that instead of relying on the chance that a red extension would be triggered randomly by another vehicle, simple increase the length of the red clearance interval for all cycles. The difficulty in doing this is that drivers may be able to detect this increased red clearance duration and may adapt to it. When the red clearance interval is extended dynamically, drivers may not be able to detect the extension. Second, when you increase the red clearance interval, you increase delay at the intersection. One possible solution however might be to increase the red clearance interval by time of day. Knowing that there is an increase in angle crashes during certain off-peak times as noted earlier, one could increase the red clearance interval for those times. 


\subsection{Future Analysis}

In going forward, there is great potential to use this initial research as a spring board in analyzing red extensions in great detail. A delay analysis might be useful in determining the theoretical number of red extensions that are triggered and a comparison to the number of times that a crash is prevented could be performed. Unfortunately the simulation model was unable to replicate the time of day results that was shown in Figure 30. With higher resolution inter-arrival rates, the simulation may be able to replicate the results seen with the real-world data. Also, knowing exactly when activations occur, a correlation could be drawn between the time-of-day crash data and when red light running occurs. Additionally there may be some value in looking at borderline crashes. A crash that almost occurred but was off by 0.1 seconds was not recorded. Storing and recording this data could yield trend information of red light runners.

The statistical program $\mathrm{R}$ is probably not the ideal software to use to model an intersection. For 100,000 simulation runs, it took 16 hours for the program to run. Using a program like VISSIM, which it catered to simulating traffic conditions could be worth the investment of time. Determining how to measure crashes or close calls within VISSIM would be a challenge. However VISSIM does provide some improvement in the simulation with regards to simulating driver aggression, decision making, vehicle speed, lane changing, and arrival rates.

Finally, additional thought should be put into how the red extension technology is currently used. Providing an extension to vehicles detected during amber might not be the 
best. Making a decision during the red clearance interval could serve a better purpose. The location and method that vehicles are detected should be analyzed further. 


\subsection{REFERENCES}

Barnett, A. G., van der Pols, J. C., \& Dobson, A. J. (2005). Regression to the mean: what is is and how to deal with it. Internation Journal of Epidemiology, 34:215-220.

Bonneson, J. A., \& Zimmerman, K. H. (2004). Effect of Yellow-Interval Timing on the Frequency of Red-Light Violations at Urban Intersections. Transportation Research Record: Journal of the Transportation Research Board, 20-27.

Centers for Disease Control and Prevention. (2010, October 12). CDC - Motor Vehicle Safety. Retrieved from Centers for Disease Control and Prevention: http://www.cdc.gov/motorvehiclesafety/

City of Portland. (2004). US26: Powell Blvd. at 82nd Ave.

Dixon, K., Monsere, C., Xie, F., \& Gladhill, K. (2012). Calibrating the Future Highway Safety Manual Predictive Methods for Oregon State Highways.

Federal Highway Administration. (2009). Engineering Countermeasures to Reduce RedLight Running. U.S. Department of Transportation.

Federal Highway Administration. (2009, May). Low-Cost Safety Enhancements for StopControlled and Signalized Intersections. Retrieved from FHWA Safety Program: http://safety.fhwa.dot.gov/intersection/resources/fhwasa09020/chap_3.cfm

Federal Highway Administration. (2012, 09 14). Red-Light Running - FHWA Safety $\begin{array}{llll}\text { Program. } & \text { Retrieved }\end{array}$ http://safety.fhwa.dot.gov/intersection/redlight/ 
Federal Highway Administration. (2012). Safety at Signalized Intersections. Retrieved from Federal Highway Administration Safety: http://safety.fhwa.dot.gov/intersection/signalized/presentations/sign_int_pps0515 08/long/

Federal Highway Administration, U.S. DOT. (2012, September 14). Guidelines for Applying Traffic Microsimulation Modelling Software. Retrieved from Traffic $\begin{array}{llll}\text { Analysis } & \text { Toolbox } & \text { Volume }\end{array}$ http://ops.fhwa.dot.gov/trafficanalysistools/tat_vol3/sect2.htm

Figliozzi, M. (2012, October 29). (C. Olson, Interviewer)

Hatch, D. (2012, June 4). (C. Olson, Interviewer)

Hauer, E. (1997). Observation Before-After Studies in Road Safety. New York: Elsevier Science Ltd.

Highway Safety Manual. (2010). Washington, DC: American Association of State Highway and Transportation Officials.

Hurwitz, D. S., Wang, H., Knodler, M. A., Ni, D., \& Moore, D. (2012). Fuzzy Sets to Describe Driver Behavior in the Dilemma Zone of High-Speed Signalized Intersections. Elsevier.

Insurance Institute for Highway Safety. (2007). Status Report Vol. 42, No. 1. Arlington: Insurance Institute for Highwa Safety. 
Korn, P. (2010, November 18). Danger! It's getting more dangerous to cross Portland streets. PortlandTribune.

Malik, S., Bertini, R. L., \& Monsere, C. M. (2003). Crash Data Reporting and Analysis An Oregon Case Study.

National Highway Traffic Safety Administration. (2010). Traffic Safety Facts 2010. U.S. Department of Transportation.

Oregon Department of Transportation. (2007). Benefit/Cost Analysis Worksheet. Retrieved from Oregon Department of Transportation: http://www.oregon.gov/ODOT/HWY/TRAFFIC-

ROADWAY/docs/excel/bc_form.xls

Oregon Department of Transportation. (2007). Statewide Crash Data System - Motor Vehicle Traffic Crash Analysis and Code Manual. Salem: Transportation Data Section Crash Analysis and Reporting Unit.

Oregon Department of Transportation. (2010). 2010 Traffic Volumes on State Highways. Retrieved from http:/www.oregon.gov/ODOT/TD/TDATA/tsm/docs/2010_TVT.pdf

Oregon Department of Transportation. (2012, May 8). Oregon DMV. Retrieved May 20, 2012, from Accident Reporting: www.oregon.gov/ODOT/DMV/driverid/accidentreport.shtml 
Retting, R. A., Ferguson, S. A., \& Hakkert, A. S. (2003). Effects of Red Light Cameras on Violations and Crashes: A Review of the Internation Literature. Traffic Injury Prevention, 4:17-23.

Shattler, K. L., McAvoy, D., Christ, M. T., \& Glauber, C. M. (2011). Impact of Signal Mounting Configurations on Red-Light Running at Urban Signalized Intersections. Institute of Transportation Engineers, 22-24, 29-30.

Tanner, T. (2012, April 12). (C. Olson, Interviewer)

U.S. Department of Transportation, Federal Highway Administration. (2005). Safety Evaluation of Red-Light Cameras. McLean: FHWA.

U.S. Department of Transportation, Federal Highway Administration. (2012). Crash Modification Factors Clearinghouse. Retrieved from Crash Modification Factors Clearinghouse: http://www.cmfclearinghouse.org

Wang, L., Zhang, L., Zhou, K., Zhang, W.-B., \& Wang, X. (2011). Red Light Running Prediction Based on Inductive Loop Detectors for Dynamic All-Red Extension.

Zimmerman, K., \& Bonneson, J. A. (2005). Investigation of Time into Red for Red Light-Related Crashes. Transportation Research Record: Journal of the Transportation Research Board, No. 1922, 21-28. 


\subsection{APPENDIX A - CRASH ANALYSIS}

Table A.1: AADT for Treatment Intersections

\begin{tabular}{|l|r|r|r|r|r|r|r|r|r|r|r|r|}
\hline Year & $\mathbf{2 0 0 0}$ & $\mathbf{2 0 0 1}$ & $\mathbf{2 0 0 2}$ & $\mathbf{2 0 0 3}$ & $\mathbf{2 0 0 4}$ & $\mathbf{2 0 0 5}$ & $\mathbf{2 0 0 6}$ & $\mathbf{2 0 0 7}$ & $\mathbf{2 0 0 8}$ & $\mathbf{2 0 0 9}$ & $\mathbf{2 0 1 0}$ & $\mathbf{2 0 1 1}$ \\
\hline 82nd & 29550 & 30150 & 30900 & 31550 & 31950 & 27650 & 27750 & 27550 & 26050 & 26400 & 26450 & 25000 \\
\hline Powell & 32350 & 32650 & 33050 & 30250 & 30600 & 31200 & 27600 & 27400 & 26200 & 24600 & 24600 & 23300 \\
\hline Powell & 45100 & 45900 & 46800 & 39600 & 39700 & 40500 & 38800 & 38500 & 36900 & 37400 & 37400 & 35400 \\
\hline 50th & 28200 & 28700 & 29300 & 24800 & 24900 & 24600 & 24400 & 24100 & 23900 & 24200 & 24200 & 22900 \\
\hline Powell & 48250 & 48850 & 49550 & 38500 & 38450 & 39250 & 37500 & 37250 & 35600 & 34100 & 34100 & 32300 \\
\hline 39th & 23700 & 24000 & 24300 & 18900 & 21900 & 20100 & 18400 & 20900 & 23300 & 23100 & 22800 & 21600 \\
\hline Powell & 50000 & 50600 & 51200 & 49100 & 48700 & 49700 & 45500 & 45200 & 43200 & 41000 & 41000 & 38800 \\
\hline Milwaukie & 18500 & 18700 & 18900 & 18200 & 18500 & 18800 & 17200 & 17100 & 16300 & 15500 & 15500 & 14700 \\
\hline 122nd & 26600 & 26800 & 27700 & 28000 & 30500 & 27300 & 27100 & 26900 & 25700 & 26100 & 26100 & 24700 \\
\hline Halsey & 19700 & 19900 & 20600 & 20800 & 20800 & 20800 & 20800 & 20800 & 20800 & 20700 & 20500 & 19400 \\
\hline 122nd & 26600 & 26800 & 27700 & 28000 & 30500 & 26900 & 26700 & 26500 & 25300 & 25700 & 25700 & 24300 \\
\hline Glisan & 18400 & 18600 & 19200 & 19400 & 18700 & 18900 & 19000 & 19200 & 19400 & 19600 & 19700 & 18700 \\
\hline 122nd & 29600 & 29900 & 30900 & 31200 & 30000 & 26900 & 26700 & 26500 & 25300 & 25700 & 25700 & 24300 \\
\hline Stark & 38000 & 38300 & 39600 & 40000 & 38500 & 34500 & 34200 & 33900 & 32500 & 32900 & 33000 & 31200 \\
\hline 122nd & 26500 & 26800 & 27700 & 26600 & 25600 & 22900 & 22700 & 22500 & 21600 & 21900 & 21900 & 20700 \\
\hline Division & 38400 & 38800 & 40100 & 40500 & 39900 & 39300 & 38800 & 38500 & 36800 & 37300 & 38500 & 36400 \\
\hline
\end{tabular}

Table A.2: AADT for Comparison Group Intersections

\begin{tabular}{|l|r|r|r|r|r|r|r|r|r|r|r|r|}
\hline Year & $\mathbf{2 0 0 0}$ & $\mathbf{2 0 0 1}$ & $\mathbf{2 0 0 2}$ & $\mathbf{2 0 0 3}$ & $\mathbf{2 0 0 4}$ & $\mathbf{2 0 0 5}$ & $\mathbf{2 0 0 6}$ & $\mathbf{2 0 0 7}$ & $\mathbf{2 0 0 8}$ & $\mathbf{2 0 0 9}$ & $\mathbf{2 0 1 0}$ & $\mathbf{2 0 1 1}$ \\
\hline 82nd & 29000 & 29700 & 29800 & 30500 & 30900 & 27600 & 27700 & 27500 & 25600 & 26000 & 26000 & 24600 \\
\hline Division & 25100 & 25800 & 25800 & 26400 & 26800 & 23900 & 24000 & 23800 & 22200 & 22500 & 22500 & 21300 \\
\hline 82nd & 29900 & 31400 & 31400 & 32900 & 33300 & 26300 & 26400 & 26200 & 24400 & 24700 & 24800 & 23500 \\
\hline Foster & 23800 & 25000 & 25000 & 26200 & 26500 & 23300 & 23400 & 23200 & 21600 & 21900 & 22000 & 20800 \\
\hline Milwaukie & 12100 & 12200 & 12600 & 12800 & 13000 & 13200 & 11500 & 9700 & 9300 & 9400 & 9400 & 8900 \\
\hline Holgate & 14600 & 14700 & 15200 & 13800 & 13200 & 11900 & 11800 & 11700 & 11200 & 11300 & 11300 & 10700 \\
\hline Powell & 40700 & 41000 & 41300 & 38400 & 38300 & 39100 & 35100 & 34800 & 33300 & 31500 & 31500 & 29800 \\
\hline 26th & 9700 & 9800 & 9900 & 9200 & 9100 & 8400 & 7600 & 7500 & 7200 & 6800 & 6800 & 6500 \\
\hline 82nd & 26900 & 28200 & 28200 & 29600 & 30000 & 26100 & 26200 & 26000 & 24700 & 25100 & 25100 & 23700 \\
\hline Holgate & 12800 & 13400 & 13400 & 14100 & 14300 & 13600 & 12900 & 12200 & 11500 & 11700 & 11700 & 11100 \\
\hline Glisan & 43200 & 43600 & 45100 & 45500 & 43800 & 39200 & 38900 & 38600 & 36900 & 37500 & 37500 & 35500 \\
\hline 102nd & 25700 & 26000 & 26900 & 27100 & 26100 & 25200 & 24400 & 23500 & 22600 & 21800 & 20900 & 19800 \\
\hline Division & 35400 & 35800 & 37000 & 37300 & 35900 & 33500 & 31200 & 30900 & 29600 & 30000 & 30100 & 28400 \\
\hline 148th & 13100 & 13200 & 13700 & 13800 & 13300 & 11900 & 11800 & 11700 & 11200 & 11400 & 11400 & 10800 \\
\hline Powell & 22500 & 22800 & 23200 & 21700 & 21500 & 21900 & 20500 & 20300 & 19500 & 18600 & 18700 & 17700 \\
\hline 122nd & 26900 & 27200 & 27700 & 26600 & 25600 & 26000 & 24400 & 24100 & 23200 & 22100 & 22200 & 21000 \\
\hline Division & 13300 & 13400 & 13900 & 14000 & 13500 & 14500 & 15400 & 13900 & 12400 & 12600 & 12600 & 11900 \\
\hline 39th & 29700 & 29900 & 31000 & 31200 & 30100 & 26900 & 26700 & 25700 & 24800 & 24300 & 22800 & 21600 \\
\hline Stark & 21100 & 21300 & 22100 & 22300 & 23300 & 24300 & 25300 & 25100 & 24100 & 24400 & 24400 & 23100 \\
\hline 162nd & 13800 & 14000 & 14500 & 14600 & 14600 & 14600 & 14500 & 14500 & 14500 & 14500 & 14500 & 13700 \\
\hline
\end{tabular}


Table A.3: Simple Method of Total Crashes

\begin{tabular}{|c|c|c|c|c|c|c|c|}
\hline $\begin{array}{l}\text { Entity } \\
\text { Number }\end{array}$ & Years Before & $\begin{array}{l}\text { Years } \\
\text { After }\end{array}$ & $\begin{array}{l}\text { Crashes } \\
\text { Before }\end{array}$ & $\begin{array}{c}\text { Crashes } \\
\text { After }\end{array}$ & & & \\
\hline $\mathrm{j}$ & & & $\mathrm{K}(\mathrm{j})$ & $\mathrm{L}(\mathrm{j})$ & $r_{d}(j)$ & $r_{d}(j) K(j)$ & $r_{d}(j)^{2} K(j)$ \\
\hline 1 & 5.60 & 6.40 & 108 & 96 & 1.14 & 123.54 & 141.32 \\
\hline 2 & 5.60 & 6.40 & 41 & 42 & 1.14 & 46.90 & 53.65 \\
\hline 3 & 5.67 & 6.33 & 58 & 62 & 1.12 & 64.72 & 72.23 \\
\hline 4 & 7.95 & 4.05 & 54 & 22 & 0.51 & 27.53 & 14.04 \\
\hline 5 & 9.25 & 2.75 & 119 & 27 & 0.30 & 35.44 & 10.55 \\
\hline 6 & 9.26 & 2.74 & 101 & 28 & 0.30 & 29.84 & 8.82 \\
\hline 7 & 9.27 & 2.73 & 129 & 31 & 0.30 & 38.07 & 11.23 \\
\hline 8 & 9.27 & 2.73 & 155 & 39 & 0.29 & 45.68 & 13.46 \\
\hline Sums & & & & 347 & & 411.72 & 325.30 \\
\hline & OUTPUT: & & & \multicolumn{3}{|c|}{$\%$ Effectiveness } & \\
\hline \multirow[t]{2}{*}{ Step 1: } & Lambda-hat= & 347 & & 10.06 & to & 21.70 & \\
\hline & pi-hat $=$ & 411.72 & & \multicolumn{3}{|c|}{$95 \%$ Effectiveness } & \\
\hline \multirow[t]{2}{*}{ Step 2: } & $\operatorname{Var}\{$ lambda-hat $\}=$ & 347 & & 4.48 & to & 27.28 & \\
\hline & Var $\{$ pi-hat $\}=$ & 325.30 & & & & & \\
\hline \multirow[t]{4}{*}{ Step 3: } & Delta-hat= & 64.72 & & & & & \\
\hline & Theta-hat= & 0.841 & & & & & \\
\hline & Var\{Delta-hat\} & 672.300 & & & & & \\
\hline & Var\{Theta-hat\} & 0.003 & & & & & \\
\hline \multirow[t]{2}{*}{ Step 4: } & Sigma $\{$ Delta-hat $\}=$ & 25.93 & & & & & \\
\hline & Sigma $\{$ Theta-hat $\}=$ & 0.058 & & & & & \\
\hline
\end{tabular}

Table A.4: Simple Method of Fatal and Injury Crashes

\begin{tabular}{|c|c|c|c|c|c|c|c|}
\hline $\begin{array}{l}\text { Entity } \\
\text { Number }\end{array}$ & Years Before & $\begin{array}{l}\text { Years } \\
\text { After }\end{array}$ & $\begin{array}{l}\text { Crashes } \\
\text { Before }\end{array}$ & $\begin{array}{c}\text { Crashes } \\
\text { After }\end{array}$ & & & \\
\hline $\mathrm{j}$ & & & $\mathrm{K}(\mathrm{j})$ & $\mathrm{L}(\mathrm{j})$ & $r_{d}(j)$ & $r_{d}(j) K(j)$ & $r_{d}(j)^{2} K(j)$ \\
\hline 1 & 5.60 & 6.40 & 38 & 50 & 1.14 & 43.47 & 49.72 \\
\hline 2 & 5.60 & 6.40 & 16 & 21 & 1.14 & 18.30 & 20.94 \\
\hline 3 & 5.67 & 6.33 & 27 & 32 & 1.12 & 30.13 & 33.62 \\
\hline 4 & 7.95 & 4.05 & 18 & 10 & 0.51 & 9.18 & 4.68 \\
\hline 5 & 9.25 & 2.75 & 54 & 13 & 0.30 & 16.08 & 4.79 \\
\hline 6 & 9.26 & 2.74 & 46 & 17 & 0.30 & 13.59 & 4.02 \\
\hline 7 & 9.27 & 2.73 & 54 & 17 & 0.30 & 15.93 & 4.70 \\
\hline 8 & 9.27 & 2.73 & 60 & 19 & 0.29 & 17.68 & 5.21 \\
\hline \multirow[t]{3}{*}{ Sums } & & & & 179 & & 164.37 & 127.68 \\
\hline & & & & \multirow{2}{*}{\multicolumn{3}{|c|}{$\%$ Effectiveness }} & \\
\hline & OUTPUT: & & & & & & \\
\hline \multirow[t]{2}{*}{ Step 1: } & Lambda-hat= & 179 & & -19.35 & to & 2.57 & \\
\hline & pi-hat & 164.37 & & \multicolumn{3}{|c|}{$95 \%$ Effectiveness } & \\
\hline \multirow[t]{2}{*}{ Step 2: } & $\operatorname{Var}\{$ lambda-hat $\}=$ & 179 & & -29.86 & to & 13.08 & \\
\hline & $\operatorname{Var}\{$ pi-hat $\}=$ & 127.68 & & & & & \\
\hline \multirow[t]{4}{*}{ Step 3: } & Delta-hat= & -14.63 & & & & & \\
\hline & Theta-hat= & 1.084 & & & & & \\
\hline & Var\{Delta-hat $\}$ & 306.680 & & & & & \\
\hline & Var\{Theta-hat\} & 0.012 & & & & & \\
\hline \multirow[t]{2}{*}{ Step 4: } & Sigma $\{$ Delta-hat $\}=$ & 17.51 & & & & & \\
\hline & Sigma $\{$ Theta-hat $\}=$ & 0.110 & & & & & \\
\hline
\end{tabular}


Table A.5: Simple Method of PDO Crashes

\begin{tabular}{|c|c|c|c|c|c|c|c|}
\hline $\begin{array}{l}\text { Entity } \\
\text { Number }\end{array}$ & Years Before & $\begin{array}{l}\text { Years } \\
\text { After }\end{array}$ & $\begin{array}{l}\text { Crashes } \\
\text { Before }\end{array}$ & $\begin{array}{c}\text { Crashes } \\
\text { After }\end{array}$ & & & \\
\hline $\mathrm{j}$ & & & $\mathrm{K}(\mathrm{j})$ & L(j) & $r_{d}(j)$ & $r_{d}(j) K(j)$ & $r_{d}(j)^{2} K(j)$ \\
\hline 1 & 5.60 & 6.40 & 70 & 46 & 1.14 & 80.07 & 91.60 \\
\hline 2 & 5.60 & 6.40 & 25 & 21 & 1.14 & 28.60 & 32.71 \\
\hline 3 & 5.67 & 6.33 & 31 & 30 & 1.12 & 34.59 & 38.61 \\
\hline 4 & 7.95 & 4.05 & 36 & 12 & 0.51 & 18.35 & 9.36 \\
\hline 5 & 9.25 & 2.75 & 65 & 14 & 0.30 & 19.36 & 5.76 \\
\hline 6 & 9.26 & 2.74 & 55 & 11 & 0.30 & 16.25 & 4.80 \\
\hline 7 & 9.27 & 2.73 & 75 & 14 & 0.30 & 22.13 & 6.53 \\
\hline 8 & 9.27 & 2.73 & 95 & 20 & 0.29 & 28.00 & 8.25 \\
\hline Sums & & & & 168 & & 247.35 & 197.62 \\
\hline & OUTPUT: & & & \multicolumn{3}{|c|}{ \% Effectiveness } & \\
\hline \multirow[t]{2}{*}{ Step 1: } & Lambda-hat= & 168 & & 25.83 & to & 38.77 & \\
\hline & pi-hat= & 247.35 & & \multicolumn{3}{|c|}{$95 \%$ Effectiveness } & \\
\hline \multirow[t]{2}{*}{ Step 2: } & $\operatorname{Var}\{$ lambda-hat $\}=$ & 168 & & 19.63 & to & 44.97 & \\
\hline & $\operatorname{Var}\{$ pi-hat $\}=$ & 197.62 & & & & & \\
\hline \multirow[t]{4}{*}{ Step 3: } & Delta-hat $=$ & 79.35 & & & & & \\
\hline & Theta-hat= & 0.677 & & & & & \\
\hline & Var\{Delta-hat\} & 365.619 & & & & & \\
\hline & Var\{Theta-hat\} & 0.004 & & & & & \\
\hline \multirow[t]{2}{*}{ Step 4: } & Sigma $\{$ Delta-hat $\}=$ & 19.12 & & & & & \\
\hline & Sigma $\{$ Theta-hat $\}=$ & 0.065 & & & & & \\
\hline
\end{tabular}

Table A.6: Simple Method of Angle Crashes

\begin{tabular}{|c|c|c|c|c|c|c|c|}
\hline $\begin{array}{l}\text { Entity } \\
\text { Number }\end{array}$ & Years Before & $\begin{array}{l}\text { Years } \\
\text { After }\end{array}$ & $\begin{array}{c}\text { Crashes } \\
\text { Before }\end{array}$ & $\begin{array}{c}\text { Crashes } \\
\text { After }\end{array}$ & & & \\
\hline $\mathrm{j}$ & & & $\mathrm{K}(\mathrm{j})$ & $\mathrm{L}(\mathrm{j})$ & $r_{d}(j)$ & $r_{d}(j) K(j)$ & $r_{d}(j)^{2} K(j)$ \\
\hline 1 & 5.597260274 & 6.40 & 13 & 6 & 1.14 & 14.87 & 17.01 \\
\hline 2 & 5.59726027 & 6.40 & 9 & 7 & 1.14 & 10.30 & 11.78 \\
\hline 3 & 5.671232877 & 6.33 & 0 & 7 & 1.12 & 0.00 & 0.00 \\
\hline 4 & 7.947945205 & 4.05 & 11 & 2 & 0.51 & 5.61 & 2.86 \\
\hline 5 & 9.246575342 & 2.75 & 33 & 2 & 0.30 & 9.83 & 2.93 \\
\hline 6 & 9.263013699 & 2.74 & 8 & 0 & 0.30 & 2.36 & 0.70 \\
\hline 7 & 9.265753425 & 2.73 & 9 & 2 & 0.30 & 2.66 & 0.78 \\
\hline 8 & 9.268493151 & 2.73 & 10 & 2 & 0.29 & 2.95 & 0.87 \\
\hline Sums & & & & 28 & & 48.57 & 36.92 \\
\hline & & & & & & & \\
\hline & OUTPUT: & & & \multicolumn{3}{|c|}{ \% Effectiveness } & \\
\hline \multirow[t]{2}{*}{ Step 1: } & Lambda-hat= & 28 & & 30.57 & to & 55.90 & \\
\hline & pi-hat= & 48.57 & & \multicolumn{3}{|c|}{$95 \%$ Effectiveness } & \\
\hline \multirow[t]{2}{*}{ Step 2: } & Var\{lambda-hat $\}=$ & 28 & & 18.41 & to & 68.06 & \\
\hline & $\operatorname{Var}\{$ pi-hat $\}=$ & 36.92 & & & & & \\
\hline \multirow[t]{4}{*}{ Step 3: } & Delta-hat= & 20.57 & & & & & \\
\hline & Theta-hat= & 0.568 & & & & & \\
\hline & Var\{Delta-hat\} & 64.923 & & & & & \\
\hline & Var\{Theta-hat\} & 0.016 & & & & & \\
\hline \multirow[t]{2}{*}{ Step 4: } & Sigma $\{$ Delta-hat $\}=$ & 8.06 & & & & & \\
\hline & Sigma $\{$ Theta-hat $\}=$ & 0.127 & & & & & \\
\hline
\end{tabular}


Table A.7: Estimated Number of Total Crashes at Treatment Intersections

\begin{tabular}{|c|c|c|c|c|c|c|c|c|}
\hline INDEX & 1 & 2 & 3 & 4 & 5 & 6 & 7 & 8 \\
\hline Install Date & $8 / 9 / 2005$ & $8 / 9 / 2005$ & 9/6/2005 & $12 / 17 / 2007$ & $4 / 1 / 2009$ & $4 / 7 / 2009$ & $4 / 8 / 2009$ & $4 / 9 / 2009$ \\
\hline Factor & 0.60 & 0.60 & 0.67 & 0.95 & 0.25 & 0.26 & 0.27 & 0.27 \\
\hline 2000 & 7.325 & 12.053 & 9.474 & 10.724 & 4.723 & 5.055 & 7.973 & 7.272 \\
\hline 2001 & 7.425 & 12.314 & 9.620 & 10.881 & 4.768 & 5.104 & 8.053 & 7.365 \\
\hline 2002 & 7.556 & 12.612 & 9.785 & 11.037 & 4.960 & 5.305 & 8.384 & 7.663 \\
\hline 2003 & 7.204 & 10.298 & 7.187 & 10.491 & 5.023 & 5.373 & 8.485 & 7.659 \\
\hline 2004 & 7.309 & 10.333 & 7.441 & 10.446 & 5.443 & 5.768 & 8.100 & 7.479 \\
\hline \multirow{2}{*}{2005} & 4.161 & 6.273 & 4.990 & \multirow{2}{*}{10.701} & \multirow{2}{*}{4.906} & \multirow{2}{*}{5.142} & \multirow{2}{*}{7.100} & \multirow{2}{*}{7.170} \\
\hline & 2.806 & 4.230 & 2.444 & & & & & \\
\hline 2006 & 6.276 & 10.058 & 6.959 & 9.594 & 4.872 & 5.114 & 7.028 & 7.067 \\
\hline \multirow{2}{*}{2007} & \multirow{2}{*}{6.215} & \multirow{2}{*}{9.953} & \multirow{2}{*}{7.133} & 9.023 & \multirow{2}{*}{4.839} & \multirow{2}{*}{5.092} & \multirow{2}{*}{6.957} & \multirow{2}{*}{7.000} \\
\hline & & & & 0.495 & & & & \\
\hline 2008 & 5.865 & 9.537 & 7.013 & 8.997 & 4.639 & 4.892 & 6.607 & 6.637 \\
\hline \multirow{2}{*}{2009} & \multirow{2}{*}{5.816} & \multirow{2}{*}{9.690} & \multirow{2}{*}{6.715} & \multirow{2}{*}{8.441} & 1.159 & 1.309 & 1.783 & 1.811 \\
\hline & & & & & 3.541 & 3.667 & 4.927 & 4.934 \\
\hline 2010 & 5.826 & 9.690 & 6.693 & 8.441 & 4.688 & 4.982 & 6.730 & 6.953 \\
\hline 2011 & 5.283 & 9.070 & 6.271 & 7.893 & 4.393 & 4.670 & 6.294 & 6.499 \\
\hline Total & 79.067 & 126.109 & 91.724 & 117.164 & 57.954 & 61.472 & 88.422 & 85.508 \\
\hline
\end{tabular}

Table A.8: Actual Number of Total Crashes at Treatment Intersections

\begin{tabular}{|c|c|c|c|c|c|c|c|c|}
\hline INDEX & 1 & 2 & 3 & 4 & 5 & 6 & 7 & 8 \\
\hline Install Date & $8 / 9 / 2005$ & $8 / 9 / 2005$ & 9/6/2005 & $12 / 17 / 2007$ & $4 / 1 / 2009$ & $4 / 7 / 2009$ & $4 / 8 / 2009$ & $4 / 9 / 2009$ \\
\hline 2000 & 20 & 5 & 8 & 2 & 13 & 19 & 15 & 14 \\
\hline 2001 & 19 & 8 & 8 & 4 & 12 & 16 & 14 & 15 \\
\hline 2002 & 26 & 13 & 14 & 9 & 13 & 7 & 13 & 19 \\
\hline 2003 & 16 & 10 & 15 & 11 & 15 & 9 & 20 & 20 \\
\hline 2004 & 18 & 3 & 9 & 8 & 12 & 13 & 12 & 10 \\
\hline \multirow{2}{*}{2005} & 9 & 2 & 4 & \multirow{2}{*}{9} & \multirow{2}{*}{14} & \multirow{2}{*}{7} & \multirow{2}{*}{16} & \multirow{2}{*}{14} \\
\hline & 3 & 1 & 3 & & & & & \\
\hline 2006 & 15 & 3 & 6 & 7 & 13 & 9 & 6 & 18 \\
\hline \multirow{2}{*}{2007} & \multirow{2}{*}{14} & \multirow{2}{*}{5} & \multirow{2}{*}{8} & 4 & \multirow{2}{*}{11} & \multirow{2}{*}{5} & \multirow{2}{*}{10} & \multirow{2}{*}{18} \\
\hline & & & & 1 & & & & \\
\hline 2008 & 14 & 5 & 17 & 5 & 14 & 16 & 14 & 23 \\
\hline \multirow{2}{*}{2009} & \multirow{2}{*}{18} & \multirow{2}{*}{6} & \multirow{2}{*}{9} & \multirow{2}{*}{5} & 2 & 0 & 9 & 4 \\
\hline & & & & & 8 & 7 & 5 & 9 \\
\hline 2010 & 13 & 12 & 5 & 5 & 9 & 9 & 14 & 18 \\
\hline 2011 & 19 & 10 & 14 & 6 & 10 & 12 & 12 & 12 \\
\hline Total & 204 & 83 & 120 & 76 & 146 & 129 & 160 & 194 \\
\hline
\end{tabular}


Table A.9: Expected Number of Total Crashes at Treatment Intersections (EB Method)

\begin{tabular}{|c|c|c|c|c|c|c|c|c|c|c|c|}
\hline Site & $\mathrm{K}(\mathrm{j})$ & $\mathrm{L}(\mathrm{j})$ & $\mathrm{Cb}$ & $\mathrm{Ca}$ & $\mathrm{w}(\mathrm{i}) \mathrm{b}$ & $\mathrm{N}\left(\exp \_\mathrm{B}\right)$ & $\mathrm{r}(\mathrm{i})$ & $\mathrm{N}\left(\exp \_\mathrm{A}\right)$ & $\mathrm{OR}(\mathrm{i})$ & $\mathrm{SE}(\mathrm{i})$ & \\
\hline 1 & 108 & 96 & 40.980 & 38.087 & 0.059 & 104.054 & 0.929 & 96.709 & 0.993 & 0.733 & 84.590 \\
\hline 2 & 41 & 42 & 63.883 & 62.226 & 0.039 & 41.883 & 0.974 & 40.797 & 1.029 & -2.950 & 38.205 \\
\hline 3 & 58 & 62 & 48.496 & 43.229 & 0.050 & 57.523 & 0.891 & 51.276 & 1.209 & -20.915 & 43.412 \\
\hline 4 & 54 & 22 & 82.897 & 34.267 & 0.030 & 54.867 & 0.413 & 22.680 & 0.970 & 2.999 & 9.094 \\
\hline 5 & 119 & 27 & 45.332 & 12.622 & 0.054 & 115.056 & 0.278 & 32.036 & 0.843 & 15.720 & 8.442 \\
\hline 6 & 101 & 28 & 48.153 & 13.319 & 0.051 & 98.328 & 0.277 & 27.198 & 1.030 & -2.950 & 7.142 \\
\hline 7 & 129 & 31 & 70.471 & 17.951 & 0.035 & 126.945 & 0.255 & 32.337 & 0.959 & 4.134 & 7.948 \\
\hline 8 & 155 & 39 & 67.122 & 18.386 & 0.037 & 151.767 & 0.274 & 41.572 & 0.938 & 6.188 & 10.969 \\
\hline Totals & 765 & 347 & 467.33 & 240.087 & & & & 344.604 & 1.007 & -0.695 & 209.802 \\
\hline
\end{tabular}

Table A.10: Estimated Number of Fatal \& Injury Crashes at Treatment Intersections

\begin{tabular}{|c|c|c|c|c|c|c|c|c|}
\hline INDEX & 1 & 2 & 3 & 4 & 5 & 6 & 7 & 8 \\
\hline Install Date & $8 / 9 / 2005$ & $8 / 9 / 2005$ & $9 / 6 / 2005$ & $12 / 17 / 2007$ & $4 / 1 / 2009$ & $4 / 7 / 2009$ & $4 / 8 / 2009$ & $4 / 9 / 2009$ \\
\hline Factor & 0.597 & 0.597 & 0.671 & 0.948 & 0.247 & 0.263 & 0.266 & 0.268 \\
\hline 2000 & 3.619 & 5.744 & 4.471 & 5.037 & 2.270 & 2.436 & 3.802 & 3.490 \\
\hline 2001 & 3.667 & 5.868 & 4.540 & 5.111 & 2.291 & 2.459 & 3.839 & 3.533 \\
\hline 2002 & 3.731 & 6.009 & 4.619 & 5.186 & 2.380 & 2.553 & 3.994 & 3.674 \\
\hline 2003 & 3.568 & 4.917 & 3.393 & 4.926 & 2.409 & 2.584 & 4.042 & 3.669 \\
\hline 2004 & 3.617 & 4.933 & 3.515 & 4.905 & 2.599 & 2.760 & 3.861 & 3.583 \\
\hline \multirow[t]{2}{*}{2005} & 2.059 & 2.993 & 2.356 & \multirow[t]{2}{*}{5.026} & \multirow[t]{2}{*}{2.356} & \multirow[t]{2}{*}{2.478} & \multirow[t]{2}{*}{3.394} & \multirow[t]{2}{*}{3.434} \\
\hline & 1.388 & 2.018 & 1.154 & & & & & \\
\hline 2006 & 3.138 & 4.804 & 3.286 & 4.501 & 2.341 & 2.465 & 3.360 & 3.386 \\
\hline \multirow[t]{2}{*}{2007} & \multirow[t]{2}{*}{3.109} & \multirow[t]{2}{*}{4.754} & \multirow[t]{2}{*}{3.371} & 4.233 & \multirow[t]{2}{*}{2.326} & \multirow[t]{2}{*}{2.456} & \multirow[t]{2}{*}{3.327} & \multirow[t]{2}{*}{3.354} \\
\hline & & & & 0.232 & & & & \\
\hline 2008 & 2.945 & 4.561 & 3.320 & 4.219 & 2.237 & 2.368 & 3.164 & 3.183 \\
\hline \multirow[t]{2}{*}{2009} & \multirow[t]{2}{*}{2.914} & \multirow[t]{2}{*}{4.633} & \multirow[t]{2}{*}{3.183} & \multirow[t]{2}{*}{3.958} & 0.558 & 0.633 & 0.854 & 0.868 \\
\hline & & & & & 1.705 & 1.773 & 2.359 & 2.366 \\
\hline 2010 & 2.918 & 4.633 & 3.172 & 3.958 & 2.258 & 2.410 & 3.221 & 3.331 \\
\hline 2011 & 2.569 & 4.342 & 2.976 & 3.701 & 2.122 & 2.266 & 3.018 & 3.117 \\
\hline Total & 39.240 & 60.209 & 43.355 & 54.992 & 27.853 & 29.642 & 42.236 & 40.989 \\
\hline
\end{tabular}


Table A.11: Actual Number of Fatal \& Injury Crashes at Treatment Intersections

\begin{tabular}{|c|c|c|c|c|c|c|c|c|}
\hline INDEX & 1 & 2 & 3 & 4 & 5 & 6 & 7 & 8 \\
\hline Install Date & $8 / 9 / 2005$ & $8 / 9 / 2005$ & $9 / 6 / 2005$ & $12 / 17 / 2007$ & $4 / 1 / 2009$ & $4 / 7 / 2009$ & $4 / 8 / 2009$ & $4 / 9 / 2009$ \\
\hline 2000 & 6 & 3 & 4 & 1 & 4 & 9 & 5 & 7 \\
\hline 2001 & 7 & 3 & 4 & 1 & 6 & 6 & 5 & 8 \\
\hline 2002 & 11 & 7 & 6 & 3 & 8 & 2 & 4 & 6 \\
\hline 2003 & 4 & 1 & 8 & 2 & 4 & 5 & 7 & 5 \\
\hline 2004 & 9 & 2 & 3 & 5 & 7 & 5 & 5 & 4 \\
\hline \multirow[t]{2}{*}{2005} & 1 & 0 & 2 & \multirow[t]{2}{*}{4} & \multirow[t]{2}{*}{8} & \multirow[t]{2}{*}{2} & \multirow[t]{2}{*}{11} & \multirow[t]{2}{*}{4} \\
\hline & 1 & 0 & 0 & & & & & \\
\hline 2006 & 10 & 3 & 2 & 1 & 4 & 4 & 2 & 6 \\
\hline \multirow[t]{2}{*}{2007} & \multirow[t]{2}{*}{8} & \multirow[t]{2}{*}{1} & \multirow[t]{2}{*}{3} & 1 & \multirow[t]{2}{*}{6} & \multirow[t]{2}{*}{1} & \multirow[t]{2}{*}{4} & \multirow[t]{2}{*}{5} \\
\hline & & & & 1 & & & & \\
\hline 2008 & 6 & 3 & 9 & 3 & 5 & 12 & 5 & 13 \\
\hline \multirow[t]{2}{*}{2009} & \multirow[t]{2}{*}{7} & \multirow[t]{2}{*}{3} & \multirow[t]{2}{*}{5} & \multirow[t]{2}{*}{2} & 2 & 0 & 6 & 2 \\
\hline & & & & & 3 & 5 & 4 & 3 \\
\hline 2010 & 8 & 4 & 5 & 1 & 5 & 6 & 7 & 11 \\
\hline 2011 & 10 & 7 & 8 & 3 & 5 & 6 & 6 & 5 \\
\hline Total & 88 & 37 & 59 & 28 & 67 & 63 & 71 & 79 \\
\hline
\end{tabular}

Table A.12: Expected Number of Fatal \& Injury Crashes at Treatment Intersections (EB Method)

\begin{tabular}{|c|c|c|c|c|c|c|c|c|c|c|c|}
\hline Site & $\mathrm{K}(\mathrm{j})$ & $\mathrm{L}(\mathrm{j})$ & $\mathrm{Cb}$ & $\mathrm{Ca}$ & $\mathrm{w}(\mathrm{i}) \mathrm{b}$ & $\mathrm{N}\left(\exp \_\mathrm{B}\right)$ & $\mathrm{r}(\mathrm{i})$ & $\mathrm{N}\left(\exp \_\mathrm{A}\right)$ & $\mathrm{OR}(\mathrm{i})$ & $\mathrm{SE}(\mathrm{i})$ & \\
\hline 1 & 38 & 50 & 20.260 & 18.980 & 0.112 & 36.007 & 0.937 & 33.732 & 1.482 & -48.228 & 28.050 \\
\hline 2 & 16 & 21 & 30.464 & 29.745 & 0.078 & 17.123 & 0.976 & 16.719 & 1.256 & -25.607 & 15.057 \\
\hline 3 & 27 & 32 & 22.894 & 20.462 & 0.101 & 26.586 & 0.894 & 23.762 & 1.347 & -34.667 & 19.099 \\
\hline 4 & 18 & 10 & 38.925 & 16.067 & 0.062 & 19.293 & 0.413 & 7.964 & 1.256 & -25.568 & 3.084 \\
\hline 5 & 54 & 13 & 21.768 & 6.085 & 0.105 & 50.604 & 0.280 & 14.145 & 0.919 & 8.095 & 3.537 \\
\hline 6 & 46 & 17 & 23.193 & 6.449 & 0.100 & 43.730 & 0.278 & 12.159 & 1.398 & -39.811 & 3.044 \\
\hline 7 & 54 & 17 & 33.638 & 8.598 & 0.071 & 52.558 & 0.256 & 13.434 & 1.265 & -26.542 & 3.191 \\
\hline 8 & 60 & 19 & 32.174 & 8.814 & 0.074 & 57.946 & 0.274 & 15.874 & 1.197 & -19.691 & 4.028 \\
\hline Totals & 313 & 179 & 223.32 & 115.200 & & & & 137.789 & 1.299 & -29.908 & 79.090 \\
\hline
\end{tabular}


Table A.13: Estimated Number of PDO Crashes at Treatment Intersections

\begin{tabular}{|c|c|c|c|c|c|c|c|c|}
\hline INDEX & 1 & 2 & 3 & 4 & 5 & 6 & 7 & 8 \\
\hline Install Date & $8 / 9 / 2005$ & $8 / 9 / 2005$ & $9 / 6 / 2005$ & $12 / 17 / 2007$ & $4 / 1 / 2009$ & $4 / 7 / 2009$ & $4 / 8 / 2009$ & $4 / 9 / 2009$ \\
\hline Factor & 0.597 & 0.597 & 0.671 & 0.948 & 0.247 & 0.263 & 0.266 & 0.268 \\
\hline 2000 & 3.706 & 6.309 & 5.003 & 5.687 & 2.453 & 2.618 & 4.171 & 3.782 \\
\hline 2001 & 3.758 & 6.446 & 5.079 & 5.769 & 2.477 & 2.644 & 4.214 & 3.831 \\
\hline 2002 & 3.826 & 6.603 & 5.166 & 5.851 & 2.580 & 2.753 & 4.389 & 3.989 \\
\hline 2003 & 3.636 & 5.382 & 3.794 & 5.564 & 2.614 & 2.789 & 4.443 & 3.990 \\
\hline 2004 & 3.692 & 5.400 & 3.925 & 5.542 & 2.844 & 3.008 & 4.239 & 3.895 \\
\hline 2005 & 2.102 & 3.280 & 2.634 & 5.675 & 2.549 & 2.664 & 3.706 & 3.736 \\
\cline { 2 - 3 } & 1.417 & 2.212 & 1.290 & & & & & \\
\hline 2006 & 3.138 & 5.254 & 3.673 & 5.093 & 2.531 & 2.648 & 3.668 & 3.682 \\
\hline 2007 & 3.106 & 5.198 & 3.762 & 4.790 & 2.513 & 2.635 & 3.630 & 3.646 \\
& & & & 0.263 & & & & \\
\hline 2008 & 2.920 & 4.976 & 3.693 & 4.777 & 2.402 & 2.524 & 3.443 & 3.453 \\
\hline 2009 & 2.902 & 5.057 & 3.532 & 4.483 & 0.601 & 0.676 & 0.930 & 0.943 \\
\cline { 1 - 1 } & & & & & 1.835 & 1.894 & 2.569 & 2.568 \\
\hline 2010 & 2.908 & 5.057 & 3.521 & 4.483 & 2.430 & 2.573 & 3.509 & 3.622 \\
\hline 2011 & 2.715 & 4.727 & 3.295 & 4.193 & 2.271 & 2.404 & 3.276 & 3.381 \\
\hline Total & 39.827 & 65.900 & 48.369 & 62.171 & 30.101 & 31.830 & 46.186 & 44.520 \\
\hline
\end{tabular}

Table A.14: Actual Number of PDO Crashes at Treatment Intersections

\begin{tabular}{|c|c|c|c|c|c|c|c|c|}
\hline INDEX & 1 & 2 & 3 & 4 & 5 & 6 & 7 & 8 \\
\hline Install Date & $8 / 9 / 2005$ & $8 / 9 / 2005$ & $9 / 6 / 2005$ & $12 / 17 / 2007$ & $4 / 1 / 2009$ & $4 / 7 / 2009$ & $4 / 8 / 2009$ & $4 / 9 / 2009$ \\
\hline 2000 & 14 & 2 & 4 & 1 & 9 & 10 & 10 & 7 \\
\hline 2001 & 12 & 5 & 4 & 3 & 6 & 10 & 9 & 7 \\
\hline 2002 & 15 & 6 & 8 & 6 & 5 & 5 & 9 & 13 \\
\hline 2003 & 12 & 9 & 7 & 9 & 11 & 4 & 13 & 15 \\
\hline 2004 & 9 & 1 & 6 & 3 & 5 & 8 & 7 & 6 \\
\hline 2005 & 8 & 2 & 2 & 5 & 6 & 5 & 5 & 10 \\
\cline { 2 - 5 } & 2 & 1 & 3 & & & & & \\
\hline 2006 & 5 & 0 & 4 & 6 & 9 & 5 & 4 & 12 \\
\hline 2007 & 6 & 4 & 5 & 3 & 5 & 4 & 6 & 13 \\
& & & & 0 & & & & \\
\hline 2008 & 8 & 2 & 8 & 2 & 9 & 4 & 9 & 10 \\
\hline 2009 & 11 & 3 & 4 & 3 & 0 & 0 & 3 & 2 \\
\hline 2010 & 5 & 8 & 0 & 4 & 4 & 3 & 7 & 7 \\
\hline 2011 & 9 & 3 & 6 & 3 & 5 & 6 & 6 & 7 \\
\hline Total & 116 & 43 & 55 & 45 & 74 & 60 & 83 & 108 \\
\hline
\end{tabular}


Table A.15: Expected Number of PDO Crashes at Treatment Intersections (EB Method)

\begin{tabular}{|c|c|c|c|c|c|c|c|c|c|c|c|}
\hline Site & $\mathrm{K}(\mathrm{j})$ & $\mathrm{L}(\mathrm{j})$ & $\mathrm{Cb}$ & $\mathrm{Ca}$ & $\mathrm{w}(\mathrm{i}) \mathrm{b}$ & $\mathrm{N}\left(\exp \_\mathrm{B}\right)$ & $\mathrm{r}(\mathrm{i})$ & $\mathrm{N}\left(\exp \_\mathrm{A}\right)$ & $\mathrm{OR}(\mathrm{i})$ & $\mathrm{SE}(\mathrm{i})$ & \\
\hline 1 & 70 & 46 & 20.720 & 19.107 & 0.110 & 64.573 & 0.922 & 59.548 & 0.772 & 22.752 & 48.867 \\
\hline 2 & 25 & 21 & 33.419 & 32.481 & 0.071 & 25.600 & 0.972 & 24.881 & 0.844 & 15.599 & 22.460 \\
\hline 3 & 31 & 30 & 25.602 & 22.767 & 0.091 & 30.509 & 0.889 & 27.131 & 1.106 & -10.577 & 21.930 \\
\hline 4 & 36 & 12 & 43.972 & 18.200 & 0.055 & 36.439 & 0.414 & 15.082 & 0.796 & 20.434 & 5.898 \\
\hline 5 & 65 & 14 & 23.563 & 6.537 & 0.098 & 60.933 & 0.277 & 16.905 & 0.828 & 17.183 & 4.230 \\
\hline 6 & 55 & 11 & 24.960 & 6.870 & 0.093 & 52.202 & 0.275 & 14.368 & 0.766 & 23.443 & 3.586 \\
\hline 7 & 75 & 14 & 36.833 & 9.353 & 0.065 & 72.516 & 0.254 & 18.414 & 0.760 & 23.970 & 4.371 \\
\hline 8 & 95 & 20 & 34.948 & 9.572 & 0.068 & 90.895 & 0.274 & 24.896 & 0.803 & 19.666 & 6.353 \\
\hline Totals & 452 & 168 & 244.02 & 124.887 & & & & 201.225 & 0.835 & 16.511 & 117.695 \\
\hline
\end{tabular}

Table A.16: Estimated Number of Angle Crashes at Treatment Intersections

\begin{tabular}{|c|c|c|c|c|c|c|c|c|}
\hline & & & & & & & & \\
\hline INDEX & 1 & 2 & 3 & 4 & 5 & 6 & 7 & 8 \\
\hline Install Date & $8 / 9 / 2005$ & $8 / 9 / 2005$ & $9 / 6 / 2005$ & $12 / 17 / 2007$ & $4 / 1 / 2009$ & $4 / 7 / 2009$ & $4 / 8 / 2009$ & $4 / 9 / 2009$ \\
\hline Factor & 0.597 & 0.597 & 0.671 & 0.948 & 0.247 & 0.263 & 0.266 & 0.268 \\
\hline 2000 & 1.336 & 2.343 & 1.873 & 2.141 & 0.873 & 0.932 & 1.525 & 1.386 \\
\hline 2001 & 1.355 & 2.397 & 1.903 & 2.174 & 0.882 & 0.942 & 1.541 & 1.405 \\
\hline 2002 & 1.381 & 2.459 & 1.938 & 2.207 & 0.921 & 0.983 & 1.610 & 1.466 \\
\hline 2003 & 1.307 & 1.978 & 1.395 & 2.092 & 0.934 & 0.997 & 1.631 & 1.468 \\
\hline 2004 & 1.329 & 1.986 & 1.441 & 2.082 & 1.024 & 1.084 & 1.551 & 1.432 \\
\hline & 0.756 & 1.208 & 0.970 & & & & & \\
\hline 2005 & 0.510 & 0.815 & 0.475 & 2.135 & 0.909 & 0.949 & 1.345 & 1.374 \\
\hline 2006 & 1.117 & 1.928 & 1.348 & 1.903 & 0.902 & 0.943 & 1.330 & 1.352 \\
\hline & & & & 1.789 & & & & \\
\hline 2007 & 1.105 & 1.907 & 1.378 & 0.098 & 0.894 & 0.938 & 1.315 & 1.338 \\
\hline 2008 & 1.035 & 1.818 & 1.346 & 1.778 & 0.852 & 0.894 & 1.244 & 1.263 \\
\hline & & & & & 0.213 & 0.240 & 0.336 & 0.345 \\
\hline 2009 & 1.030 & 1.850 & 1.283 & 1.661 & 0.652 & 0.672 & 0.929 & 0.940 \\
\hline 2010 & 1.032 & 1.850 & 1.279 & 1.661 & 0.863 & 0.913 & 1.269 & 1.330 \\
\hline 2011 & 0.959 & 1.722 & 1.191 & 1.547 & 0.803 & 0.849 & 1.179 & 1.236 \\
\hline Total & 14.251 & 24.263 & 17.820 & 23.269 & 10.721 & 11.337 & 16.805 & 16.337 \\
\hline
\end{tabular}


Table A.17: Actual Number of Angle Crashes at Treatment Intersections

\begin{tabular}{|c|c|c|c|c|c|c|c|c|}
\hline INDEX & 1 & 2 & 3 & 4 & 5 & 6 & 7 & 8 \\
\hline Install Date & $8 / 9 / 2005$ & $8 / 9 / 2005$ & 9/6/2005 & $12 / 17 / 2007$ & 4/1/2009 & 4/7/2009 & $4 / 8 / 2009$ & $4 / 9 / 2009$ \\
\hline 2000 & 1 & 3 & 0 & 0 & 4 & 0 & 1 & 2 \\
\hline 2001 & 1 & 2 & 0 & 0 & 3 & 2 & 1 & 1 \\
\hline 2002 & 5 & 3 & 0 & 2 & 6 & 0 & 0 & 1 \\
\hline 2003 & 2 & 1 & 0 & 2 & 3 & 0 & 2 & 0 \\
\hline 2004 & 3 & 0 & 0 & 2 & 4 & 2 & 2 & 2 \\
\hline \multirow[t]{2}{*}{2005} & 1 & 0 & 0 & \multirow[t]{2}{*}{1} & \multirow[t]{2}{*}{5} & \multirow[t]{2}{*}{0} & \multirow[t]{2}{*}{1} & \multirow[t]{2}{*}{1} \\
\hline & 0 & 1 & 1 & & & & & \\
\hline 2006 & 2 & 0 & 1 & 1 & 1 & 0 & 0 & 1 \\
\hline \multirow[t]{2}{*}{2007} & \multirow[t]{2}{*}{2} & \multirow[t]{2}{*}{0} & \multirow[t]{2}{*}{0} & 3 & \multirow[t]{2}{*}{3} & \multirow[t]{2}{*}{2} & \multirow[t]{2}{*}{2} & \multirow[t]{2}{*}{0} \\
\hline & & & & 1 & & & & \\
\hline 2008 & 0 & 0 & 2 & 1 & 3 & 2 & 0 & 1 \\
\hline \multirow[t]{2}{*}{2009} & \multirow[t]{2}{*}{1} & \multirow[t]{2}{*}{1} & \multirow[t]{2}{*}{0} & \multirow[t]{2}{*}{0} & 1 & 0 & 0 & 1 \\
\hline & & & & & 1 & 0 & 0 & 0 \\
\hline 2010 & 1 & 3 & 1 & 0 & 1 & 0 & 0 & 1 \\
\hline 2011 & 0 & 2 & 2 & 0 & 0 & 0 & 2 & 1 \\
\hline Total & 19 & 16 & 7 & 13 & 35 & 8 & 11 & 12 \\
\hline
\end{tabular}

Table A.18: Expected Number of Angle Crashes at Treatment Intersections (EB Method)

\begin{tabular}{|r|r|r|r|r|r|r|r|r|r|r|r|}
\hline \multicolumn{1}{|c|}{ Site } & $\mathrm{K}(\mathrm{j})$ & $\mathrm{L}(\mathrm{j})$ & \multicolumn{1}{c|}{$\mathrm{Cb}$} & \multicolumn{1}{c|}{$\mathrm{Ca}$} & $\mathrm{w}(\mathrm{i}) \mathrm{b}$ & $\mathrm{N}\left(\exp \_\right.$B & $\mathrm{r}(\mathrm{i})$ & $\mathrm{N}\left(\exp \_\mathrm{A}\right)$ & $\mathrm{OR}(\mathrm{i})$ & \multicolumn{1}{c|}{$\mathrm{SE}(\mathrm{i})$} & \\
\hline 1 & 13 & 6 & 7.464 & 6.787 & 0.256 & 11.585 & 0.909 & 10.533 & 0.570 & 43.038 & 7.129 \\
\hline 2 & 9 & 7 & 12.372 & 11.891 & 0.172 & 9.579 & 0.961 & 9.207 & 0.760 & 23.967 & 7.330 \\
\hline 3 & 0 & 7 & 9.520 & 8.300 & 0.212 & 2.020 & 0.872 & 1.761 & 3.975 & -297.487 & 1.210 \\
\hline 4 & 11 & 2 & 16.523 & 6.746 & 0.134 & 11.742 & 0.408 & 4.794 & 0.417 & 58.280 & 1.694 \\
\hline 5 & 33 & 2 & 8.403 & 2.318 & 0.234 & 27.249 & 0.276 & 7.517 & 0.266 & 73.393 & 1.589 \\
\hline 6 & 8 & 0 & 8.903 & 2.434 & 0.224 & 8.202 & 0.273 & 2.242 & 0.000 & 100.000 & 0.476 \\
\hline 7 & 9 & 2 & 13.429 & 3.377 & 0.160 & 9.710 & 0.251 & 2.442 & 0.819 & 18.092 & 0.516 \\
\hline 8 & 10 & 2 & 12.831 & 3.507 & 0.167 & 10.471 & 0.273 & 2.862 & 0.699 & 30.117 & 0.652 \\
\hline Totals & 93 & 28 & 89.44443 & 45.359 & & & & 41.357 & 0.677 & 32.297 & 20.594 \\
\hline
\end{tabular}


Table A.19: Estimated Number of Rear End Crashes at Treatment Intersections (EB Method)

\begin{tabular}{|c|c|c|c|c|c|c|c|c|}
\hline INDEX & 1 & 2 & 3 & 4 & 5 & 6 & 7 & 8 \\
\hline Install Date & $8 / 9 / 2005$ & $8 / 9 / 2005$ & $9 / 6 / 2005$ & $12 / 17 / 2007$ & $4 / 1 / 2009$ & $4 / 7 / 2009$ & $4 / 8 / 2009$ & $4 / 9 / 2009$ \\
\hline Factor & 0.597 & 0.597 & 0.671 & 0.948 & 0.247 & 0.263 & 0.266 & 0.268 \\
\hline 2000 & 2.648 & 4.652 & 3.720 & 4.255 & 1.729 & 1.847 & 3.025 & 2.749 \\
\hline 2001 & 2.687 & 4.761 & 3.781 & 4.321 & 1.747 & 1.866 & 3.058 & 2.788 \\
\hline 2002 & 2.738 & 4.884 & 3.850 & 4.387 & 1.825 & 1.948 & 3.194 & 2.910 \\
\hline 2003 & 2.591 & 3.926 & 2.769 & 4.157 & 1.850 & 1.976 & 3.236 & 2.914 \\
\hline 2004 & 2.634 & 3.941 & 2.860 & 4.136 & 2.029 & 2.149 & 3.078 & 2.843 \\
\hline 2005 & 1.498 & 2.398 & 1.925 & 4.243 & 1.800 & 1.881 & 2.667 & 2.726 \\
\cline { 2 - 3 } & 1.010 & 1.617 & 0.943 & & & & & \\
\hline 2006 & 2.212 & 3.826 & 2.675 & 3.780 & 1.786 & 1.868 & 2.637 & 2.684 \\
\hline 2007 & 2.189 & 3.784 & 2.734 & 3.553 & 1.772 & 1.857 & 2.608 & 2.656 \\
& & & & 0.195 & & & & \\
\hline 2008 & 2.049 & 3.608 & 2.670 & 3.531 & 1.687 & 1.771 & 2.466 & 2.506 \\
\hline 2009 & 2.039 & 3.671 & 2.543 & 3.299 & 0.422 & 0.475 & 0.666 & 0.685 \\
\cline { 1 - 1 } & & & & & 1.291 & 1.331 & 1.841 & 1.866 \\
\hline 2010 & 2.044 & 3.671 & 2.536 & 3.299 & 1.709 & 1.808 & 2.516 & 2.639 \\
\hline 2011 & 1.899 & 3.416 & 2.362 & 3.071 & 1.590 & 1.681 & 2.338 & 2.453 \\
\hline Total & 28.239 & 48.155 & 35.369 & 46.227 & 21.237 & 22.458 & 33.332 & 32.419 \\
\hline
\end{tabular}

Table A.20: Actual Number of Rear End Crashes at Treatment Intersections

\begin{tabular}{|c|c|c|c|c|c|c|c|c|}
\hline INDEX & 1 & 2 & 3 & 4 & 5 & 6 & 7 & 8 \\
\hline Install Date & $8 / 9 / 2005$ & $8 / 9 / 2005$ & $9 / 6 / 2005$ & $12 / 17 / 2007$ & $4 / 1 / 2009$ & $4 / 7 / 2009$ & $4 / 8 / 2009$ & $4 / 9 / 2009$ \\
\hline 2000 & 12 & 1 & 4 & 1 & 4 & 14 & 9 & 7 \\
\hline 2001 & 13 & 3 & 6 & 4 & 6 & 8 & 8 & 10 \\
\hline 2002 & 17 & 5 & 10 & 5 & 5 & 4 & 5 & 13 \\
\hline 2003 & 11 & 3 & 9 & 8 & 8 & 4 & 14 & 12 \\
\hline 2004 & 11 & 1 & 5 & 3 & 5 & 8 & 5 & 7 \\
\hline \multirow[t]{2}{*}{2005} & 6 & 1 & 3 & \multirow[t]{2}{*}{5} & \multirow[t]{2}{*}{5} & \multirow[t]{2}{*}{4} & \multirow[t]{2}{*}{9} & \multirow[t]{2}{*}{10} \\
\hline & 2 & 0 & 1 & & & & & \\
\hline 2006 & 10 & 2 & 2 & 4 & 5 & 6 & 3 & 8 \\
\hline \multirow[t]{2}{*}{2007} & \multirow[t]{2}{*}{6} & \multirow[t]{2}{*}{2} & \multirow[t]{2}{*}{4} & 0 & \multirow[t]{2}{*}{4} & \multirow[t]{2}{*}{1} & \multirow[t]{2}{*}{5} & \multirow[t]{2}{*}{7} \\
\hline & & & & 0 & & & & \\
\hline 2008 & 8 & 3 & 8 & 2 & 5 & 9 & 7 & 11 \\
\hline \multirow[t]{2}{*}{2009} & \multirow[t]{2}{*}{14} & \multirow[t]{2}{*}{3} & \multirow[t]{2}{*}{7} & \multirow[t]{2}{*}{1} & 0 & 0 & 4 & 2 \\
\hline & & & & & 4 & 4 & 5 & 6 \\
\hline 2010 & 10 & 3 & 3 & 3 & 4 & 5 & 10 & 10 \\
\hline 2011 & 15 & 5 & 11 & 5 & 6 & 10 & 10 & 5 \\
\hline Total & 135 & 32 & 73 & 41 & 61 & 77 & 94 & 108 \\
\hline
\end{tabular}


Table A.21: Expected Number of Rear End Crashes at Treatment Intersections (EB Method)

\begin{tabular}{|c|c|c|c|c|c|c|c|c|c|c|c|}
\hline Site & $\mathrm{K}(\mathrm{j})$ & $\mathrm{L}(\mathrm{j})$ & $\mathrm{Cb}$ & $\mathrm{Ca}$ & $\mathrm{w}(\mathrm{i}) \mathrm{b}$ & $\mathrm{N}\left(\exp \_\mathrm{B}\right)$ & $\mathrm{r}(\mathrm{i})$ & $\mathrm{N}\left(\exp \_\mathrm{A}\right)$ & $\mathrm{OR}(\mathrm{i})$ & $\mathrm{SE}(\mathrm{i})$ & \\
\hline 1 & 70 & 65 & 14.796 & 13.443 & 0.148 & 61.847 & 0.909 & 56.189 & 1.157 & -15.681 & 43.509 \\
\hline 2 & 14 & 18 & 24.562 & 23.593 & 0.095 & 14.998 & 0.961 & 14.406 & 1.249 & -24.945 & 12.530 \\
\hline 3 & 37 & 36 & 18.905 & 16.463 & 0.119 & 34.839 & 0.871 & 30.338 & 1.187 & -18.662 & 23.264 \\
\hline 4 & 30 & 11 & 32.833 & 13.394 & 0.072 & 30.205 & 0.408 & 12.322 & 0.893 & 10.731 & 4.663 \\
\hline 5 & 47 & 14 & 16.647 & 4.591 & 0.133 & 42.949 & 0.276 & 11.844 & 1.182 & -18.207 & 2.830 \\
\hline 6 & 58 & 19 & 17.638 & 4.820 & 0.127 & 52.877 & 0.273 & 14.449 & 1.315 & -31.499 & 3.447 \\
\hline 7 & 69 & 25 & 26.637 & 6.695 & 0.088 & 65.280 & 0.251 & 16.407 & 1.524 & -52.377 & 3.761 \\
\hline 8 & 87 & 21 & 25.461 & 6.958 & 0.091 & 81.370 & 0.273 & 22.236 & 0.944 & 5.560 & 5.521 \\
\hline Totals & 412 & 209 & 177.48 & 89.956 & & & & 178.191 & 1.173 & -17.290 & 99.524 \\
\hline
\end{tabular}

Table A.22: Estimated Number of Side Swipe Crashes at Treatment Intersections (EB Method)

\begin{tabular}{|c|c|c|c|c|c|c|c|c|}
\hline INDEX & 1 & 2 & 3 & 4 & 5 & 6 & 7 & 8 \\
\hline Install Date & $8 / 9 / 2005$ & 8/9/2005 & 9/6/2005 & $12 / 17 / 2007$ & 4/1/2009 & 4/7/2009 & $4 / 8 / 2009$ & $4 / 9 / 2009$ \\
\hline Factor & 0.597 & 0.597 & 0.671 & 0.948 & 0.247 & 0.263 & 0.266 & 0.268 \\
\hline 2000 & 0.051 & 0.089 & 0.071 & 0.081 & 0.034 & 0.036 & 0.058 & 0.053 \\
\hline 2001 & 0.052 & 0.091 & 0.072 & 0.082 & 0.034 & 0.036 & 0.059 & 0.054 \\
\hline 2002 & 0.053 & 0.093 & 0.073 & 0.083 & 0.036 & 0.038 & 0.062 & 0.056 \\
\hline 2003 & 0.050 & 0.076 & 0.053 & 0.079 & 0.036 & 0.039 & 0.062 & 0.056 \\
\hline 2004 & 0.051 & 0.076 & 0.055 & 0.079 & 0.039 & 0.042 & 0.059 & 0.055 \\
\hline \multirow[t]{2}{*}{2005} & 0.029 & 0.046 & 0.037 & \multirow[t]{2}{*}{0.081} & \multirow[t]{2}{*}{0.035} & \multirow[t]{2}{*}{0.037} & \multirow[t]{2}{*}{0.052} & \multirow[t]{2}{*}{0.052} \\
\hline & 0.020 & 0.031 & 0.018 & & & & & \\
\hline 2006 & 0.043 & 0.074 & 0.052 & 0.072 & 0.035 & 0.037 & 0.051 & 0.052 \\
\hline \multirow[t]{2}{*}{2007} & \multirow[t]{2}{*}{0.043} & \multirow[t]{2}{*}{0.073} & \multirow[t]{2}{*}{0.053} & 0.068 & \multirow[t]{2}{*}{0.035} & \multirow[t]{2}{*}{0.036} & \multirow[t]{2}{*}{0.051} & \multirow[t]{2}{*}{0.051} \\
\hline & & & & 0.004 & & & & \\
\hline 2008 & 0.040 & 0.070 & 0.052 & 0.068 & 0.033 & 0.035 & 0.048 & 0.048 \\
\hline \multirow[t]{2}{*}{2009} & \multirow[t]{2}{*}{0.040} & \multirow[t]{2}{*}{0.071} & \multirow[t]{2}{*}{0.049} & \multirow[t]{2}{*}{0.063} & 0.008 & 0.009 & 0.013 & 0.013 \\
\hline & & & & & 0.025 & 0.026 & 0.036 & 0.036 \\
\hline 2010 & 0.040 & 0.071 & 0.049 & 0.063 & 0.033 & 0.035 & 0.049 & 0.051 \\
\hline 2011 & 0.037 & 0.066 & 0.046 & 0.059 & 0.031 & 0.033 & 0.045 & 0.047 \\
\hline Total & 0.551 & 0.926 & 0.680 & 0.881 & 0.415 & 0.439 & 0.645 & 0.624 \\
\hline
\end{tabular}


Table A.23: Actual Number of Side Swipe Crashes at Treatment Intersections

\begin{tabular}{|c|c|c|c|c|c|c|c|c|}
\hline INDEX & 1 & 2 & 3 & 4 & 5 & 6 & 7 & 8 \\
\hline Install Date & $8 / 9 / 2005$ & $8 / 9 / 2005$ & $9 / 6 / 2005$ & $12 / 17 / 2007$ & $4 / 1 / 2009$ & $4 / 7 / 2009$ & $4 / 8 / 2009$ & $4 / 9 / 2009$ \\
\hline 2000 & 0 & 1 & 1 & 0 & 0 & 0 & 0 & 1 \\
\hline 2001 & 0 & 0 & 0 & 0 & 0 & 0 & 0 & 0 \\
\hline 2002 & 0 & 0 & 0 & 0 & 1 & 0 & 0 & 0 \\
\hline 2003 & 1 & 1 & 0 & 1 & 0 & 0 & 2 & 0 \\
\hline 2004 & 0 & 0 & 2 & 0 & 0 & 0 & 0 & 0 \\
\hline 2005 & 0 & 1 & 0 & 1 & 0 & 0 & 0 & 0 \\
\cline { 2 - 5 } & 0 & 0 & 0 & & & & 0 & 2 \\
\hline 2006 & 1 & 0 & 1 & 0 & 1 & 0 & 0 & 1 \\
\hline 2007 & 0 & 0 & 0 & 0 & 0 & 0 & 0 & 0 \\
\hline
\end{tabular}

Table A.24: Expected Number of Side Swipe Crashes at Treatment Intersections (EB Method)

\begin{tabular}{|c|c|c|c|c|c|c|c|c|c|c|c|}
\hline Site & $\mathrm{K}(\mathrm{j})$ & $\mathrm{L}(\mathrm{j})$ & $\mathrm{Cb}$ & $\mathrm{Ca}$ & $\mathrm{w}(\mathrm{i}) \mathrm{b}$ & $\mathrm{N}\left(\exp \_\mathrm{B}\right)$ & $\mathrm{r}(\mathrm{i})$ & $\mathrm{N}\left(\exp \_\mathrm{A}\right)$ & $\mathrm{OR}(\mathrm{i})$ & $\mathrm{SE}(\mathrm{i})$ & \\
\hline 1 & 1 & 6 & 0.288 & 0.263 & 0.899 & 0.360 & 0.915 & 0.329 & 18.236 & -1723.639 & 0.030 \\
\hline 2 & 3 & 1 & 0.471 & 0.455 & 0.845 & 0.863 & 0.966 & 0.834 & 1.199 & -19.899 & 0.125 \\
\hline 3 & 3 & 2 & 0.362 & 0.318 & 0.876 & 0.688 & 0.880 & 0.605 & 3.306 & -230.561 & 0.066 \\
\hline 4 & 2 & 0 & 0.625 & 0.257 & 0.804 & 0.894 & 0.411 & 0.367 & 0.000 & 100.000 & 0.030 \\
\hline 5 & 2 & 1 & 0.325 & 0.090 & 0.887 & 0.514 & 0.277 & 0.142 & 7.036 & -603.614 & 0.004 \\
\hline 6 & 0 & 2 & 0.345 & 0.095 & 0.882 & 0.304 & 0.274 & 0.083 & 24.006 & -2300.647 & 0.003 \\
\hline 7 & 3 & 1 & 0.515 & 0.130 & 0.833 & 0.930 & 0.253 & 0.235 & 4.256 & -325.599 & 0.010 \\
\hline 8 & 4 & 0 & 0.490 & 0.134 & 0.839 & 1.054 & 0.274 & 0.288 & 0.000 & 100.000 & 0.013 \\
\hline Totals & 18 & 13 & 3.42 & 1.742 & & & & 2.884 & 4.508 & -350.762 & 0.280 \\
\hline
\end{tabular}


Table A.25: Estimated Number of Ped Crashes at Treatment Intersections (EB Method)

\begin{tabular}{|c|c|c|c|c|c|c|c|c|}
\hline INDEX & 1 & 2 & 3 & 4 & 5 & 6 & 7 & 8 \\
\hline Install Date & $8 / 9 / 2005$ & $8 / 9 / 2005$ & $9 / 6 / 2005$ & $12 / 17 / 2007$ & $4 / 1 / 2009$ & $4 / 7 / 2009$ & $4 / 8 / 2009$ & $4 / 9 / 2009$ \\
\hline Factor & 0.597 & 0.597 & 0.671 & 0.948 & 0.247 & 0.263 & 0.266 & 0.268 \\
\hline 2000 & 0.919 & 0.907 & 0.582 & 0.570 & 0.522 & 0.567 & 0.689 & 0.656 \\
\hline 2001 & 0.927 & 0.913 & 0.585 & 0.573 & 0.524 & 0.570 & 0.691 & 0.659 \\
\hline 2002 & 0.937 & 0.921 & 0.588 & 0.575 & 0.531 & 0.577 & 0.701 & 0.668 \\
\hline 2003 & 0.930 & 0.861 & 0.532 & 0.567 & 0.533 & 0.579 & 0.703 & 0.657 \\
\hline 2004 & 0.934 & 0.863 & 0.564 & 0.570 & 0.532 & 0.570 & 0.692 & 0.646 \\
\hline 2005 & 0.534 & 0.513 & 0.366 & 0.574 & 0.533 & 0.574 & 0.663 & 0.618 \\
\cline { 2 - 3 } & 0.360 & 0.346 & 0.179 & & & & & \\
\hline 2006 & 0.901 & 0.856 & 0.526 & 0.554 & 0.534 & 0.575 & 0.661 & 0.615 \\
\hline 2007 & 0.896 & 0.852 & 0.553 & 0.524 & 0.534 & 0.578 & 0.659 & 0.613 \\
& & & & 0.029 & & & & \\
\hline 2008 & 0.878 & 0.849 & 0.579 & 0.542 & 0.535 & 0.581 & 0.647 & 0.603 \\
\hline 2009 & 0.855 & 0.853 & 0.577 & 0.531 & 0.131 & 0.153 & 0.173 & 0.163 \\
\cline { 1 - 1 } & & & & & 0.402 & 0.430 & 0.478 & 0.444 \\
\hline 2010 & 0.855 & 0.853 & 0.574 & 0.531 & 0.531 & 0.585 & 0.651 & 0.607 \\
\hline 2011 & 0.656 & 0.835 & 0.562 & 0.520 & 0.519 & 0.573 & 0.636 & 0.593 \\
\hline Total & 10.581 & 10.421 & 6.765 & 6.659 & 6.360 & 6.912 & 8.043 & 7.543 \\
\hline
\end{tabular}

Table A.26: Actual Number of Ped Crashes at Treatment Intersections

\begin{tabular}{|c|c|c|c|c|c|c|c|c|}
\hline INDEX & 1 & 2 & 3 & 4 & 5 & 6 & 7 & 8 \\
\hline Install Date & $8 / 9 / 2005$ & $8 / 9 / 2005$ & 9/6/2005 & $12 / 17 / 2007$ & $4 / 1 / 2009$ & $4 / 7 / 2009$ & $4 / 8 / 2009$ & $4 / 9 / 2009$ \\
\hline 2000 & 1 & 0 & 0 & 0 & 0 & 1 & 0 & 0 \\
\hline 2001 & 2 & 0 & 0 & 0 & 0 & 1 & 0 & 0 \\
\hline 2002 & 0 & 0 & 1 & 0 & 0 & 0 & 0 & 0 \\
\hline 2003 & 0 & 0 & 0 & 0 & 1 & 0 & 0 & 1 \\
\hline 2004 & 0 & 0 & 0 & 0 & 1 & 0 & 1 & 0 \\
\hline \multirow[t]{2}{*}{2005} & 0 & 0 & 0 & \multirow[t]{2}{*}{0} & \multirow[t]{2}{*}{0} & \multirow[t]{2}{*}{0} & \multirow[t]{2}{*}{1} & \multirow[t]{2}{*}{0} \\
\hline & 0 & 0 & 0 & & & & & \\
\hline 2006 & 0 & 0 & 0 & 0 & 1 & 0 & 0 & 0 \\
\hline \multirow[t]{2}{*}{2007} & \multirow[t]{2}{*}{3} & \multirow[t]{2}{*}{0} & \multirow[t]{2}{*}{1} & 0 & \multirow[t]{2}{*}{0} & \multirow[t]{2}{*}{0} & \multirow[t]{2}{*}{2} & \multirow[t]{2}{*}{1} \\
\hline & & & & 0 & & & & \\
\hline 2008 & 1 & 0 & 2 & 0 & 0 & 0 & 0 & 1 \\
\hline \multirow[t]{2}{*}{2009} & \multirow[t]{2}{*}{0} & \multirow[t]{2}{*}{0} & \multirow[t]{2}{*}{0} & \multirow[t]{2}{*}{1} & 0 & 0 & 1 & 0 \\
\hline & & & & & 0 & 0 & 0 & 1 \\
\hline 2010 & 1 & 0 & 1 & 0 & 0 & 0 & 0 & 0 \\
\hline 2011 & 0 & 0 & 0 & 0 & 0 & 0 & 0 & 1 \\
\hline Total & 8 & 0 & 5 & 1 & 3 & 2 & 5 & 5 \\
\hline
\end{tabular}


Table A.27: Expected Number of Ped Crashes at Treatment Intersections (EB Method)

\begin{tabular}{|c|c|c|c|c|c|c|c|c|c|c|c|}
\hline Site & $\mathrm{K}(\mathrm{j})$ & $\mathrm{L}(\mathrm{j})$ & $\mathrm{Cb}$ & $\mathrm{Ca}$ & $\mathrm{w}(\mathrm{i}) \mathrm{b}$ & $\mathrm{N}\left(\exp \_\mathrm{B}\right)$ & $\mathrm{r}(\mathrm{i})$ & $\mathrm{N}\left(\exp \_\mathrm{A}\right)$ & $\mathrm{OR}(\mathrm{i})$ & $\mathrm{SE}(\mathrm{i})$ & \\
\hline 1 & 3 & 5 & 5.181 & 5.400 & 0.331 & 3.722 & 1.042 & 3.880 & 1.289 & -28.871 & 2.705 \\
\hline 2 & 0 & 0 & 4.978 & 5.444 & 0.340 & 1.692 & 1.094 & 1.851 & 0.000 & 100.000 & 1.336 \\
\hline 3 & 1 & 4 & 3.215 & 3.550 & 0.444 & 1.983 & 1.104 & 2.189 & 1.827 & -82.725 & 1.345 \\
\hline 4 & 0 & 1 & 4.506 & 2.153 & 0.363 & 1.634 & 0.478 & 0.781 & 1.281 & -28.092 & 0.238 \\
\hline 5 & 3 & 0 & 4.908 & 1.452 & 0.343 & 3.655 & 0.296 & 1.081 & 0.000 & 100.000 & 0.210 \\
\hline 6 & 2 & 0 & 5.324 & 1.587 & 0.325 & 3.081 & 0.298 & 0.918 & 0.000 & 100.000 & 0.185 \\
\hline 7 & 5 & 0 & 6.278 & 1.765 & 0.290 & 5.371 & 0.281 & 1.510 & 0.000 & 100.000 & 0.301 \\
\hline 8 & 3 & 2 & 5.900 & 1.643 & 0.303 & 3.878 & 0.279 & 1.080 & 1.851 & -85.123 & 0.210 \\
\hline Totals & 17 & 12 & 40.3 & 22.994 & & & & 13.290 & 0.903 & 9.709 & 6.530 \\
\hline
\end{tabular}

Table A.28: Estimated Number of Other Multivehicle Crashes at Treatment Intersections (EB

Method)

\begin{tabular}{|c|c|c|c|c|c|c|c|c|}
\hline INDEX & 1 & 2 & 3 & 4 & 5 & 6 & 7 & 8 \\
\hline Install Date & $8 / 9 / 2005$ & 8/9/2005 & 9/6/2005 & $12 / 17 / 2007$ & $4 / 1 / 2009$ & $4 / 7 / 2009$ & $4 / 8 / 2009$ & $4 / 9 / 2009$ \\
\hline Factor & 0.597 & 0.597 & 0.671 & 0.948 & 0.247 & 0.263 & 0.266 & 0.268 \\
\hline 2000 & 1.924 & 3.354 & 2.676 & 3.057 & 1.260 & 1.346 & 2.190 & 1.989 \\
\hline 2001 & 1.951 & 3.431 & 2.720 & 3.103 & 1.273 & 1.360 & 2.213 & 2.016 \\
\hline 2002 & 1.988 & 3.519 & 2.769 & 3.150 & 1.329 & 1.418 & 2.310 & 2.103 \\
\hline 2003 & 1.884 & 2.838 & 2.001 & 2.987 & 1.347 & 1.438 & 2.340 & 2.106 \\
\hline 2004 & 1.914 & 2.848 & 2.068 & 2.973 & 1.474 & 1.561 & 2.227 & 2.055 \\
\hline \multirow[t]{2}{*}{2005} & 1.089 & 1.732 & 1.390 & \multirow[t]{2}{*}{3.049} & \multirow[t]{2}{*}{1.311} & \multirow[t]{2}{*}{1.370} & \multirow[t]{2}{*}{1.934} & \multirow[t]{2}{*}{1.970} \\
\hline & 0.734 & 1.168 & 0.681 & & & & & \\
\hline 2006 & 1.612 & 2.767 & 1.934 & 2.721 & 1.301 & 1.361 & 1.913 & 1.940 \\
\hline \multirow[t]{2}{*}{2007} & \multirow[t]{2}{*}{1.595} & \multirow[t]{2}{*}{2.736} & \multirow[t]{2}{*}{1.978} & 2.558 & \multirow[t]{2}{*}{1.291} & \multirow[t]{2}{*}{1.354} & \multirow[t]{2}{*}{1.892} & \multirow[t]{2}{*}{1.920} \\
\hline & & & & 0.140 & & & & \\
\hline 2008 & 1.495 & 2.611 & 1.934 & 2.544 & 1.230 & 1.292 & 1.790 & 1.813 \\
\hline \multirow[t]{2}{*}{2009} & \multirow[t]{2}{*}{1.487} & \multirow[t]{2}{*}{2.656} & \multirow[t]{2}{*}{1.844} & \multirow[t]{2}{*}{2.379} & 0.308 & 0.346 & 0.484 & 0.495 \\
\hline & & & & & 0.941 & 0.970 & 1.336 & 1.350 \\
\hline 2010 & 1.490 & 2.656 & 1.838 & 2.379 & 1.246 & 1.318 & 1.826 & 1.908 \\
\hline 2011 & 1.387 & 2.475 & 1.714 & 2.217 & 1.161 & 1.228 & 1.699 & 1.775 \\
\hline Total & 20.551 & 34.790 & 25.548 & 33.257 & 15.473 & 16.362 & 24.153 & 23.441 \\
\hline
\end{tabular}


Table A.29: Actual Number of Other Multivehicle Crashes at Treatment Intersections

\begin{tabular}{|c|c|c|c|c|c|c|c|c|}
\hline INDEX & 1 & 2 & 3 & 4 & 5 & 6 & 7 & 8 \\
\hline Install Date & $8 / 9 / 2005$ & $8 / 9 / 2005$ & $9 / 6 / 2005$ & $12 / 17 / 2007$ & $4 / 1 / 2009$ & $4 / 7 / 2009$ & $4 / 8 / 2009$ & $4 / 9 / 2009$ \\
\hline 2000 & 6 & 0 & 3 & 1 & 5 & 4 & 5 & 4 \\
\hline 2001 & 3 & 3 & 2 & 0 & 3 & 4 & 5 & 4 \\
\hline 2002 & 4 & 4 & 3 & 2 & 1 & 3 & 8 & 5 \\
\hline 2003 & 2 & 4 & 5 & 0 & 3 & 5 & 2 & 7 \\
\hline 2004 & 3 & 2 & 2 & 2 & 2 & 3 & 3 & 1 \\
\hline 2005 & 2 & 0 & 1 & 2 & 4 & 3 & 5 & 3 \\
\cline { 2 - 4 } & 1 & 0 & 1 & & & & & \\
\hline 2006 & 1 & 1 & 2 & 2 & 5 & 3 & 3 & 7 \\
\hline 2007 & 3 & 2 & 3 & 1 & 4 & 2 & 1 & 9 \\
& & & & 0 & & & & \\
\hline 2008 & 5 & 1 & 4 & 2 & 5 & 5 & 6 & 8 \\
\hline 2009 & 1 & 1 & 2 & 3 & 1 & 0 & 4 & 1 \\
\hline 2010 & 1 & 4 & 0 & 2 & 4 & 3 & 3 & 5 \\
\hline 2011 & 1 & 2 & 1 & 1 & 4 & 2 & 0 & 5 \\
\hline Total & 33 & 24 & 29 & 18 & 42 & 39 & 45 & 61 \\
\hline
\end{tabular}

Table A.30: Expected Number of Other Multivehicle Crashes at Treatment Intersections (EB Method)

\begin{tabular}{|c|c|c|c|c|c|c|c|c|c|c|c|}
\hline Site & $\mathrm{K}(\mathrm{j})$ & $\mathrm{L}(\mathrm{j})$ & $\mathrm{Cb}$ & $\mathrm{Ca}$ & $\mathrm{w}(\mathrm{i}) \mathrm{b}$ & $\mathrm{N}\left(\exp \_\mathrm{B}\right)$ & $\mathrm{r}(\mathrm{i})$ & $\mathrm{N}\left(\exp \_\mathrm{A}\right)$ & $\mathrm{OR}(\mathrm{i})$ & $\mathrm{SE}(\mathrm{i})$ & \\
\hline 1 & 20 & 13 & 10.749 & 9.801 & 0.193 & 18.218 & 0.912 & 16.611 & 0.783 & 21.740 & 12.229 \\
\hline 2 & 13 & 11 & 17.721 & 17.069 & 0.126 & 13.597 & 0.963 & 13.097 & 0.840 & 16.011 & 11.021 \\
\hline 3 & 16 & 13 & 13.624 & 11.924 & 0.158 & 15.624 & 0.875 & 13.674 & 0.951 & 4.929 & 10.072 \\
\hline 4 & 10 & 8 & 23.597 & 9.660 & 0.098 & 11.333 & 0.409 & 4.639 & 1.724 & -72.444 & 1.713 \\
\hline 5 & 33 & 9 & 12.125 & 3.348 & 0.175 & 29.356 & 0.276 & 8.107 & 1.110 & -11.015 & 1.848 \\
\hline 6 & 32 & 7 & 12.846 & 3.516 & 0.166 & 28.813 & 0.274 & 7.887 & 0.888 & 11.247 & 1.800 \\
\hline 7 & 42 & 3 & 19.293 & 4.861 & 0.117 & 39.336 & 0.252 & 9.911 & 0.303 & 69.730 & 2.204 \\
\hline 8 & 49 & 12 & 18.408 & 5.033 & 0.122 & 45.260 & 0.273 & 12.375 & 0.970 & 3.030 & 2.970 \\
\hline Totals & 215 & 76 & 128.36 & 65.212 & & & & 86.301 & 0.881 & 11.936 & 43.856 \\
\hline
\end{tabular}


Table A.31: Estimated Number of Fixed Object Crashes at Treatment Intersections (EB Method)

\begin{tabular}{|c|c|c|c|c|c|c|c|c|}
\hline INDEX & 1 & 2 & 3 & 4 & 5 & 6 & 7 & 8 \\
\hline Install Date & $8 / 9 / 2005$ & $8 / 9 / 2005$ & $9 / 6 / 2005$ & $12 / 17 / 2007$ & $4 / 1 / 2009$ & $4 / 7 / 2009$ & $4 / 8 / 2009$ & $4 / 9 / 2009$ \\
\hline Factor & 0.597 & 0.597 & 0.671 & 0.948 & 0.247 & 0.263 & 0.266 & 0.268 \\
\hline 2000 & 0.195 & 0.307 & 0.238 & 0.267 & 0.134 & 0.143 & 0.211 & 0.191 \\
\hline 2001 & 0.197 & 0.312 & 0.241 & 0.270 & 0.135 & 0.144 & 0.213 & 0.193 \\
\hline 2002 & 0.201 & 0.318 & 0.245 & 0.273 & 0.140 & 0.149 & 0.220 & 0.199 \\
\hline 2003 & 0.193 & 0.269 & 0.190 & 0.262 & 0.141 & 0.150 & 0.223 & 0.199 \\
\hline 2004 & 0.195 & 0.270 & 0.197 & 0.262 & 0.151 & 0.159 & 0.214 & 0.194 \\
\hline 2005 & 0.111 & 0.163 & 0.131 & 0.267 & 0.139 & 0.145 & 0.192 & 0.187 \\
\cline { 2 - 3 } & 0.075 & 0.110 & 0.064 & & & & & \\
\hline 2006 & 0.171 & 0.264 & 0.185 & 0.244 & 0.138 & 0.144 & 0.190 & 0.185 \\
\hline 2007 & 0.169 & 0.261 & 0.190 & 0.230 & 0.137 & 0.144 & 0.188 & 0.183 \\
& & & & 0.013 & & & & \\
\hline 2008 & 0.161 & 0.253 & 0.189 & 0.232 & 0.132 & 0.139 & 0.180 & 0.175 \\
\hline 2009 & 0.160 & 0.256 & 0.183 & 0.220 & 0.033 & 0.037 & 0.049 & 0.048 \\
\cline { 1 - 1 } & & & & & 0.101 & 0.104 & 0.134 & 0.130 \\
\hline 2010 & 0.160 & 0.256 & 0.182 & 0.220 & 0.133 & 0.142 & 0.183 & 0.182 \\
\hline 2011 & 0.151 & 0.242 & 0.172 & 0.208 & 0.126 & 0.134 & 0.173 & 0.172 \\
\hline Total & 2.139 & 3.281 & 2.407 & 2.968 & 1.640 & 1.735 & 2.372 & 2.236 \\
\hline
\end{tabular}

Table A.32: Actual Number of Fixed Object Crashes at Treatment Intersections

\begin{tabular}{|c|c|c|c|c|c|c|c|c|}
\hline INDEX & 1 & 2 & 3 & 4 & 5 & 6 & 7 & 8 \\
\hline Install Date & $8 / 9 / 2005$ & $8 / 9 / 2005$ & $9 / 6 / 2005$ & $12 / 17 / 2007$ & $4 / 1 / 2009$ & $4 / 7 / 2009$ & $4 / 8 / 2009$ & $4 / 9 / 2009$ \\
\hline 2000 & 0 & 0 & 0 & 0 & 0 & 0 & 0 & 0 \\
\hline 2001 & 0 & 0 & 0 & 0 & 0 & 1 & 0 & 0 \\
\hline 2002 & 0 & 1 & 0 & 0 & 0 & 0 & 0 & 0 \\
\hline 2003 & 0 & 1 & 1 & 0 & 0 & 0 & 0 & 0 \\
\hline 2004 & 0 & 0 & 0 & 1 & 0 & 0 & 0 & 0 \\
\hline \multirow[t]{2}{*}{2005} & 0 & 0 & 0 & \multirow[t]{2}{*}{0} & \multirow[t]{2}{*}{0} & \multirow[t]{2}{*}{0} & \multirow[t]{2}{*}{0} & \multirow[t]{2}{*}{0} \\
\hline & 0 & 0 & 0 & & & & & \\
\hline 2006 & 1 & 0 & 0 & 0 & 0 & 0 & 0 & 0 \\
\hline \multirow[t]{2}{*}{2007} & \multirow[t]{2}{*}{0} & \multirow[t]{2}{*}{1} & \multirow[t]{2}{*}{0} & 0 & \multirow[t]{2}{*}{0} & \multirow[t]{2}{*}{0} & \multirow[t]{2}{*}{0} & \multirow[t]{2}{*}{0} \\
\hline & & & & 0 & & & & \\
\hline 2008 & 0 & 1 & 0 & 0 & 1 & 0 & 0 & 2 \\
\hline \multirow[t]{2}{*}{2009} & \multirow[t]{2}{*}{0} & \multirow[t]{2}{*}{0} & \multirow[t]{2}{*}{0} & \multirow[t]{2}{*}{0} & 0 & 0 & 0 & 0 \\
\hline & & & & & 1 & 0 & 0 & 0 \\
\hline 2010 & 0 & 2 & 0 & 0 & 0 & 0 & 0 & 1 \\
\hline 2011 & 0 & 1 & 0 & 0 & 0 & 0 & 0 & 0 \\
\hline Total & 1 & 7 & 1 & 1 & 2 & 1 & 0 & 3 \\
\hline
\end{tabular}


Table A.33: Expected Number of Fixed Object Crashes at Treatment Intersections (EB Method)

\begin{tabular}{|c|c|c|c|c|c|c|c|c|c|c|c|}
\hline Site & $\mathrm{K}(\mathrm{j})$ & $\mathrm{L}(\mathrm{j})$ & $\mathrm{Cb}$ & $\mathrm{Ca}$ & $\mathrm{w}(\mathrm{i}) \mathrm{b}$ & $\mathrm{N}\left(\exp \_\mathrm{B}\right)$ & $\mathrm{r}(\mathrm{i})$ & $\mathrm{N}\left(\exp \_\mathrm{A}\right)$ & $\mathrm{OR}(\mathrm{i})$ & $\mathrm{SE}(\mathrm{i})$ & \\
\hline 1 & 0 & 1 & 1.092 & 1.047 & 0.701 & 0.766 & 0.959 & 0.734 & 1.362 & -36.197 & 0.210 \\
\hline 2 & 2 & 5 & 1.639 & 1.642 & 0.610 & 1.780 & 1.002 & 1.783 & 2.804 & -180.367 & 0.697 \\
\hline 3 & 1 & 0 & 1.242 & 1.165 & 0.674 & 1.163 & 0.938 & 1.091 & 0.000 & 100.000 & 0.334 \\
\hline 4 & 1 & 0 & 2.076 & 0.892 & 0.553 & 1.595 & 0.430 & 0.685 & 0.000 & 100.000 & 0.132 \\
\hline 5 & 1 & 1 & 1.279 & 0.360 & 0.667 & 1.186 & 0.282 & 0.334 & 2.992 & -199.215 & 0.031 \\
\hline 6 & 1 & 0 & 1.355 & 0.380 & 0.654 & 1.232 & 0.280 & 0.345 & 0.000 & 100.000 & 0.033 \\
\hline 7 & 0 & 0 & 1.881 & 0.491 & 0.577 & 1.085 & 0.261 & 0.283 & 0.000 & 100.000 & 0.031 \\
\hline 8 & 2 & 1 & 1.753 & 0.483 & 0.594 & 1.853 & 0.276 & 0.511 & 1.957 & -95.693 & 0.057 \\
\hline Totals & 8 & 8 & 12.3 & 6.461 & & & & 5.768 & 1.387 & -38.705 & 1.526 \\
\hline
\end{tabular}

Table A.34: Estimated Number of Head On Crashes at Treatment Intersections (EB Method)

\begin{tabular}{|c|c|c|c|c|c|c|c|c|}
\hline INDEX & 1 & 2 & 3 & 4 & 5 & 6 & 7 & 8 \\
\hline Install Date & $8 / 9 / 2005$ & $8 / 9 / 2005$ & 9/6/2005 & $12 / 17 / 2007$ & $4 / 1 / 2009$ & $4 / 7 / 2009$ & $4 / 8 / 2009$ & $4 / 9 / 2009$ \\
\hline Factor & 0.597 & 0.597 & 0.671 & 0.948 & 0.247 & 0.263 & 0.266 & 0.268 \\
\hline 2000 & 0.005 & 0.009 & 0.007 & 0.008 & 0.003 & 0.003 & 0.006 & 0.005 \\
\hline 2001 & 0.005 & 0.009 & 0.007 & 0.009 & 0.003 & 0.004 & 0.006 & 0.005 \\
\hline 2002 & 0.005 & 0.010 & 0.008 & 0.009 & 0.003 & 0.004 & 0.006 & 0.006 \\
\hline 2003 & 0.005 & 0.008 & 0.005 & 0.008 & 0.003 & 0.004 & 0.006 & 0.006 \\
\hline 2004 & 0.005 & 0.008 & 0.006 & 0.008 & 0.004 & 0.004 & 0.006 & 0.006 \\
\hline \multirow[t]{2}{*}{2005} & 0.003 & 0.005 & 0.004 & \multirow[t]{2}{*}{0.008} & \multirow[t]{2}{*}{0.003} & \multirow[t]{2}{*}{0.004} & \multirow[t]{2}{*}{0.005} & \multirow[t]{2}{*}{0.005} \\
\hline & 0.002 & 0.003 & 0.002 & & & & & \\
\hline 2006 & 0.004 & 0.007 & 0.005 & 0.007 & 0.003 & 0.004 & 0.005 & 0.005 \\
\hline \multirow[t]{2}{*}{2007} & \multirow[t]{2}{*}{0.004} & \multirow[t]{2}{*}{0.007} & \multirow[t]{2}{*}{0.005} & 0.007 & \multirow[t]{2}{*}{0.003} & \multirow[t]{2}{*}{0.003} & \multirow[t]{2}{*}{0.005} & \multirow[t]{2}{*}{0.005} \\
\hline & & & & 0.000 & & & & \\
\hline 2008 & 0.004 & 0.007 & 0.005 & 0.007 & 0.003 & 0.003 & 0.005 & 0.005 \\
\hline \multirow[t]{2}{*}{2009} & \multirow[t]{2}{*}{0.004} & \multirow[t]{2}{*}{0.007} & \multirow[t]{2}{*}{0.005} & \multirow[t]{2}{*}{0.006} & 0.001 & 0.001 & 0.001 & 0.001 \\
\hline & & & & & 0.002 & 0.002 & 0.004 & 0.004 \\
\hline 2010 & 0.004 & 0.007 & 0.005 & 0.006 & 0.003 & 0.003 & 0.005 & 0.005 \\
\hline 2011 & 0.004 & 0.007 & 0.005 & 0.006 & 0.003 & 0.003 & 0.004 & 0.005 \\
\hline Total & 0.053 & 0.093 & 0.069 & 0.091 & 0.040 & 0.042 & 0.064 & 0.063 \\
\hline
\end{tabular}


Table A.35: Actual Number of Head On Crashes at Treatment Intersections

\begin{tabular}{|c|c|c|c|c|c|c|c|c|}
\hline INDEX & 1 & 2 & 3 & 4 & 5 & 6 & 7 & 8 \\
\hline Install Date & $8 / 9 / 2005$ & $8 / 9 / 2005$ & $9 / 6 / 2005$ & $12 / 17 / 2007$ & $4 / 1 / 2009$ & $4 / 7 / 2009$ & $4 / 8 / 2009$ & $4 / 9 / 2009$ \\
\hline 2000 & 0 & 0 & 0 & 0 & 0 & 0 & 0 & 0 \\
\hline 2001 & 0 & 0 & 0 & 0 & 0 & 0 & 0 & 0 \\
\hline 2002 & 0 & 0 & 0 & 0 & 0 & 0 & 0 & 0 \\
\hline 2003 & 0 & 0 & 0 & 0 & 0 & 0 & 0 & 0 \\
\hline 2004 & 1 & 0 & 0 & 0 & 0 & 0 & 1 & 0 \\
\hline 2005 & 0 & 0 & 0 & 0 & 0 & 0 & 0 & 0 \\
\cline { 2 - 5 } & 0 & 0 & 0 & & & & 0 & 0 \\
\hline 2006 & 0 & 0 & 0 & 0 & 0 & 0 & 0 & 0 \\
\hline 2007 & 0 & 0 & 0 & 0 & 0 & 0 & 0 & 0 \\
\hline & & & & 0 & & 0 & 0 & 0 \\
\hline 2008 & 0 & 0 & 0 & 0 & 0 & 0 & 0 & 0 \\
\hline
\end{tabular}

Table A.36: Expected Number of Head On Crashes at Treatment Intersections (EB Method)

\begin{tabular}{|c|c|c|c|c|c|c|c|c|c|c|c|}
\hline Site & $\mathrm{K}(\mathrm{j})$ & $\mathrm{L}(\mathrm{j})$ & $\mathrm{Cb}$ & $\mathrm{Ca}$ & $\mathrm{w}(\mathrm{i}) \mathrm{b}$ & $\mathrm{N}\left(\exp \_\mathrm{B}\right)$ & $\mathrm{r}(\mathrm{i})$ & $\mathrm{N}\left(\exp \_\mathrm{A}\right)$ & $\mathrm{OR}(\mathrm{i})$ & $\mathrm{SE}(\mathrm{i})$ & \\
\hline 1 & 1 & 0 & 0.028 & 0.025 & 0.989 & 0.039 & 0.896 & 0.035 & 0.000 & 100.000 & 0.000 \\
\hline 2 & 0 & 0 & 0.048 & 0.046 & 0.982 & 0.047 & 0.951 & 0.045 & 0.000 & 100.000 & 0.001 \\
\hline 3 & 0 & 0 & 0.037 & 0.032 & 0.986 & 0.036 & 0.855 & 0.031 & 0.000 & 100.000 & 0.000 \\
\hline 4 & 0 & 0 & 0.065 & 0.026 & 0.975 & 0.063 & 0.403 & 0.026 & 0.000 & 100.000 & 0.000 \\
\hline 5 & 0 & 0 & 0.031 & 0.009 & 0.988 & 0.031 & 0.274 & 0.008 & 0.000 & 100.000 & 0.000 \\
\hline 6 & 0 & 0 & 0.033 & 0.009 & 0.987 & 0.033 & 0.271 & 0.009 & 0.000 & 100.000 & 0.000 \\
\hline 7 & 1 & 0 & 0.051 & 0.013 & 0.980 & 0.070 & 0.249 & 0.017 & 0.000 & 100.000 & 0.000 \\
\hline 8 & 0 & 1 & 0.049 & 0.013 & 0.981 & 0.048 & 0.273 & 0.013 & 75.873 & -7487.298 & 0.000 \\
\hline Totals & 2 & 1 & 0.34 & 0.172 & & & & 0.184 & 5.436 & -443.632 & 0.002 \\
\hline
\end{tabular}


Table A.37: Estimated Number of Fatal \& Injury less Bike/Ped Crashes at Treatment Intersections (EB Method)

\begin{tabular}{|c|c|c|c|c|c|c|c|c|}
\hline INDEX & 1 & 2 & 3 & 4 & 5 & 6 & 7 & 8 \\
\hline Install Date & $8 / 9 / 2005$ & $8 / 9 / 2005$ & $9 / 6 / 2005$ & $12 / 17 / 2007$ & $4 / 1 / 2009$ & $4 / 7 / 2009$ & $4 / 8 / 2009$ & $4 / 9 / 2009$ \\
\hline Factor & 0.597 & 0.597 & 0.671 & 0.948 & 0.247 & 0.263 & 0.266 & 0.268 \\
\hline 2000 & 3.619 & 5.744 & 4.471 & 5.037 & 2.270 & 2.436 & 3.802 & 3.490 \\
\hline 2001 & 3.667 & 5.868 & 4.540 & 5.111 & 2.291 & 2.459 & 3.839 & 3.533 \\
\hline 2002 & 3.731 & 6.009 & 4.619 & 5.186 & 2.380 & 2.553 & 3.994 & 3.674 \\
\hline 2003 & 3.568 & 4.917 & 3.393 & 4.926 & 2.409 & 2.584 & 4.042 & 3.669 \\
\hline 2004 & 3.617 & 4.933 & 3.515 & 4.905 & 2.599 & 2.760 & 3.861 & 3.583 \\
\hline \multirow{2}{*}{2005} & 2.059 & 2.993 & 2.356 & \multirow[t]{2}{*}{5.026} & \multirow{2}{*}{2.356} & \multirow{2}{*}{2.478} & \multirow[t]{2}{*}{3.394} & \multirow[t]{2}{*}{3.434} \\
\hline & 1.388 & 2.018 & 1.154 & & & & & \\
\hline 2006 & 3.138 & 4.804 & 3.286 & 4.501 & 2.341 & 2.465 & 3.360 & 3.386 \\
\hline \multirow[t]{2}{*}{2007} & \multirow[t]{2}{*}{3.109} & \multirow[t]{2}{*}{4.754} & \multirow[t]{2}{*}{3.371} & 4.233 & \multirow[t]{2}{*}{2.326} & \multirow[t]{2}{*}{2.456} & \multirow[t]{2}{*}{3.327} & \multirow[t]{2}{*}{3.354} \\
\hline & & & & 0.232 & & & & \\
\hline 2008 & 2.945 & 4.561 & 3.320 & 4.219 & 2.237 & 2.368 & 3.164 & 3.183 \\
\hline \multirow[t]{2}{*}{2009} & \multirow[t]{2}{*}{2.914} & \multirow[t]{2}{*}{4.633} & \multirow[t]{2}{*}{3.183} & \multirow[t]{2}{*}{3.958} & 0.558 & 0.633 & 0.854 & 0.868 \\
\hline & & & & & 1.705 & 1.773 & 2.359 & 2.366 \\
\hline 2010 & 2.918 & 4.633 & 3.172 & 3.958 & 2.258 & 2.410 & 3.221 & 3.331 \\
\hline 2011 & 2.569 & 4.342 & 2.976 & 3.701 & 2.122 & 2.266 & 3.018 & 3.117 \\
\hline Total & 39.240 & 60.209 & 43.355 & 54.992 & 27.853 & 29.642 & 42.236 & 40.989 \\
\hline
\end{tabular}

Table A.38: Actual Number of Fatal \& Injury less Bike/Ped Crashes at Treatment Intersections

\begin{tabular}{|c|c|c|c|c|c|c|c|c|}
\hline INDEX & 1 & 2 & 3 & 4 & 5 & 6 & 7 & 8 \\
\hline Install Date & $8 / 9 / 2005$ & $8 / 9 / 2005$ & 9/6/2005 & $12 / 17 / 2007$ & $4 / 1 / 2009$ & $4 / 7 / 2009$ & $4 / 8 / 2009$ & $4 / 9 / 2009$ \\
\hline 2000 & 5 & 3 & 4 & 1 & 4 & 8 & 5 & 7 \\
\hline 2001 & 5 & 3 & 4 & 1 & 6 & 5 & 5 & 8 \\
\hline 2002 & 11 & 7 & 5 & 3 & 8 & 2 & 2 & 6 \\
\hline 2003 & 3 & 1 & 8 & 2 & 3 & 5 & 7 & 4 \\
\hline 2004 & 9 & 2 & 3 & 5 & 6 & 5 & 4 & 4 \\
\hline \multirow[t]{2}{*}{2005} & 1 & 0 & 2 & \multirow[t]{2}{*}{4} & \multirow[t]{2}{*}{8} & \multirow[t]{2}{*}{2} & \multirow[t]{2}{*}{10} & \multirow[t]{2}{*}{4} \\
\hline & 1 & 0 & 0 & & & & & \\
\hline 2006 & 10 & 3 & 1 & 1 & 3 & 4 & 2 & 6 \\
\hline \multirow[t]{2}{*}{2007} & \multirow[t]{2}{*}{6} & \multirow[t]{2}{*}{1} & \multirow[t]{2}{*}{3} & 1 & \multirow[t]{2}{*}{6} & \multirow[t]{2}{*}{1} & \multirow[t]{2}{*}{2} & \multirow[t]{2}{*}{5} \\
\hline & & & & 1 & & & & \\
\hline 2008 & 5 & 3 & 7 & 2 & 5 & 12 & 5 & 12 \\
\hline \multirow[t]{2}{*}{2009} & \multirow[t]{2}{*}{7} & \multirow[t]{2}{*}{3} & \multirow[t]{2}{*}{5} & \multirow[t]{2}{*}{1} & 2 & 0 & 5 & 2 \\
\hline & & & & & 3 & 5 & 4 & 2 \\
\hline 2010 & 7 & 4 & 4 & 0 & 5 & 6 & 7 & 11 \\
\hline 2011 & 10 & 7 & 8 & 3 & 5 & 6 & 6 & 5 \\
\hline Total & 80 & 37 & 54 & 25 & 64 & 61 & 64 & 76 \\
\hline
\end{tabular}


Table A.39: Expected Number of Fatal \& Injury less Bike/Ped Crashes at Treatment Intersections (EB Method)

\begin{tabular}{|c|c|c|c|c|c|c|c|c|c|c|c|}
\hline Site & $\mathrm{K}(\mathrm{j})$ & $\mathrm{L}(\mathrm{j})$ & $\mathrm{Cb}$ & $\mathrm{Ca}$ & $\mathrm{w}(\mathrm{i}) \mathrm{b}$ & $\mathrm{N}\left(\exp \_\mathrm{B}\right)$ & $\mathrm{r}(\mathrm{i})$ & $\mathrm{N}\left(\exp \_\mathrm{A}\right)$ & $\mathrm{OR}(\mathrm{i})$ & $\mathrm{SE}(\mathrm{i})$ & \\
\hline 1 & 34 & 46 & 20.260 & 18.980 & 0.112 & 32.456 & 0.937 & 30.405 & 1.513 & -51.289 & 25.284 \\
\hline 2 & 16 & 21 & 30.464 & 29.745 & 0.078 & 17.123 & 0.976 & 16.719 & 1.256 & -25.607 & 15.057 \\
\hline 3 & 26 & 28 & 22.894 & 20.462 & 0.101 & 25.687 & 0.894 & 22.959 & 1.220 & -21.959 & 18.453 \\
\hline 4 & 18 & 7 & 38.925 & 16.067 & 0.062 & 19.293 & 0.413 & 7.964 & 0.879 & 12.102 & 3.084 \\
\hline 5 & 51 & 13 & 21.768 & 6.085 & 0.105 & 47.920 & 0.280 & 13.395 & 0.971 & 2.948 & 3.350 \\
\hline 6 & 44 & 17 & 23.193 & 6.449 & 0.100 & 41.929 & 0.278 & 11.658 & 1.458 & -45.816 & 2.919 \\
\hline 7 & 47 & 17 & 33.638 & 8.598 & 0.071 & 46.054 & 0.256 & 11.772 & 1.444 & -44.414 & 2.796 \\
\hline 8 & 58 & 18 & 32.174 & 8.814 & 0.074 & 56.094 & 0.274 & 15.367 & 1.171 & -17.136 & 3.899 \\
\hline Totals & 294 & 167 & 223.32 & 115.200 & & & & 130.238 & 1.282 & -28.226 & 74.842 \\
\hline
\end{tabular}

Table A.40: Estimated Number of Total Crashes at Comparison Group Intersections

\begin{tabular}{|l|l|l|l|l|l|l|l|l|l|l|}
\hline INDEX & $\mathbf{1}(\mathbf{9})$ & $\mathbf{2}(\mathbf{1 0})$ & $\mathbf{3 ( 1 1 )}$ & $\mathbf{4}(\mathbf{1 2})$ & $\mathbf{5}(\mathbf{1 3})$ & $\mathbf{6}(\mathbf{1 4})$ & $\mathbf{7}(\mathbf{1 5})$ & $\mathbf{8}(\mathbf{1 6})$ & $\mathbf{9}(\mathbf{1 7})$ & $\mathbf{1 0}(\mathbf{1 8})$ \\
\hline $\mathbf{2 0 0 0}$ & 6.154 & 6.241 & 3.722 & 7.667 & 4.999 & 8.980 & 5.828 & 5.186 & 6.382 & 4.059 \\
\hline $\mathbf{2 0 0 1}$ & 6.332 & 6.616 & 3.754 & 7.742 & 5.288 & 9.087 & 5.901 & 5.257 & 6.422 & 4.109 \\
\hline $\mathbf{2 0 0 2}$ & 6.351 & 6.616 & 3.903 & 7.817 & 5.288 & 9.473 & 6.142 & 5.370 & 6.646 & 4.289 \\
\hline $\mathbf{2 0 0 3}$ & 6.524 & 6.997 & 3.589 & 7.152 & 5.609 & 9.573 & 6.200 & 5.085 & 6.686 & 4.333 \\
\hline $\mathbf{2 0 0 4}$ & 6.627 & 7.098 & 3.462 & 7.115 & 5.701 & 9.137 & 5.928 & 4.898 & 6.463 & 4.512 \\
\hline $\mathbf{2 0 0 5}$ & 5.813 & 5.508 & 3.171 & 7.122 & 4.931 & 8.126 & 5.406 & 4.992 & 5.815 & 4.693 \\
\hline $\mathbf{2 0 0 6}$ & 5.838 & 5.534 & 3.034 & 6.258 & 4.884 & 8.002 & 5.052 & 4.632 & 5.775 & 4.865 \\
\hline $\mathbf{2 0 0 7}$ & 5.788 & 5.483 & 2.879 & 6.186 & 4.783 & 7.869 & 4.997 & 4.568 & 5.574 & 4.829 \\
\hline $\mathbf{2 0 0 8}$ & 5.335 & 5.042 & 2.740 & 5.870 & 4.490 & 7.460 & 4.751 & 4.368 & 5.393 & 4.649 \\
\hline $\mathbf{2 0 0 9}$ & 5.427 & 5.117 & 2.769 & 5.487 & 4.578 & 7.511 & 4.832 & 4.130 & 5.293 & 4.703 \\
\hline $\mathbf{2 0 1 0}$ & 5.427 & 5.142 & 2.769 & 5.487 & 4.578 & 7.434 & 4.846 & 4.153 & 4.993 & 4.703 \\
\hline $\mathbf{2 0 1 1}$ & 5.096 & 4.825 & 2.601 & 5.145 & 4.281 & 6.955 & 4.534 & 3.896 & 4.621 & 4.405 \\
\hline Total & 70.712 & 70.220 & 38.393 & 79.046 & 59.409 & 99.607 & 64.418 & 56.535 & 70.061 & 54.149 \\
\hline
\end{tabular}

Table A.41: Actual Number of Total Crashes at Comparison Group Intersections

\begin{tabular}{|c|c|c|c|c|c|c|c|c|c|c|}
\hline INDEX & $\mathbf{1}(\mathbf{9})$ & $\mathbf{2}(\mathbf{1 0})$ & $\mathbf{3}(\mathbf{1 1})$ & $\mathbf{4}(\mathbf{1 2})$ & $\mathbf{5}(\mathbf{1 3})$ & $\mathbf{6}(\mathbf{1 4})$ & $\mathbf{7}(\mathbf{1 5})$ & $\mathbf{8}(\mathbf{1 6})$ & $\mathbf{9}(\mathbf{1 7})$ & $\mathbf{1 0}(\mathbf{1 8})$ \\
\hline $\mathbf{2 0 0 0}$ & 8 & 18 & 11 & 7 & 9 & 7 & 7 & 11 & 10 & 3 \\
\hline $\mathbf{2 0 0 1}$ & 13 & 15 & 6 & 6 & 9 & 9 & 9 & 6 & 5 & 5 \\
\hline $\mathbf{2 0 0 2}$ & 20 & 16 & 5 & 5 & 7 & 10 & 4 & 14 & 4 & 4 \\
\hline $\mathbf{2 0 0 3}$ & 25 & 18 & 5 & 7 & 11 & 13 & 13 & 13 & 9 & 10 \\
\hline $\mathbf{2 0 0 4}$ & 15 & 9 & 9 & 5 & 4 & 3 & 7 & 14 & 5 & 7 \\
\hline $\mathbf{2 0 0 5}$ & 10 & 9 & 4 & 2 & 9 & 9 & 3 & 8 & 3 & 3 \\
\hline $\mathbf{2 0 0 6}$ & 11 & 14 & 6 & 5 & 6 & 11 & 2 & 6 & 1 & 5 \\
\hline $\mathbf{2 0 0 7}$ & 10 & 3 & 6 & 9 & 4 & 7 & 12 & 7 & 6 & 2 \\
\hline $\mathbf{2 0 0 8}$ & 6 & 13 & 8 & 6 & 6 & 5 & 8 & 8 & 3 & 2 \\
\hline $\mathbf{2 0 0 9}$ & 12 & 7 & 8 & 7 & 6 & 12 & 10 & 13 & 1 & 9 \\
\hline $\mathbf{2 0 1 0}$ & 11 & 11 & 7 & 8 & 5 & 11 & 7 & 9 & 4 & 8 \\
\hline $\mathbf{2 0 1 1}$ & 11 & 11 & 8 & 5 & 3 & 15 & 8 & 3 & 6 & 7 \\
\hline Total & 152 & 144 & 83 & 72 & 79 & 112 & 90 & 112 & 57 & 65 \\
\hline
\end{tabular}


Table A.42: Expected Number of Total Crashes at Treatment Intersections (CG Method)

\begin{tabular}{|c|c|c|c|c|c|c|c|c|c|c|c|}
\hline Site & $\begin{array}{l}\text { Adj. crash } \\
\text { freq in } \\
\text { before } \\
\text { period }\end{array}$ & $\begin{array}{l}\text { Adj. crash } \\
\text { freq in } \\
\text { after } \\
\text { period }\end{array}$ & Ratio & $\begin{array}{l}\text { Exp. Avg. } \\
\text { crash freq in } \\
\text { after period } \\
\text { w/o } \\
\text { treatment }\end{array}$ & $\begin{array}{l}\text { Obs } \\
\text { crash } \\
\text { freq in } \\
\text { before } \\
\text { period }\end{array}$ & $\begin{array}{l}\text { Obs } \\
\text { crash } \\
\text { freq in } \\
\text { after } \\
\text { period }\end{array}$ & $\begin{array}{l}\text { Odds } \\
\text { Ratio }\end{array}$ & $\begin{array}{l}\text { Log } \\
\text { odds } \\
\text { ratio, } \\
\text { R }\end{array}$ & $\begin{array}{l}\text { Sqrd } \\
\text { Std } \\
\text { error of } \\
\text { log } \\
\text { odds } \\
\text { ratio }\end{array}$ & $\begin{array}{l}\text { Weighted } \\
\text { adj, w }\end{array}$ & $\begin{array}{l}\text { Weighted } \\
\text { product }\end{array}$ \\
\hline 1 & 632.16 & 566.15 & 0.896 & 96.72 & 108 & 96 & 0.993 & -0.008 & 0.023 & 43.43 & -0.33 \\
\hline 2 & 985.47 & 924.96 & 0.939 & 38.48 & 41 & 42 & 1.091 & 0.087 & 0.050 & 19.88 & 1.74 \\
\hline 3 & 745.56 & 644.70 & 0.865 & 50.15 & 58 & 62 & 1.236 & 0.212 & 0.036 & 27.58 & 5.85 \\
\hline 4 & 1210.31 & 560.73 & 0.463 & 25.02 & 54 & 22 & 0.879 & -0.129 & 0.067 & 15.02 & -1.93 \\
\hline 5 & 662.06 & 216.04 & 0.326 & 38.83 & 119 & 27 & 0.695 & -0.363 & 0.052 & 19.39 & -7.05 \\
\hline 6 & 703.52 & 227.90 & 0.324 & 32.72 & 101 & 28 & 0.856 & -0.156 & 0.051 & 19.45 & -3.03 \\
\hline 7 & 1029.65 & 307.14 & 0.298 & 38.48 & 129 & 31 & 0.806 & -0.216 & 0.044 & 22.61 & -4.89 \\
\hline 8 & 980.78 & 314.57 & 0.321 & 49.71 & 155 & 39 & 0.784 & -0.243 & 0.036 & 27.55 & -6.69 \\
\hline Total & 6949.52 & 3762.20 & & 370.12 & 765 & 347 & & & & 194.90 & -16.32 \\
\hline
\end{tabular}

Table A.43: Estimated Number of Fatal \& Injury Crashes at Comparison Group Intersections

\begin{tabular}{|c|c|c|c|c|c|c|c|c|c|c|}
\hline INDEX & $\mathbf{1}(\mathbf{9})$ & $\mathbf{2}(\mathbf{1 0})$ & $\mathbf{3 ( 1 1 )}$ & $\mathbf{4}(\mathbf{1 2})$ & $\mathbf{5}(\mathbf{1 3})$ & $\mathbf{6}(\mathbf{1 4})$ & $\mathbf{7}(\mathbf{1 5})$ & $\mathbf{8}(\mathbf{1 6})$ & $\mathbf{9}(\mathbf{1 7})$ & $\mathbf{1 0}(\mathbf{1 8})$ \\
\hline $\mathbf{2 0 0 0}$ & 3.082 & 2.985 & 1.749 & 3.643 & 2.366 & 4.214 & 2.881 & 2.519 & 3.066 & 1.949 \\
\hline $\mathbf{2 0 0 1}$ & 3.166 & 3.159 & 1.763 & 3.678 & 2.499 & 4.265 & 2.915 & 2.552 & 3.084 & 1.972 \\
\hline $\mathbf{2 0 0 2}$ & 3.175 & 3.159 & 1.829 & 3.713 & 2.499 & 4.446 & 3.030 & 2.604 & 3.187 & 2.054 \\
\hline $\mathbf{2 0 0 3}$ & 3.256 & 3.336 & 1.697 & 3.399 & 2.647 & 4.493 & 3.057 & 2.470 & 3.206 & 2.074 \\
\hline $\mathbf{2 0 0 4}$ & 3.305 & 3.383 & 1.645 & 3.381 & 2.690 & 4.288 & 2.928 & 2.386 & 3.103 & 2.154 \\
\hline $\mathbf{2 0 0 5}$ & 2.922 & 2.654 & 1.525 & 3.385 & 2.338 & 3.816 & 2.678 & 2.430 & 2.808 & 2.235 \\
\hline $\mathbf{2 0 0 6}$ & 2.934 & 2.666 & 1.455 & 2.977 & 2.314 & 3.757 & 2.514 & 2.263 & 2.790 & 2.312 \\
\hline $\mathbf{2 0 0 7}$ & 2.910 & 2.643 & 1.375 & 2.943 & 2.266 & 3.694 & 2.487 & 2.234 & 2.699 & 2.295 \\
\hline $\mathbf{2 0 0 8}$ & 2.698 & 2.440 & 1.314 & 2.795 & 2.131 & 3.503 & 2.372 & 2.141 & 2.617 & 2.215 \\
\hline $\mathbf{2 0 0 9}$ & 2.741 & 2.474 & 1.327 & 2.615 & 2.171 & 3.526 & 2.410 & 2.032 & 2.572 & 2.239 \\
\hline $\mathbf{2 0 1 0}$ & 2.741 & 2.486 & 1.327 & 2.615 & 2.171 & 3.489 & 2.416 & 2.042 & 2.438 & 2.239 \\
\hline $\mathbf{2 0 1 1}$ & 2.585 & 2.340 & 1.253 & 2.455 & 2.035 & 3.266 & 2.269 & 1.924 & 2.262 & 2.102 \\
\hline Total & 35.516 & 33.725 & 18.258 & 37.598 & 28.127 & 46.758 & 31.957 & 27.595 & 33.831 & 25.840 \\
\hline
\end{tabular}

Table A.44: Actual Number of Fatal \& Injury Crashes at Comparison Group Intersections

\begin{tabular}{|c|c|c|c|c|c|c|c|c|c|c|}
\hline INDEX & $\mathbf{1}(\mathbf{9})$ & $\mathbf{2}(\mathbf{1 0})$ & $\mathbf{3}(\mathbf{1 1})$ & $\mathbf{4}(\mathbf{1 2})$ & $\mathbf{5}(\mathbf{1 3})$ & $\mathbf{6}(\mathbf{1 4})$ & $\mathbf{7}(\mathbf{1 5})$ & $\mathbf{8}(\mathbf{1 6})$ & $\mathbf{9}(\mathbf{1 7})$ & $\mathbf{1 0}(\mathbf{1 8})$ \\
\hline $\mathbf{2 0 0 0}$ & 1 & 6 & 8 & 2 & 6 & 2 & 2 & 4 & 5 & 0 \\
\hline $\mathbf{2 0 0 1}$ & 7 & 6 & 1 & 1 & 6 & 5 & 4 & 3 & 0 & 4 \\
\hline $\mathbf{2 0 0 2}$ & 9 & 4 & 1 & 2 & 2 & 0 & 1 & 8 & 1 & 1 \\
\hline $\mathbf{2 0 0 3}$ & 14 & 6 & 1 & 2 & 6 & 5 & 7 & 5 & 4 & 5 \\
\hline $\mathbf{2 0 0 4}$ & 8 & 5 & 6 & 4 & 3 & 2 & 5 & 8 & 2 & 4 \\
\hline $\mathbf{2 0 0 5}$ & 6 & 6 & 4 & 1 & 4 & 4 & 1 & 4 & 1 & 0 \\
\hline $\mathbf{2 0 0 6}$ & 5 & 6 & 3 & 4 & 3 & 3 & 0 & 3 & 0 & 3 \\
\hline $\mathbf{2 0 0 7}$ & 4 & 2 & 1 & 6 & 1 & 4 & 6 & 3 & 2 & 0 \\
\hline $\mathbf{2 0 0 8}$ & 1 & 7 & 4 & 3 & 1 & 1 & 4 & 0 & 0 & 0 \\
\hline $\mathbf{2 0 0 9}$ & 7 & 4 & 3 & 2 & 2 & 9 & 7 & 11 & 0 & 3 \\
\hline $\mathbf{2 0 1 0}$ & 4 & 4 & 7 & 5 & 2 & 6 & 3 & 3 & 2 & 4 \\
\hline $\mathbf{2 0 1 1}$ & 8 & 7 & 6 & 3 & 2 & 5 & 6 & 3 & 3 & 4 \\
\hline Total & 74 & 63 & 45 & 35 & 38 & 46 & 46 & 55 & 20 & 28 \\
\hline
\end{tabular}


Table A.45: Expected Number of Fatal \& Injury Crashes at Treatment Intersections (CG Method)

\begin{tabular}{|c|c|c|c|c|c|c|c|c|c|c|c|}
\hline Site & $\begin{array}{c}\text { Adj. crash } \\
\text { freq in } \\
\text { before } \\
\text { period }\end{array}$ & $\begin{array}{c}\text { Adj. crash } \\
\text { freq in } \\
\text { after } \\
\text { period }\end{array}$ & Ratio & $\begin{array}{c}\text { Exp. Avg. } \\
\text { crash freq in } \\
\text { after period } \\
\text { w/o } \\
\text { treatment }\end{array}$ & $\begin{array}{c}\text { Obs } \\
\text { crash } \\
\text { freq in } \\
\text { before } \\
\text { period }\end{array}$ & $\begin{array}{c}\text { Obs } \\
\text { crash } \\
\text { freq in } \\
\text { after } \\
\text { period }\end{array}$ & $\begin{array}{c}\text { Odds } \\
\text { Ratio }\end{array}$ & $\begin{array}{c}\text { Log } \\
\text { odds } \\
\text { ratio, } \\
\text { R }\end{array}$ & $\begin{array}{c}\text { Sqrd } \\
\text { Std } \\
\text { error of } \\
\text { log } \\
\text { odds } \\
\text { ratio }\end{array}$ & $\begin{array}{c}\text { Weighted } \\
\text { adj, w }\end{array}$ & $\begin{array}{c}\text { Weighted } \\
\text { product }\end{array}$ \\
\hline 1 & 294.53 & 288.18 & 0.978 & 37.18 & 38 & 50 & 1.345 & 0.296 & 0.053 & 18.80 & 5.57 \\
\hline 2 & 442.86 & 451.63 & 1.020 & 16.32 & 16 & 21 & 1.287 & 0.252 & 0.115 & 8.73 & 2.20 \\
\hline 3 & 332.12 & 311.44 & 0.938 & 25.32 & 27 & 32 & 1.264 & 0.234 & 0.075 & 13.42 & 3.14 \\
\hline 4 & 533.62 & 279.62 & 0.524 & 9.43 & 18 & 10 & 1.060 & 0.058 & 0.161 & 6.21 & 0.36 \\
\hline 5 & 292.53 & 122.47 & 0.419 & 22.61 & 54 & 13 & 0.575 & -0.553 & 0.107 & 9.34 & -5.17 \\
\hline 6 & 311.93 & 129.80 & 0.416 & 19.14 & 46 & 17 & 0.888 & -0.119 & 0.091 & 10.93 & -1.30 \\
\hline 7 & 452.46 & 173.05 & 0.382 & 20.65 & 54 & 17 & 0.823 & -0.195 & 0.085 & 11.72 & -2.28 \\
\hline 8 & 432.83 & 177.40 & 0.410 & 24.59 & 60 & 19 & 0.773 & -0.258 & 0.077 & 12.95 & -3.34 \\
\hline Total & 3092.87 & 1933.60 & & 175.24 & 313 & 179 & & & & 92.10 & -0.81 \\
\hline
\end{tabular}

Table A.46: Estimated Number of PDO Crashes at Comparison Group Intersections

\begin{tabular}{|c|c|c|c|c|c|c|c|c|c|c|}
\hline INDEX & $\mathbf{1}(\mathbf{9})$ & $\mathbf{2}(\mathbf{1 0})$ & $\mathbf{3 ( 1 1 )}$ & $\mathbf{4}(\mathbf{1 2})$ & $\mathbf{5}(\mathbf{1 3})$ & $\mathbf{6}(\mathbf{1 4})$ & $\mathbf{7}(\mathbf{1 5})$ & $\mathbf{8}(\mathbf{1 6})$ & $\mathbf{9}(\mathbf{1 7})$ & $\mathbf{1 0}(\mathbf{1 8})$ \\
\hline $\mathbf{2 0 0 0}$ & 3.072 & 3.256 & 1.974 & 4.025 & 2.633 & 4.766 & 2.948 & 2.667 & 3.316 & 2.110 \\
\hline $\mathbf{2 0 0 1}$ & 3.165 & 3.457 & 1.991 & 4.064 & 2.789 & 4.823 & 2.986 & 2.705 & 3.338 & 2.137 \\
\hline $\mathbf{2 0 0 2}$ & 3.176 & 3.457 & 2.074 & 4.103 & 2.789 & 5.027 & 3.112 & 2.766 & 3.459 & 2.235 \\
\hline $\mathbf{2 0 0 3}$ & 3.268 & 3.661 & 1.892 & 3.753 & 2.961 & 5.080 & 3.143 & 2.615 & 3.481 & 2.258 \\
\hline $\mathbf{2 0 0 4}$ & 3.322 & 3.715 & 1.817 & 3.733 & 3.011 & 4.849 & 3.000 & 2.512 & 3.360 & 2.358 \\
\hline $\mathbf{2 0 0 5}$ & 2.891 & 2.854 & 1.646 & 3.738 & 2.593 & 4.310 & 2.728 & 2.562 & 3.007 & 2.458 \\
\hline $\mathbf{2 0 0 6}$ & 2.904 & 2.868 & 1.580 & 3.281 & 2.570 & 4.245 & 2.538 & 2.369 & 2.985 & 2.554 \\
\hline $\mathbf{2 0 0 7}$ & 2.878 & 2.840 & 1.504 & 3.243 & 2.517 & 4.175 & 2.509 & 2.335 & 2.875 & 2.534 \\
\hline $\mathbf{2 0 0 8}$ & 2.637 & 2.603 & 1.426 & 3.075 & 2.359 & 3.956 & 2.380 & 2.227 & 2.776 & 2.434 \\
\hline $\mathbf{2 0 0 9}$ & 2.686 & 2.643 & 1.442 & 2.872 & 2.407 & 3.985 & 2.422 & 2.099 & 2.720 & 2.464 \\
\hline $\mathbf{2 0 1 0}$ & 2.686 & 2.657 & 1.442 & 2.872 & 2.407 & 3.945 & 2.430 & 2.111 & 2.555 & 2.464 \\
\hline $\mathbf{2 0 1 1}$ & 2.510 & 2.485 & 1.348 & 2.690 & 2.246 & 3.689 & 2.265 & 1.972 & 2.358 & 2.303 \\
\hline Total & 35.196 & 36.496 & 20.135 & 41.448 & 31.282 & 52.849 & 32.461 & 28.939 & 36.230 & 28.309 \\
\hline
\end{tabular}

Table A.47: Actual Number of PDO Crashes at Comparison Group Intersections

\begin{tabular}{|c|c|c|c|c|c|c|c|c|c|c|}
\hline INDEX & $\mathbf{1}(\mathbf{9})$ & $\mathbf{2}(\mathbf{1 0})$ & $\mathbf{3}(\mathbf{1 1})$ & $\mathbf{4}(\mathbf{1 2})$ & $\mathbf{5}(\mathbf{1 3})$ & $\mathbf{6}(\mathbf{1 4})$ & $\mathbf{7}(\mathbf{1 5})$ & $\mathbf{8}(\mathbf{1 6})$ & $\mathbf{9}(\mathbf{1 7})$ & $\mathbf{1 0}(\mathbf{1 8})$ \\
\hline $\mathbf{2 0 0 0}$ & 7 & 12 & 3 & 5 & 3 & 5 & 5 & 7 & 5 & 3 \\
\hline $\mathbf{2 0 0 1}$ & 6 & 9 & 5 & 5 & 3 & 4 & 5 & 3 & 5 & 1 \\
\hline $\mathbf{2 0 0 2}$ & 11 & 12 & 4 & 3 & 5 & 10 & 3 & 6 & 3 & 3 \\
\hline $\mathbf{2 0 0 3}$ & 11 & 12 & 4 & 5 & 5 & 8 & 6 & 8 & 5 & 5 \\
\hline $\mathbf{2 0 0 4}$ & 7 & 4 & 3 & 1 & 1 & 1 & 2 & 6 & 3 & 3 \\
\hline $\mathbf{2 0 0 5}$ & 4 & 3 & 0 & 1 & 5 & 5 & 2 & 4 & 2 & 3 \\
\hline $\mathbf{2 0 0 6}$ & 6 & 8 & 3 & 1 & 3 & 8 & 2 & 3 & 1 & 2 \\
\hline $\mathbf{2 0 0 7}$ & 6 & 1 & 5 & 3 & 3 & 3 & 6 & 4 & 4 & 2 \\
\hline $\mathbf{2 0 0 8}$ & 5 & 6 & 4 & 3 & 5 & 4 & 4 & 8 & 3 & 2 \\
\hline $\mathbf{2 0 0 9}$ & 5 & 3 & 5 & 5 & 4 & 3 & 3 & 2 & 1 & 6 \\
\hline $\mathbf{2 0 1 0}$ & 7 & 7 & 0 & 3 & 3 & 5 & 4 & 6 & 2 & 4 \\
\hline $\mathbf{2 0 1 1}$ & 3 & 4 & 2 & 2 & 1 & 10 & 2 & 0 & 3 & 3 \\
\hline Total & 78 & 81 & 38 & 37 & 41 & 66 & 44 & 57 & 37 & 37 \\
\hline
\end{tabular}


Table A.48: Expected Number of PDO Crashes at Treatment Intersections (CG Method)

\begin{tabular}{|c|c|c|c|c|c|c|c|c|c|c|c|}
\hline Site & $\begin{array}{c}\text { Adj. crash } \\
\text { freq in } \\
\text { before } \\
\text { period }\end{array}$ & $\begin{array}{c}\text { Adj. crash } \\
\text { freq in } \\
\text { after } \\
\text { period }\end{array}$ & Ratio & $\begin{array}{c}\text { Exp. Avg. } \\
\text { crash freq in } \\
\text { after period } \\
\text { w/o } \\
\text { treatment }\end{array}$ & $\begin{array}{c}\text { Obs } \\
\text { crash } \\
\text { freq in } \\
\text { before } \\
\text { period }\end{array}$ & $\begin{array}{c}\text { Obs } \\
\text { crash } \\
\text { freq in } \\
\text { after } \\
\text { period }\end{array}$ & $\begin{array}{c}\text { Odds } \\
\text { Ratio }\end{array}$ & $\begin{array}{c}\text { Log } \\
\text { odds } \\
\text { ratio, } \\
\text { R }\end{array}$ & $\begin{array}{c}\text { Sqrd } \\
\text { Std } \\
\text { error of } \\
\text { log } \\
\text { odds } \\
\text { ratio }\end{array}$ & $\begin{array}{c}\text { Weighted } \\
\text { adj, w }\end{array}$ & $\begin{array}{c}\text { Weighted } \\
\text { product }\end{array}$ \\
\hline 1 & 336.68 & 278.27 & 0.827 & 57.86 & 70 & 46 & 0.795 & -0.229 & 0.043 & 23.48 & -5.38 \\
\hline 2 & 543.04 & 473.04 & 0.871 & 21.78 & 25 & 21 & 0.964 & -0.036 & 0.092 & 10.92 & -0.40 \\
\hline 3 & 414.15 & 332.95 & 0.804 & 24.92 & 31 & 30 & 1.204 & 0.185 & 0.071 & 14.08 & 2.61 \\
\hline 4 & 678.50 & 279.80 & 0.412 & 14.85 & 36 & 12 & 0.808 & -0.213 & 0.116 & 8.61 & -1.83 \\
\hline 5 & 369.80 & 93.18 & 0.252 & 16.38 & 65 & 14 & 0.855 & -0.157 & 0.100 & 9.98 & -1.56 \\
\hline 6 & 391.72 & 97.87 & 0.250 & 13.74 & 55 & 11 & 0.801 & -0.222 & 0.122 & 8.21 & -1.83 \\
\hline 7 & 578.06 & 133.22 & 0.230 & 17.28 & 75 & 14 & 0.810 & -0.211 & 0.094 & 10.64 & -2.24 \\
\hline 8 & 548.47 & 136.33 & 0.249 & 23.61 & 95 & 20 & 0.847 & -0.166 & 0.070 & 14.35 & -2.38 \\
\hline Total & 3860.41 & 1824.66 & & 190.42 & 452 & 168 & & & & 100.26 & -13.02 \\
\hline
\end{tabular}

Table A.49: Estimated Number of Angle Crashes at Comparison Group Intersections

\begin{tabular}{|c|c|c|c|c|c|c|c|c|c|c|}
\hline INDEX & $\mathbf{1}(\mathbf{9})$ & $\mathbf{2}(\mathbf{1 0})$ & $\mathbf{3}(\mathbf{1 1})$ & $\mathbf{4}(\mathbf{1 2})$ & $\mathbf{5}(\mathbf{1 3})$ & $\mathbf{6}(\mathbf{1 4})$ & $\mathbf{7}(\mathbf{1 5})$ & $\mathbf{8}(\mathbf{1 6})$ & $\mathbf{9}(\mathbf{1 7})$ & $\mathbf{1 0}(\mathbf{1 8})$ \\
\hline $\mathbf{2 0 0 0}$ & 1.098 & 1.168 & 0.670 & 1.498 & 0.942 & 1.765 & 1.080 & 0.949 & 1.196 & 0.738 \\
\hline $\mathbf{2 0 0 1}$ & 1.134 & 1.245 & 0.676 & 1.513 & 1.001 & 1.787 & 1.095 & 0.963 & 1.205 & 0.748 \\
\hline $\mathbf{2 0 0 2}$ & 1.138 & 1.245 & 0.706 & 1.529 & 1.001 & 1.868 & 1.144 & 0.986 & 1.253 & 0.785 \\
\hline $\mathbf{2 0 0 3}$ & 1.173 & 1.323 & 0.639 & 1.390 & 1.067 & 1.889 & 1.156 & 0.930 & 1.261 & 0.794 \\
\hline $\mathbf{2 0 0 4}$ & 1.194 & 1.344 & 0.611 & 1.383 & 1.086 & 1.798 & 1.100 & 0.890 & 1.214 & 0.832 \\
\hline $\mathbf{2 0 0 5}$ & 1.030 & 1.013 & 0.549 & 1.388 & 0.925 & 1.583 & 0.996 & 0.909 & 1.076 & 0.871 \\
\hline $\mathbf{2 0 0 6}$ & 1.035 & 1.018 & 0.527 & 1.208 & 0.917 & 1.558 & 0.921 & 0.836 & 1.067 & 0.908 \\
\hline $\mathbf{2 0 0 7}$ & 1.025 & 1.008 & 0.502 & 1.194 & 0.898 & 1.532 & 0.910 & 0.823 & 1.024 & 0.900 \\
\hline $\mathbf{2 0 0 8}$ & 0.934 & 0.918 & 0.475 & 1.128 & 0.839 & 1.447 & 0.860 & 0.783 & 0.986 & 0.861 \\
\hline $\mathbf{2 0 0 9}$ & 0.953 & 0.933 & 0.480 & 1.049 & 0.857 & 1.460 & 0.876 & 0.735 & 0.964 & 0.873 \\
\hline $\mathbf{2 0 1 0}$ & 0.953 & 0.938 & 0.480 & 1.049 & 0.857 & 1.446 & 0.879 & 0.740 & 0.901 & 0.873 \\
\hline $\mathbf{2 0 1 1}$ & 0.887 & 0.874 & 0.447 & 0.978 & 0.796 & 1.346 & 0.816 & 0.688 & 0.828 & 0.813 \\
\hline Total & 12.554 & 13.029 & 6.765 & 15.307 & 11.187 & 19.479 & 11.833 & 10.233 & 12.974 & 9.996 \\
\hline
\end{tabular}

Table A.50: Actual Number of Angle Crashes at Comparison Group Intersections

\begin{tabular}{|c|c|c|c|c|c|c|c|c|c|c|}
\hline INDEX & $\mathbf{1}(\mathbf{9})$ & $\mathbf{2}(\mathbf{1 0})$ & $\mathbf{3}(\mathbf{1 1})$ & $\mathbf{4}(\mathbf{1 2})$ & $\mathbf{5}(\mathbf{1 3})$ & $\mathbf{6}(\mathbf{1 4})$ & $\mathbf{7}(\mathbf{1 5})$ & $\mathbf{8}(\mathbf{1 6})$ & $\mathbf{9}(\mathbf{1 7})$ & $\mathbf{1 0}(\mathbf{1 8})$ \\
\hline $\mathbf{2 0 0 0}$ & 2 & 0 & 1 & 0 & 2 & 1 & 0 & 4 & 1 & 0 \\
\hline $\mathbf{2 0 0 1}$ & 1 & 3 & 1 & 0 & 1 & 4 & 0 & 1 & 1 & 0 \\
\hline $\mathbf{2 0 0 2}$ & 4 & 1 & 0 & 0 & 0 & 1 & 2 & 0 & 0 & 2 \\
\hline $\mathbf{2 0 0 3}$ & 0 & 4 & 1 & 1 & 0 & 1 & 3 & 0 & 1 & 3 \\
\hline $\mathbf{2 0 0 4}$ & 0 & 1 & 0 & 0 & 0 & 0 & 0 & 0 & 0 & 0 \\
\hline $\mathbf{2 0 0 5}$ & 1 & 9 & 1 & 0 & 2 & 3 & 0 & 0 & 1 & 0 \\
\hline $\mathbf{2 0 0 6}$ & 1 & 1 & 0 & 0 & 1 & 2 & 2 & 0 & 0 & 2 \\
\hline $\mathbf{2 0 0 7}$ & 2 & 0 & 4 & 3 & 0 & 1 & 0 & 2 & 4 & 0 \\
\hline $\mathbf{2 0 0 8}$ & 1 & 2 & 0 & 2 & 2 & 0 & 0 & 0 & 0 & 0 \\
\hline $\mathbf{2 0 0 9}$ & 0 & 0 & 1 & 0 & 0 & 2 & 2 & 2 & 1 & 2 \\
\hline $\mathbf{2 0 1 0}$ & 0 & 1 & 1 & 0 & 3 & 1 & 0 & 1 & 1 & 0 \\
\hline $\mathbf{2 0 1 1}$ & 1 & 0 & 1 & 0 & 0 & 2 & 1 & 0 & 4 & 1 \\
\hline Total & 13 & 22 & 11 & 6 & 11 & 18 & 10 & 10 & 14 & 10 \\
\hline
\end{tabular}


Table A.51: Expected Number of Angle Crashes at Treatment Intersections (CG Method)

\begin{tabular}{|c|c|c|c|c|c|c|c|c|c|c|c|}
\hline Site & $\begin{array}{c}\text { Adj. crash } \\
\text { freq in before } \\
\text { period }\end{array}$ & $\begin{array}{c}\text { Adj. crash } \\
\text { freq in after } \\
\text { period }\end{array}$ & $\begin{array}{c}\text { Ratio } \\
\text { Exp. Avg. crash freq }\end{array}$ & $\begin{array}{c}\text { Obs crash } \\
\text { in after period w/o } \\
\text { treatment }\end{array}$ & $\begin{array}{c}\text { Obs crash } \\
\text { freq before } \\
\text { freriod }\end{array}$ & $\begin{array}{c}\text { Odds after } \\
\text { period }\end{array}$ & $\begin{array}{c}\text { Log } \\
\text { Ratio } \\
\text { odds } \\
\text { ratio, } R\end{array}$ & $\begin{array}{c}\text { Sqrd Std } \\
\text { error of log } \\
\text { odds ratio }\end{array}$ & $\begin{array}{c}\text { Weighted } \\
\text { adj, } w\end{array}$ & $\begin{array}{c}\text { Weighted } \\
\text { product }\end{array}$ \\
\hline 1 & 70.35 & 80.43 & 1.143 & 14.86 & 13 & 6 & 0.404 & -0.907 & 0.270 & 3.70 & -3.36 \\
\hline 2 & 116.59 & 140.91 & 1.209 & 10.88 & 9 & 7 & 0.644 & -0.441 & 0.270 & 3.71 & -1.63 \\
\hline 4 & 176.06 & 69.66 & 0.396 & 4.35 & 11 & 2 & 0.460 & -0.778 & 0.611 & 1.64 & -1.27 \\
\hline 5 & 87.49 & 25.80 & 0.295 & 9.73 & 33 & 2 & 0.206 & -1.582 & 0.580 & 1.72 & -2.73 \\
\hline 7 & 139.86 & 37.57 & 0.269 & 2.42 & 9 & 2 & 0.827 & -0.190 & 0.645 & 1.55 & -0.29 \\
\hline 8 & 133.64 & 39.01 & 0.292 & 2.92 & 10 & 2 & 0.685 & -0.378 & 0.633 & 1.58 & -0.60 \\
\hline Total & 723.99 & 393.38 & & 45.16 & 85 & 21 & & & & 13.90 & -9.88 \\
\hline
\end{tabular}




\subsection{APPENDIX B - R CODE}

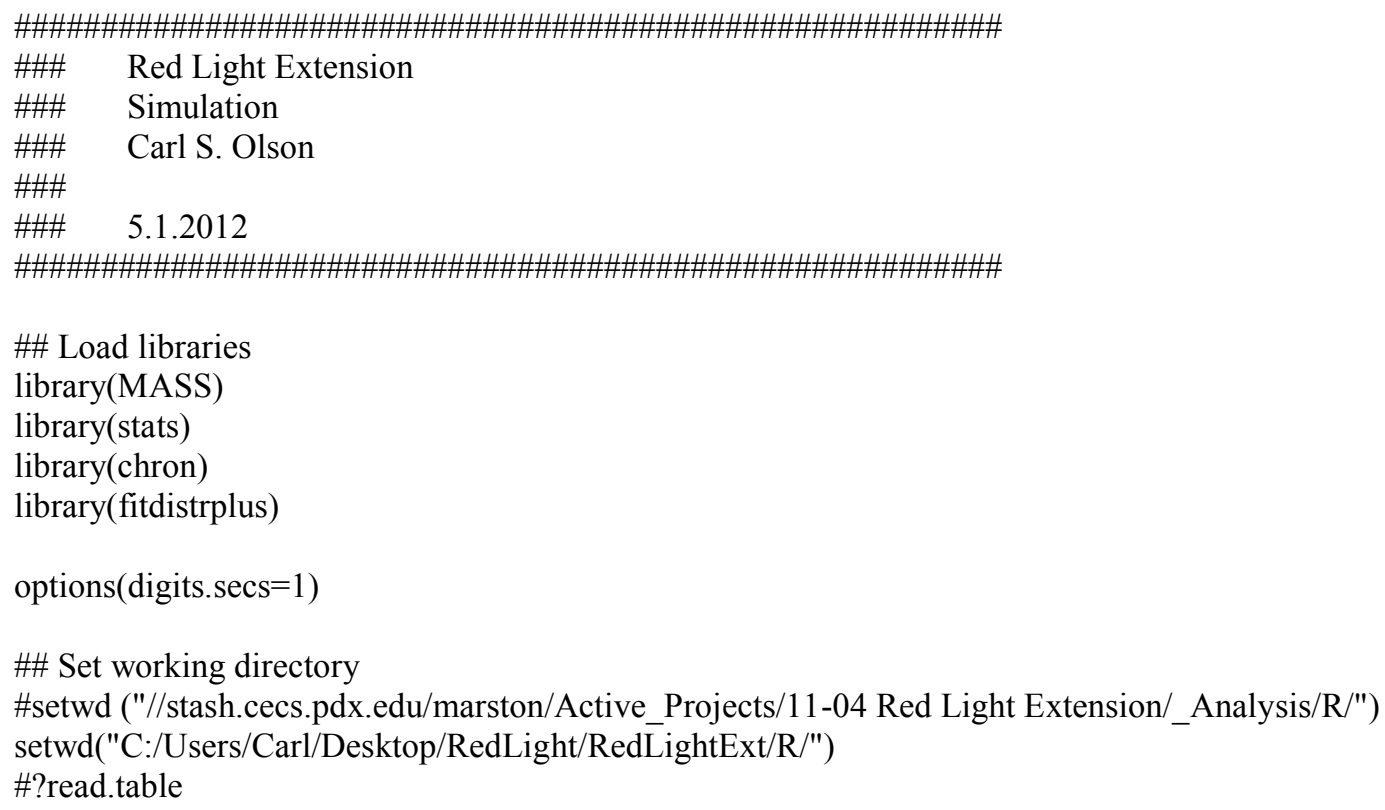

\#\# Determining the time that cars are counted. Take the count for a minute and \#\# distribute throughout that minute. For example, 1 car at 15:00. 2 car at \#\# 15:00 and 15:30. 3 Cars at 15:00, 15:20, 15:40. 


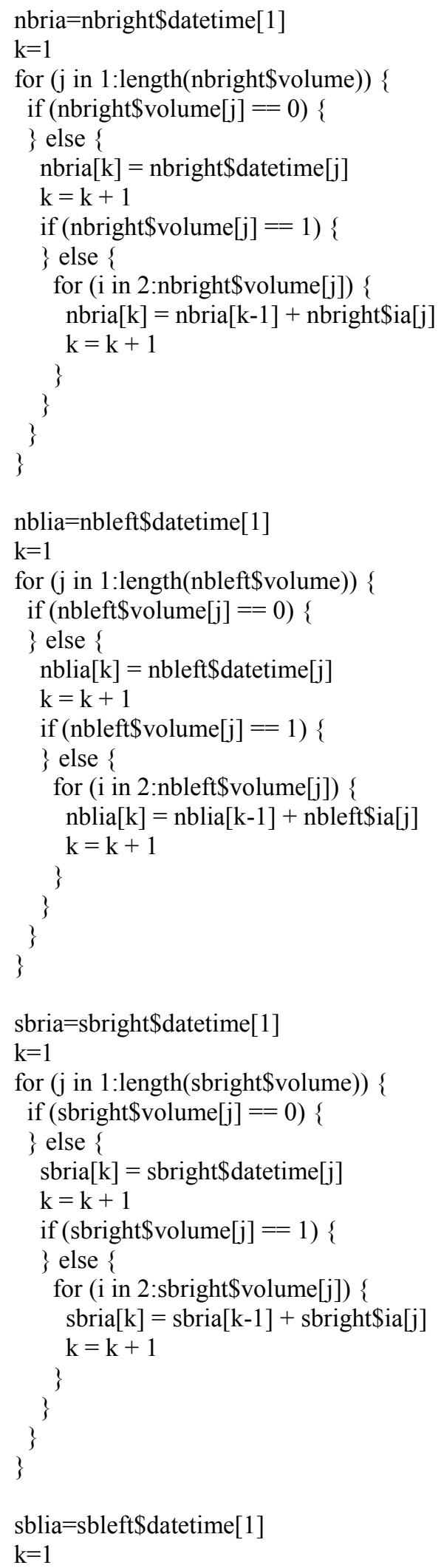




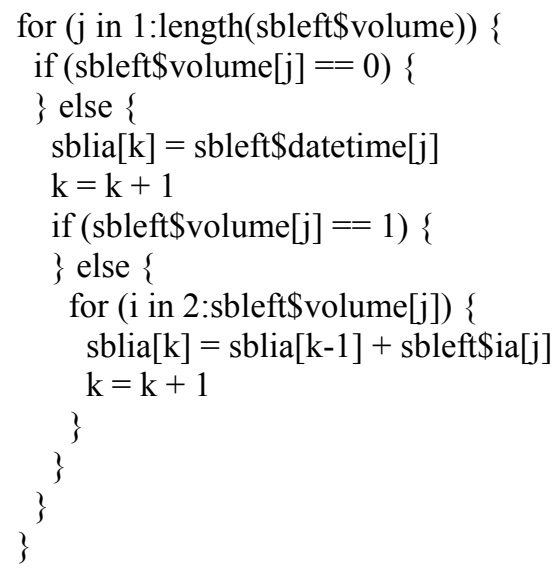

round(abs(nbria\$datetime[2:length(nbria[[1]])]round(abs(nblia\$datetime[2:length(nblia[[1]])]round(abs(sbria\$datetime[2:length(sbria[[1]])]round(abs(sblia\$datetime[2:length(sblia[[1]])]-

\#\# Adding two columns, numeric day of the month and seconds on that day

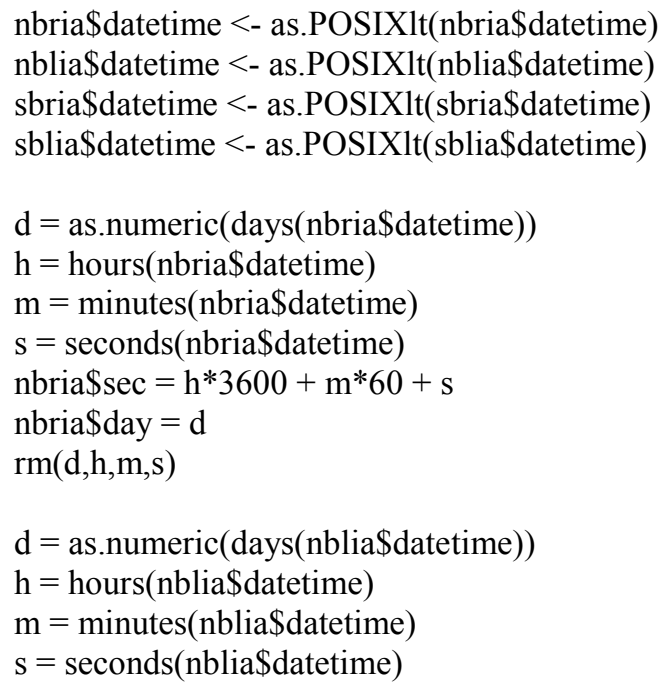




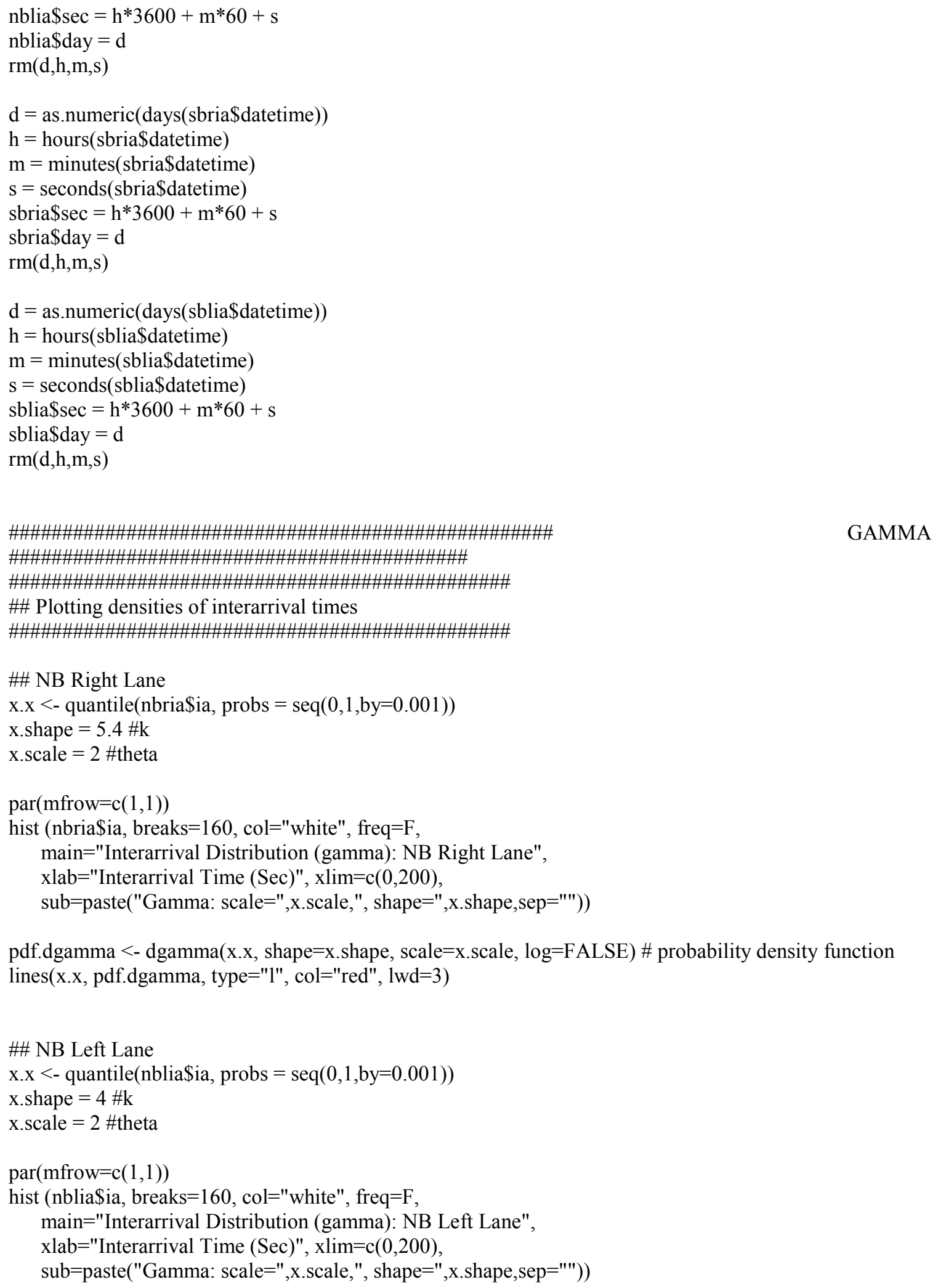

GAMMA 
pdf.dgamma $<-$ dgamma $(x . x$, shape $=$ x.shape, scale=x.scale, log=FALSE) \# probability density function lines(x.x, pdf.dgamma, type="l", col="red", lwd=3)

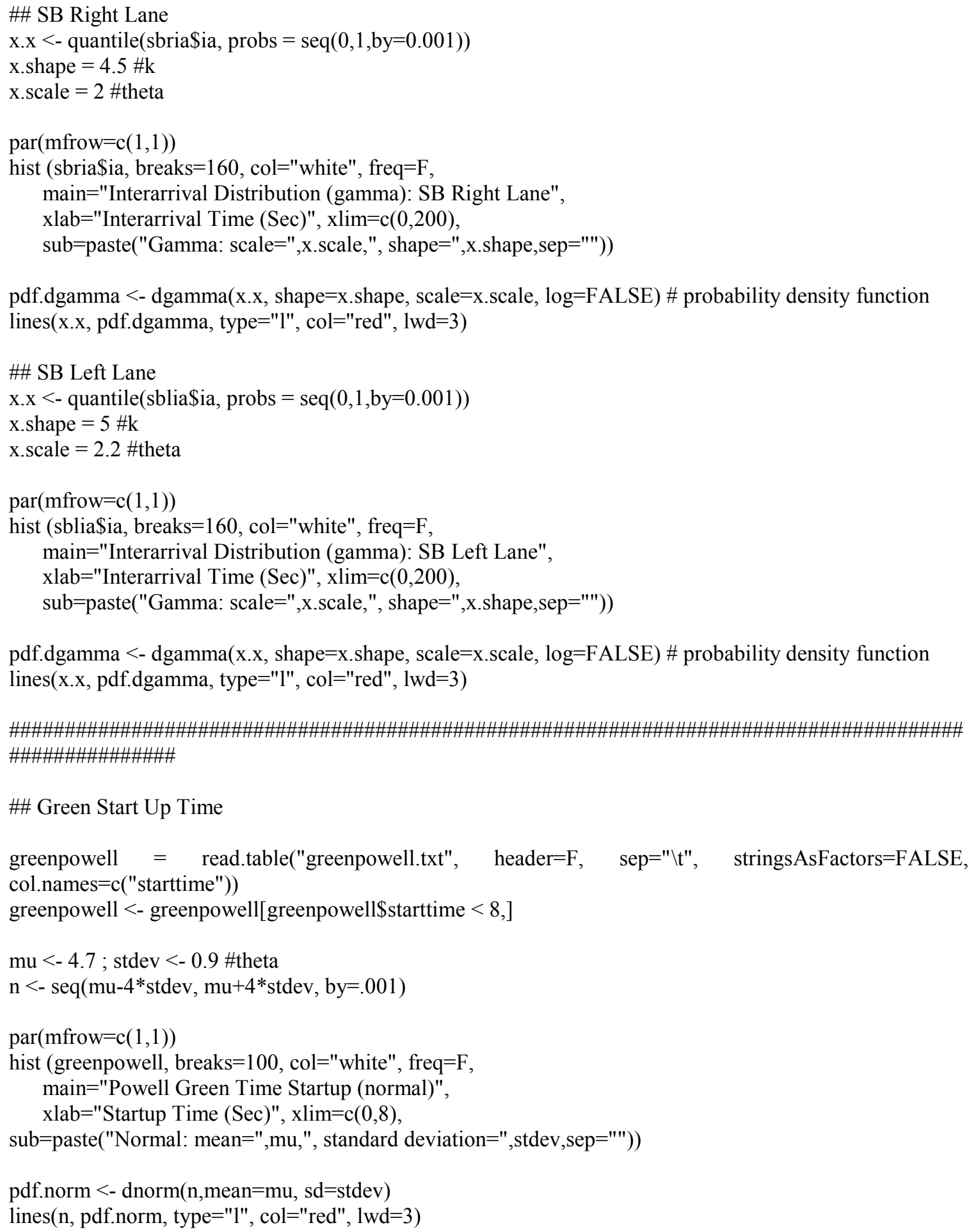




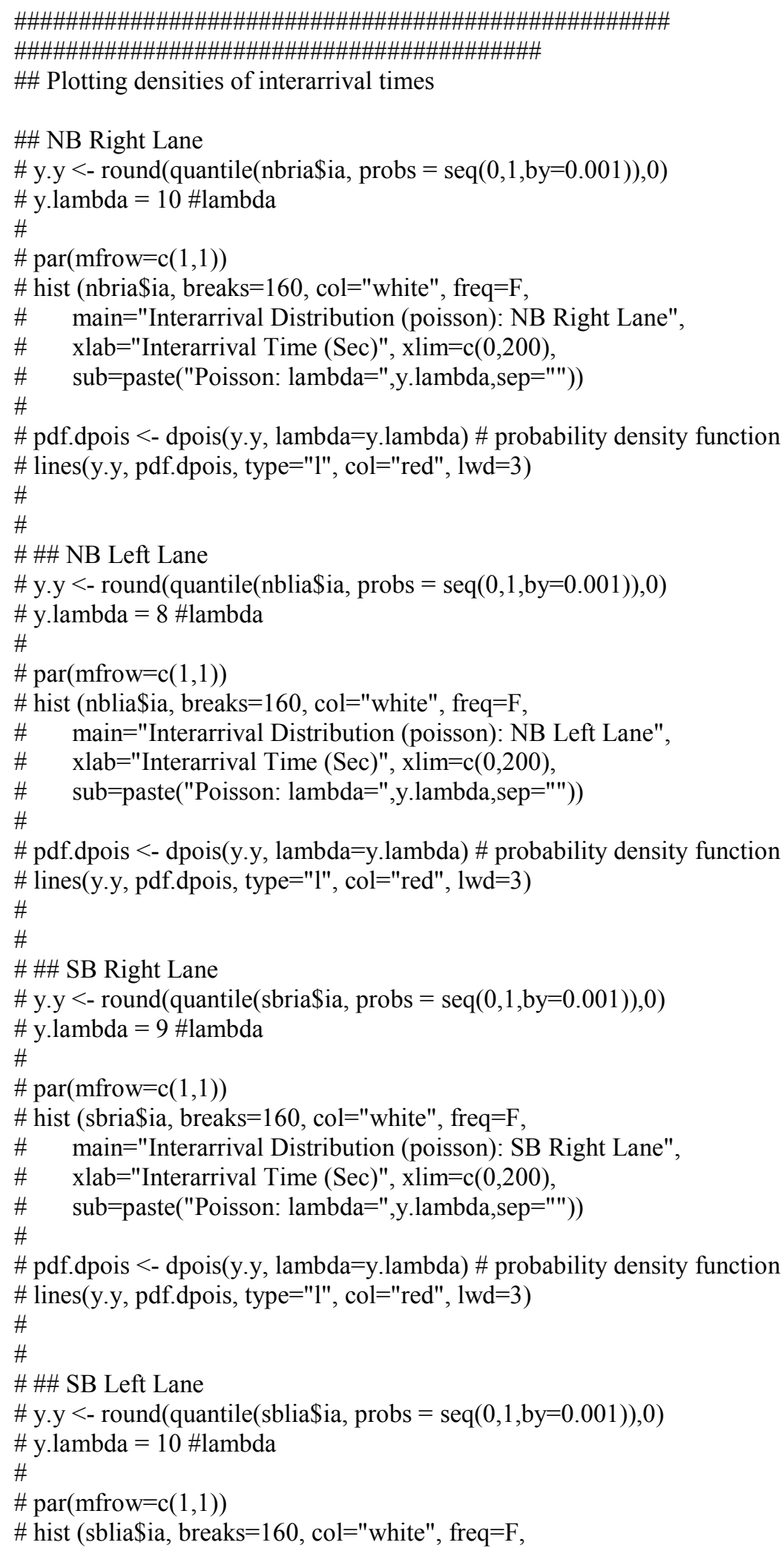




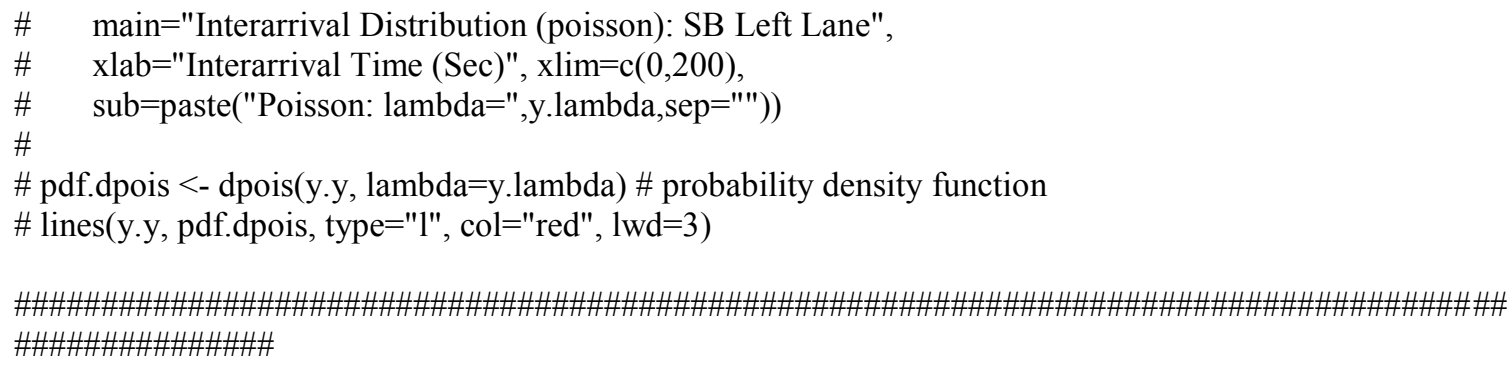




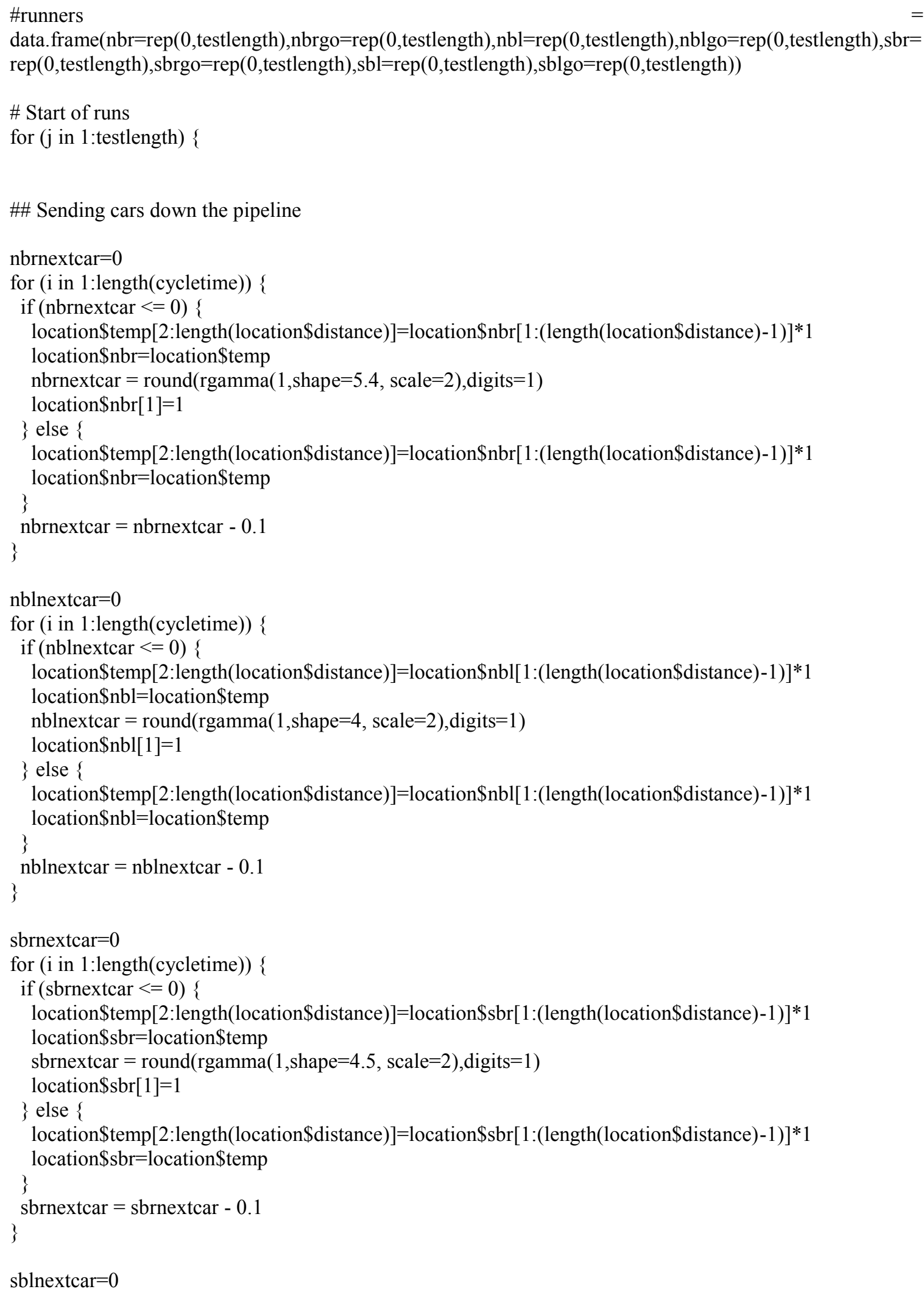




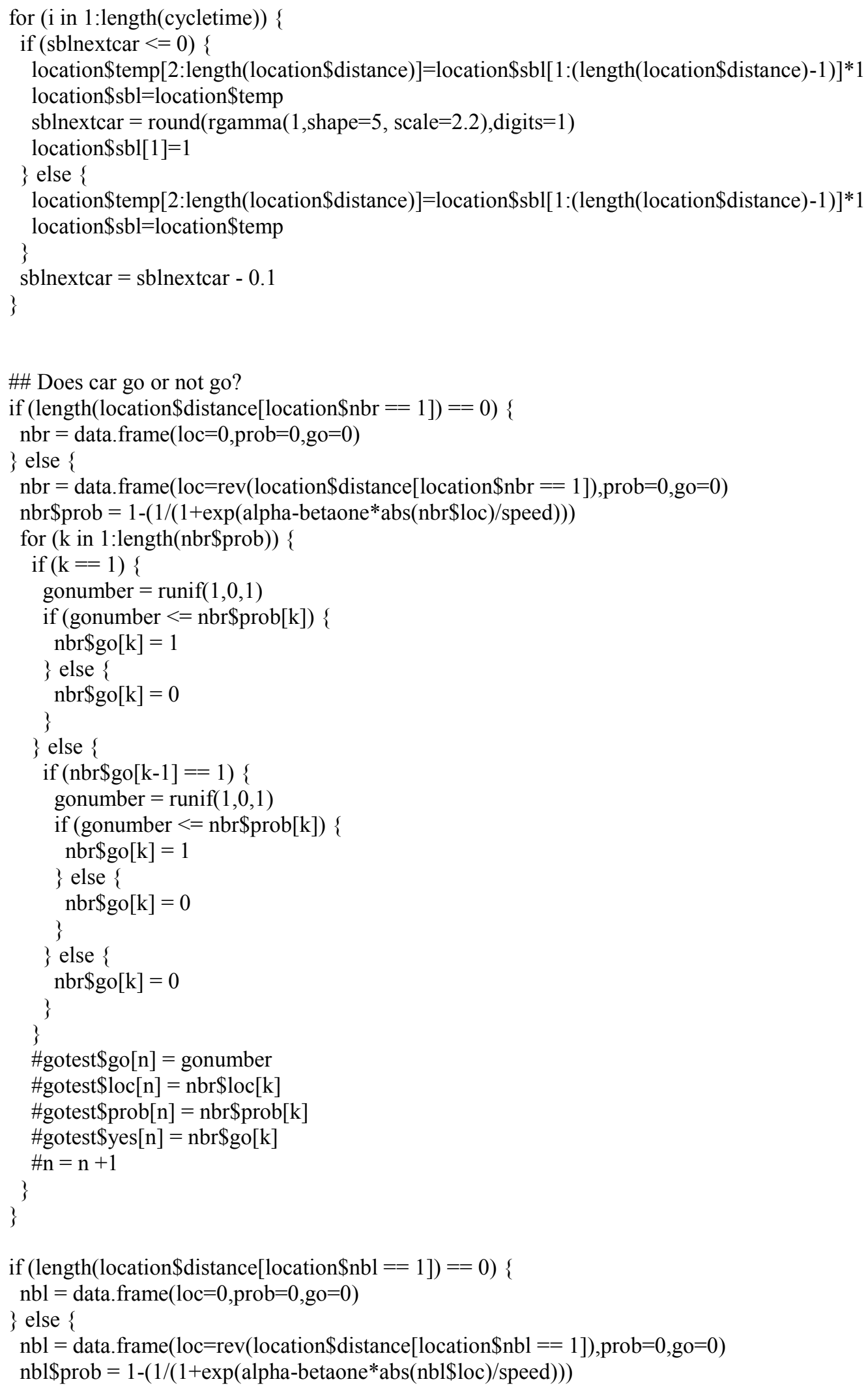




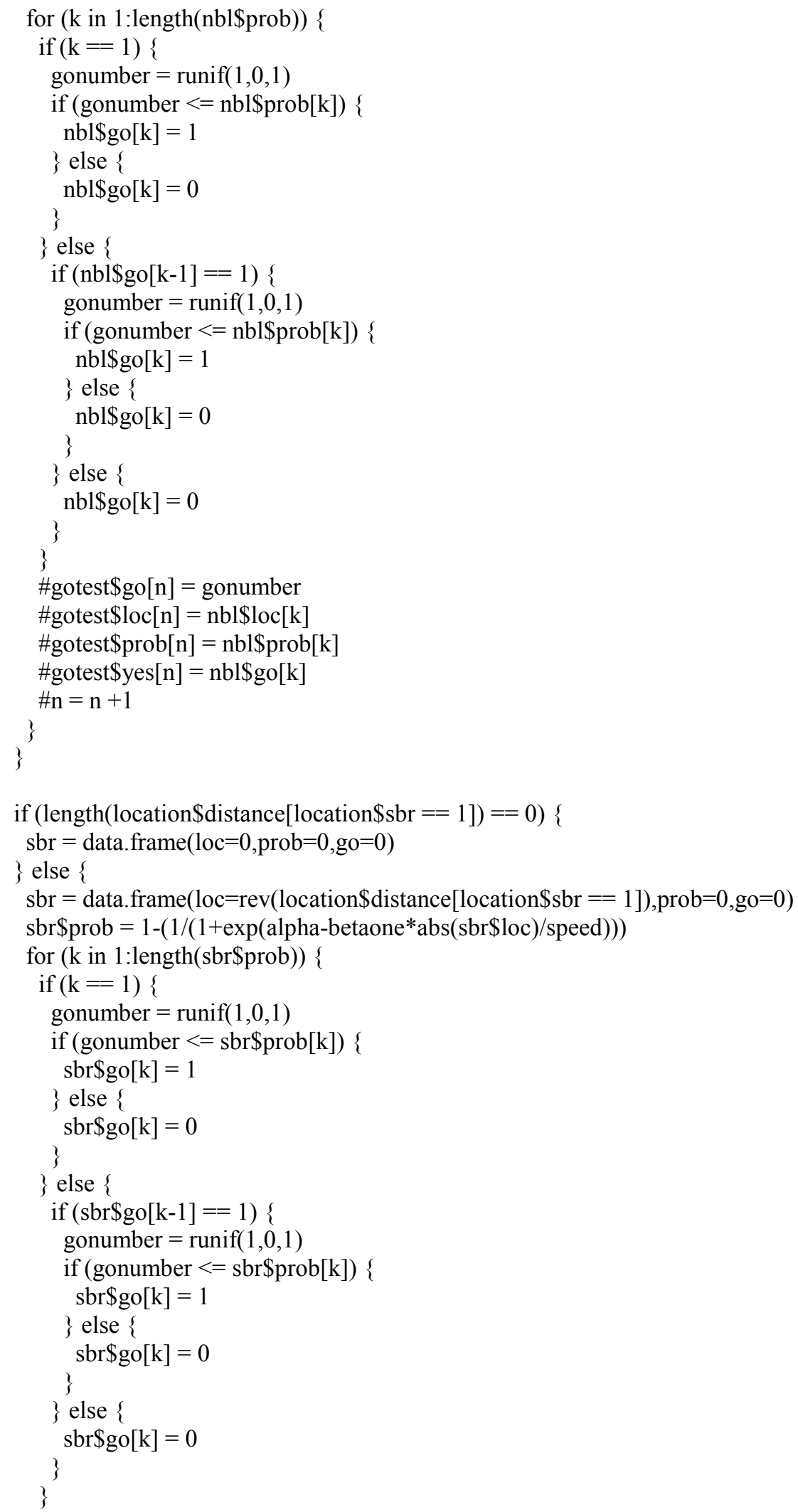




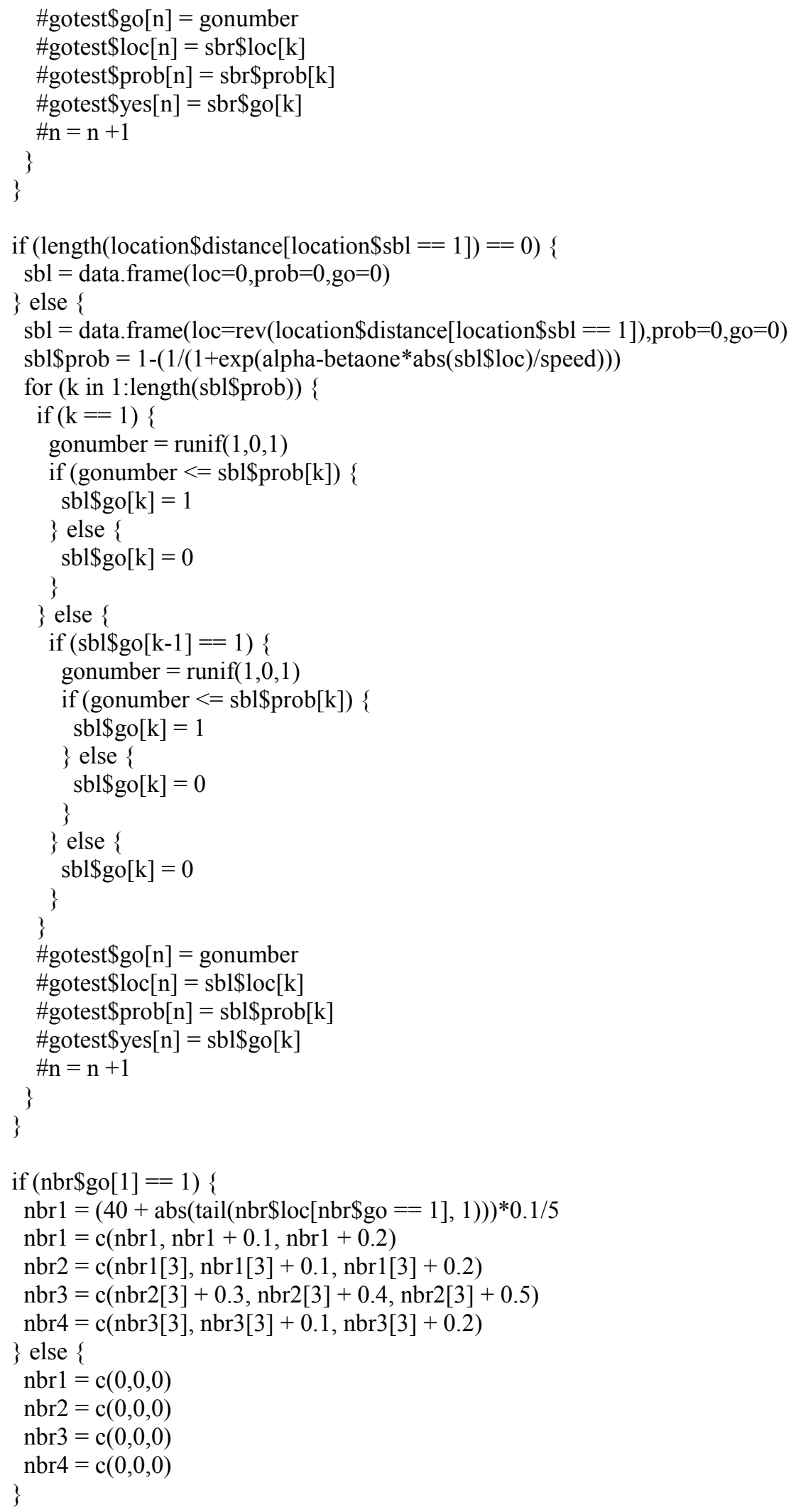




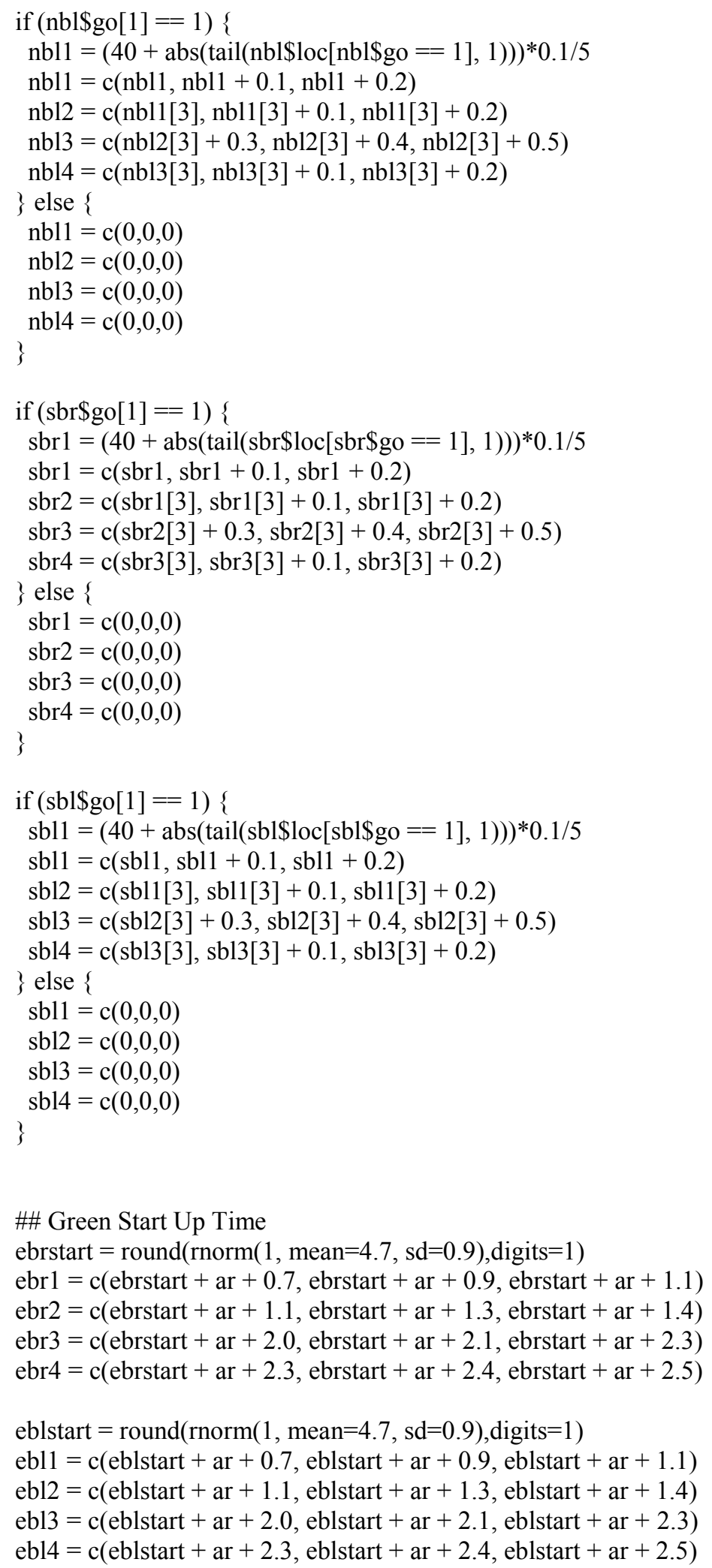




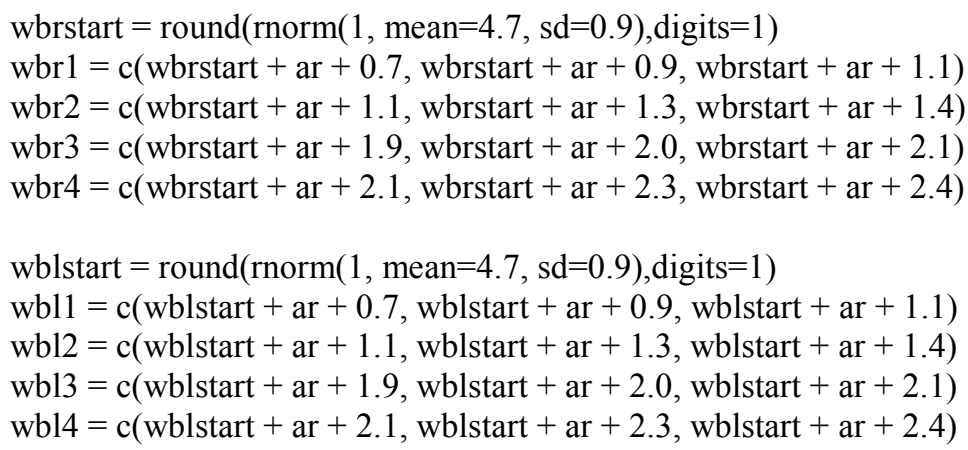

\# Test for interactions

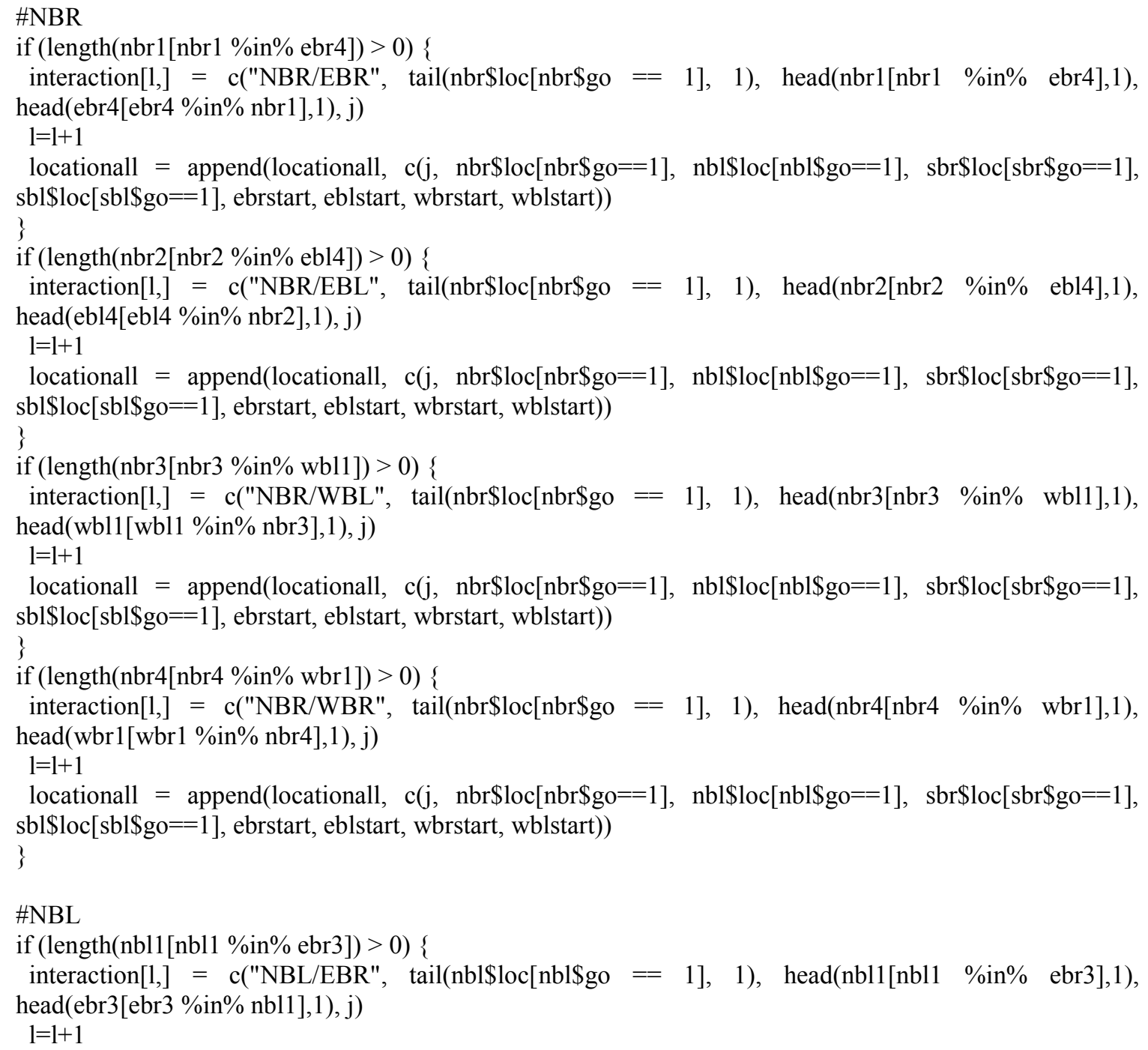


locationall $=$ append(locationall, $\mathrm{c}\left(\mathrm{j}, \operatorname{nbr} \$ \operatorname{loc}\left[\mathrm{nbr} \$ \mathrm{go}_{\mathrm{o}}=1\right], \operatorname{nbl} \$ \operatorname{loc}[\mathrm{nbl} \$ \mathrm{go}==1], \operatorname{sbr} \$ \operatorname{loc}\left[\mathrm{sbr} \$ \mathrm{go}_{\mathrm{o}}=1\right]\right.$, sbl\$loc[sbl\$go==1], ebrstart, eblstart, wbrstart, wblstart))

\}

if (length $(\mathrm{nbl} 2[\mathrm{nbl} 2 \%$ in $\%$ ebl3] $)>0)\{$

interaction[1,] =c("NBL/EBL", tail(nbl\$loc[nbl\$go == 1], 1), head(nbl2[nbl2 \%in\% ebl3],1), head(ebl3[ebl3 \%in\% nbl2],1), j)

$1=1+1$

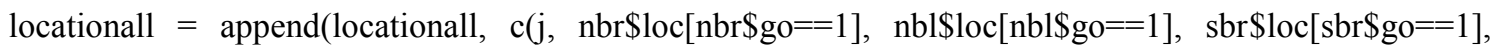
$\operatorname{sbl} \$ 10 c[\operatorname{sbl} \$ g o==1]$, ebrstart, eblstart, wbrstart, wblstart))

\}

if (length(nbl3[nbl3 \%in\% wbl2]) >0) \{

interaction[1,] = $(" N B L / W B L "$, tail(nbl\$loc[nbl\$go == 1], 1), head(nbl3[nbl3 \%in\% wbl2],1), head(wbl2[wbl2 \%in\% nbl3],1), j)

$1=1+1$

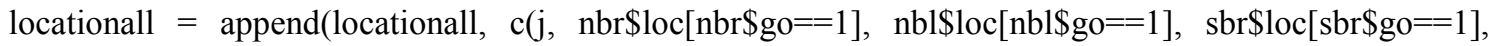
$\left.\operatorname{sbl} \$ \operatorname{loc}_{\text {sbl }} \$ g_{0}==1\right]$, ebrstart, eblstart, wbrstart, wblstart))

\}

if (length(nbl4[nbl4 \%in\% wbr2]) >0) \{

interaction[1,] = c("NBL/WBR", tail(nbl\$loc[nbl\$go == 1], 1), head(nbl4[nb14 \%in\% wbr2],1), head(wbr2[wbr2 \%in\% nbl4],1), j)

$1=1+1$

locationall $=$ append(locationall, $\mathrm{c}(\mathrm{j}, \mathrm{nbr} \$ \operatorname{loc}[\mathrm{nbr} \$ \mathrm{go}==1], \mathrm{nb} 1 \$ \operatorname{loc}[\mathrm{nb} \mid \$ \mathrm{go}==1], \operatorname{sbr} \$ \operatorname{loc}[\mathrm{sbr} \$ \mathrm{go}==1]$, sbl\$loc [sbl\$go==1], ebrstart, eblstart, wbrstart, wblstart))

\}

\#SBR

if (length(sbr1[sbr1 \%in\% wbr4]) >0) \{

interaction[1,] = $c("$ SBR/WBR", tail(sbr\$loc[sbr\$go == 1], 1), head(sbr1[sbr1 \%in\% wbr4],1), head(wbr4[wbr4 \%in\% sbr1],1), j)

$1=1+1$

locationall $=$ append(locationall, $\mathrm{c}(\mathrm{j}, \operatorname{nbr} \$ \operatorname{loc}[\mathrm{nbr} \$ g \mathrm{go}=1], \operatorname{nbl} \$ \operatorname{loc}[\mathrm{nbl} \$ \mathrm{go}==1], \operatorname{sbr} \$ \operatorname{loc}[\mathrm{sbr} \$ g \mathrm{~g}==1]$, $\operatorname{sbl} \$ \operatorname{loc}\left[\operatorname{sbl} \$ g_{0}==1\right]$, ebrstart, eblstart, wbrstart, wblstart))

\}

if (length(sbr2[sbr2 \%in\% wbl4]) >0) \{

interaction[1,] = c("SBR/WBL", tail(sbr\$loc[sbr\$go == 1], 1), head(sbr2[sbr2 \%in\% wbl4],1), head(wbl4[wbl4 \%in\% sbr2],1), j)

$1=1+1$

locationall $=$ append(locationall, $\mathrm{c}\left(\mathrm{j}, \operatorname{nbr} \$ \operatorname{loc}\left[\mathrm{nbr} \$ \mathrm{go}_{\mathrm{o}}=1\right], \operatorname{nbl} \$ \operatorname{loc}[\mathrm{nbl} \$ \mathrm{go}==1], \operatorname{sbr} \$ \operatorname{loc}\left[\mathrm{sbr} \$ \mathrm{go}_{\mathrm{o}}=1\right]\right.$, $\operatorname{sbl} \$ \operatorname{loc}\left[\mathrm{sbl} \$ \mathrm{go}_{0}==1\right]$, ebrstart, eblstart, wbrstart, wblstart))

\}

if (length(sbr3[sbr3 \%in\% ebl1]) >0) \{

interaction[1,] $=\mathrm{c}($ "SBR/EBL", tail(sbr\$loc[sbr\$go $==1], 1)$, head(sbr3[sbr3 \%in\% ebl1],1), head(ebl1[ebl1 \%in\% sbr3],1), j)

$1=1+1$

locationall $=$ append(locationall, $\mathrm{c}\left(\mathrm{j}, \operatorname{nbr} \$ \operatorname{loc}\left[\mathrm{nbr} \$ \mathrm{go}_{\mathrm{o}}=1\right], \mathrm{nb} \$ \mathrm{loc}[\mathrm{nb} 1 \$ \mathrm{go}==1], \operatorname{sbr} \$ \operatorname{loc}[\operatorname{sbr} \$ \mathrm{go}==1]\right.$, $\operatorname{sbl} \$ 1$ oc $[\operatorname{sbl} \$ g o==1]$, ebrstart, eblstart, wbrstart, wblstart))

\}

if (length(sbr4[sbr4 \%in\% ebr1]) >0) \{

interaction[1,] = $\mathrm{c}($ "SBR/EBR", tail(sbr\$loc[sbr\$go $==1], 1), \quad$ head(sbr4[sbr4 \%in\% ebr1],1), head(ebr1[ebr1\%in\% sbr4],1), j)

$1=1+1$

locationall $=$ append(locationall, $\mathrm{c}(\mathrm{j}, \operatorname{nbr} \$ \operatorname{loc}[\mathrm{nbr} \$ \mathrm{go}==1], \operatorname{nbl} \$ \operatorname{loc}[\mathrm{nbl} \$ \mathrm{go}==1], \operatorname{sbr} \$ \operatorname{loc}[\operatorname{sbr} \$ g o==1]$, $\operatorname{sbl} \$ \operatorname{loc}[\operatorname{sbl} \$ g o==1]$, ebrstart, eblstart, wbrstart, wblstart)) 


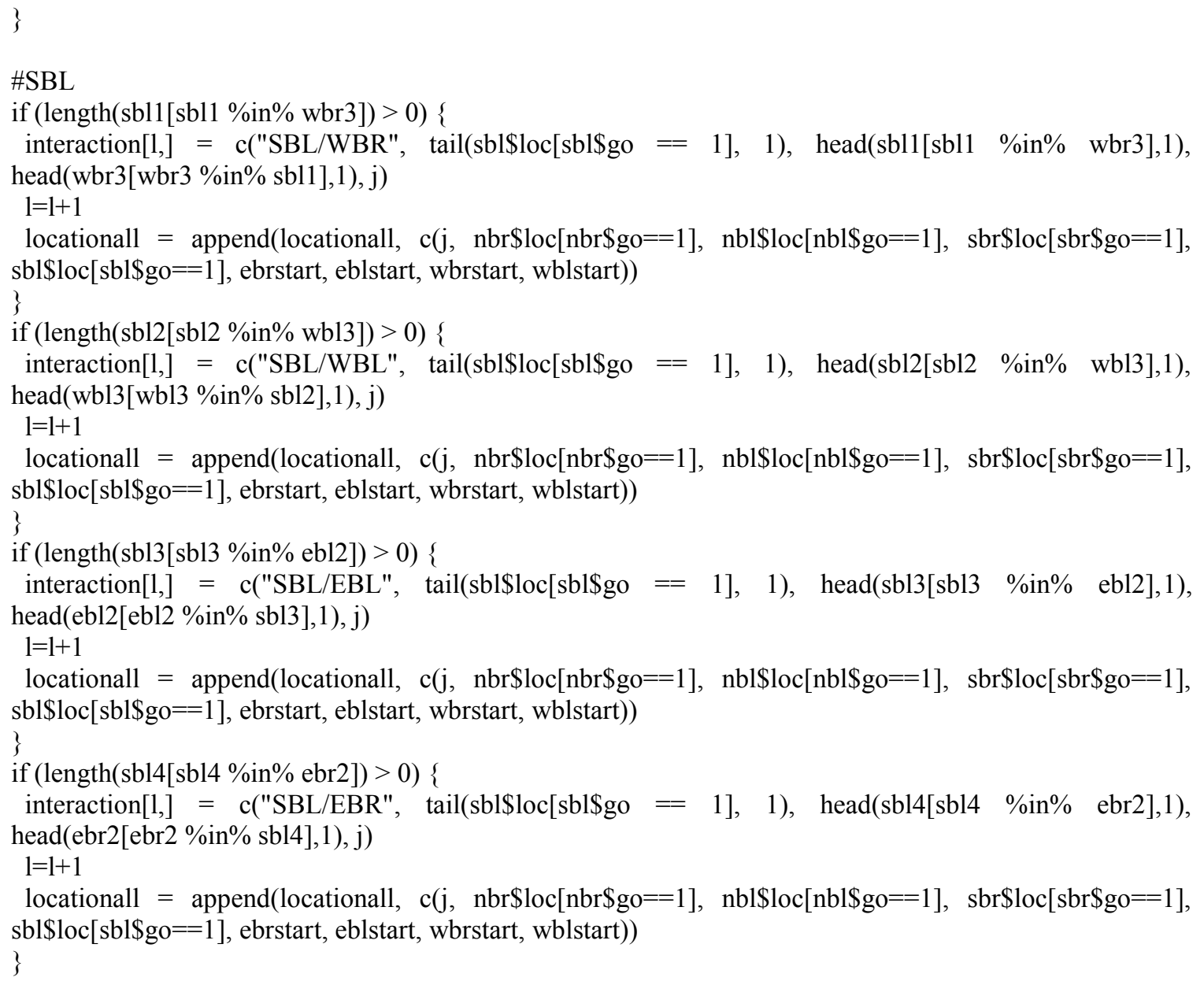

